\title{
PUBLIC LANDSCAPE: \\ THE REINVENTION OF TORONTO'S UNION STATION \& CENTRAL RAILWAY LANDS
}

\author{
by \\ Clayton Uilliam Hamish Payer \\ Bachelor of Architectural Science, Ryerson University, Toronto, 2007 \\ A design thesis/project \\ Presented to Ryerson University \\ In partial fulfillment of the \\ Master of Architecture \\ in the Program of \\ Master of Architecture
}

Toronto, Ontario, Canada, 2009

(C) Clayton Payer 2009 


\section{Author's Declaration}

I hereby declare that I am the sole author of this thesis.

I authorize Ryerson University to lend this thesis to other institutions or individuals for their purpose of scholarly research.

further authorize Ryerson University to reproduce this thesis by photocopying or by other means, in total or in part, at the request of other institutions or individuals for the purpose of scholarly research. 


\section{Abstract}

\section{PUBLIC LANDSCAPE: \\ THE REINVENTION OF TORONTO'S UNION STATION \& CENTRAL RAILWAY LANDS}

Clayton Uilliam Hamish Payer

Master of Architecture, Ryerson University, Toronto, 2009

There is concern for Toronto's outdated, underutilized, and underdeveloped transit hubs and their subsequent lack of developed public spaces. One such hub is Toronto's Union Station, central portal of the GTA's mass transit system. This site was selected for a comprehensive analysis and critique of the station's physiology, the urban morphology of its immediate context, and its future needs. Research found that the station and its context are poorly organized requiring a redesign to unify the disjointed characteristics of the site. A design proposal formulates a continuous surface of public space over a redesigned train hall that stretches over the rail lands to bind, connect, and integrate an urban park in order to reorganize the areas existing venues and to recognize the station's importance as the region's and city's central transit hub. 


\section{Acknowledgements}

Many thanks to my adviser Cheryl Atkinson, my colleagues for their generous input and the support of my family and friends. 


\section{Contents}

PUBLIC LANDSCAPE: THE REINVENTION OF TORONTO'S

UNION STATION AND CENTRAL RAILWAY LANDS I

Author's Declaration III

Abstract $\quad V$

Acknowledgements $\quad$ VII

Contents IX

List of Figures XIII

List of Appendices XXIII

1.0 Introduction 1

1.1 Union Station - A Rotting Beaux-Art's Carcass 3

2.0 Union Station History

3.0 Contextual Evolution 17

3.1 Request for Expression $\quad 23$

$\begin{array}{ll}3.2 \text { Current Trends } & 27\end{array}$

4.0 So Many Issues ... 35

4.1 Fragmented Station $\quad 35$

4.2 Missing Identity

4.3 A Solution ? 65

5.0 What is Union Station? 67

5.1 Space and Atmosphere 68

5.2 Urban Exchange Complex $\quad 73$

5.3 An Ideal Station $\quad 76$

5.4 Not Important $\quad 81$

6.0 Porous vs. Smooth 83

6.1 Striated vs. Smooth $\quad 86$ 
7.0 Case Studies

7.1 Warped Lasagna - Yokohama International Port Terminal 93

7.2 An organ, like the heart or a kidney - An Arnhem Central Interchange 101

7.3 Hard-to-Find Examples

7.4\$7 Billion Station - Stuttgart Main Station

7.5 Z-Shaped - Olympic Sculpture Park

7.6 Last Two Examples

8.0 Proposal for Union Station

8.1 What Did We Learn From Node-Place?

8.2 New Characteristics

8.3 Final Thoughts

\subsection{Design Introduction}

9.1 Regional Importance

9.2 Central Railway Land Circulation

10.0 Intervention - the Surface

10.1 Intervention - the Surface formally

10.2 Intervention - Programming

CN Tower Media Park

10.2 .2

Roundhouse Info Plaza

10.2 .3

Roundhouse Park

10.2 .4

MTCC Expo Building

10.2 .5

CN Tower Plaza

10.2 .6

Outdoor Gallery

10.2.7

Rail Line Plaza

10.2 .8

Park Concourse

10.2 .9

Forested Meadow Park

10.2.10

ACC Grandstand

10.2.11

Front Street Plaza 
10.5 Structure 


\section{List of Figures}

1.0.0 Toronto's Union Station

2.0.1 Future Site of Union Station with mapped properties burned down in 1904. Source: Carr, A. (2005) Toronto Union Station Historical Structure Report. Toronto: Fournier Gersovitz Moss \& Associes architectes. Pg. 22

2.0.2 Proposed Elevation as of 1916.

Source: Carr, A. (2005) Toronto Union Station Historical Structure Report. Toronto: Fournier Gersovitz Moss \& Associes architectes. Pg. 25

2.0.3 Original Union Station Layout (notice how the original plan allowed the Departures concourse access the Great Hall in 3 locations)

Source: Carr, A. (2005) Toronto Union Station Historical Structure Report. Toronto: Fournier Gersovitz Moss \& Associes architectes. Pg. 27

2.0.4 Union Station Bush Style Trainshed Source: Clayton Payer

2.0.5 Traditional Terminating Station vs. Through Station Source: Clayton Payer

2.0.6 Union Station's Great Hall Source: Clayton Payer

2.0.7 Departure \& Arrivals Separation Source: Courtesy of Clayton Payer

2.0.8 Additions of GO Transit and TTC Subway connection Source: Clayton Payer

2.0.9 Skywalk Connection and Canadian Express Building Source: Clayton Payer

2.0.10 Skywalk Connection with boarded up amenities fronts Source: Clayton Payer

2.0.11 Construction of West Teamways Source: Clayton Payer

2.0.12 Construction of Go Concourse South Platforms Source: Clayton Payer

2.0.13 New South Entrance - Rendering Source: Union Station District Plan. (2006, May). Toronot: architectsAlliance Retrieved October 10, 2008, from http://www.toronto.ca/union_station/ district_plan.htm. Pg. 23

3.0.1 Growth of Toronto's Waterfront Source: Clayton Payer

3.0.2 Canyon of Stone (Union Station to the right, facing the Royal York Hotel) Source: Union Station District Plan. (2006, May). Toronot: architectsAlliance. Retrieved October 10, 2008, from http://www.toronto.ca/union_station/ district_plan.htm. Pg. 6

3.0.3 Financial District Source: Clayton Payer

3.0.4 Construction of Union Station's concourse with Stock Yards to the left Source: City of Toronto Archives, Union Station from old tower looking east, Fonds 1231, Item 71, Retrieved Nov, 23, 2008 from www.toronto.ca

3.0.5 Gardiner Expressway as seen from Cherry St. Source: http://farm4.static.flickr.com/3008/2702301488_0ecf376a7a_b.jpg)

3.0.6 Model of the 1968 Metro Centre Proposal 
Source: Union Station District Plan. (2006, May). Toronot: architectsAlliance.

Retrieved October 10, 2008, from http://www.toronto.ca/union_station/

district_plan.htm. Pg. 34

3.0.7 Revised Metro Centre section plan to include Union Station

Source: Union Station District Plan. (2006, May). Toronot: architectsAlliance.

Retrieved October 10, 2008, from http://www.toronto.ca/union_station/

district_plan.htm. Pg. 33

3.0.8 Metro Centre Model compared to present day Toronto

Source: Clayton Payer

3.0.9 Large scale develops still cannot consume the rail lands, circa 1999

Source: http://map.toronto.ca/imapit/iMaplt.jsp?app=TOMaps

3.1.1 Rem Koolhaas Master plan, vague representations.

Source: Retrieved October 10, 2008, from www.oma.nl

3.1.2 Rem Koolhaas Master plan, new concourse

Source: Retrieved October 10, 2008, from www.oma.nl

3.1.3 OMA Master plan vs. existing public park spaces

Source: Clayton Payer

3.1.4 Current GO Transit platform canopy proposal

Source: Retrieved October 10, 2008, from http://www.cdnarchitect.com

3.2.1 Finer Grain vs. Larger Grain Property divisions

Source: Clayton Payer

3.2.2 Road Conditions in the Union Station area

Source: Clayton Payer

3.2.3 Typical weekday, devoid of activity (Roundhouse to the left, Rogers Centre to the Right)

Source: Clayton Payer

3.2.4 Recently renovated Simcoe Tuneel

Source: Retrieved September 23, 2009, from http://urbantoronto.ca/

Source: Clayton Payer

3.2.5 New Telus building designed by \&Co (Under construction)

Source: Retrieved October 10, 2008, from http://www.andco.com/

3.2.6 Proposed Maple Leafs Square (Under construction)

Source: Retrieved October 10, 2008, from www.mapleleafsquare.com/

Initial Proposal renderings for ICE Condo's. No relation to surrounding context

Source: Retrieved October 10, 2008, from www.icecondo.ca

Locations of New Developments, defining York St.

Source: Clayton Payer

KPMB design ibIMC office tower

Source: Retrieved October 10, 2008, from www.bcimc.com/

3.2.10 Union Station District Plan boudaries enclosing historical structures (brown)

Source: Clayton Payer

4.1.1 Layout of Infrastructural Services, only Go Transit is located within Union Station

Source: Clayton Payer

4.1.2 GO Bus Terminal separated by 4-lane road and pedestrian barrier

Source: Clayton Payer

4.1.3 Porter Kiosk location relative to pickup

Source: Clayton Payer

4.1.4 York Teamway entrance located off from direct pedestrian movement

Source: Clayton Payer 
4.1.5 York Concourse located deep within the terminal

Source: Clayton Payer

4.1.6 Converted Postal Sorting Room provides the most basic creature comforts

Source: Clayton Payer

4.1.7 Dedicated, Influenced and Non-Affiliated GO Transit Spaces.

Source: Clayton Payer

4.1.8 Old Men's Sitting room converted into an interstitial space

Source: Clayton Payer

4.1.9 Current state of the arrivals concourse - barren when GO Transit users are not occupying it

Source: Clayton Payer

4.2.1 Comparison of Public Park's in various American cities

Source: Clayton Payer

4.2.2 Front St. Plaza, unattractive and unused

Source: Clayton Payer

4.2.3 Union Station Master plan proposal for a continuous paved surface

Source: Union Station District Plan. (2006, May). Toronot: architectsAlliance.

Retrieved October 10, 2008, from http://www.toronto.ca/union_station/

district_plan.htm. Pg. 127

4.2.4 Union Station Master plan proposal for removal of centre median

Source: Union Station District Plan. (2006, May). Toronot: architectsAlliance.

Retrieved October 10, 2008, from http://www.toronto.ca/union_station/

district_plan.htm. Pg. 17

4.2.5 Congested sidewalk during rush hour

Source: Clayton Payer

4.2.6 Typical Weekday in front of the MTCC - barren and lifeless

Source: Clayton Payer

4.2.7 Union Plaza and Major access points - not a traditionally shaped public space

Source: Union Station District Plan. (2006, May). Toronot: architectsAlliance.

Retrieved October 10, 2008, from http://www.toronto.ca/union_station/

district_plan.htm. Pg. 106

4.2.8 Visual journey through Union Station to Union Plaza - not linear, and does not provide easy visual cues to target

Source: Clayton Payer

4.2.9 Toronto Maple Leafs Proposal, images apart of the Unbuilt Toronto conducted by the Toronto Society of Architects

Source: Retrieved October 10, 2008, from http://www.unbuilttoronto.ca/

4.2.10 Original Union Plaza before developments and ACC extension

Source: http://basketball.ballparks.com/NBA/TorontoRaptors/newaerial.jpg

4.2.11 Future PATH system connections

Source: Union Station District Plan. (2006, May). Toronot: architectsAlliance.

Retrieved October 10, 2008, from http://www.toronto.ca/union_station/

district_plan.htm. Pg. 106

4.2.12 Park spaces in the Contextual Area of Union Station

Source: Clayton Payer

4.2.13 John St. Bridge - connects over the rail yard

Source: Clayton Payer

4.2.14 MTCC Skywalk Connection, connects over the rail yard

Source: Clayton Payer 
4.2.15 Rogers Centre Plaza \& CN Tower Park - uninspiring places to visit Source: Clayton Payer

4.2.16 Steep elevation change adjacent to Roundhouse Source: Clayton Payer

4.2.17 Union Station District Plans detail public spaces, contrasted against what actually exists and addition areas where it is highly resistant to public space Source: Union Station District Plan. (2006, May). Toronot: architectsAlliance. Retrieved October 10, 2008, from http://www.toronto.ca/union_station/ district_plan.htm. Pg. 101

4.2.18 Difficult to put tall buildings into context Source: Clayton Payer

4.2.19 HtO Park in relation to Harbourfront condo's and streets. Source: Clayton Payer

4.2.20 Yellow: Elevated Barriers, Red: Rail Yard Barrier Source: Clayton Payer

4.2.21 Impenetrable stone façades along the south side of Front St. Source: Clayton Payer

4.2.22 Elevation Change from Front St. to waterfront Source: Clayton Payer

4.2.23 The rail yards form a visually barrier that inhibits a clear view of the rail lands and waterfront.

Source: Clayton Payer

4.2.24 Steep climb blocks views to the waterfront Source: Clayton Payer

4.2.25 GO Transit Teamways - signage, colour scheme and doors define the teamways as transit spaces and not public throughways

Source: Clayton Payer

4.2.26 The sidewalk provides a direct route while the teamway is placed out the direct path of movement.

Source: Clayton Payer

4.2.27 Elevated Gardiner Expressway with Lakeshore Blvd below. Source: Clayton Payer

4.2.28 Intersection of Lakeshore Blvd. \& Yonge St.

Source: Clayton Payer

5.1.1 500m walking radius from Union Station

Source: Clayton Payer

5.1.2 $500 \mathrm{~m}$ radius augmented by PATH system

Source: Clayton Payer

5.1.3 Walk distance based on PATH system and restricted by barriers Source: Clayton Payer.

5.1.4 Historical Boundaries defined by historical structures related to Union Station. Source: Clayton Payer

5.1.5 Topographical extents, primarily formed by the elevated rail lines Source: Clayton Payer

5.1.6 Defined Union Station District Plan Boundaries Source: Clayton Payer

5.1.7 The strongest overlap that defines the extent of Union Station is north of the topographical features Source: Clayton Payer 
Bertonlini Node-Place Model

Source: Bruinsma, F., Pels, E., Priemus, H., Rietveld, P., \& van Wee, B., (Ed.). (2008). Railway Development: Impacts on urban dynamics [Electronic Version]. Physica-Verlag Heidelberg. Pg. 38

5.3.1 Four approaches to railway station development

Source: Bruinsma, F., Pels, E., Priemus, H., Rietveld, P., \& van Wee, B., (Ed.). (2008). Railway Development: Impacts on urban dynarnics [Electronic Version]. Physica-Verlag Heidelberg. Pg. 127

5.3.2 Red: Shortest route to the USA Border. Orange \& Yellow dashed Lines are the next shortest routes to the US Border.

Source: Clayton Payer - GoogleEarth Modification

5.3.3 Kyoto Station, a multilevel complex with various amenities and services.

Source: Swerling, G., (Ed.). (2004). Railway Stations: from the gare de l'est to open penn station. Hong Kong: Electa Architecture. Pg. 113

5.3.4 Kyoto Station central atrium space

Source: Swerling, G., (Ed.). (2004). Railway Stations: from the gare de l'est to open penn station. Hong Kong: Electa Architecture. Pg. 117

5.3.5 Calthorpe Associates Transit Oriented Diagram

Source: Retrieved October 10, 2008, from www.calthorpe.com/

5.3.6 Available areas for development in a $500 \mathrm{~m}$ radius of Union Station

Source: Clayton Payer

6.0.1 Original plans for the subway connection from Union Station to Union Subway

Station

Source: Retrieved October 10, 2008, from http://stevemunro.ca/wp-content/ uploads/2007/11/unionstn19531977.jpg

6.0.2 First Subway connection interrupted the original flow patterns of the station.

Source: Clayton Payer

6.0.3 New subway connection from the GO Concourse - functional convenience

Source: Clayton Payer

6.1.1 Smooth Space of the Desert Meeting the Striated Space of the cultivated

field

Source: Retrieved October 10, 2008, from http://www.christianhubert.com/

writings/smooth_striated.html)

6.1.2 Sectional Perspective of OMA's Souterrain Tunnel-Building

Source: Cecilia, F.M., Levene, R., (Ed.). (2007). Elcroquis editorial: OMA/Rem Koolhaas. Madrid: Premio COAM. Pg. 46

6.1.3 OMA's Souterrain - Clear Span space

Source: Cecilia, F.M., Levene, R., (Ed.). (2007). Elcroquis editorial: OMA/Rem Koolhaas. Madrid: Premio COAM. Pg. 56

6.1.4 OMA's Souterrain - In this one instance the outdoors, parking garage and Tram platforms can be view all at once.

Source: Cecilia, F.M., Levene, R., (Ed.). (2007). Elcroquis editorial: OMA/Rem

Koolhaas. Madrid: Premio COAM. Pg. 61

6.1.5 OMA's Souterrain - Glass topped floor display cases and Poster work wall displays

Source: Retrieved October 10, 2008, from http://www.architecture-page.com/go/ projects/souterrain-the-hague_2

6.1.6 Brentwood Station (floating station) vs. Souterrain (design is infrastructure)

Source: (source: http://www.busby.ca/clients/9910brentwood/index.htm 
Source: Source: Cecilia, F.M., Levene, R., (Ed.). (2007). Elcroquis editorial: OMAVRem Koolhaas. Madrid: Premio COAM. Pg. 56

7.1.1 Yokohama International Port Terminal

Source: Kubo, M., Sakamoto, T., Ferre, A. (Ed.). (2002). The Yokohama Project. Barcelona: Actar. Pg. 315-316

7.1.2 No-Return Diagram - interlaced loops

Source: Kubo, M., Sakamoto, T., Ferre, A. (Ed.). (2002). The Yokohama Project. Barcelona: Actar. Pg. 11

7.1.3 Longitudinal Section and Plan - lasagna effect

Source: Kubo, M., Sakamoto, T., Ferre, A. (Ed.). (2002). The Yokohama Project. Barcelona: Actar. Pg. 266-267

7.1.4 Interior of the main gathering space

Source: Kubo, M., Sakamoto, T., Ferre, A. (Ed.). (2002). The Yokohama Project. Barcelona: Actar. Pg. 112.

7.1.5 Circulation influencing structural layout

Source: Kubo, M., Sakamoto, T., Ferre, A. (Ed.). (2002). The Yokohama Project. Barcelona: Actar. Pg. 101

7.1.6 Corrugated Glass with buried mullions

Source: Kubo, M., Sakamoto, T., Ferre, A. (Ed.). (2002). The Yokohama Project. Barcelona: Actar. Pg. 212

7.1.7 . GO Concourse Signage - over stimulation

Source: Clayton Payer

7.1.8 Warping wook deck surface of Yokohama Terminal

Source: Kubo, M., Sakamoto, T., Ferre, A. (Ed.). (2002). The Yokohama Project. Barcelona: Actar. Pg. 176

7.2.1 Arnhem Central Interchange - Mixed Use Terminal

Source: Retrieved October 10, 2008, from http://www.unstudio.com/projects/ workfield/urban/1/146\#img2

7.2.2 Traffic Trajectories in three-dimensions

Source: Swerling, G., (Ed.). (2004). Railway Stations: from the gare de l'est to open penn station. Hong Kong: Electa Architecture. Pg. 196

7.2.3 The 3-Models Used to form the resultant structural form

Source: van Berkel, B., \& Bos, C. (2006). Design Models: Architecture, urbanism, infrastructure. London: Thames \& Hudson. Pg. 274

7.2.4 Arups (structural engineers) rending of interior, expansive and few programmed elements.

Source: Retrieved October 10, 2008, from http://www.arup.com/netherlands/ gallery.cfm?pageid=10463\#

7.2.5 Arnhem Central - Fast Flow vs. Slow Flow - trajectory based design

Source: Swerling, G., (Ed.). (2004). Railway Stations: from the gare de l'est to open penn station. Hong Kong: Electa Architecture. Pg. 200

7.2.6 Public Space slopping and converging at the knot, the interchange

Source: http://www.unstudio.com/projects/workfield/urban/1/146\#img1

7.4.1 Stuttgart Main Station - original terminal

Source: Retrieved October 10, 2008, from http://www.flickr.com/ photos/23835393@N04/2844908357/sizes/l/

7.4.2 Model of Ingenhoven Overdiek's new Stuttgart Station terminal Source: (Davey, P. (2003). Underground Station, Stuttgart, Germany: Ingenhoven Overdiek Architekten. The Architectural Review. Vol. 213, No. 1274, Pg. 66 
7.4.3 Diagram of where the new park space is located

Source: Clayton Payer - Modified GoogleEarth

7.4.4 Structure becomes one with skylights and park space

Source: http://www.core.form-ula.com/wp-content/uploads/2007/12/

1281126016_stuttgart-2thumbnail.jpg

7.5.1 Olympic Sculpture Park

Source: Busquets, J. (Ed.). (2008). Olympic Sculpture Park for the Seattle Art Museum. Harvard Graduate School of Design. Pg. 26-27

7.5.2 Before and after of Olympic Sculpture Park

Source: Busquets, J. (Ed.). (2008). Olympic Sculpture Park for the Seattle Art Museum. Harvard Graduate School of Design. Pg. 26-27

7.5.3 Olympic Sculpture Park Plans

Source: Busquets, J. (Ed.). (2008). Olympic Sculpture Park for the Seattle Art Museum. Harvard Graduate School of Design. Pg. 65

7.5.4 Mapped routes and entrances

Source: Busquets, J. (Ed.). (2008). Olympic Sculpture Park for the Seattle Art Museum. Harvard Graduate School of Design. Pg. 65

9.1.1 Graham Steward's TTC map,

Source: Retrieved on September 2009 from http://www.readingt.readingcities. com/index.php/toronto/comments/1111/

9.1.2 Convergent Infrastructure Systems - RED: Highway, SOLID GREEN, YELLOW, BLUE, PURPLE: Subway, and DASHED GREEN: GO Transit/VIA Links

Source: Clayton Payer

9.1.3 Venues and districts

Source: Clayton Payer

9.1.4 Transition Zone

Source: Clayton Payer

9.1.5 Shipping and Rail Industry, Union Station to the Rlght, 1929.

Source: City of Toronto Archives, Union Station from old tower looking east, Fonds 1231, Item 11, Retrieved Sept, 23, 2009 from www.toronto.ca

9.1.6 he extent of the railway yards and their peak usage.

Source: Clayton Payer

9.1.7 Gardiner Expressway.

Source: Clayton Payer

9.2.1 Simcoe Street, York Street and Bay Street subdividing the site into 3 zones.

Source: Clayton Payer

9.2.2 Simcoe Street and MTCC gates.

Source: Clayton Payer

9.2.3 Bremner Boulevard with surrounding park spaces (note Bremners termination at the ACC with a minor park space).

Source: Clayton Payer

9.2.4 Typical day condition of the ACC devoid of users until an event is held.

Source: Clayton Payer

9.2.5 Roundhouse Park with new turntable display and miniture steam engine ride.

Source: Retrieved on Sept 23, 2009 from http://www.trha.cal 
9.2.6 Evolution of Toronto's Harbourfront.

Source: Clayton Payer

9.2.7 3 Elevation Regions

Source: Clayton Payer

9.2.8 present north-South connections

Source: Clayton Payer

9.2.9 Skywalk connection from Union Station (RIGHT) to MTCC South building (LEFT) Source: Clayton Payer

9.2.10 RED: no overpass, GREEN: Overpass (only one overpass, John Street Bridge) Source: Clayton Payer

10.0.1 Central Railway Land district

Source: Clayton Payer

10.0.2 Surface generated by the extents of the CRL

Source: Clayton Payer

10.0.3 Spaces presently occupied by structures are cut from the surface.

Source: Clayton Payer

10.0.4 Removed element begins to define the surfaces extends and boundaries.

Source: Clayton Payer

10.0.5 Surface dropped down over the CRL's underdeveloped territories.

Source: Clayton Payer

10.0.6 The existing Roundhouse Park defines the form of the southern edge.

Source: Clayton Payer

10.0.7 Final proto-form for the navigable surface.

Source: Clayton Payer

10.0.8 Existing north-south routes and areas not supporting pedestrian movements.

Source: Clayton Payer

10.0.9 New trajectories developed to provide the most direct connections across the CRL Territory.

Source: Clayton Payer

10.0.10 New North to South connections over top over the surface.

Source: Clayton Payer

10.0.11 Increased South - North connections in conjunction with existing tunnels.

Source: Clayton Payer

10.0.12 Direct East-West connections provided over the surface.

Source: Clayton Payer

10.0.12 New central train hall provides multi-direction access to the CRL.

Source: Clayton Payer

10.0.13 Vehicular access is provided through John St. Bridge and southern terraced sec ions of the surface.

Source: Clayton Payer

10.1.1 Surface is subdivided into $8 \mathrm{~m}$ wide strips to coincide with the centre-to-centre distances of Union Station's platforms.

Source: Clayton Payer

10.1.2 Various conditions generated by the ribbon effect.

Source: Clayton Payer 
10.1.3 Strip can form an overlap to become programmable amenity spaces. Source: Clayton Payer

10.1.4 Rolling effect can generate naturalistic landscapes for parks and tree lines. Source: Clayton Payer

10.1.5 Subtle ripples form places to relax under the shape of adjacent tree lines. Source: Clayton Payer

10.1.6 A separation of the surface can form bridges to provide multi-direction move ment over the surface.

Source: Clayton Payer

10.1.7 A larger separation of the surface can provide large interior spaces such as the new MTCC Expo Hall

Source: Clayton Payer

10.1.8 Increased dips and rises can form places of play such as a waterpark.

Source: Clayton Payer

10.1.9 During the winter the rolling surface provides places for families to enjoy the snow in an urban condition.

Source: Clayton Payer

10.1.10 Sectional Variations from Front Street to Bremner Boulevard

Source: Clayton Payer

10.1.11 LEFT: east-west perspective reveals a continuous surface, RIGHT: continuous surface is broken up by subtle verticals.

Source: Clayton Payer

10.1.12 First Level: Multi colored strips represent various planting materials.

Source: Clayton Payer

10.1.13 Sub Level: ORANGE: Interior public spaces, PURPLE: Amenity spaces, PINK: Union Station extents.

Source: Clayton Payer

10.1.14 Base Level: PURPLE - Amenity spaces, PINK: Union Station Sub Level Ex tents, ORANGE: interior public spaces.

Source: Clayton Payer

10.2.1 Major programmed areas outlined in RED.

Source: Clayton Payer

10.2.2 GREEN: Park Concourse, BLUE: Front Street Plaza, YELLOW: Stramp access from Front Street to top of surface.

Source: Clayton Payer

10.2.3 DARK GREEN: Field, LIGHT GREEN: Urban Forest, BROWN: Water Park (skating rink in winter), YELLOW: ACC Grandstand.

Source: Clayton Payer

10.2.4 BLUE: Amenity space, BEIGE: Plaza, PURPLE: Stage, BROWN: Treeline and benches, YELLOW: Amenity spaces and integrated Skywalk connection.

Source: Clayton Payer

10.2.5 GREEN: Mixed gardens and ecosystems, BEIGE: North-South Plaza space, YELLOW: Enclosed public spaces

Source: Clayton Payer 
10.2.6 PURPLE: Terraced southern access, BEIGE: Plaza, YELLOW: Historical Train buildings, GREEN: Park space, LIGHT BROWN: water retention marsh. Source: Clayton Payer

10.2.7 Section through Union Station from the Royal York to Air Canada Centre. Source: Clayton Payer

10.2.8 Section through new MTCC south building. RED DASHED LINE: Existing condition below.

Source: Clayton Payer

10.2.9 Section through CN Tower Plaza to Roundhouse Park. Source: Clayton Payer

10.2.10 Interior Perspective of Train Hall looking East from elevated concourse. Source: Clayton Payer

10.2.11 Interior Perspective of Train Hall looking South from platforms.

Source: Clayton Payer

10.2.12 Forested Meadow Park looking West.

Source: Clayton Payer

10.2.13 Front Street Plaza including stramp and escalators to access the park space above the rail corridor.

Source: Clayton Payer

10.2.14 Perspective of outdoor gallery and CN Tower Media Park

Source: Clayton Payer

10.2.15 Bremner Boulevard beneath Roundhouse Info Plaza looking West. Source: Clayton Payer

10.2.16 Perspective from Roundhouse Park looking North.

Source: Clayton Payer

10.2.17 Surface rising to accommodate stairs from Roundhouse Info Plaza to Bremner Blvd.

Source: Clayton Payer

10.2.18 ACC Grandstand. A stage surrounded by tree lines and terraced landscaping. The terracing also provides vertical access to the park.

Source: Clayton Payer 


\section{List of Appendices}

Appendix A1 Top Level Layout

Source: Clayton Payer

Appendix A2 Mid Level Layout

Source: Clayton Payer

Appendix A3 Base Level Layout

Source: Clayton Payer 
[XXIV] 


\title{
PUBLIC LANDSCAPE: \\ THE REINVENTION OF TORONTO'S UNION STATION \& CENTRAL RAILWAY LANDS
}

\author{
by \\ Clayton Uilliam Hamish Payer \\ Bachelor of Architectural Science, Ryerson University, Toronto, 2007 \\ A design thesis/project \\ Presented to Ryerson University \\ In partial fulfillment of the \\ Master of Architecture \\ in the Program of \\ Master of Architecture
}

Toronto, Ontario, Canada, 2009

(C) Clayton Payer 2009 


\section{Author's Declaration}

I hereby declare that I am the sole author of this thesis.

I authorize Ryerson University to lend this thesis to other institutions or individuals for their purpose of scholarly research.

Signature

I further authorize Ryerson University to reproduce this thesis by photocopying or by other means, in total or in part, at the request of other institutions or individuals for the purpose of scholarly research.

Signature 


\title{
Abstract
}

\author{
Clayton Uilliam Hamish Payer \\ Master of Architecture, Ryerson University, Toronto, 2009
}

There is concern for Toronto's outdated, underutilized, and underdeveloped transit hubs and their subsequent lack of developed public spaces. One such hub is Toronto's Union Station, central portal of the GTA's mass transit system. This site was selected for a comprehensive analysis and critique of the station's physiology, the urban morphology of its immediate context, and its future needs. Research found that the station and its context are poorly organized requiring a redesign to unify the disjointed characteristics of the site. A design proposal formulates a continuous surface of public space over a redesigned train hall that stretches over the rail lands to bind, connect, and integrate an urban park in order to reorganize the areas existing venues and to recognize the station's importance as the region's and city's central transit hub. 


\section{Acknowledgements}

Many thanks to my adviser Cheryl Atkinson, my colleagues for their generous input and the support of my family and friends. 


\section{Contents}

PUBLIC LANDSCAPE: THE REINVENTION OF TORONTO'S

UNION STATION AND CENTRAL RAILWAY LANDS

Author's Declaration

Abstract

Acknowledgements

Contents

List of Figures

XIII

List of Appendices

XXIII

1.0 Introduction

1.1 Union Station -A Rotting Beaux-Art's Carcass

2.0 Union Station History

3.0 Contextual Evolution

3.1 Request for Expression

23

3.2 Current Trends

27

4.0 So Many Issues ...

4.1 Fragmented Station

4.2 Missing Identity

4.3 A Solution

5.0 What is Union Station?

5.1 Space and Atmosphere

5.2 Urban Exchange Complex

5.3 An Ideal Station

5.4 Not Important 


\subsection{Case Studies}

7.1 Warped Lasagna - Yokohama International Port Terminal

7.2 An organ, like the heart or a kidney - An Arnhem Central Interchange

7.3 Hard-to-Find Examples

7.4\$7 Billion Station - Stuttgart Main Station

7.5 Z-Shaped - Olympic Sculpture Park

7.6 Last Two Examples

\subsection{Proposal for Union Station}

8.1 What Did We Learn From Node-Place?

8.2 New Characteristics

8.3 Final Thoughts

\subsection{Design Introduction}

9.1 Regional Importance

9.2 Central Railway Land Circulation

10.0 Intervention - the Surface

10.1 Intervention - the Surface formally

10.2 Intervention - Programming

10.2.2 Roundhouse Info Plaza

10.2.4 MTCC Expo Building

10.2.5 CN Tower Plaza

10.2.6 Outdoor Gallery

10.2.7 Rail Line Plaza 
10.5 Structure

10.6 Final Remarks

11.0 Bibliography

$\begin{array}{ll}\text { Appendix A1 Top Level Layout } & 187\end{array}$

$\begin{array}{lr}\text { Appendix A2 Mid Level Layout } & 189\end{array}$

Appendix A3 Base Level Layout

191 


\section{List of Figures}

1.0 .0

2.0 .1

2.0 .2

2.0 .3

2.0 .4

2.0.5 Traditional Terminating Station vs. Through Station

2.0 .6

2.0 .7

2.0 .8

2.0 .9

2.0 .10

2.0 .11

2.0 .12

2.0 .13

3.0 .1

3.0 .2

3.0 .3

3.0 .4

3.0 .5

3.0 .6

Toronto's Union Station Proposed Elevation as of 1916. Departures concourse access the Great Hall in 3 locations)

Union Station Bush Style Trainshed

Source: Clayton Payer

Source: Clayton Payer

Union Station's Great Hall

Source: Clayton Payer

Departure \& Arrivals Separation

Source: Courtesy of Clayton Payer

Additions of GO Transit and TTC Subway connection

Source: Clayton Payer

Skywalk Connection and Canadian Express Building

Source: Clayton Payer

Skywalk Connection with boarded up amenities fronts

Source: Clayton Payer

Construction of West Teamways

Source: Clayton Payer

Construction of Go Concourse South Platforms

Source: Clayton Payer

New South Entrance - Rendering

district_plan.htm.Pg. 23

Growth of Toronto's Waterfront

Source: Clayton Payer

district_plan.htm. Pg. 6

Financial District

Source: Clayton Payer Gardiner Expressway as seen from Cherry St. Model of the 1968 Metro Centre Proposal

Future Site of Union Station with mapped properties burned down in 1904. Source: Carr, A. (2005) Toronto Union Station Historical Structure Report. Toronto: Fournier Gersovitz Moss \& Associes architectes. Pg. 22

Source: Carr, A. (2005) Toronto Union Station Historical Structure Report.

Toronto: Fournier Gersovitz Moss \& Associes architectes. Pg. 25

Original Union Station Layout (notice how the original plan allowed the

Source: Carr, A. (2005) Toronto Union Station Historical Structure Report.

Toronto: Fournier Gersovitz Moss \& Associes architectes. Pg. 27

Source: Union Station District Plan. (2006, May). Toronot: architectsAlliance Retrieved October 10, 2008, from http://www.toronto.ca/union_station/

Canyon of Stone (Union Station to the right, facing the Royal York Hotel)

Source: Union Station District Plan. (2006, May). Toronot: architectsAlliance.

Retrieved October 10, 2008, from http://www.toronto.ca/union_station/

Construction of Union Station's concourse with Stock Yards to the left

Source: City of Toronto Archives, Union Station from old tower looking east, Fonds 1231, Item 71, Retrieved Nov, 23, 2008 from www.toronto.ca

Source: http://farm4.static.flickr.com/3008/2702301488_0ecf376a7a_b.jpg) 
Source: Union Station District Plan. (2006, May). Toronot: architectsAlliance.

Retrieved October 10, 2008, from http://www.toronto.ca/union_station/

district_plan.htm. Pg. 34

3.0.7 Revised Metro Centre section plan to include Union Station

Source: Union Station District Plan. (2006, May). Toronot: architectsAlliance.

Retrieved October 10, 2008, from http://www.toronto.ca/union_station/

district_plan.htm. Pg. 33

3.0.8 Metro Centre Model compared to present day Toronto

Source: Clayton Payer

3.0.9 Large scale develops still cannot consume the rail lands, circa 1999

Source: http://map.toronto.ca/imapit/Maplt.jsp?app=TOMaps

3.1.1 Rem Koolhaas Master plan, vague representations.

Source: Retrieved October 10, 2008, from www.oma.nl

3.1.2 Rem Koolhaas Master plan, new concourse

Source: Retrieved October 10, 2008, from www.oma.nl

3.1.3 OMA Master plan vs. existing public park spaces

Source: Clayton Payer

3.1.4 Current GO Transit platform canopy proposal

Source: Retrieved October 10, 2008, from http://www.cdnarchitect.com

3.2.1 Finer Grain vs. Larger Grain Property divisions

Source: Clayton Payer

3.2.2 Road Conditions in the Union Station area

Source: Clayton Payer

3.2.3 Typical weekday, devoid of activity (Roundhouse to the left, Rogers Centre to the Right)

Source: Clayton Payer

3.2.4 Recently renovated Simcoe Tuneel

Source: Retrieved September 23, 2009, from http://urbantoronto.ca/

Source: Clayton Payer

3.2.5 New Telus building designed by \&Co (Under construction)

Source: Retrieved October 10, 2008, from http://www.andco.com/

3.2.6 Proposed Maple Leafs Square (Under construction)

Source: Retrieved October 10, 2008, from www.mapleleafsquare.com/

3.2.7 Initial Proposal renderings for ICE Condo's. No relation to surrounding context

Source: Retrieved October 10, 2008, from www.icecondo.ca

3.2.8 Locations of New Developments, defining York St.

Source: Clayton Payer

3.2.9 KPMB design ibIMC office tower

Source: Retrieved October 10, 2008, from www.bcimc.com/

3.2.10 Union Station District Plan boudaries enclosing historical structures (brown)

Source: Clayton Payer

4.1.1 Layout of Infrastructural Services, only Go Transit is located within Union Station

Source: Clayton Payer

4.1.2 GO Bus Terminal separated by 4-lane road and pedestrian barrier

Source: Clayton Payer

4.1.3 Porter Kiosk location relative to pickup

Source: Clayton Payer

4.1.4 York Teamway entrance located off from direct pedestrian movement

Source: Clayton Payer 
4.1.5 York Concourse located deep within the terminal

Source: Clayton Payer

4.1.6 Converted Postal Sorting Room provides the most basic creature comforts

Source: Clayton Payer

4.1.7 Dedicated, Influenced and Non-Affiliated GO Transit Spaces.

Source: Clayton Payer

4.1.8 Old Men's Sitting room converted into an interstitial space

Source: Clayton Payer

4.1.9 Current state of the arrivals concourse - barren when GO Transit users are not occupying it

Source: Clayton Payer

4.2.1 Comparison of Public Park's in various American cities

Source: Clayton Payer

4.2.2 Front St. Plaza, unattractive and unused

Source: Clayton Payer

4.2.3 Union Station Master plan proposal for a continuous paved surface

Source: Union Station District Plan. (2006, May). Toronot: architectsAlliance.

Retrieved October 10, 2008, from http://www.toronto.ca/union_station/

district_plan.htm. Pg. 127

4.2.4 Union Station Master plan proposal for removal of centre median

Source: Union Station District Plan. (2006, May). Toronot: architectsAlliance.

Retrieved October 10, 2008, from http://www.toronto.ca/union_station/

district_plan.htm. Pg. 17

4.2.5 Congested sidewalk during rush hour

Source: Clayton Payer

4.2.6 Typical Weekday in front of the MTCC - barren and lifeless

Source: Clayton Payer

4.2.7 Union Plaza and Major access points - not a traditionally shaped public space

Source: Union Station District Plan. (2006, May). Toronot: architectsAlliance.

Retrieved October 10, 2008, from http://www.toronto.ca/union_station/

district_plan.htm. Pg. 106

4.2.8 Visual journey through Union Station to Union Plaza - not linear, and does not provide easy visual cues to target

Source: Clayton Payer

4.2.9 Toronto Maple Leafs Proposal, images apart of the Unbuilt Toronto conducted by the Toronto Society of Architects

Source: Retrieved October 10, 2008, from http://www.unbuilttoronto.ca/

4.2.10 Original Union Plaza before developments and ACC extension

Source: http://basketball.ballparks.com/NBA/TorontoRaptors/newaerial.jpg

4.2.11 Future PATH system connections

Source: Union Station District Plan. (2006, May). Toronot: architectsAlliance.

Retrieved October 10, 2008, from http://www.toronto.ca/union_station/

district_plan.htm. Pg. 106

4.2.12 Park spaces in the Contextual Area of Union Station

Source: Clayton Payer

4.2.13 John St. Bridge - connects over the rail yard

Source: Clayton Payer

4.2.14 MTCC Skywalk Connection, connects over the rail yard

Source: Clayton Payer 
4.2.15 Rogers Centre Plaza \& CN Tower Park - uninspiring places to visit Source: Clayton Payer

4.2.16 . Steep elevation change adjacent to Roundhouse Source: Clayton Payer

4.2.17 Union Station District Plans detail public spaces, contrasted against what actually exists and addition areas where it is highly resistant to public space Source: Union Station District Plan. (2006, May). Toronot: architectsAlliance. Retrieved October 10, 2008, from http://www.toronto.ca/union_station/ district_plan.htm. Pg. 101

4.2.18 Difficult to put tall buildings into context Source: Clayton Payer

4.2.19 HtO Park in relation to Harbourfront condo's and streets.

Source: Clayton Payer

4.2.20 Yellow: Elevated Barriers, Red: Rail Yard Barrier

Source: Clayton Payer

4.2.21 Impenetrable stone façades along the south side of Front St.

Source: Clayton Payer

4.2.22 Elevation Change from Front St. to waterfront

Source: Clayton Payer

4.2.23 The rail yards form a visually barrier that inhibits a clear view of the rail lands and waterfront.

Source: Clayton Payer

4.2.24 Steep climb blocks views to the waterfront

Source: Clayton Payer

4.2.25 GO Transit Teamways - signage, colour scheme and doors define the teamways as transit spaces and not public throughways

Source: Clayton Payer

4.2.26 The sidewalk provides a direct route while the teamway is placed out the direct path of movement.

Source: Clayton Payer

4.2.27 Elevated Gardiner Expressway with Lakeshore Blvd below.

Source: Clayton Payer

4.2.28 Intersection of Lakeshore Blvd. \& Yonge St.

Source: Clayton Payer

5.1.1 500m walking radius from Union Station

Source: Clayton Payer

5.1.2 $500 \mathrm{~m}$ radius augmented by PATH system

Source: Clayton Payer

5.1.3 Walk distance based on PATH system and restricted by barriers

Source: Clayton Payer

5.1.4 Historical Boundaries defined by historical structures related to Union Station.

Source: Clayton Payer

5.1.5 Topographical extents, primarily formed by the elevated rail lines

Source: Clayton Payer

5.1.6 Defined Union Station District Plan Boundaries

Source: Clayton Payer

5.1.7 The strongest overlap that defines the extent of Union Station is north of the topographical features

Source: Clayton Payer 
5.2.1 Bertonlini Node-Place Model

Source: Bruinsma, F., Pels, E., Priemus, H., Rietveld, P., \& van Wee, B., (Ed.). (2008). Railway Development: Impacts on urban dynamics [Electronic Version]. Physica-Verlag Heidelberg. Pg. 38

5.3.1 Four approaches to railway station development

Source: Bruinsma, F., Pels, E., Priemus, H., Rietveld, P., \& van Wee, B., (Ed.). (2008). Railway Development: Impacts on urban dynamics [Electronic Version]. Physica-Verlag Heidelberg. Pg. 127

5.3.2 Red: Shortest route to the USA Border. Orange \& Yellow dashed Lines are the next shortest routes to the US Border.

Source: Clayton Payer - GoogleEarth Modification

5.3.3 Kyoto Station, a multilevel complex with various amenities and services.

Source: Swerling, G., (Ed.). (2004). Railway Stations: from the gare de l'est to open penn station. Hong Kong: Electa Architecture. Pg. 113

5.3.4 Kyoto Station central atrium space

Source: Swerling, G., (Ed.). (2004). Railway Stations: from the gare de l'est to open penn station. Hong Kong: Electa Architecture. Pg. 117

5.3.5 Calthorpe Associates Transit Oriented Diagram

Source: Retrieved October 10, 2008, from www.calthorpe.com/

5.3.6 Available areas for development in a $500 \mathrm{~m}$ radius of Union Station

Source: Clayton Payer

6.0.1 Original plans for the subway connection from Union Station to Union Subway Station

Source: Retrieved October 10, 2008, from http://stevemunro.ca/wp-content/ uploads/2007/11/unionstn19531977.jpg

6.0.2 First Subway connection interrupted the original flow patterns of the station. Source: Clayton Payer

6.0.3 New subway connection from the GO Concourse - functional convenience Source: Clayton Payer

6.1.1 Smooth Space of the Desert Meeting the Striated Space of the cultivated field

Source: Retrieved October 10, 2008, from http://www.christianhubert.com/ writings/smooth_striated.html)

6.1.2 Sectional Perspective of OMA's Souterrain Tunnel-Building

Source: Cecilia, F.M., Levene, R., (Ed.). (2007). Elcroquis editorial: OMARem Koolhaas. Madrid: Premio COAM. Pg. 46

6.1.3 OMA's Souterrain - Clear Span space

Source: Cecilia, F.M., Levene, R., (Ed.). (2007). Elcroquis editorial: OMA/Rem Koolhaas. Madrid: Premio COAM. Pg. 56

6.1.4 OMA's Souterrain - in this one instance the outdoors, parking garage and Tram platforms can be view all at once.

Source: Cecilia, F.M., Levene, R., (Ed.). (2007). Elcroquis editorial: OMAVRem Koolhaas. Madrid: Premio COAM. Pg. 61

6.1.5 OMA's Souterrain - Glass topped floor display cases and Poster work wall displays

Source: Retrieved October 10, 2008, from http://www.architecture-page.com/go/ projects/souterrain-the-hague__2

6.1.6 Brentwood Station (floating station) vs. Souterrain (design is infrastructure) Source: (source: http://www.busby.ca/clients/9910brentwood/index.htm 
Source: Source: Cecilia, F.M., Levene, R., (Ed.). (2007). Elcroquis editorial: OMAVRem Koolhaas. Madrid: Premio COAM. Pg. 56

7.1.1 Yokohama International Port Terminal

Source: Kubo, M., Sakamoto, T., Ferre, A. (Ed.). (2002). The Yokohama Project. Barcelona: Actar. Pg. 315-316

7.1.2 No-Return Diagram - interlaced loops

Source: Kubo, M., Sakamoto, T., Ferre, A. (Ed.). (2002). The Yokohama Project. Barcelona: Actar. Pg. 11

7.1.3 Longitudinal Section and Plan - lasagna effect

Source: Kubo, M., Sakamoto, T., Ferre, A. (Ed.). (2002). The Yokohama Project. Barcelona: Actar. Pg. 266-267

7.1.4 Interior of the main gathering space

Source: Kubo, M., Sakamoto, T., Ferre, A. (Ed.). (2002). The Yokohama Project. Barcelona: Actar. Pg. 112

7.1.5 Circulation influencing structural layout

Source: Kubo, M., Sakamoto, T., Ferre, A. (Ed.). (2002). The Yokohama Project. Barcelona: Actar. Pg. 101

7.1.6 Corrugated Glass with buried mullions

Source: Kubo, M., Sakamoto, T., Ferre, A. (Ed.). (2002). The Yokohama Project. Barcelona: Actar. Pg. 212

7.1.7 . GO Concourse Signage - over stimulation

Source: Clayton Payer

7.1.8 Warping wook deck surface of Yokohama Terminal

Source: Kubo, M., Sakamoto, T., Ferre, A. (Ed.). (2002). The Yokohama Project. Barcelona: Actar. Pg. 176

7.2.1 Arnhem Central Interchange - Mixed Use Terminal

Source: Retrieved October 10, 2008, from http://www.unstudio.com/projects/ workfield/urban/1/146\#img2

7.2.2 Traffic Trajectories in three-dimensions

Source: Swerling, G., (Ed.). (2004). Railway Stations: from the gare de l'est to open penn station. Hong Kong: Electa Architecture. Pg. 196

7.2.3 The 3-Models Used to form the resultant structural form

Source: van Berkel, B., \& Bos, C. (2006). Design Models: Architecture, urbanism, infrastructure. London: Thames \& Hudson. Pg. 274

7.2.4 Arups (structural engineers) rending of interior, expansive and few programmed elements.

Source: Retrieved October 10, 2008, from http://www.arup.com/netherlands/ gallery.cfm?pageid=10463\#

7.2.5 Arnhem Central - Fast Flow vs. Slow Flow - trajectory based design Source: Swerling, G., (Ed.). (2004). Railway Stations: from the gare de l'est to open penn station. Hong Kong: Electa Architecture. Pg. 200

7.2.6 Public Space slopping and converging at the knot, the interchange Source: http://www.unstudio.com/projects/workfield/urban/1/146\#img1

7.4.1 Stuttgart Main Station - original terminal Source: Retrieved October 10, 2008, from http://www.flickr.com/ photos/23835393@N04/2844908357/sizes///

7.4.2 Model of Ingenhoven Overdiek's new Stuttgart Station terminal Source: (Davey, P. (2003). Underground Station, Stuttgart, Germany: Ingenhoven Overdiek Architekten. The Architectural Review. Vol. 213, No. 1274, Pg. 66 
7.4.3 Diagram of where the new park space is located

Source: Clayton Payer - Modified GoogleEarth

7.4.4 Structure becomes one with skylights and park space

Source: http://www.core.form-ula.com/wp-content/uploads/2007/12/

1281126016_stuttgart-2thumbnail.jpg

7.5.1 Olympic Sculpture Park

Source: Busquets, J. (Ed.). (2008). Olympic Sculpture Park for the Seattle Art Museum. Harvard Graduate School of Design. Pg. 26-27

7.5.2 Before and after of Olympic Sculpture Park

Source: Busquets, J. (Ed.). (2008). Olympic Sculpture Park for the Seattle Art Museum. Harvard Graduate School of Design. Pg. 26-27

7.5.3 Olympic Sculpture Park Plans

Source: Busquets, J. (Ed.). (2008). Olympic Sculpture Park for the Seattle Art Museum. Harvard Graduate School of Design. Pg. 65

7.5.4 Mapped routes and entrances

Source: Busquets, J. (Ed.). (2008). Olympic Sculpture Park for the Seattle Art Museum. Harvard Graduate School of Design. Pg. 65

9.1.1 Graham Steward's TTC map,

Source: Retrieved on September 2009 from http://www.readingt.readingcities. com/index.php/toronto/comments/1111/

9.1.2 Convergent Infrastructure Systems - RED: Highway, SOLID GREEN, YELLOW, BLUE, PURPLE: Subway, and DASHED GREEN: GO Transit/VIA Links Source: Clayton Payer

9.1.3 Venues and districts

Source: Clayton Payer

9.1.4 Transition Zone

Source: Clayton Payer

9.1.5 Shipping and Rail Industry, Union Station to the Right, 1929.

Source: City of Toronto Archives, Union Station from old tower looking east, Fonds 1231, Item 11, Retrieved Sept, 23, 2009 from www.toronto.ca

9.1.6 he extent of the railway yards and their peak usage.

Source: Clayton Payer

9.1.7 Gardiner Expressway.

Source: Clayton Payer

9.2.1 Simcoe Street, York Street and Bay Street subdividing the site into 3 zones.

Source: Clayton Payer

9.2.2 Simcoe Street and MTCC gates.

Source: Clayton Payer

9.2.3 Bremner Boulevard with surrounding park spaces (note Bremners termination at the ACC with a minor park space).

Source: Clayton Payer

9.2.4 Typical day condition of the ACC devoid of users until an event is held.

Source: Clayton Payer

9.2.5 Roundhouse Park with new turntable display and miniture steam engine ride.

Source: Retrieved on Sept 23, 2009 from http://www.trha.ca/ 
9.2.6 Evolution of Toronto's Harbourfront.

Source: Clayton Payer

9.2.7 3 Elevation Regions

Source: Clayton Payer

9.2.8 present north-South connections

Source: Clayton Payer

9.2.9 Skywalk connection from Union Station (RIGHT) to MTCC South building (LEFT)

Source: Clayton Payer

9.2.10 RED: no overpass, GREEN: Overpass (only one overpass, John Street Bridge)

Source: Clayton Payer

10.0.1 Central Railway Land district

Source: Clayton Payer

10.0.2 Surface generated by the extents of the CRL

Source: Clayton Payer

10.0.3 Spaces presently occupied by structures are cut from the surface.

Source: Clayton Payer

10.0.4 Removed element begins to define the surfaces extends and boundaries.

Source: Clayton Payer

10.0.5 Surface dropped down over the CRL's underdeveloped territories.

Source: Clayton Payer

10.0.6 The existing Roundhouse Park defines the form of the southern edge.

Source: Clayton Payer

10.0.7 Final proto-form for the navigable surface.

Source: Clayton Payer

10.0.8 Existing north-south routes and areas not supporting pedestrian movements.

Source: Clayton Payer

10.0.9 New trajectories developed to provide the most direct connections across the CRL Territory.

Source: Clayton Payer

10.0.10 New North to South connections over top over the surface.

Source: Clayton Payer

10.0.11 Increased South - North connections in conjunction with existing tunnels.

Source: Clayton Payer

10.0.12 Direct East-West connections provided over the surface.

Source: Clayton Payer

10.0.12 New central train hall provides multi-direction access to the CRL.

Source: Clayton Payer

10.0.13 Vehicular access is provided through John St. Bridge and southern terraced sec ions of the surface.

Source: Clayton Payer

10.1.1 Surface is subdivided into $8 \mathrm{~m}$ wide strips to coincide with the centre-to-centre distances of Union Station's platforms.

Source: Clayton Payer

10.1.2 Various conditions generated by the ribbon effect.

Source: Clayton Payer 
10.1.3 Strip can form an overlap to become programmable amenity spaces.

Source: Clayton Payer

10.1.4 Rolling effect can generate naturalistic landscapes for parks and tree lines.

Source: Clayton Payer

10.1.5 Subtle ripples form places to relax under the shape of adjacent tree lines.

Source: Clayton Payer

10.1.6 A separation of the surface can form bridges to provide multi-direction move ment over the surface.

Source: Clayton Payer

10.1.7 A larger separation of the surface can provide large interior spaces such as the new MTCC Expo Hall

Source: Clayton Payer

10.1.8 Increased dips and rises can form places of play such as a waterpark.

Source: Clayton Payer

10.1.9 During the winter the rolling surface provides places for families to enjoy the snow in an urban condition.

Source: Clayton Payer

10.1.10 Sectional Variations from Front Street to Bremner Boulevard

Source: Clayton Payer

10.1.11 LEFT: east-west perspective reveals a continuous surface, RIGHT: continuous surface is broken up by subtle verticals.

Source: Clayton Payer

10.1.12 First Level: Multi colored strips represent various planting materials.

Source: Clayton Payer

10.1.13 Sub Level: ORANGE: Interior public spaces, PURPLE: Amenity spaces, PINK: Union Station extents.

Source: Clayton Payer

10.1.14 Base Level: PURPLE - Amenity spaces, PINK: Union Station Sub Level Ex tents, ORANGE: interior public spaces.

Source: Clayton Payer

10.2.1 Major programmed areas outlined in RED.

Source: Clayton Payer

10.2.2 GREEN: Park Concourse, BLUE: Front Street Plaza, YELLOW: Stramp access from Front Street to top of surface.

Source: Clayton Payer

10.2.3 DARK GREEN: Field, LIGHT GREEN: Urban Forest, BROWN: Water Park (skating rink in winter), YELLOW: ACC Grandstand.

Source: Clayton Payer

10.2.4 BLUE: Amenity space, BEIGE: Plaza, PURPLE: Stage, BROWN: Treeline and benches, YELLOW: Amenity spaces and integrated Skywalk connection.

Source: Clayton Payer

10.2.5 GREEN: Mixed gardens and ecosystems, BEIGE: North-South Plaza space, YELLOW: Enclosed public spaces

Source: Clayton Payer 
10.2.6 PURPLE: Terraced southern access, BEIGE: Plaza, YELLOW: Historical Train buildings, GREEN: Park space, LIGHT BROWN: water retention marsh.

Source: Clayton Payer

10.2.7 Section through Union Station from the Royal York to Air Canada Centre.

Source: Clayton Payer

10.2.8 Section through new MTCC south building. RED DASHED LINE: Existing condition below.

Source: Clayton Payer

10.2.9 Section through CN Tower Plaza to Roundhouse Park.

Source: Clayton Payer

10.2.10 Interior Perspective of Train Hall looking East from elevated concourse.

Source: Clayton Payer

10.2.11 Interior Perspective of Train Hall looking South from platforms.

Source: Clayton Payer

10.2.12 Forested Meadow Park looking West.

Source: Clayton Payer

10.2.13 Front Street Plaza including stramp and escalators to access the park space above the rail corridor.

Source: Clayton Payer

10.2.14 Perspective of outdoor gallery and CN Tower Media Park

Source: Clayton Payer

10.2.15 Bremner Boulevard beneath Roundhouse Info Plaza looking West.

Source: Clayton Payer

10.2.16 Perspective from Roundhouse Park looking North.

Source: Clayton Payer

10.2.17 Surface rising to accommodate stairs from Roundhouse Info Plaza to Bremner Blvd.

Source: Clayton Payer

10.2.18 ACC Grandstand. A stage surrounded by tree lines and terraced landscaping. The terracing also provides vertical access to the park.

Source: Clayton Payer 


\section{List of Appendices}

Appendix A1 Top Level Layout Source: Clayton Payer

Appendix A2 Mid Level Layout Source: Clayton Payer

Appendix A3 Base Level Layout Source: Clayton Payer 


\subsection{Introduction}

Station terminals have historically been designed as single-use facilities to promote and objectify the technological innovations that the railway industry gave to the first form of mass travel. The relationship of this type of infrastructure to the city was simple and straightforward. But over time, new modes of infrastructure involving automobile, bus, airplane and rail have forced stations to reorganize and integrate these new infrastructures (Dawes, 2001). Present design practices that objectify rail as 'temples of technology' have become incapable of handling the fluctuating modes of infrastructure, causing some architects to increasingly integrate stations into the urban 'milieu' (Dawes, 2001, p. 11). According to Stickells in Heterotopia and the city: Public space in a postcivil society (2008), the architecture of stations has shifted from objectification to experimenting with a design theory that he calls "Flow Urbanism." This new approach embraces public space as a way to integrate infrastructure, architecture and context in the design of station terminals.

This Thesis Proposes the design of the Central Railway Land Park that embraces public space as an urban framework of continuous public landscape that re-prioritizes the current hierarchy of transportation modes and public space in Toronto to generate places of social interaction. Toronto's primary multi-modal hub, Union Station primacy as a transit link and portal to the city needs to be asserted since becoming a devalued gateway to Metropolitan Toronto. While Union Station's original roll was to provide Toronto with a national gateway during the mid 20th century, it has since become a dysfunctional and underutilized transit hub that currently exists as a key new regional gateway to the city, the Pearson International Airport and the Greater Toronto Area (GTA).

Typical of many North American cities that have had their urban spaces and venues designed around the car, Toronto has continued to default to traffic design rather than urban design as its modus operandi when it comes to designing streets and plazas. These unfortunate urban design principles have left too few opportunities for new pedestrian oriented urban spaces to exist in the contemporary city. To prioritize the pedestrian, key areas of the city need to be identified as having the opportunity to serve as pedestrian focused links between strategic parts of the city.

The existing CRL in combination with Union Station were recognized as one such opportunity. The CRL's territory between Front Street and the Lakeshore Boulevard is an awkward interstitial space separating Toronto from the newly develop public space along Lake 
Ontario that reinforces the city's perception of Front Street as the southern boundary to the city. The random locations of large scale sports and entertainment venues, and now high density housing in this area has created a chaotic series of islands separated from one another by large scale transit infrastructure, poorly integrated existing park spaces and numerous awkward address and level changes. The existence of Union Station here as a major regional transit hub further increases the irnportance of creating a place that is beneficial for all the people of Toronto.

This thesis project herein proposes to redesign the operation of Union Station and function of CRL to become a major urban portal in and out of the city and to anchor the design in a New Urban Park that connects transit hub with premier entertainment venues and housing along the CLR's southern side. By researching and analyzing Union Station and its environs through historical progression in both plan and section, it was possible to begin to understand this chaotic and pedestrian hostile domain, as the result of car biased urban planning that prioritized the delivery of goods and services over more humanistic concerns. By focusing on this local as a mass transit hub for the entire region and city, it was possible to see the opportunities for re-creating a domain for the pedestrian, cyclist, and mass transit commuter.

Three initiatives were developed to encompass the research and analyses findings in order provide a reformatting of the $\mathrm{CRL}$ into a cohesive urban space. First, a grand terminal hall providing open sight-lines, easy pedestrian access, and direct connections to park spaces and venues; second, an activated continuous public park space with a functional mix of uses, merging scattered nodes of the CLR; and third, a consistent topographical form that physically and visually unites the programmed and circulatory elements of the park space with the urban fabric of Toronto. These requirements formulated a public landscape space that spans the CRL's from east-to-west above the railway corridor and merges into the Roundhouse Park to the south. Through the creation of a new contiguous surface of urban parks and plazas that lifts and warps to connect the station, the various buildings, street levels, and to bridge the existing rail corridor, it is possible to create a new public domain that prioritizes pedestrians, cyclists, venue patrons and transit users.

The public landscape was conceived as a surface on which user trajectories could be mapped out to facilitate convenient and direct links to destinations of the CRL. As a surface it provided the ability to use consistent horizontal language through the CRL, allowing isolated elements to function within a common medium. The common medium takes on the form of parallel ribbons of varying topographies and fluctuating programmatic conditions. The 
topographical changes of the ribbons navigate the awkward topographical changes of the existing site and provide vertical access up and over the present rail corridor.

A network of paths alone would have been insufficient to support the users of the various venues and thus networks of programmed spaces were created in tandem with the trajectories of circulation. This effect reinforces the use of a continuous public landscape as a medium for circulation trajectories and entertainment venues. The continuous public landscape formulates a new kind of Public Urban space, something between a park and a piazza that has the potential to reconnect some of the most disjointed and disconnected transit hubs in the contemporary North American City. As the new 20th century piazza, Central Railway Land Park integrates itself into conflicting urban fabrics while navigating various existing infrastructural systems and topographical changes; forming complex programmatic relationships to public space and amenities; establishing various levels of connections to the existing urban fabrics; and providing the GTA with a new social condenser.

\subsection{Union Station - A Rotting Beaux-Art's Carcass}

Toronto's Union Station has become a rotting Beaux-Art's carcass that no longer meets the needs of the commuters and the city (Fig. 1.0.0). The station began its life in 1927 as a passenger rail station and over the decades has lost its passenger rail use, becoming a multimodal hub for 63 million commuters a year. New infrastructures have been grafted onto a station that was never designed to adapt to new services, resulting in a fragmented multi-modal hub. Close to 200,000 commuters a day pass through spaces cobbled together out of former Postal Sorting rooms or exterior corridors adjacent to busy roads (Union Station Master Plan, 2005 , p. 2). Current proposals for upgrading and redeveloping Union Station are not meeting the expectations of many who remark that if the proposals are implemented they would "... replace one dreary train-travelling experience with another" (Gilbert, 2008) To make issues worse, none of the proposals has developed a proper response to alleviate the physical and visual barriers that inhibit pedestrian movement in and around Union Station. Union Station and the surrounding contextual area are in need of an immediate design response to connect fragmented infrastructural networks with a disjointed city fabric.

Before one can formulate an appropriate proposal for Union Station, one must first understand its history and identify the various issues affecting the station and contextual area. 
The next step would be to use models produced by Bertonlini and Peek to understand the present potentials of the Union Station and area. Both models work by identifying the nodal potentials of a station as an infrastructural hub and a point of commuter activity. They also define the 'place' potentials by identifying conditions for greater interaction with an urban context. These models help to delineate Union Station's potential as an 'urban exchange complex' where infrastructural services and urban richness are met sympathetically (Bertonlini \& Spit, 1998). To become an urban exchange complex, Union Station's infrastructural services would need to be brought up to contemporary levels and leftover spaces redeveloped to create an enjoyable urban condition.

For a successful redevelopment, Union Station would have to be transformed from a hub that objectifies rail to a hub that focuses directly on traffic flows and public space. Current proposals for Union Station call for the increase in porosity of the station, a design process that does not respond to the greater issues of Union Station's place within the city. Contemporary terminal designs do not embrace porosity, but rather the potentials of using traffic flows to formulate space. Stickells' theory of Flow Urbanism responds to a growing trend of terminal architecture to be based on an intense analysis of traffic flows, flexible programming and the seamless integration of public space (Dehaene \& de Cauter, 2008). Architectural interventions based on traffic flow and public space have been found to meet contemporary needs of stations as opposed to the historical methods of using architecture to purely objectify a station in a single form. To understand the potentials of Flow Urbanism for Union Station, works by the leaders in theory are contrasted against Union Station to provide possible answers to redeveloping the station. The major works by the leaders of Flow Urbanism include FOA's Yokohama Terminal in Yokohama and UN Studio's Arnhem Central Interchange in Arnhem. Other case studies are used to augment specific elements of flow urbanism to provide different potentials for Union Station's redevelopment.

By contrasting the beneficial elements in each case study against the present issues of Union Station and the requirements formulated by Peek and Bertonlini, it can be surmised that Union Station and the surrounding area require a redevelopment to meet three conditions: first, a modern terminal that can adapt to changing commuter needs while providing the best conditions for travel; second, an activated public space that unites fragmented urban elements in a civic focal point; and third, a master plan that integrates both a modern terminal and civic focal point into an indistinguishable surface. 


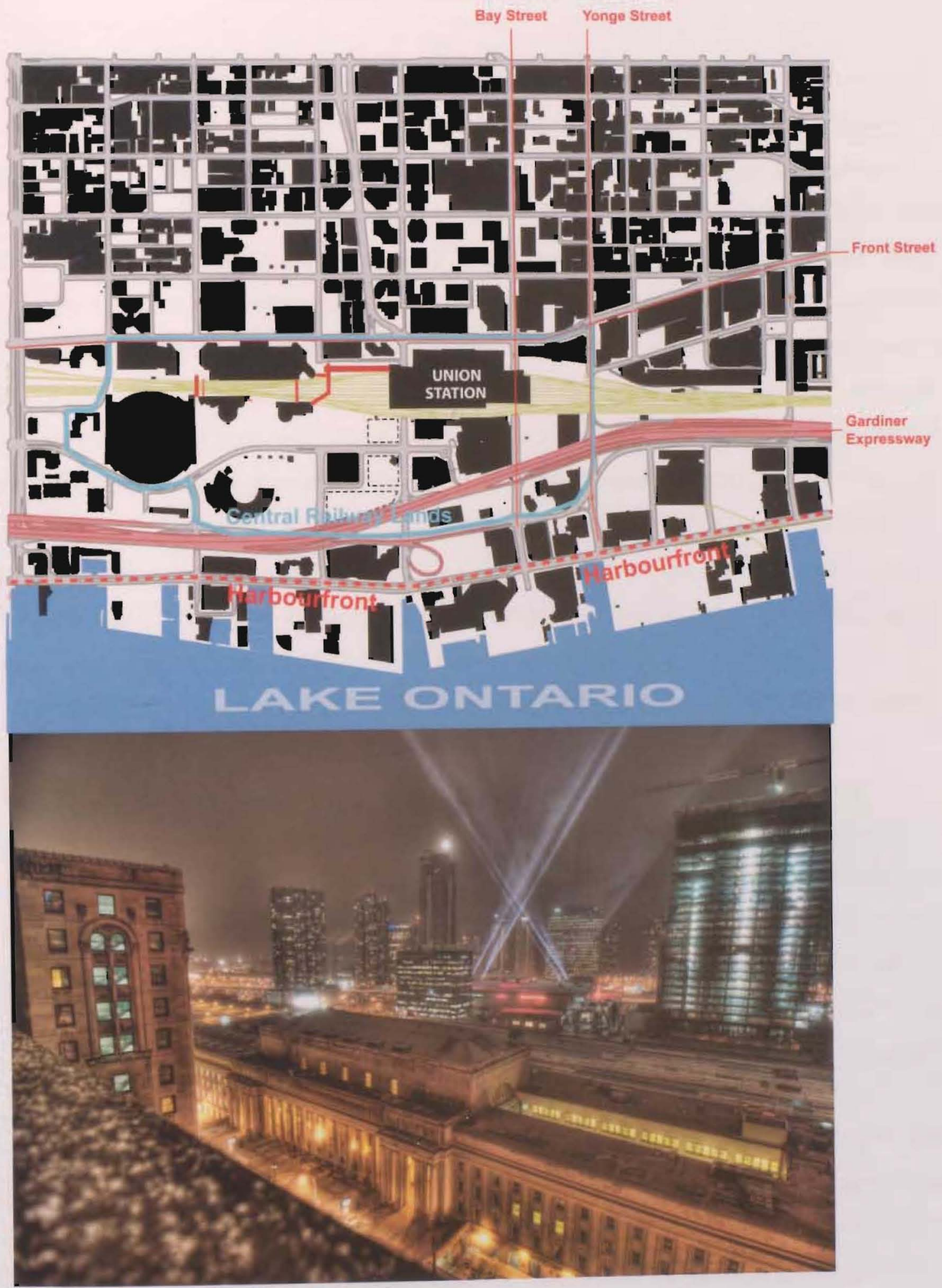

Figure 1.0.0 Toronto's Union Station urban context and image from the Royal York looking south (Air Canada Centre behind Union Station) 


\subsection{Union Station History}

In 1904, Toronto suffered its second great fire, which wiped out much of the downtown warehouse district. Realizing the original Union Station had reached its capacity, the Grand Trunk Railway (GTR, later known as Canadian Pacific Rail, CPR) brought together various competing rail lines to take possession of the burned-out lands on the south side of Front Street between York Street and Bay Street (Fig. 2.0.1). These lands were reserved for the new Union Station and by 1913 the competing rail companies formed the Toronto Terminals Railway Company (TTR) to build and operate the proposed station (Carr, 2005). A year later, the proposal for the Union Station was unveiled to the public and was said to be a station that would "rank with the finest terminals on the continent" (Carr, 2005, p. 24). Even though a design was unveiled in 1914 , the Great War put a hold on the construction of the station until the autumn of 1915. The third and present Union Station was "designed in the grand manner of the Ecole des BeauxArts," creating a monumental structure of classical design and rationale (as cited in the Union Station Master Plan, 2008). The location and grandeur of the station created a 'new front door' for Toronto upon its completion in 1927 (Fig. 2.0.2) (et al., 2008 p. 43).

The design of Union Station in the style of Beaux-Arts represents one of the last great buildings to be constructed in this style. Only the finest materials were to adorn the station. These included Bedford stone façade, granite Loggia, Zumbro stone walls for the Great Hall, Gustavina tile for the coffered ceiling and Tennessee marble for the floors. The layout was traditional, with a head house on Front Street and the rear concourse below the platforms and covered by a Bush-style train shed (Figs. $2.0 .3 \& 2.0 .4$ ). The tracks were designed in a manner allowing Union Station to function as a through station instead of a terminal station, which wasn't typical of most stations of the time. Fig. 2.0.5. This feature has allowed Union Station to handle present commuter traffic, a feature only found in the most modern European stations (Carr, 2005).

The head house is the most dramatic feature of the building, with its 250 -foot by 84 -foot Great Hall and barrel vault ceiling rising 84 feet (Fig. 2.0.6). The Great Hall, which houses the ticket lobby, "announced both the importance of the station and the city it served" (Carr, 2005, p. 26). Departure passengers would enter through the Loggia's east and west entrances into the Great Hall, making their way down to the lower concourse, where they would then ascend to the platforms once the trains had arrived. Arrivals exit the station by bypassing the Great Hall through the Arrivals Concourse, exiting through dedicated doors onto Front Street (Fig. 2.0.7). 
This design of separating arrivals from departure flows has been compared to contemporary airport design (Carr, 2005, p. 26).

For the next 40 years, little change occurred to the station, until 1967 when GO Transit, a region rail link, began providing service to the Greater Toronto Area (GTA). The GO Transit service shared the VIA Concourse until 1978, when the Post Office facilities were moved out of the east wing. GO Transit was able to redevelop the east wing into a new underground GO Concourse, creating links across the moats to the Union Subway station (Carr, 2005). Over the next 30 years, GO has developed the east and west teamways, various access stairs to platforms and recently two new platforms at the southern end of the rail yard (Fig. 2.0.8).

In 1989 the west wing of the Great Hall was converted into the west entrance for the newly created Skywalk, a raised pedestrian walkway linking Union Station to the CN Tower and Metro Toronto Convention Centre (MTCC). The Skywalk demolished the upper two floors of the three-storey Canadian Express building and integrated the walkway into the top of the building (Fig. 2.0.9) (Union Station District Plan, 2006). From the Canadian Express building the skywalk continues west as a pedestrian bridge spanning the rail yards and linking with MTCC's southern building. The portion of the Skywalk over the Canadian Express building previously included amenities for people travelling to the Roger's Centre, but a declining Toronto Blue Jay's fan base has left these amenities closed permanently. The Skywalk has become an empty pedestrian corridor that serves a minor crowd of GO Transit commuters and patrons of the Rogers Centre and MTCC (Fig. 2.0.10).

Current construction at Union Station includes the new Go Transit connections in the west teamway (Fig. 2.0.11), two new platforms south of the trainshed (Fig. 2.0.12) and a new entrance to Union Plaza (Fig. 2.0.13). The new south connection to Union Plaza will develop through the existing VIA concourse creating a north-south axis from the Great Hall to Union Plaza. The new alterations are a continuing initiative to transform the station from a passenger station into a commuter station. 


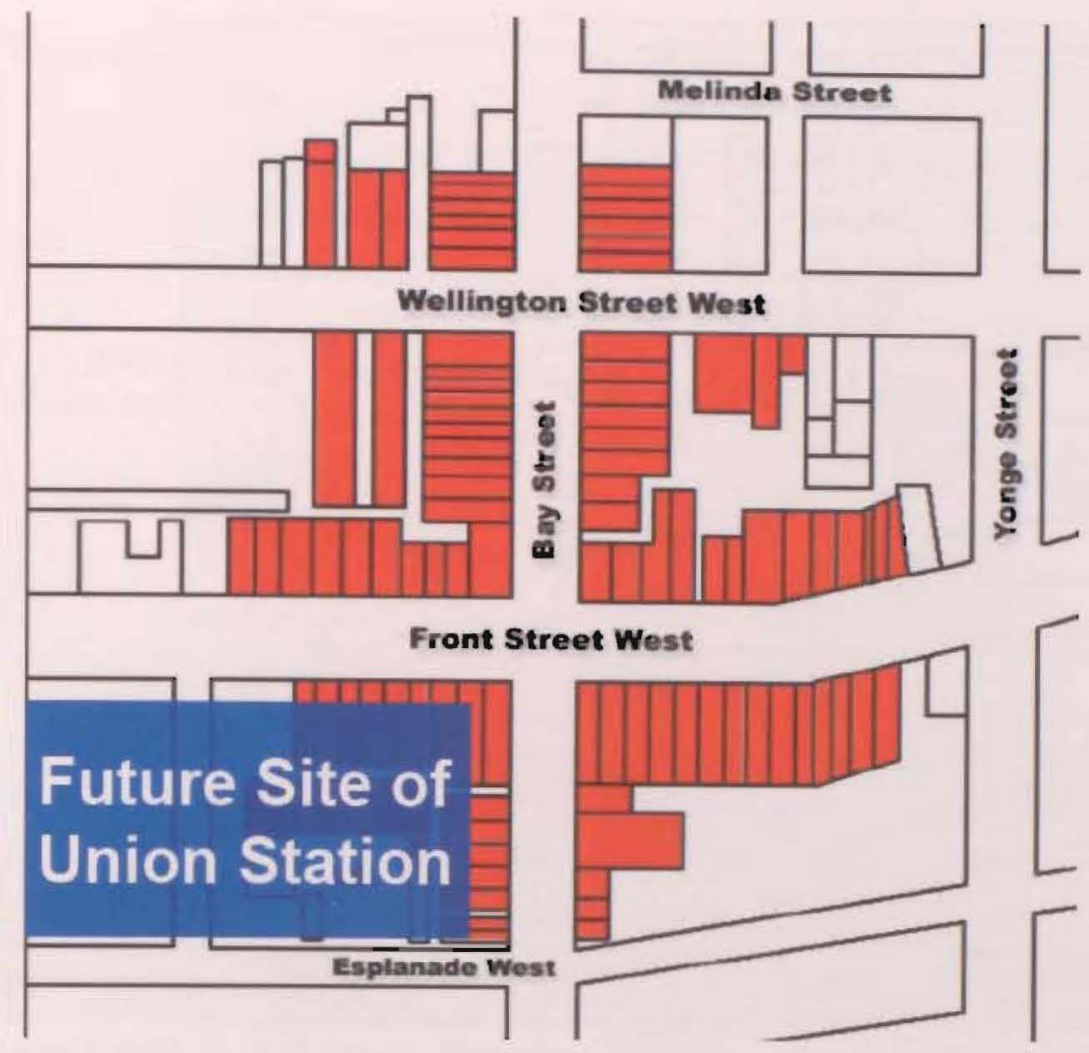

Figure 2.0.1. Future Site of Union Station with mapped properties burned down in 19040.

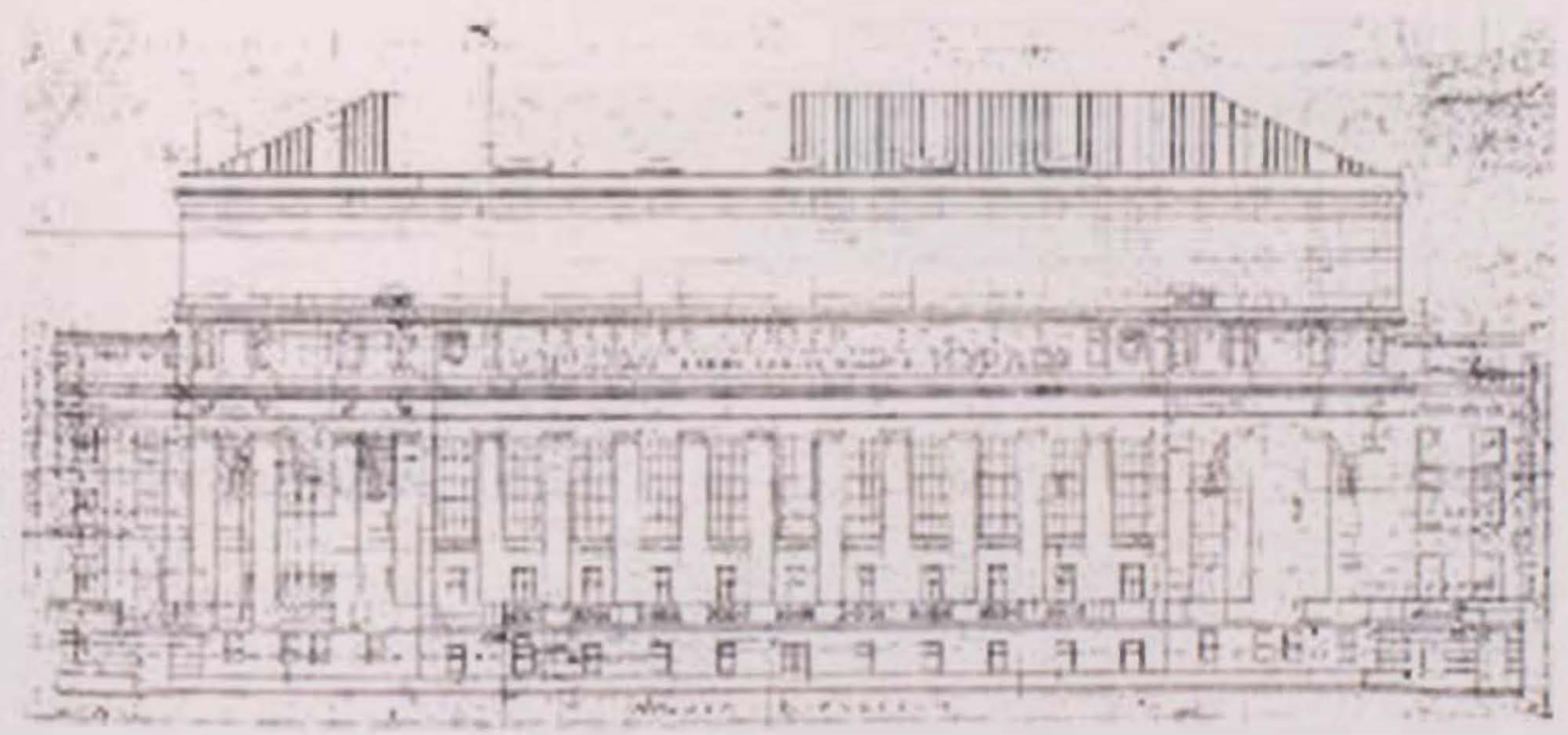

Figure 2.0.2. Proposed Elevations as of 1916 


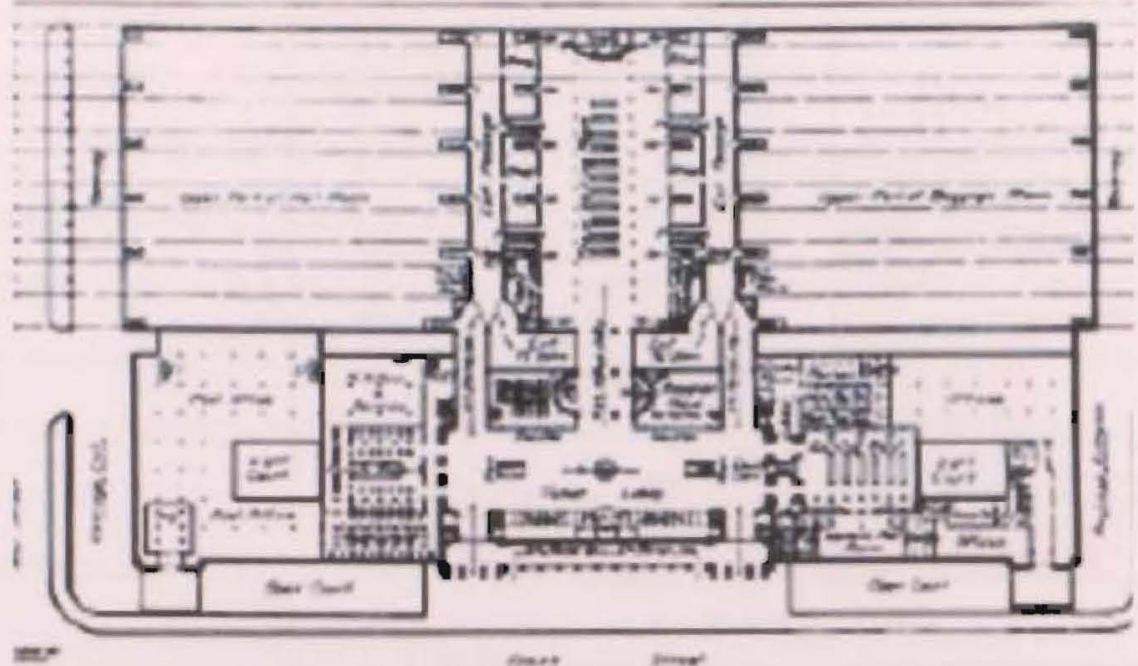

Original Floor Plan

\section{Level 1 \\ Great Hall}

Sub Level 1

Departure Concourse
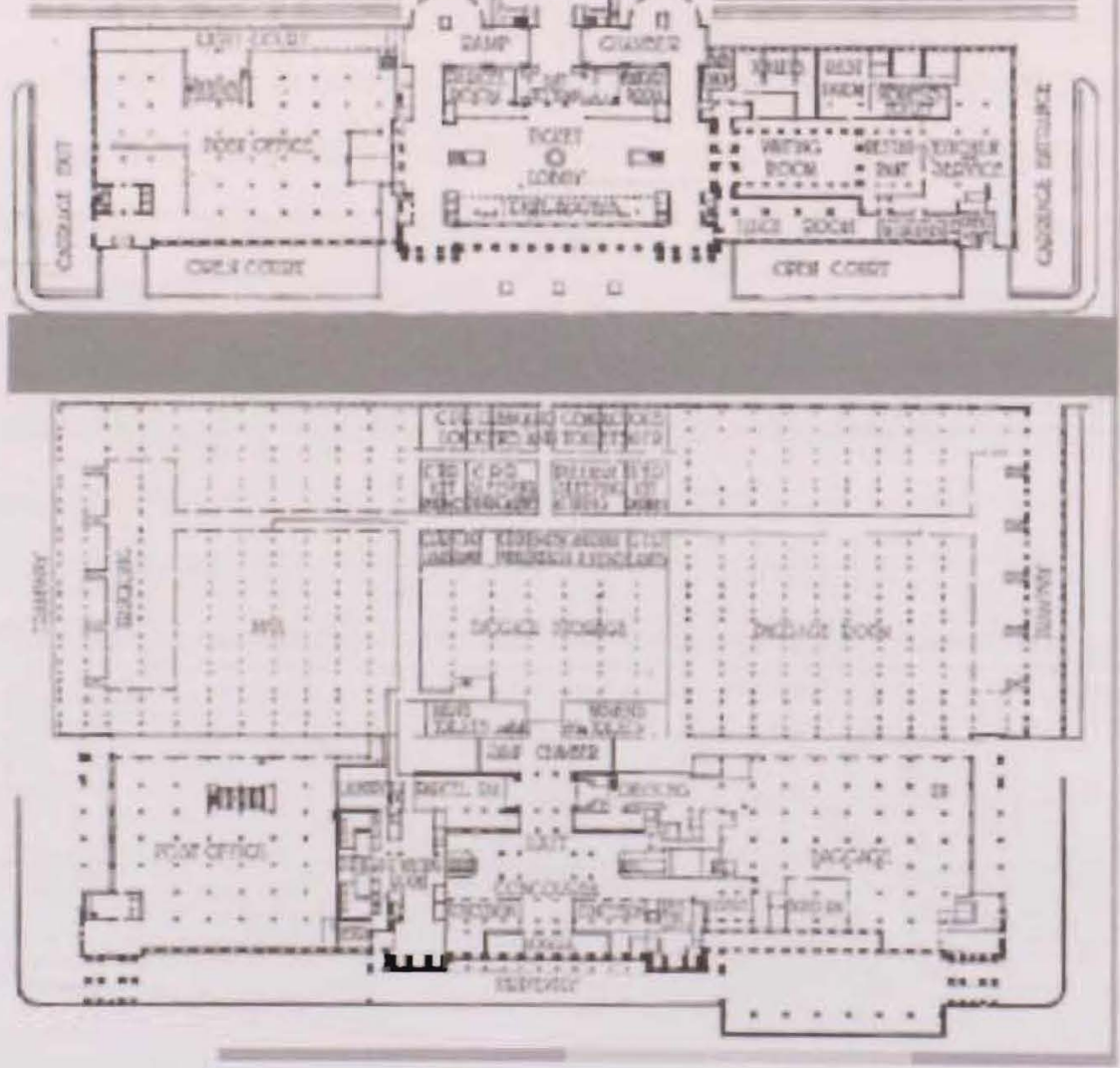

\section{Sub Level 2}

Arrivals Concourse

Figure 2.0.3 Original Union Station Layout (notice how the original plan allowed the Departures concourse access the Great Hall in 3 locations. 


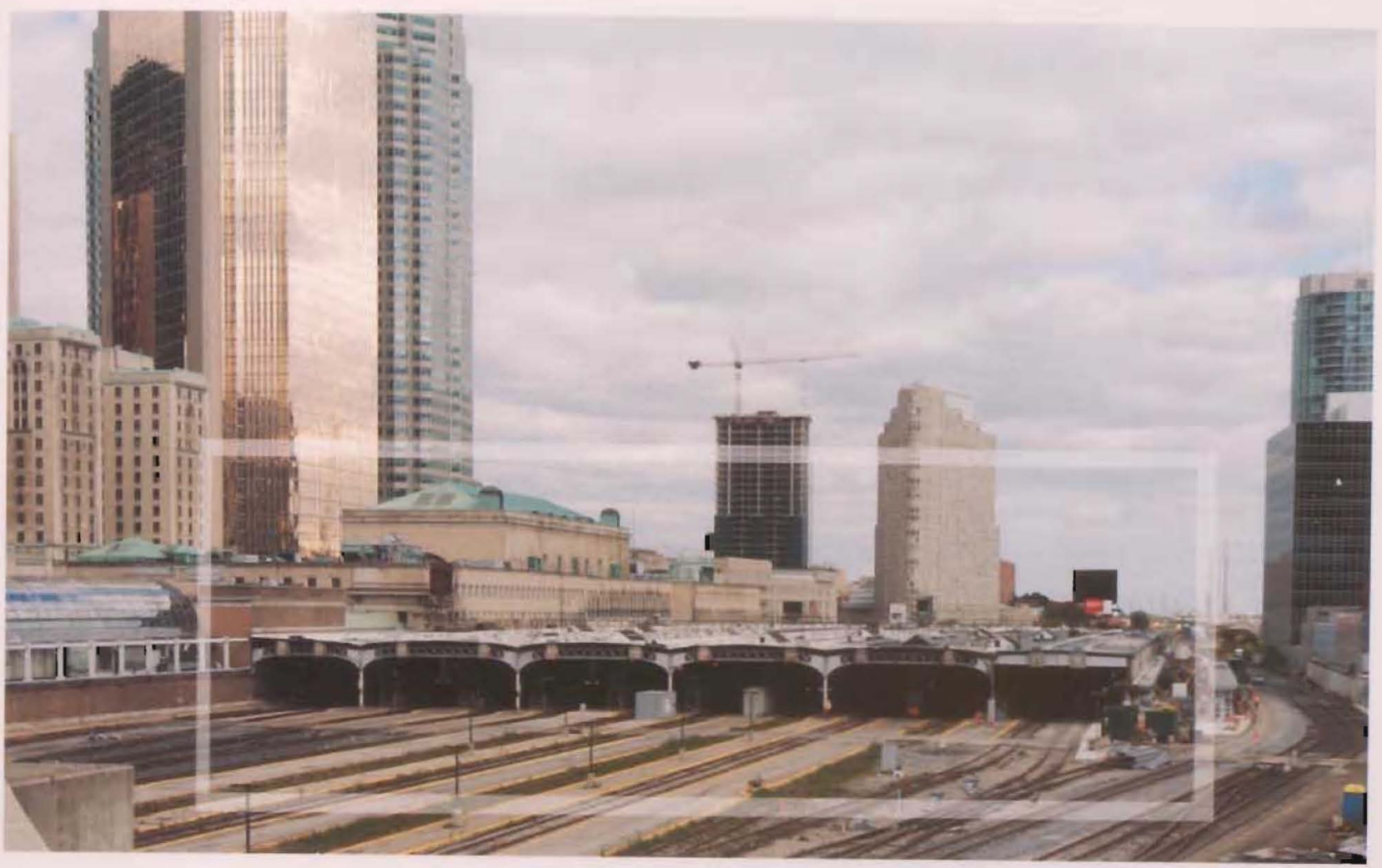

Figure 2.0.4. Union Station Bush Style Trainshed

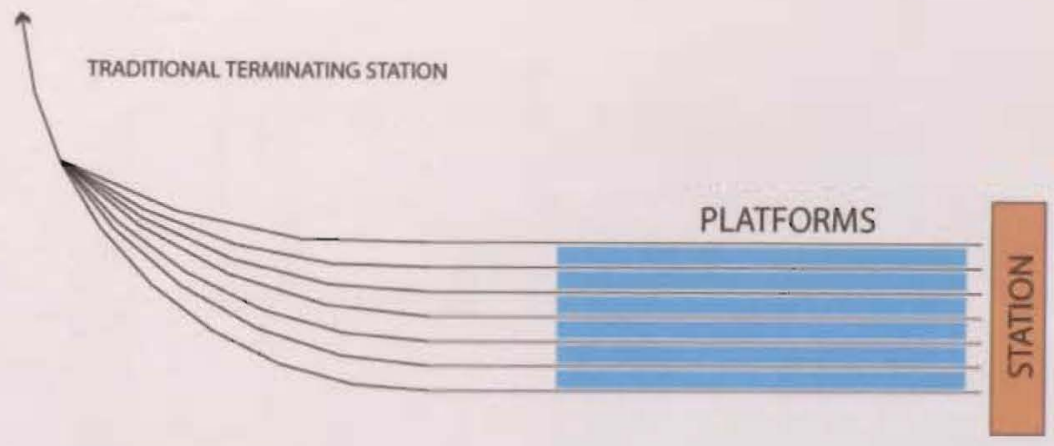

THROUGHSTATION

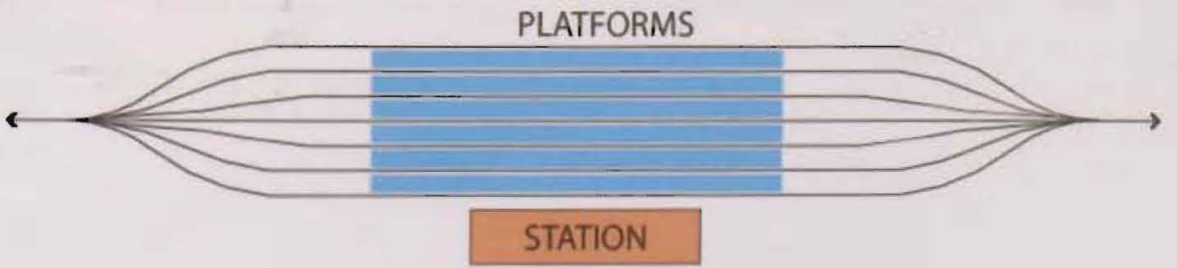

Figure 2.0.5 Traditional Terminal Station vs. Through Station 


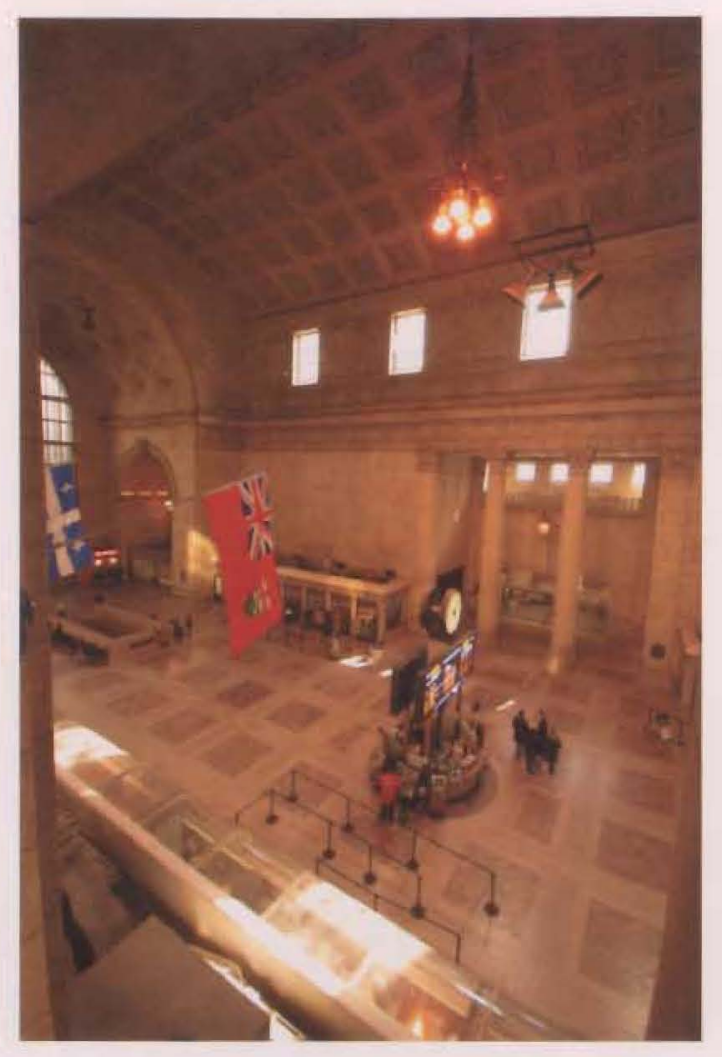

Figure 2.0.6. Union Station's Great Hall
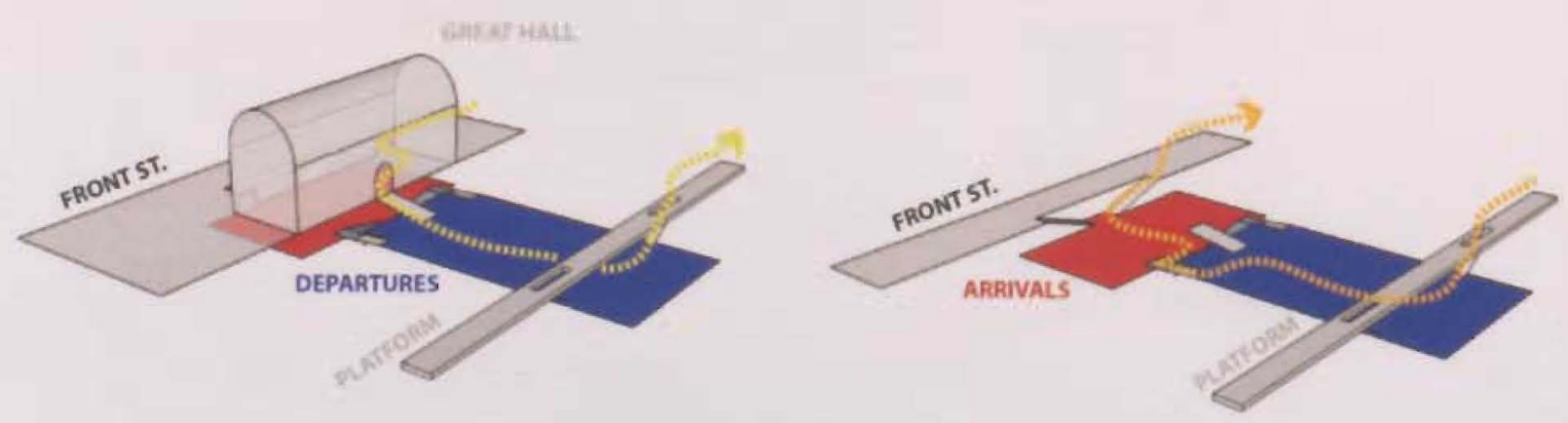

Figure 2.0.7. Departure \& Arrivals Separation 

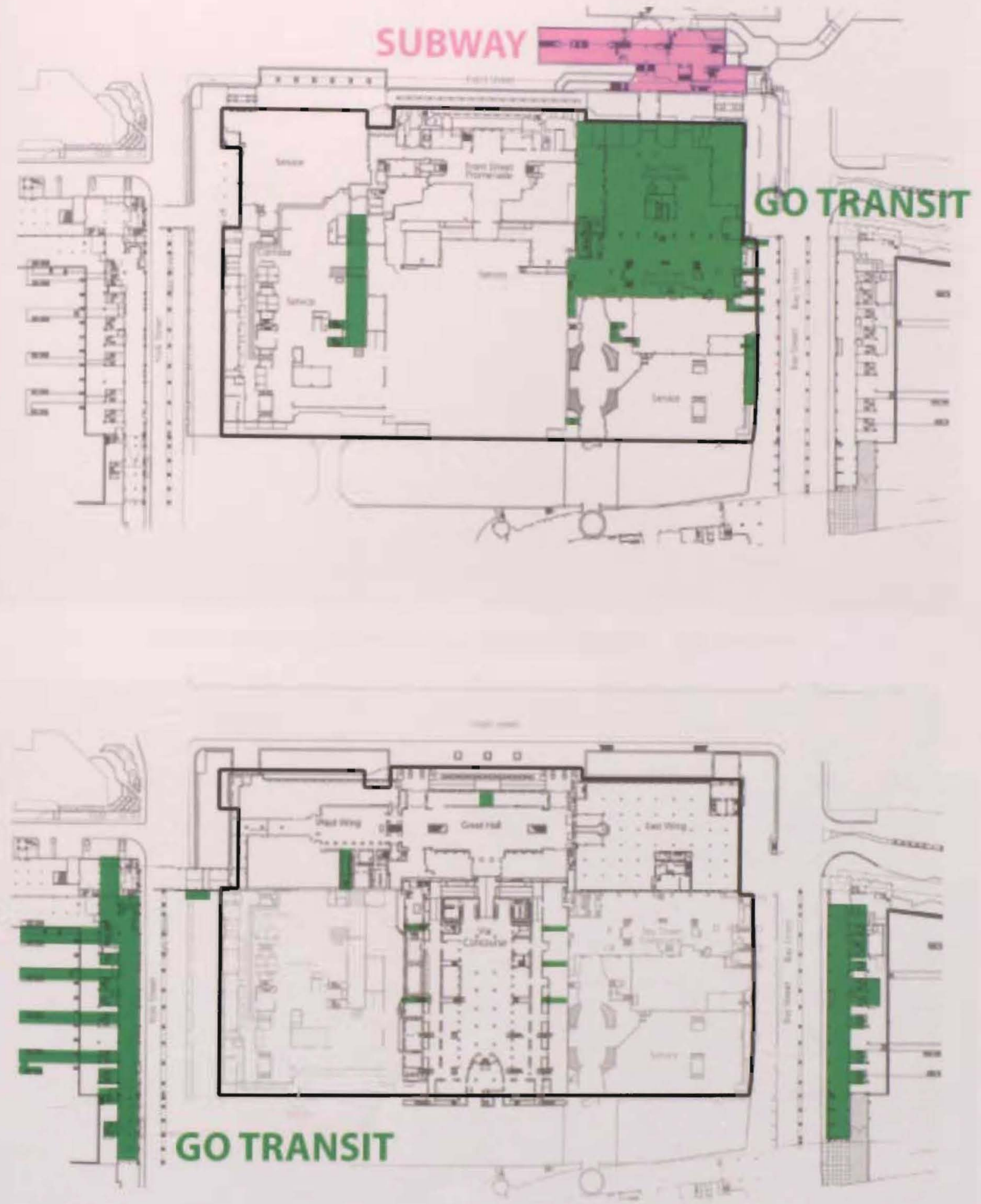

Figure 2.0.8. Additions of GO Transit and TTC Subway connections 


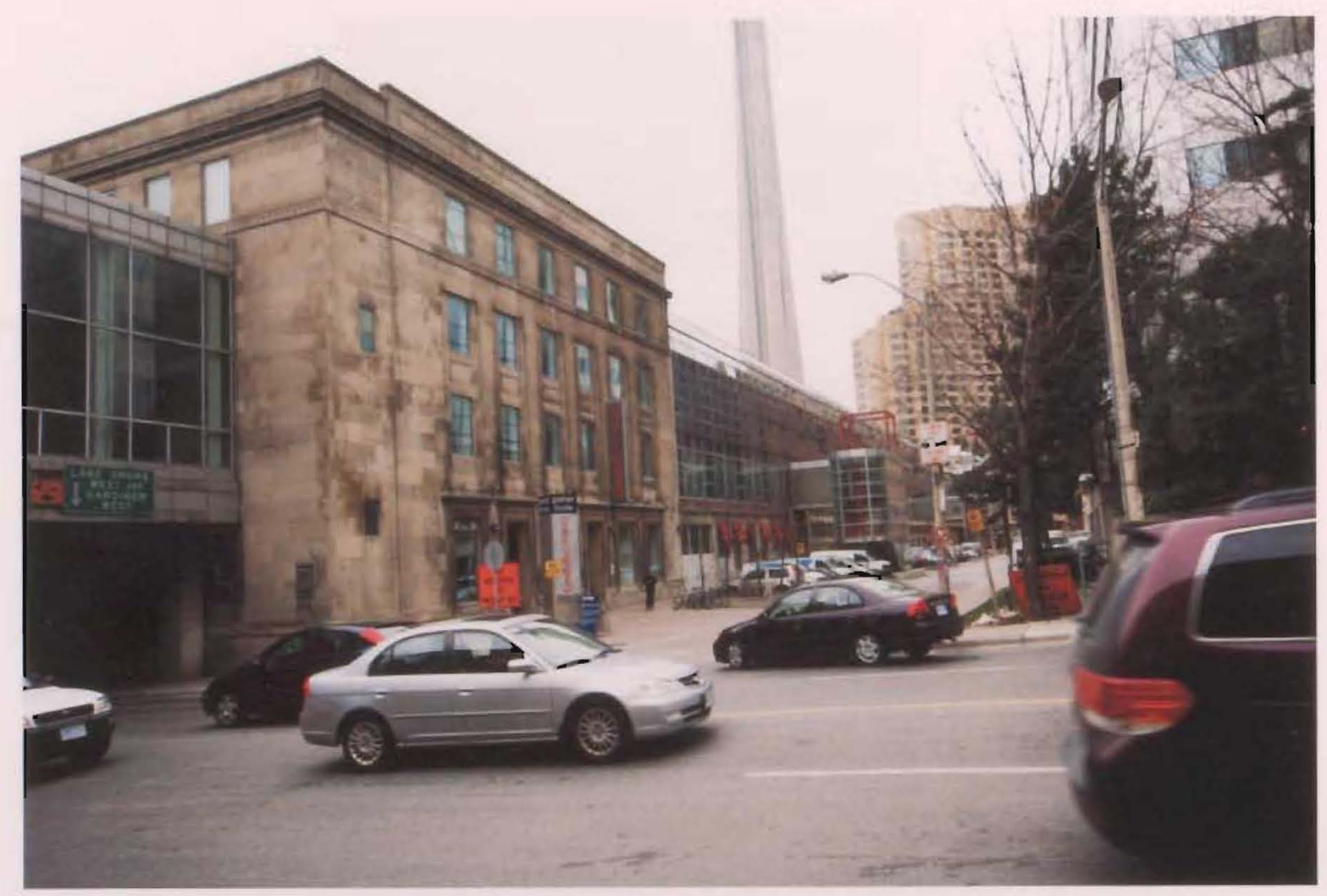

Figure 2.0.9 Skywalk Connection and Canadian Express Building

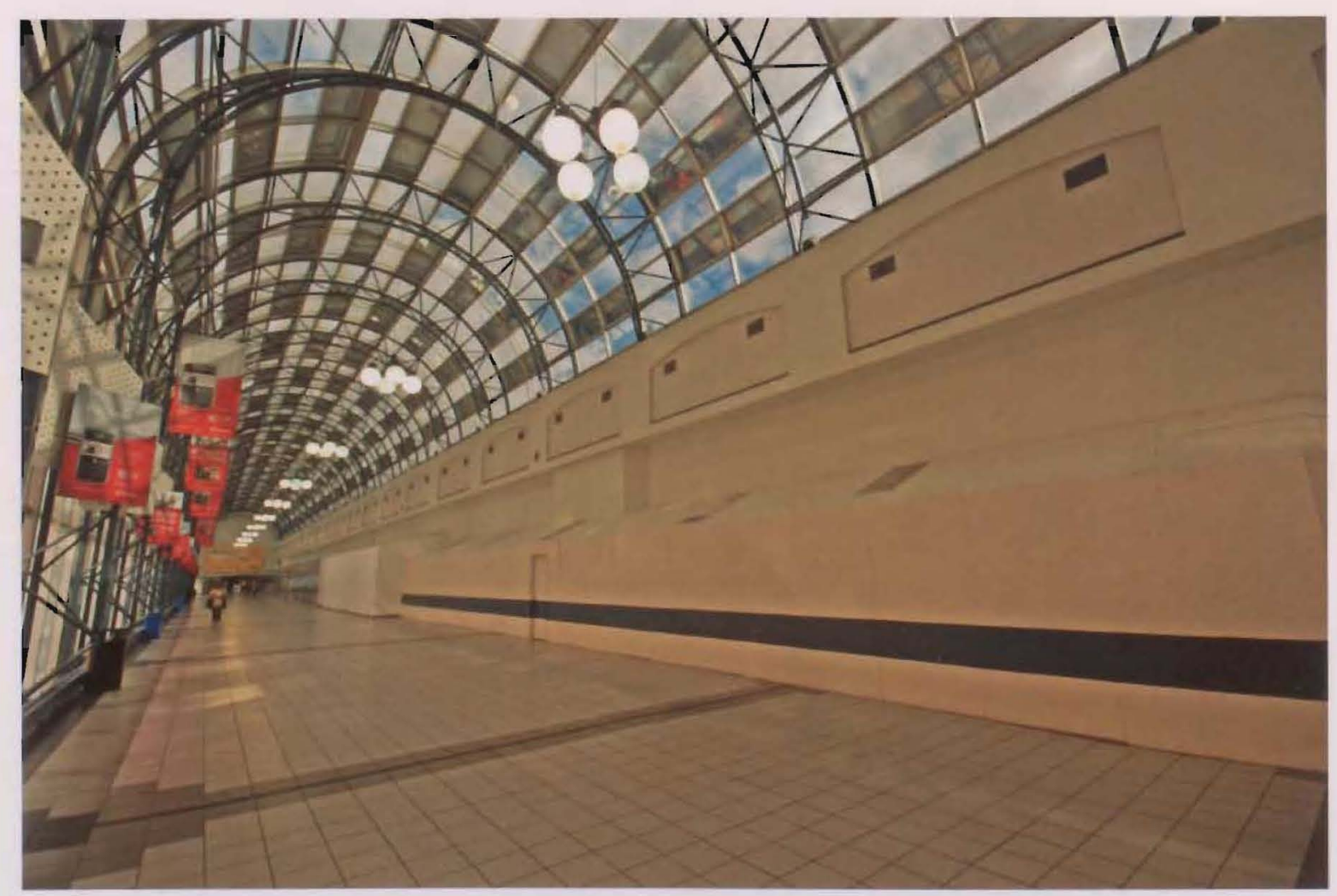

Figure 2.0.10. Skywalk Connection with boarded up amenity fronts. 


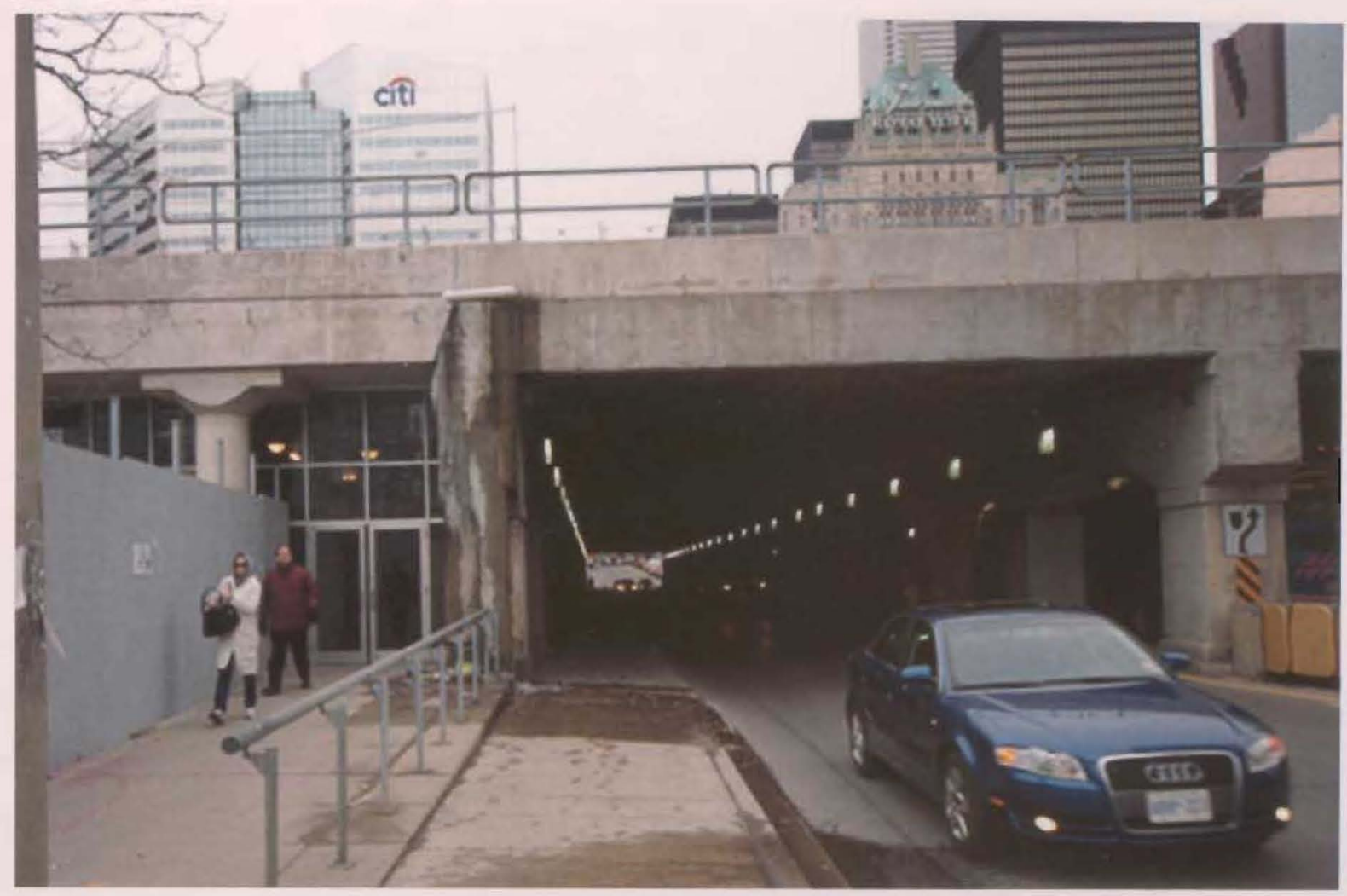

Figure 2.0.11 Construction of West Teamways

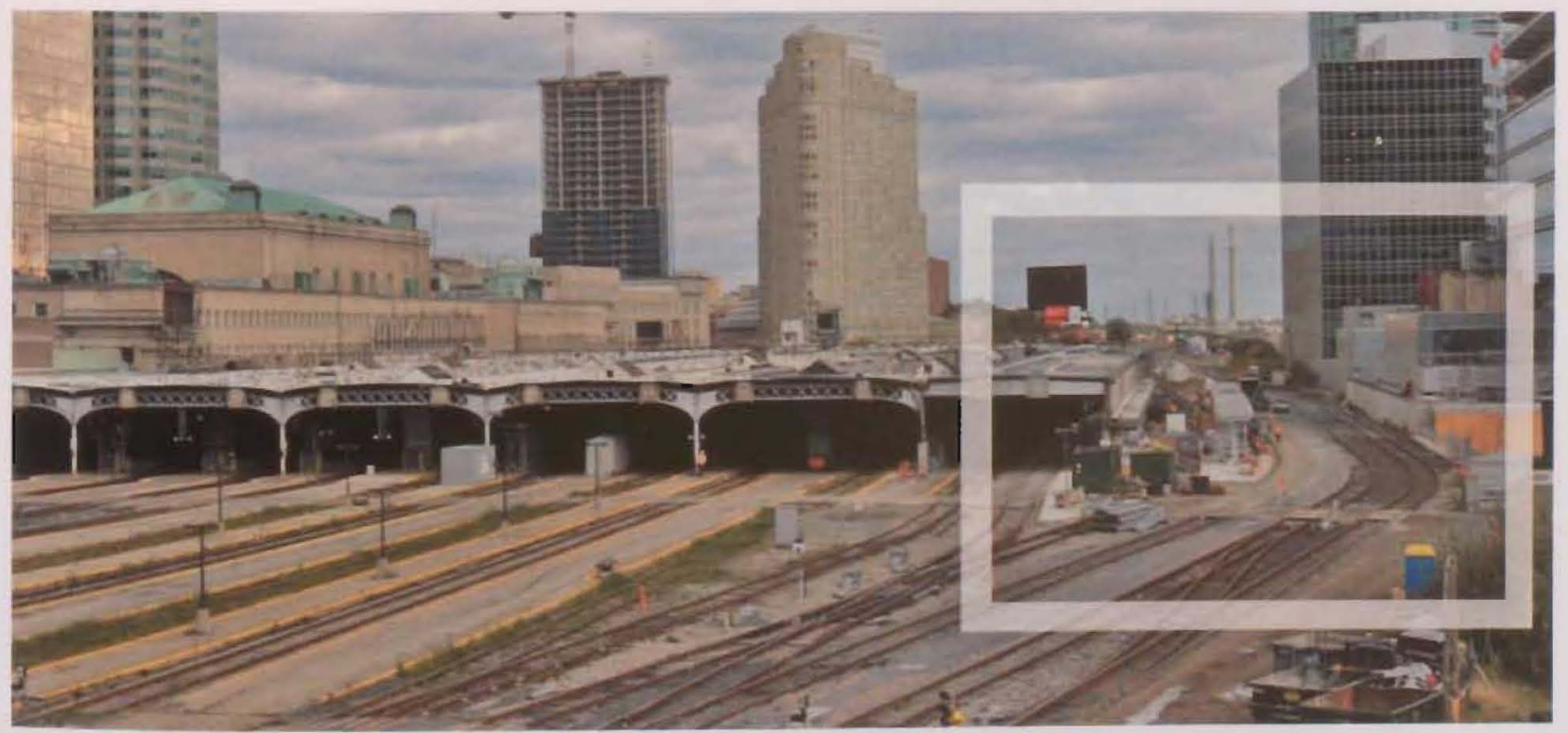

Figure 2.0.12 Construction of GO Transit South Platforms 


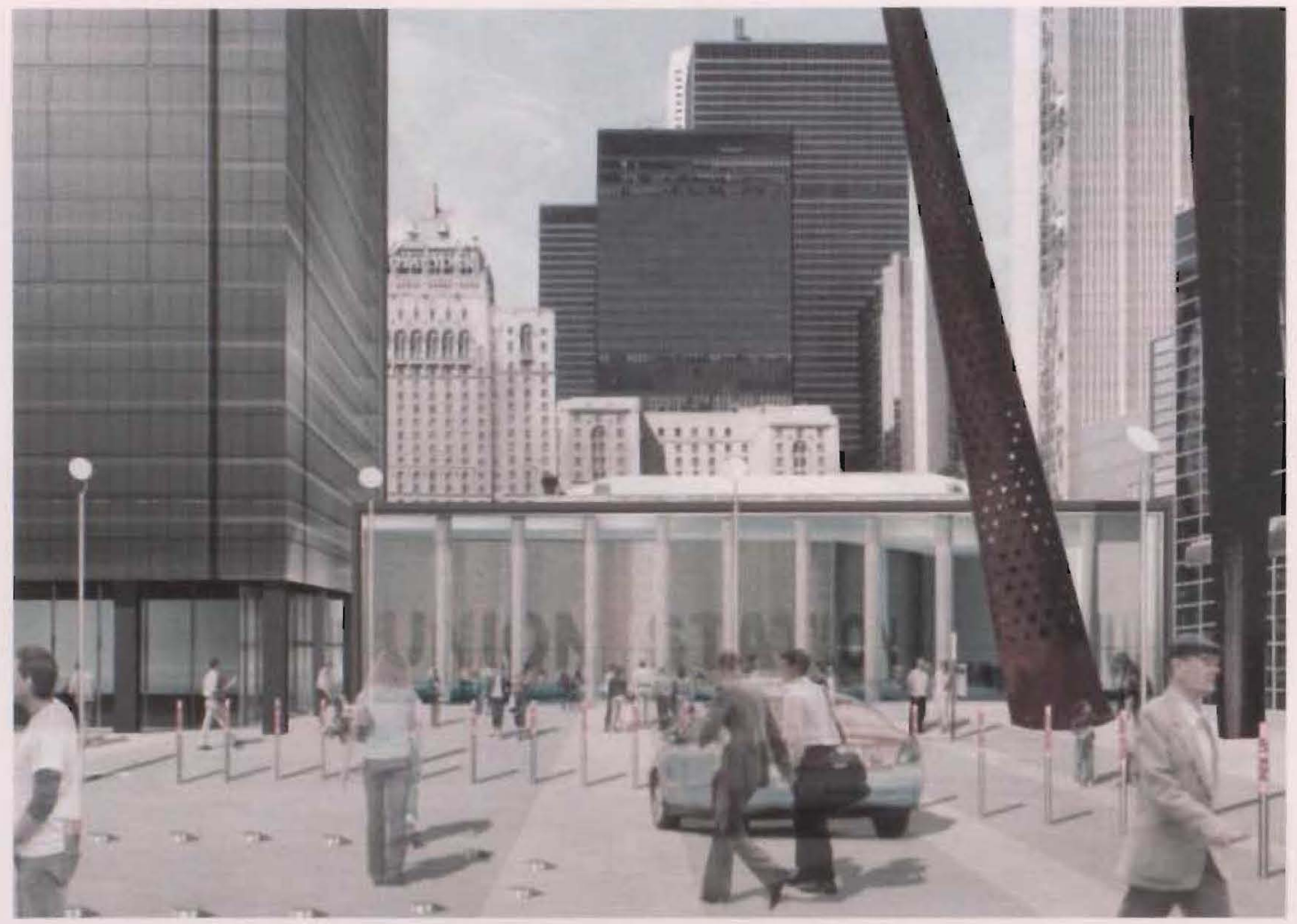

Figure 2.0.13 Union Station Plaza Entrance to Union Station-Rendering

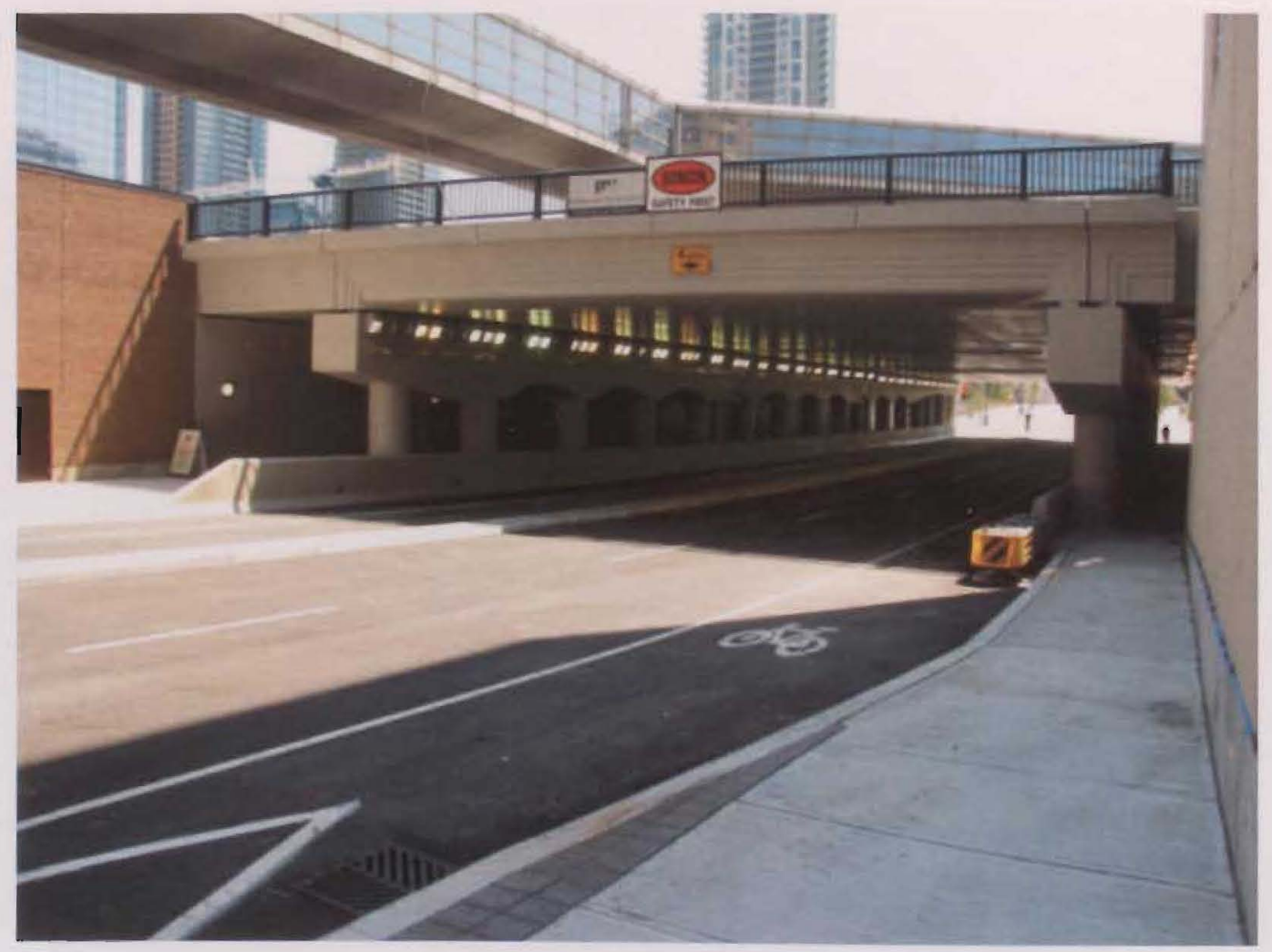

Figure 3.2.4 Recently renovated Simcoe Tunnel 


\subsection{Contextual Evolution}

Union Station was constructed on the transition point of the original Toronto shoreline and reclaimed land of the Harbourfront. Over 150 years the Toronto shoreline has gradually been growing out into Lake Ontario, reclaiming land for shipping and industrial activities (Fig. 3.0.1). The waterfront was pivotal to Toronto's early days, containing industrial services that include major roads, rail and water access (City of Toronto, n.d.).

Toronto has had a love-hate relationship with the waterfont district, and due to this relationship, most of the city has expanded away from the waterfront (Toronto, 2007). Construction of Union Station and other Front Street buildings created a physical barrier to the waterfront's rail lands and industrial centres. When Union Station opened in 1927, it was called Toronto's "new front door" and for good reason; the waterfront had become heavily industrialized and unsightly (as cited in the Union Station Master Plan, 2008). People arriving and departing from Union Station would enter and exit through the main Loggia, never having to view the waterfront. Figure 3.0.2 shows how Union Station and adjacent buildings formed and continue to form a visual and physical barrier along Front Street Over the following decades the Financial District developed to the north of Union Station (Fig. 3.0.3), while Union Station remained the southern boundary of the district. Behind Union Station the industrial lands transformed into massive stockyards for the rail and shipping industries (Fig. 3.0.4).

After the Second World War, the stockyards lost their industrial importance due to the changing economy. This caused a massive vacuum in the area that left the rail lands essentially defunct. In 1955 the Gardiner Expressway, a six-lane elevated highway, took advantage of the redundant space and passed through the rail lands as part of a modernization of Toronto's transportation infrastructure (Fig. 3.0.5) (Carr, 2005). In 1968 the first large-scale development proposal was introduced for the rail lands, setting into motion a long trend of failed master plans. The first master plan, the Metro Centre, proposed a mixed-use development that would stretch east to west from Yonge Street to Bathurst Street, span from the south side of Front Street and terminate at the Gardiner expressway (Fig. 3.0.6). The research by Carr on Union Station's history notes that the

“...1968 scheme proposed to demolish Union Station, tear up the tracks and provide office space for 50,000 people, housing for 20,000 , a new train station linked to a convention centre, and connections to the bus, subway, and possibly a mono-rail to the 
airport. Links were also anticipated to a 1500-foot communications tower, CBC's English-language headquarters, and the new

Massey (now Thomson) Hall. In all the project covered 187 acres." (Carr, 2005, p. 31)

A revised version of the Metro Centre plan kept Union Station's main building as a public focal point, but tore down the train sheds and replaced them with a public square surrounded by mixed-use development (Fig. 3.0.7). The plan was eventually tossed due to public outcry at the initial destruction of Union Station and insensitive design towards the existing city fabric. While time has shown that mega-structure projects like the Metro Centre proposal are inflexible, invasive and alienating, we cannot forget the reasons why mega-structures like this were proposed (Banham, 1976). The Metro Centre proposal was created to give a bold, holistic vision that would fulfill the potential for the empty rail lands, focusing on mixed-use development with a modern transportation hub at the core. Although the $\mathrm{CN}$ Tower was the only element to be constructed from the Metro Centre proposal, it could be argued that other elements of the proposal have survived. After the completion of the CN Tower in 1976, the rail lands have gradually filled in with development, but not with a finer grain of urban fabric comparable to the existing Toronto fabric. Large projects such as the MTCC, Rogers Centre (formerly the Skydome), Air Canada Centre (ACC), condo developments and large office blocks have contributed to creating a fabric that is analogous to the Metro Centre proposal (Fig. 3.0.8). The monolithic developments mirror a chaotic version of the Metro Centre proposal, where the only element lacking in the current incarnation is a modern transportation hub. Even as these massive developments moved into the rail lands, their large-scale presence could not consume all the empty space (Fig. 3.0.9). It would be another 30 years before a proposal would bring an answer to the remaining rail lands. 
1858

1850

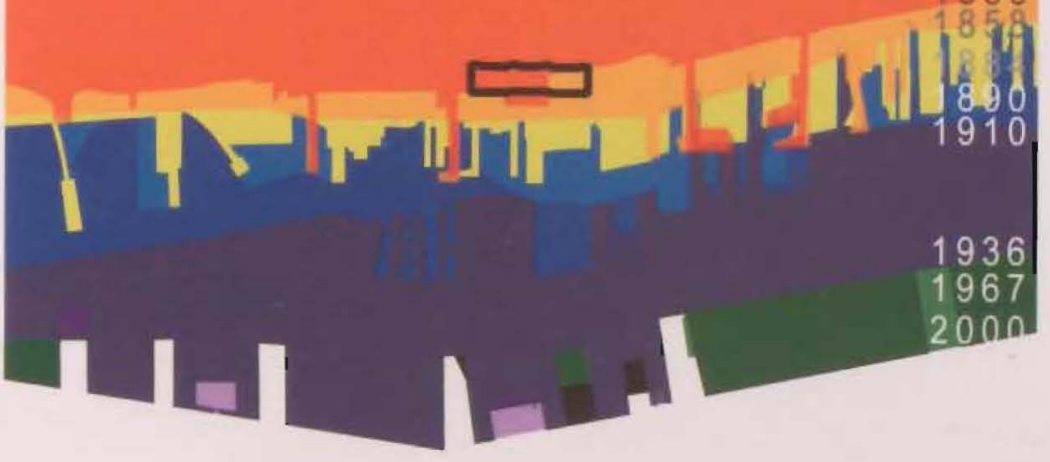

Figure 3.0.1 Growth of Toronto's Waterfront due to harbour infilling

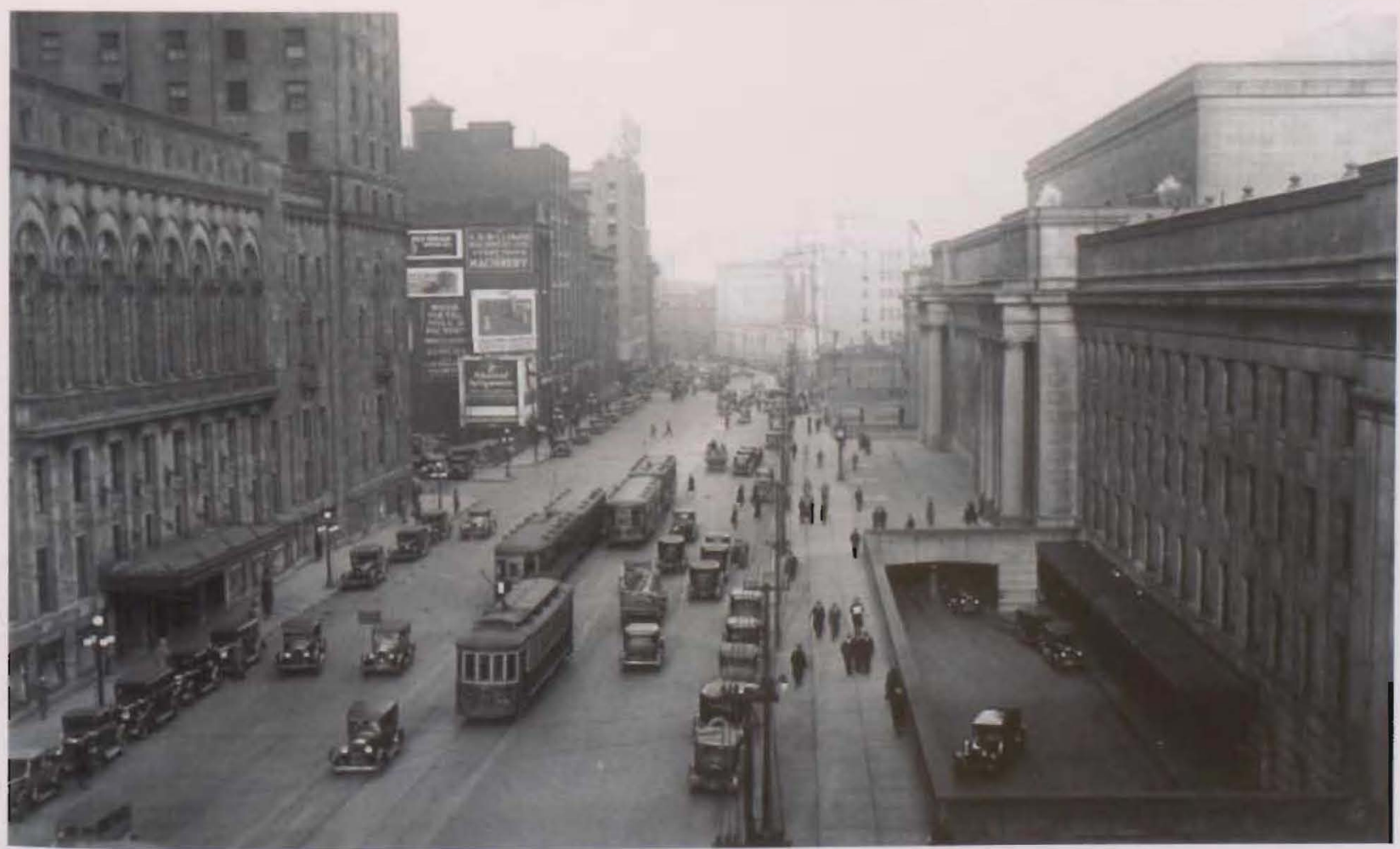

Figure 3.0.2 Canyon of Stone (Union Station to the right, facing the Royal York Hotel) 


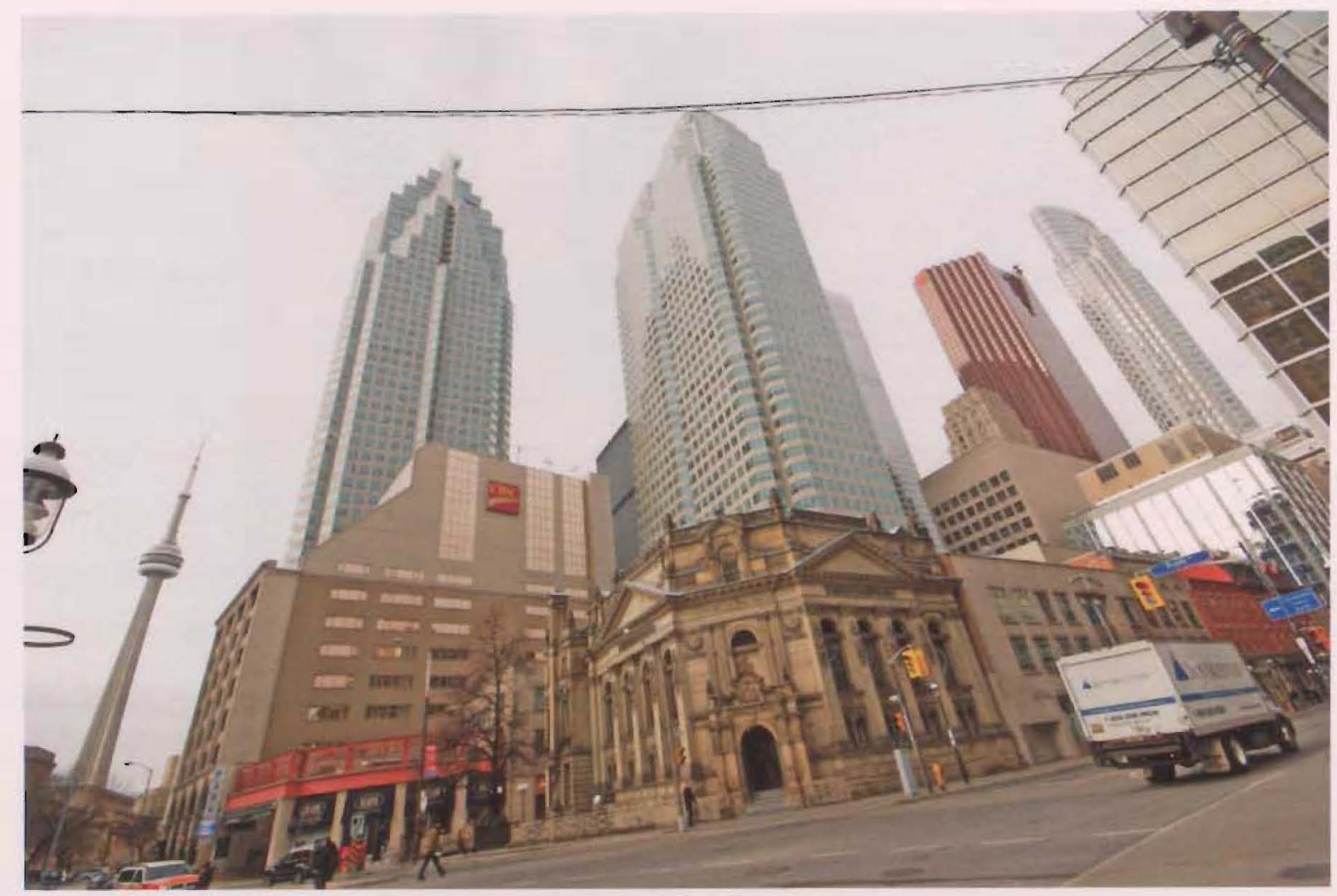

Figure 3.0.3 Financial District, 2008

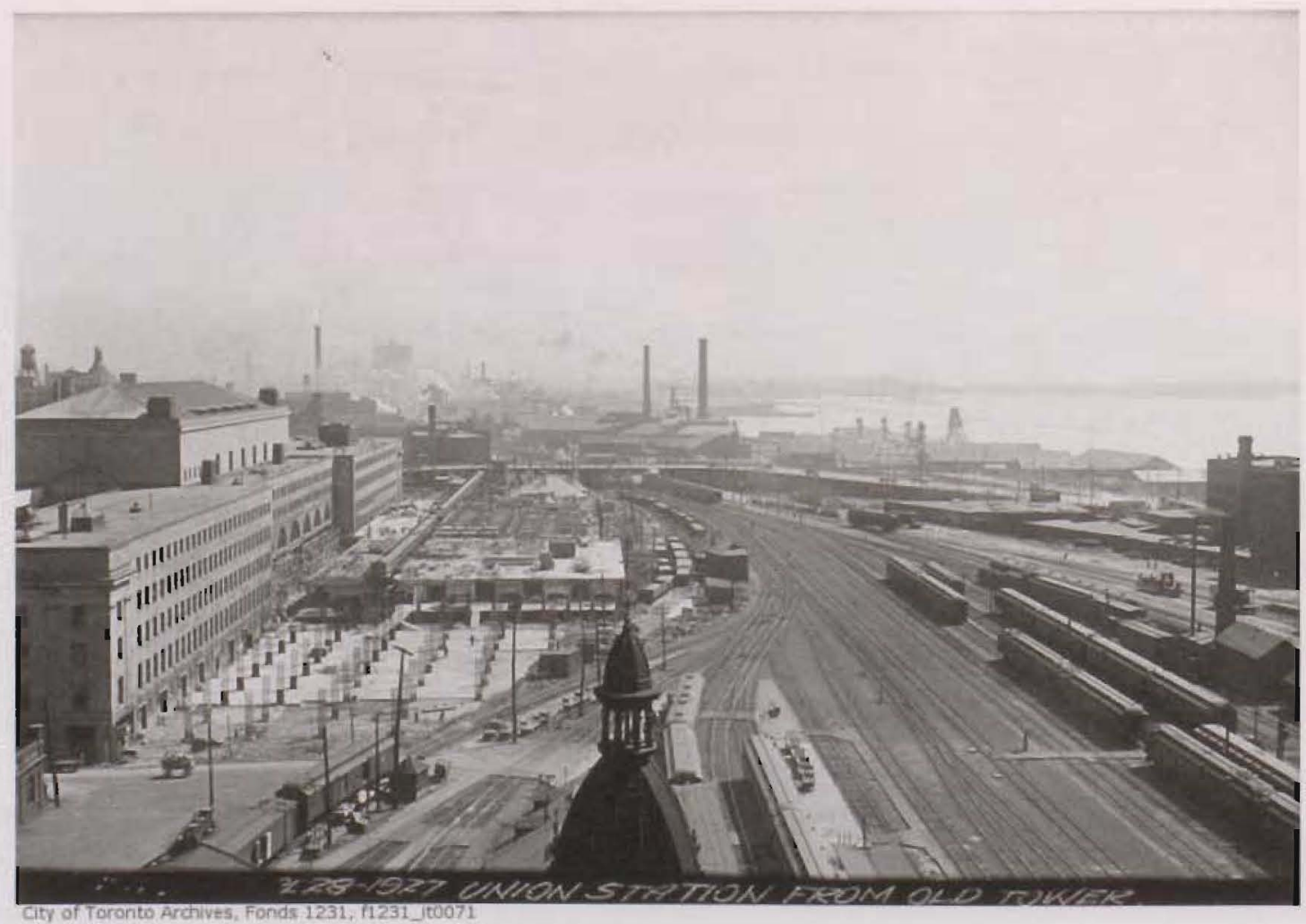

Figure 3.0.4 Construction of Union Station's concourse with stock yards to the left 


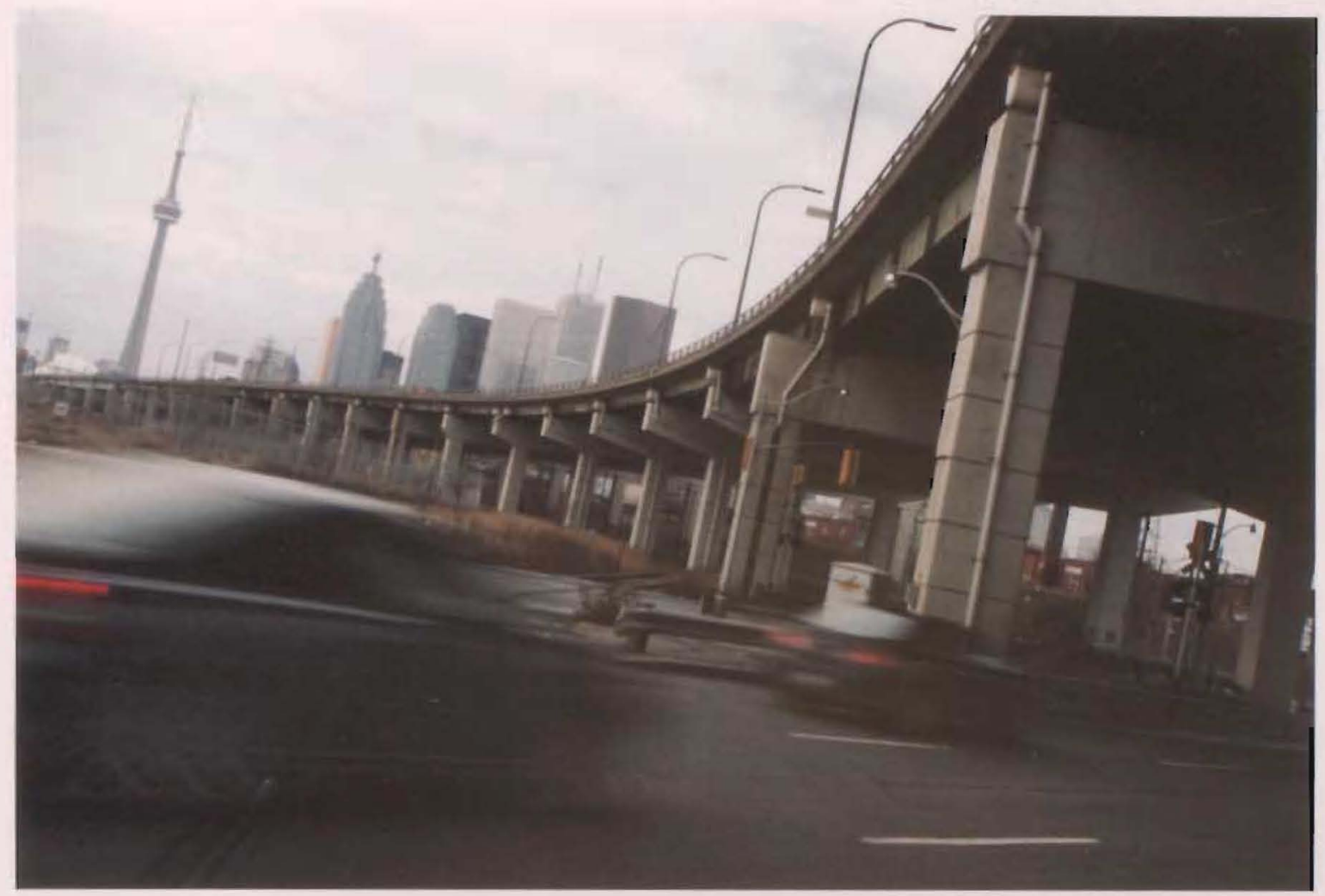

Figure 3.0.5 Gardiner Expressway as seen from Cherry Street.

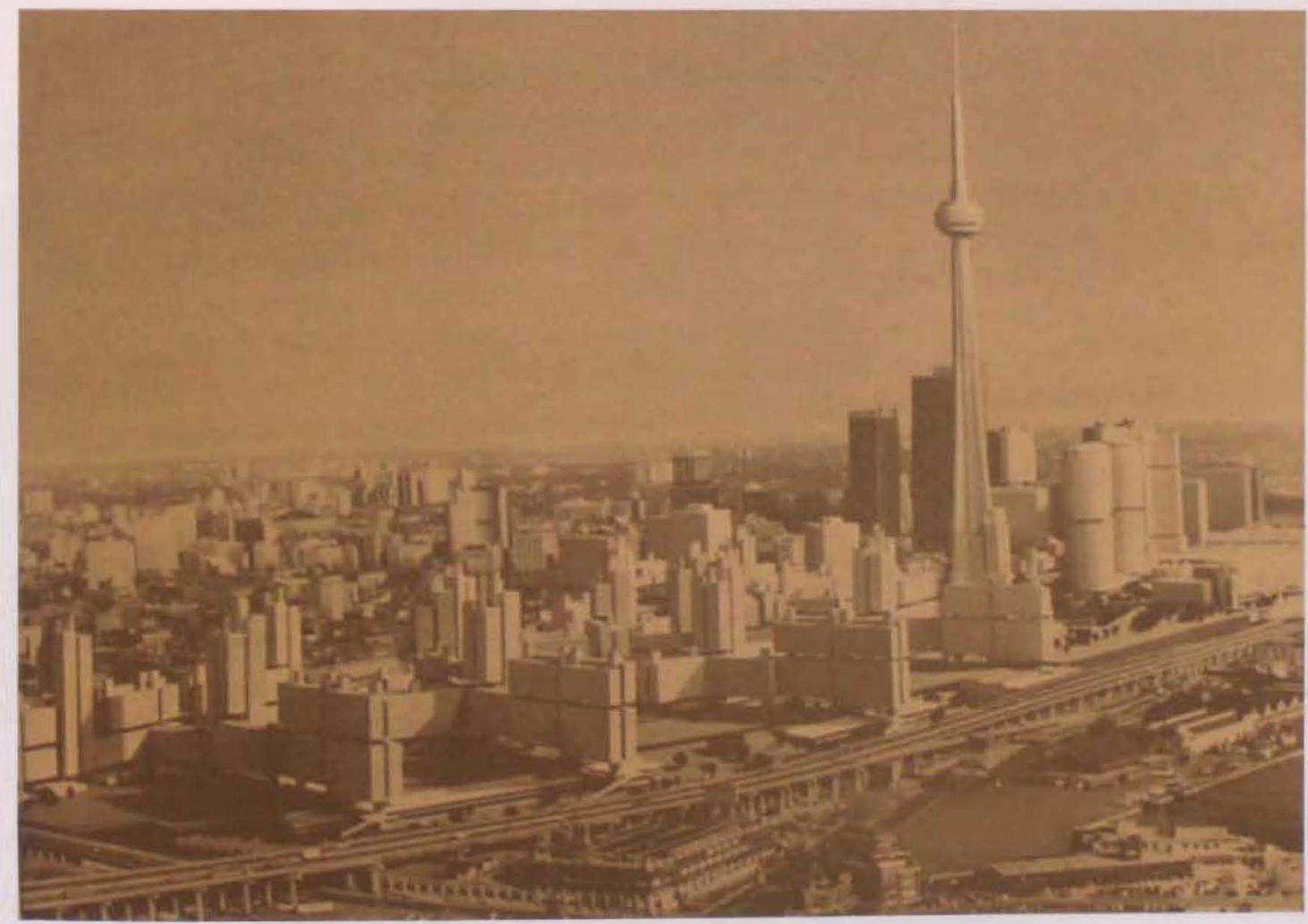

Figure 3.0.6 Model of the 1968 Metro Centre Proposal 


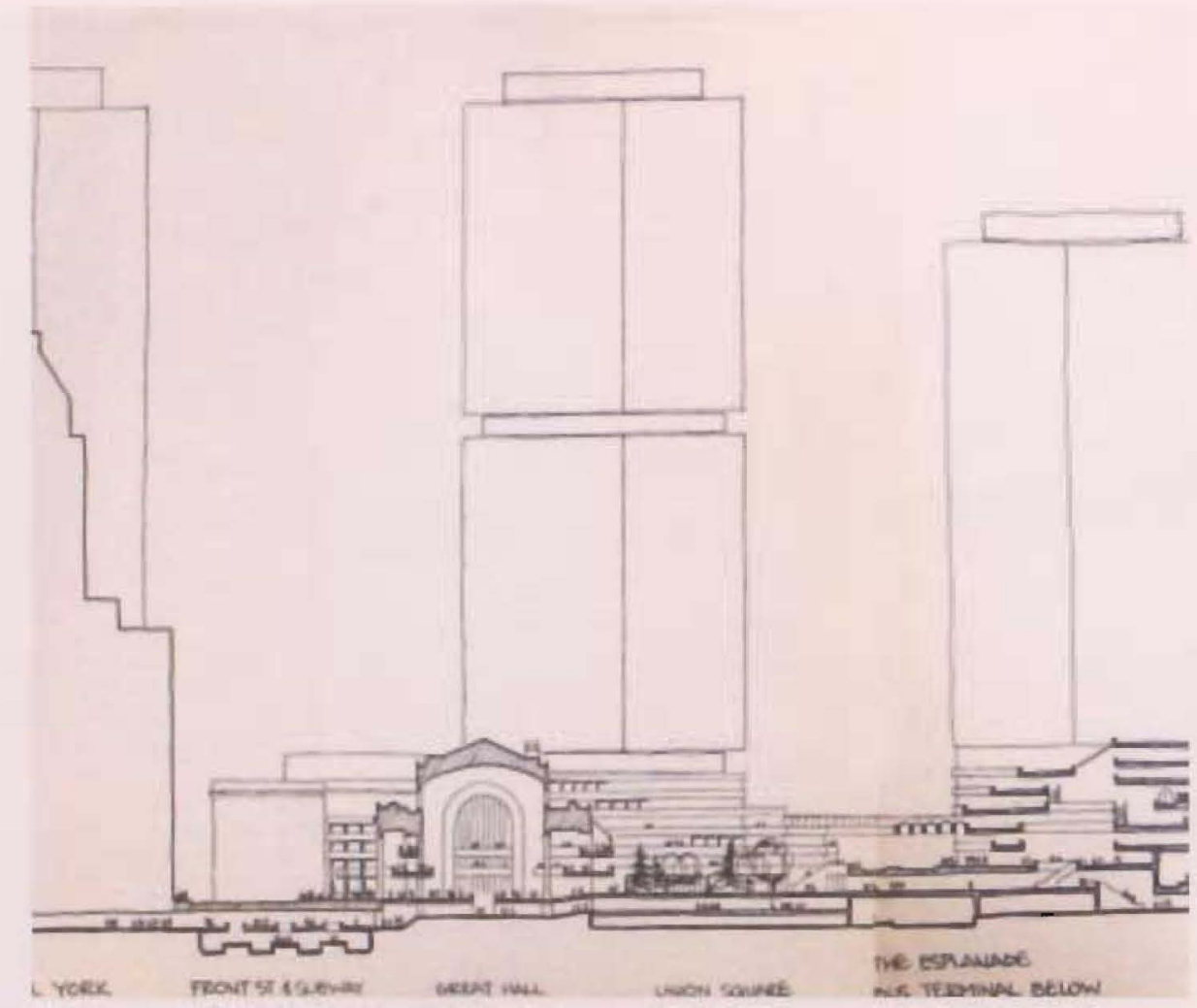

Figure 3.0.7 Revised Metro Centre section plan to include Union Station

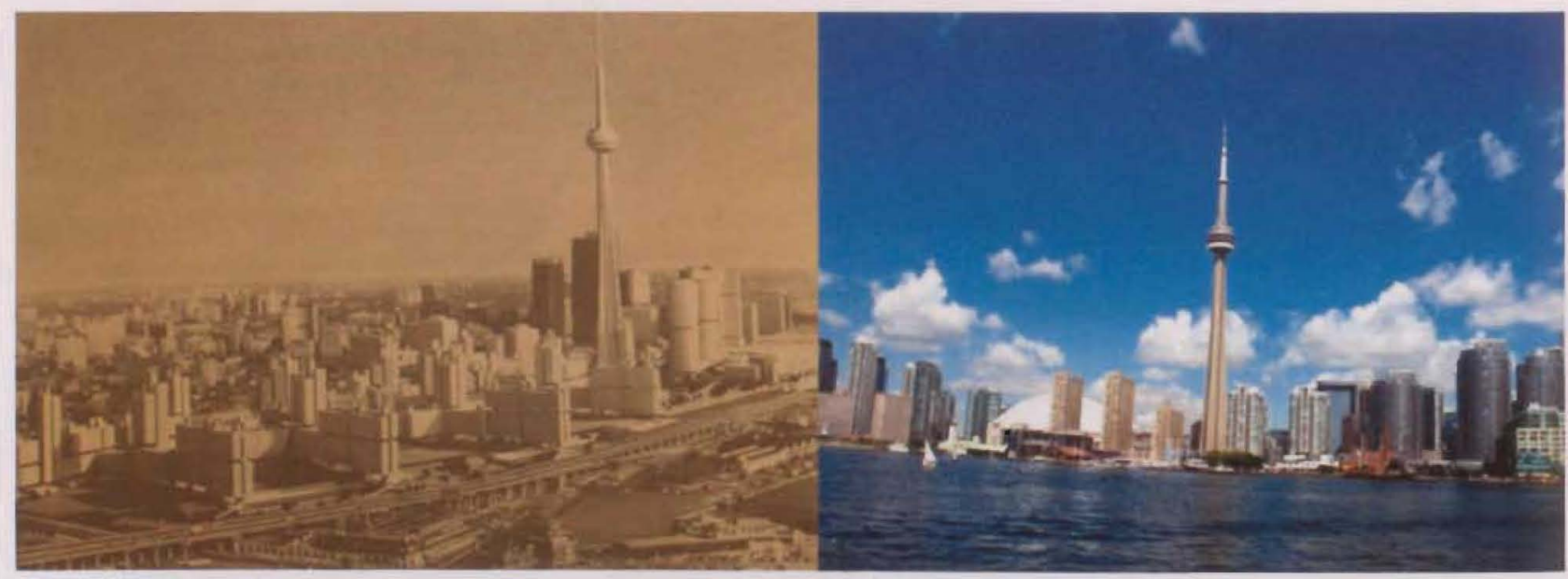

Figure 3.0.8 Metro Centre Model compared to present day Toronto 


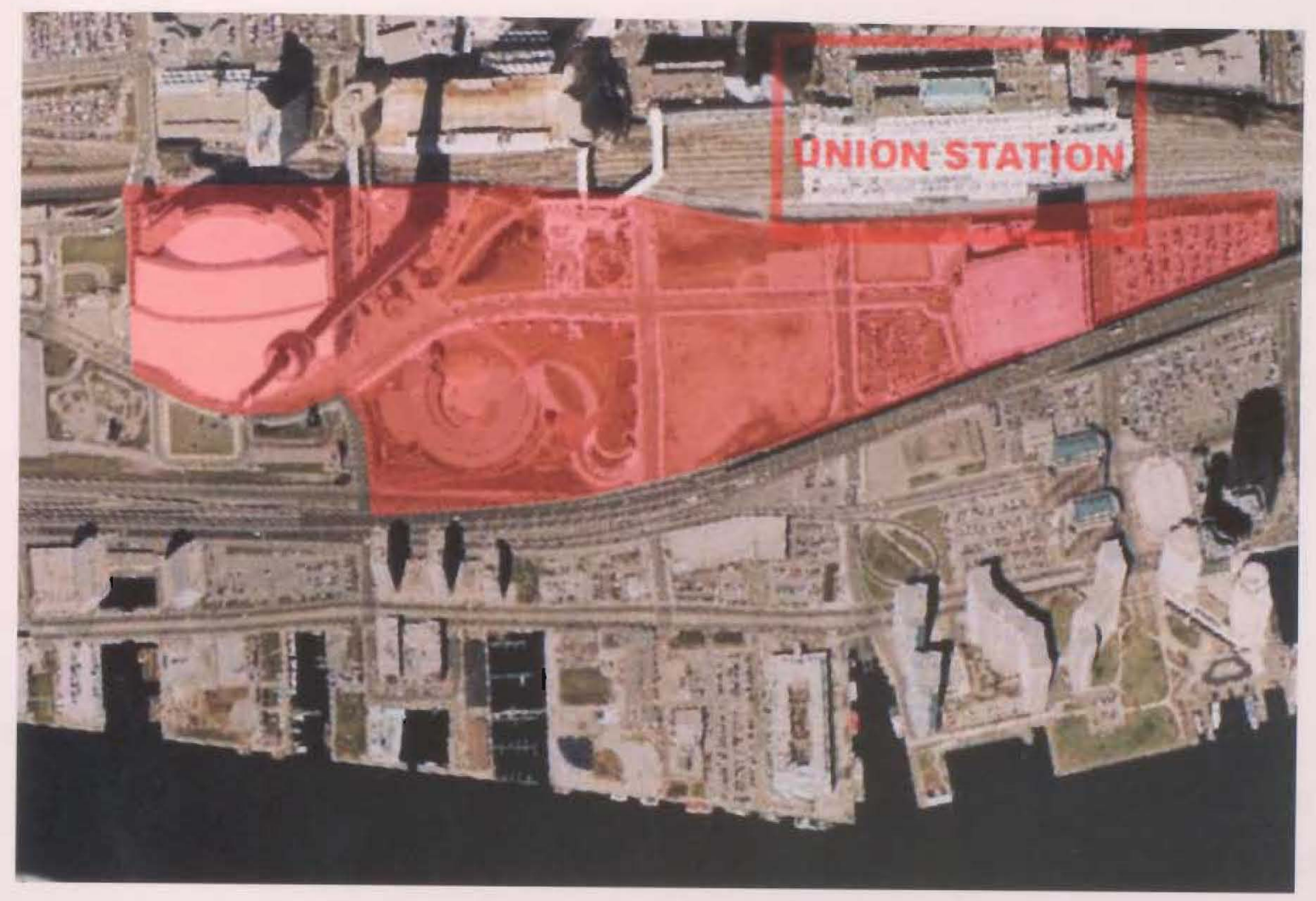

Figure 3.0.9 Circa 1999 large scale developments still cannot consume all the rail lands.

\subsection{Request for Expression}

In July 2000, Toronto City Council sent out a Request for Expression seeking international interest from developers to 'restore, revitalize and operate Union Station' (Carr, 2005, p. 33). One of the groups to submit was HP Heritage and The Union Station Consortium, which retained the Office of Metropolitan Architecture (OMA) as the conceptual design firm. The OMA proposal was headed by Rem Koolhaas and was typical of his competition work, vague and grand in ambition, but grounded in realistic possibilities such as mixed-use development consisting of a boutique hotel, a retail-adapted Union Station, condominiums, a new bus terminal and connections to the waterfront (Fig. 3.1.1). The most dramatic images of the proposal were the new station platforms featuring an overhead concourse, a row of tower developments over the existing rail yard and strong axial corridors to the waterfront (Fig. 3.1.2). While the Metro Centre Plan emphasized maximum development of the rail lands, the Koolhaas plan emphasized connections to the waterfront from a large public space. Most of the proposed 
public space was located on the rail lands, with development restricted over the existing rail yard. If the plan had been implemented, it would have been one of the largest public spaces in downtown Toronto (Fig. 3.1.3). In the end, the plan was not chosen and the Union Pearson Group Inc, which retained Toronto architect Eberhard Zeidler, won the competition. Much less ambitious in scale, the Union Pearson plan proposed:

"The Great Hall was to be refurbished without change to the fabric, while a new concourse, extending from Front Street to the Air Canada Centre, would be introduced below grade. The former teamways parallel to York and Bay streets would be excavated to open space for a doubling of the passenger volume in coming years, and the moats around the station would be enclosed by glass canopies." (Carr, 2005, p. 33)

Retail would be expanded below the existing and future concourses, taking advantage of the station's three-level basement condition. Through talks with GO Transit, the plan has evolved to include redeveloping the existing train sheds with an atrium space for views of the city (Fig. 3.1.4) (Transit Toronto, 2007). Gilbert, a consultant on urban issues, wrote in an article for the Toronto Star, "The present plans of the City of Toronto and the regional train operator, GO Transit are ill-conceived in almost ever respect. The result - if the current plans are implemented - will be to replace one dreary train-travelling experience with another" (Gilbert, 2008). Gilbert further remarks that the plans are insufficient at providing a standard level of transit service and is most critical of the addition of retail that would cost "more than $\$ 600$ per square foot, which would put it among the most expensive retail spaces in the world." He went on to write that "the possibility of charging rents high enough to cover this extraordinary cost is remote" (Gilbert, 2008). 


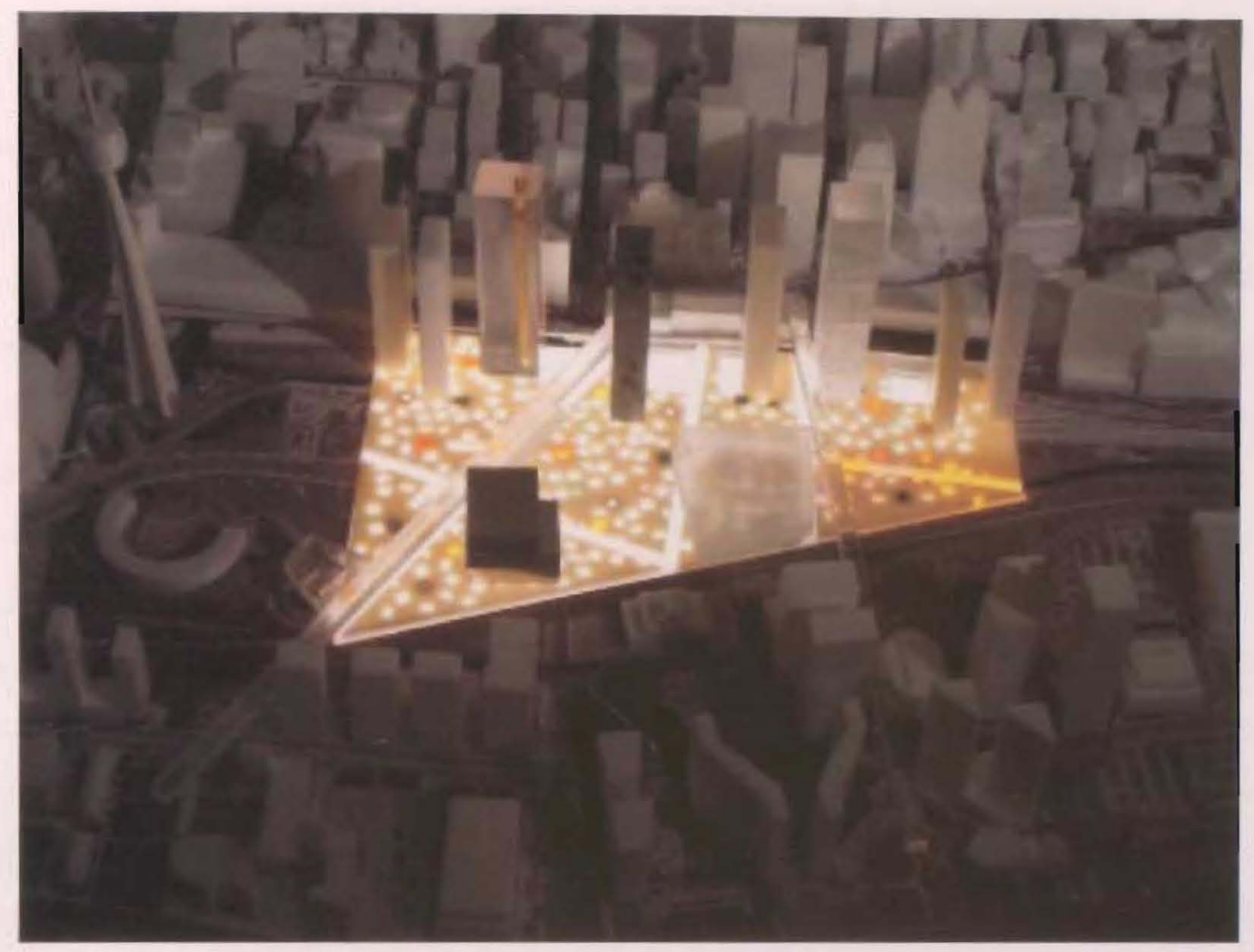

Figure 3.1.1 OMA Master plan, vague representation

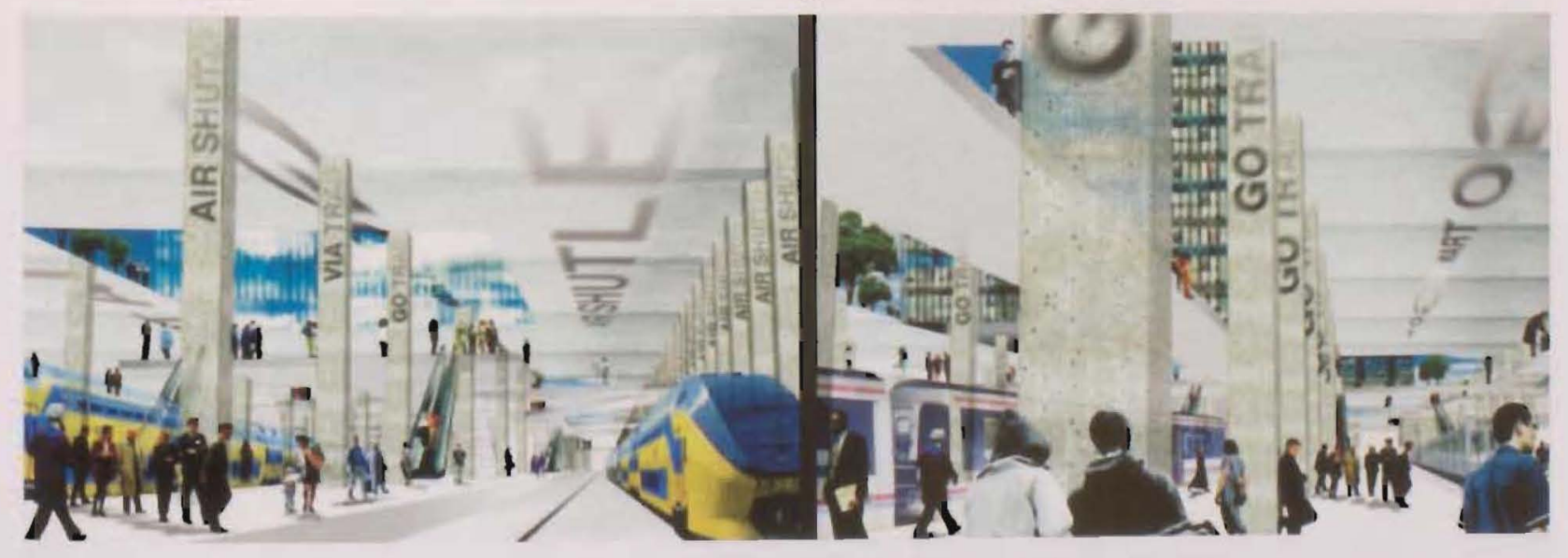

Figure 3.1.2 OMA Master plan, new concourse 


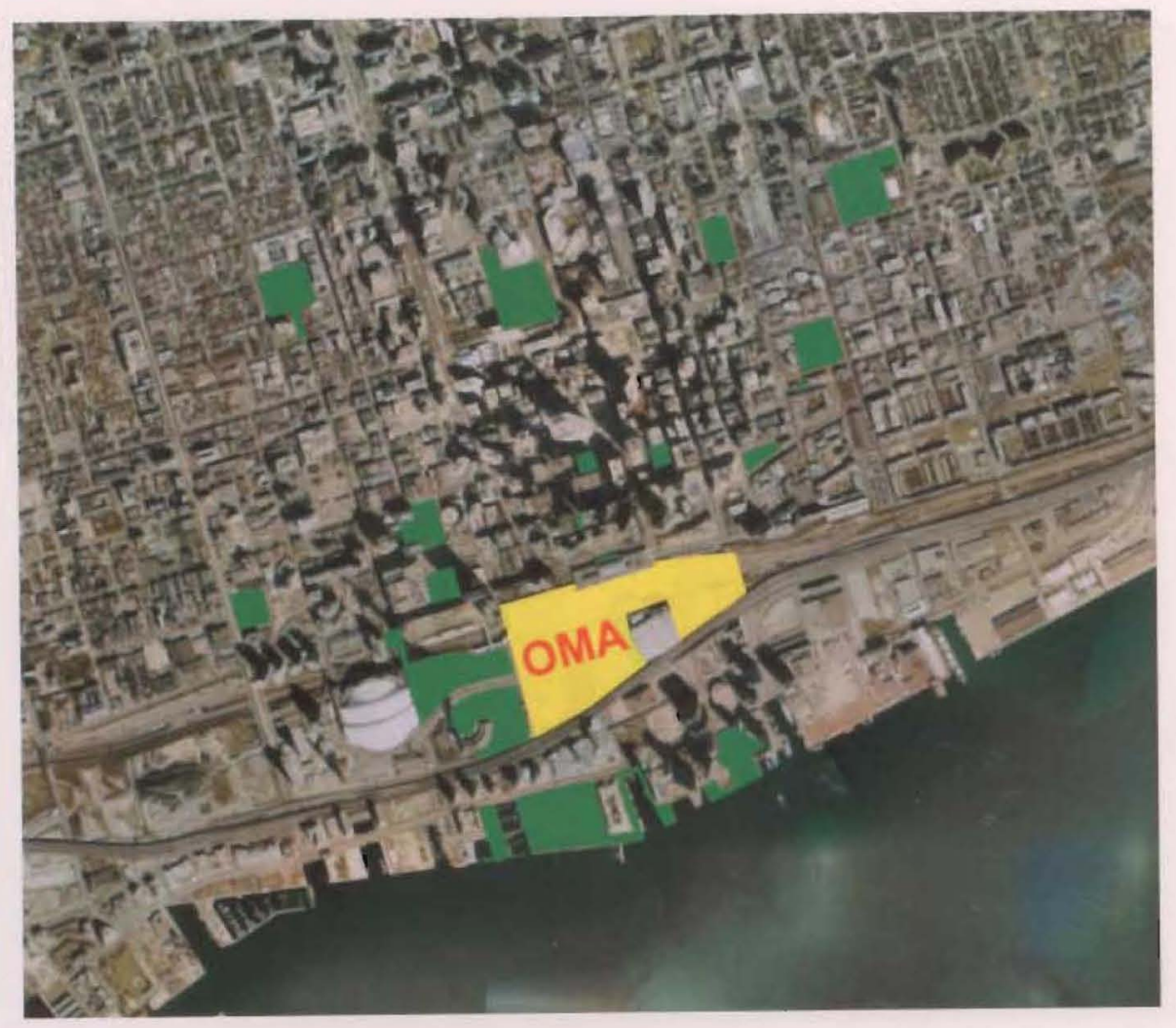

Figure 3.1.3 OMA Master plan vs. existing public park spaces

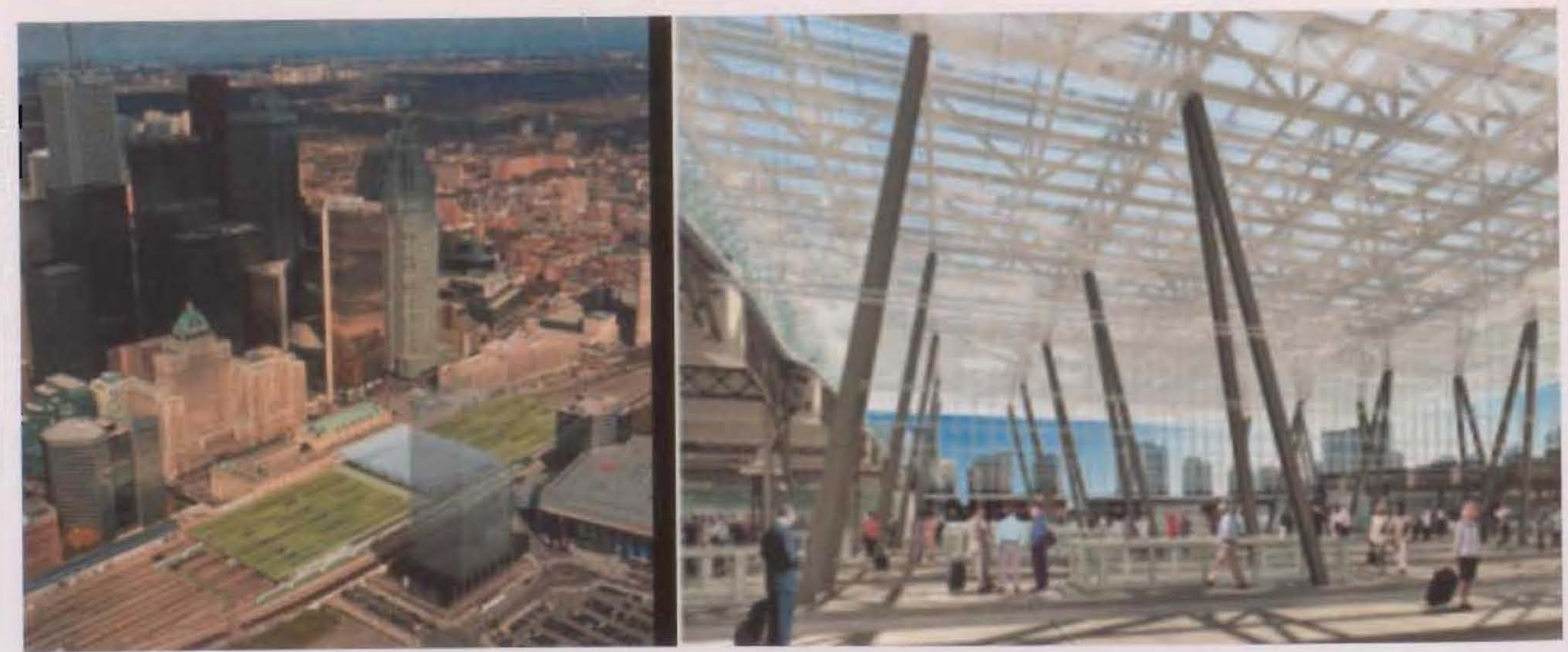

Figure 3.1.4 Current GO Transit platform canopy proposal 


\subsection{Current Trends}

Even though grandiose master plans for the rail lands did not come to fruition, roads have been spreading south of Union Station, providing access from Front Street down to the Harbourfront. Instead of a finer grain of properties, Figure 3.2.1 reveals that these blocks were sold off as large plots for single-use developments. Road surfaces are large, with many greater than two lanes wide, promoting a car-dominant environment (Fig. 3.2.2). Due to the large mono-programmed developments and wide roads, the area between the Gardiner and Union Station lacks pedestrian activity. Large events at either the ACC or Roger Centre witness a rise in pedestrian activity in the area, but after these events the streets remain devoid of activity, with many shops closed or left empty (Fig. 3.2.3). The opening of the Simcoe tunnel to connect Simcoe Street north to south might provide better pedestrian access, but without an attractor to draw in the crowds it is likely the Simcoe tunnel will serve only to reduce the congestion on York Street during the rush hour (Fig. 3.2.4).

Currently there are five developments under way in the former rail lands, the Central Railway Lands (CRL). These include three office complexes, a mixed-use twin tower and a twin tower condo development. The mixed-use development and one office complex are currently under construction adjacent to the $\mathrm{ACC}$, with the remaining developments in the planning stages. The TELUS office building currently under construction adjacent to the ACC will be a 31-storey tower with retail and integrated access to Union Station (Fig. 3.2.5). The mixed-use development, Maple Leafs Square (Fig. 3.2.6), with its sports bar and fine dining at the base, a 170-room hotel and a bridge connection to the ACC, is designed to cater to the hockey crowd at the ACC. In addition, Maple Leafs Square will contain 150,000 square feet of office space adjacent to the Gardiner (Maple Leaf Square, 2008). The twin tower condo development, ICE Condo (Fig. 3.2.7), will have one tower rise 55 storeys and the other, 65 storeys (Sutton Real Estate, 2008). In addition to the two residential towers, one of the three office complexes will occupy the northeast corner of the site (Fig. 3.2.8). The third office development, British Columbia Investment Management Corporation (bc/MC), is north of the ICE Condo development and will be a 26-storey LEED GOLD complex, designed by the Toronto firm KPMB (Fig. 3.2.9) (GWL Realty Advisors Inc., Brokerage, n.d.). Proposed is an extension of the PATH system linking Union Station to the adjacent $A C C$ developments and possible connections to the ICE Condo and the bcIMC office building. It is unclear how the PATH system will meet up with the station, but it might be a part of the larger retail scheme of Union Station. 
As development fills out the $\mathrm{CRL}$, many people in the city of Toronto feel that Union Station and the former rail lands lack an identity. To provide an identity, Toronto City Council developed with architectsAlliance in 2006 the Union Station District Plan, a 498-page proposal defining three key initiatives: heritage preservation, public realm, and enhanced connections and flows. The first component of the plan outlines the boundaries of the district based on the extent of surrounding historical properties (Fig. 3.2.10). Public realm initiatives include defining Front Street between York Street and Bay Street, the Union Plaza redevelopment and the refurbishment of the teamways for GO Transit. The third component of the Union Station District Plan is to increase the porousness of the Union Station through more internal connections and a prominent north-south connection (Union Station District Plan, 2006). The Union Station District Plan follows much of the Union Station Master Plan, a proposal done for the City of Toronto by the local firm Office of Urbanism in 2004, which outlines methods similar to the district plan's three key initiatives (Union Station Master Plan, 2004). GO Transit proposals for Union Station also follow some of the recommendations of the Union Station Master Plan, including redevelopment of the train sheds and developing retail in the lower levels of the station (Canadian Architect, 2008). Of the many initiatives put forward, the Union Plaza tunnel connection and teamway refurbishments have begun. 


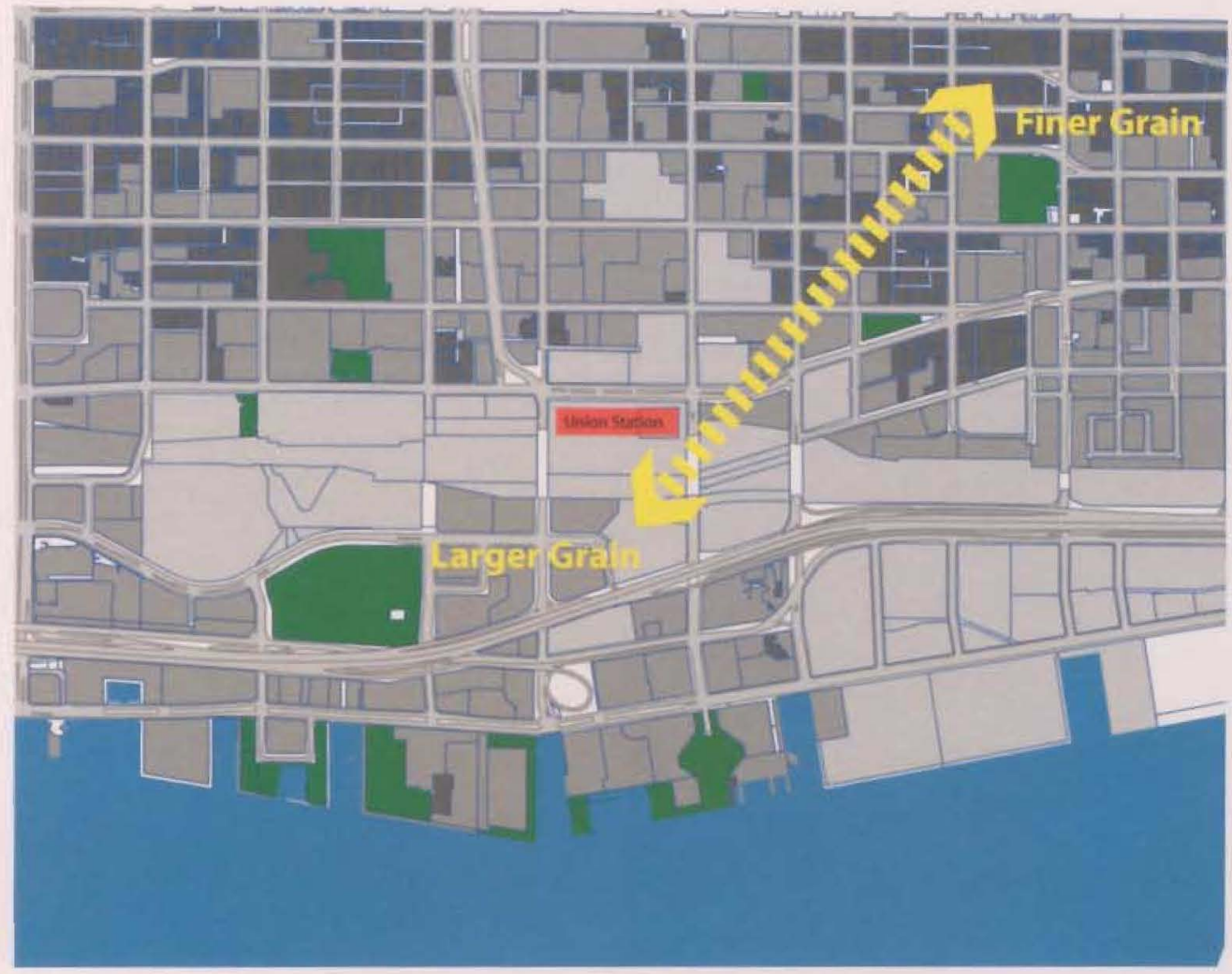

Figure 3.2.1 Finer Grain vs. Larger Grain of property divisions.

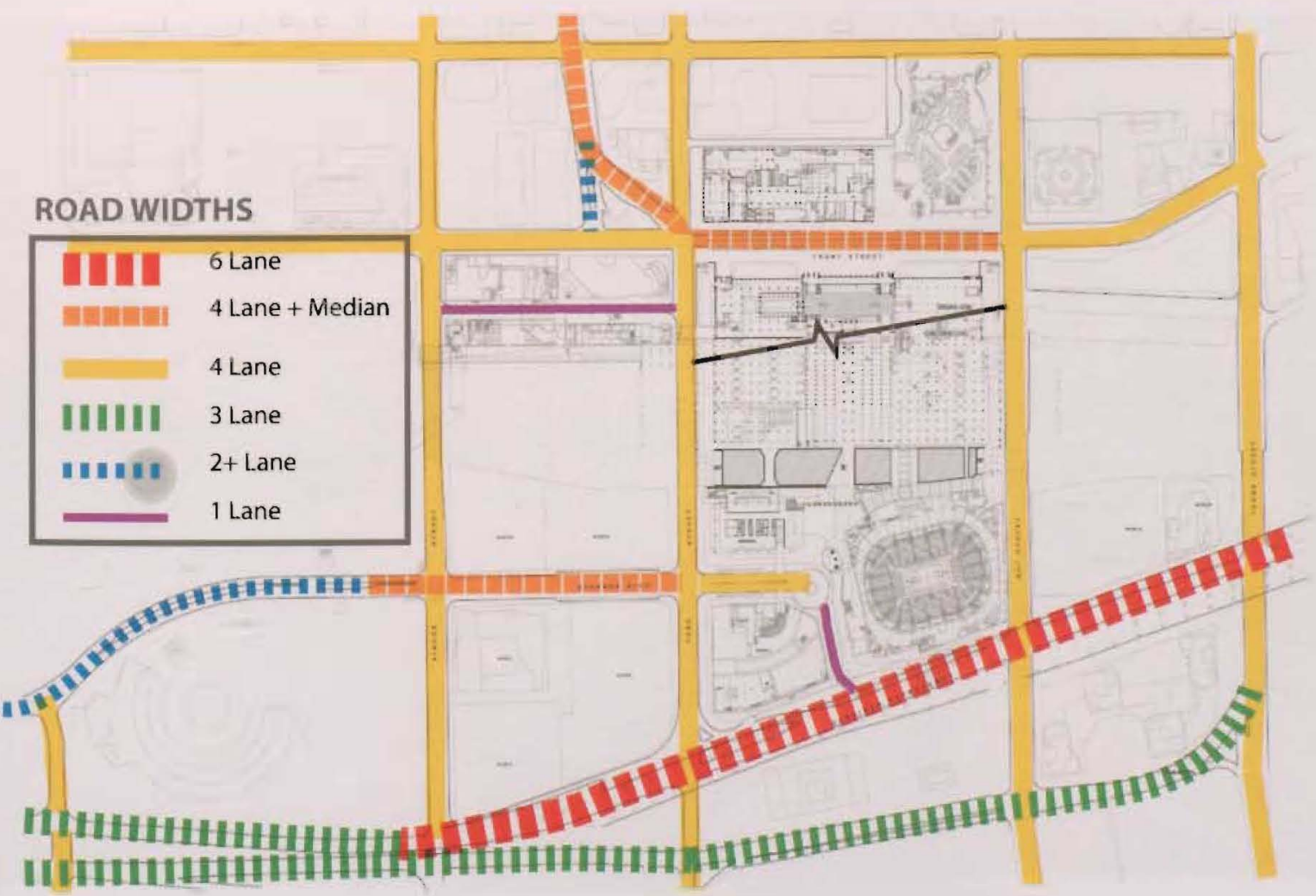

Figure 3.2.2 Road Conditions in the Central Railway Lands 


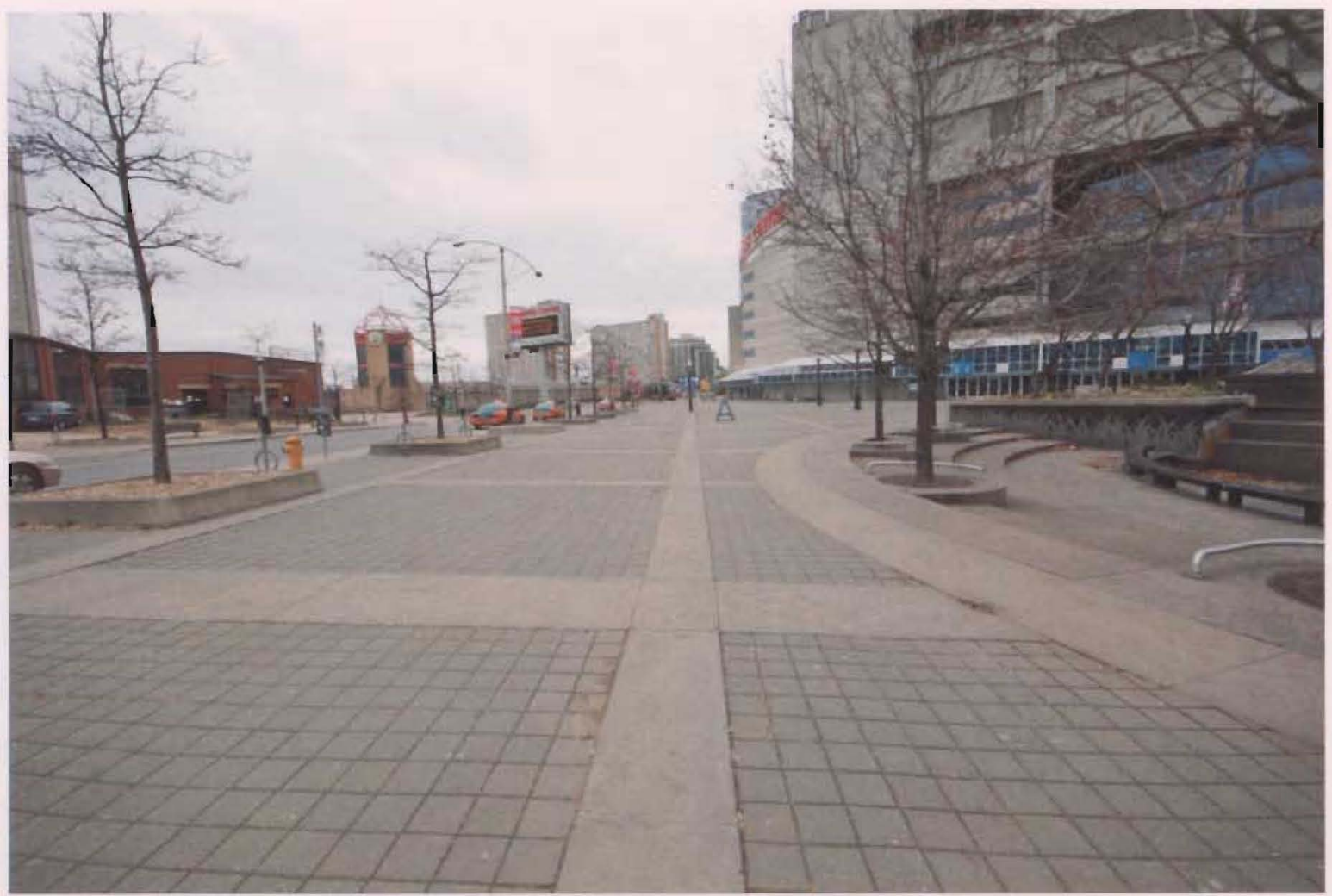

Figure 3.2.3 Typical weekday. devoid of activity (Roundhouse to the left, Rogers Centre to the right

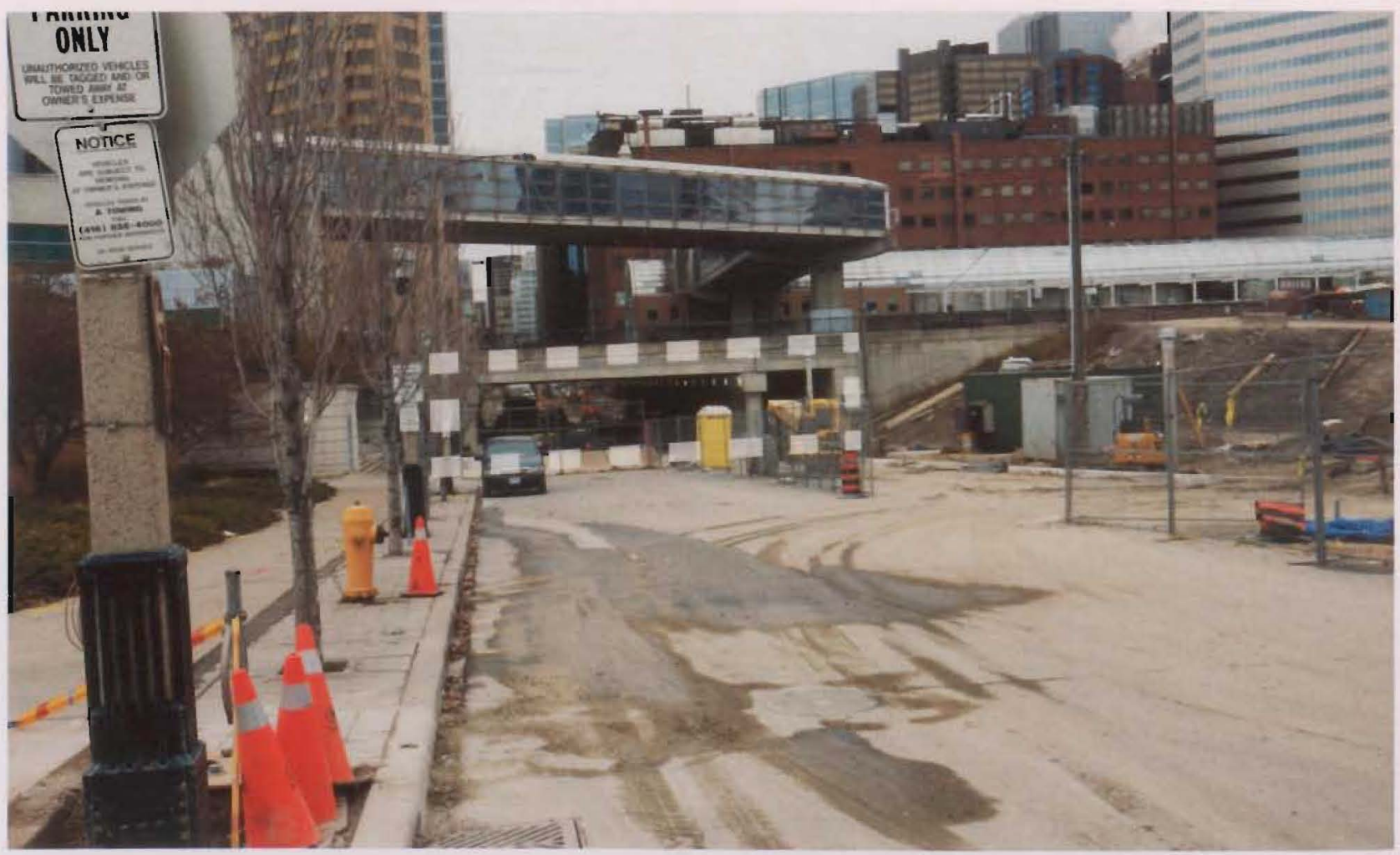

Figure 3.2.4 Simcoe Tunnel construction, not an attractive route. Skywalk bypassing Simcoe Tunnel above 


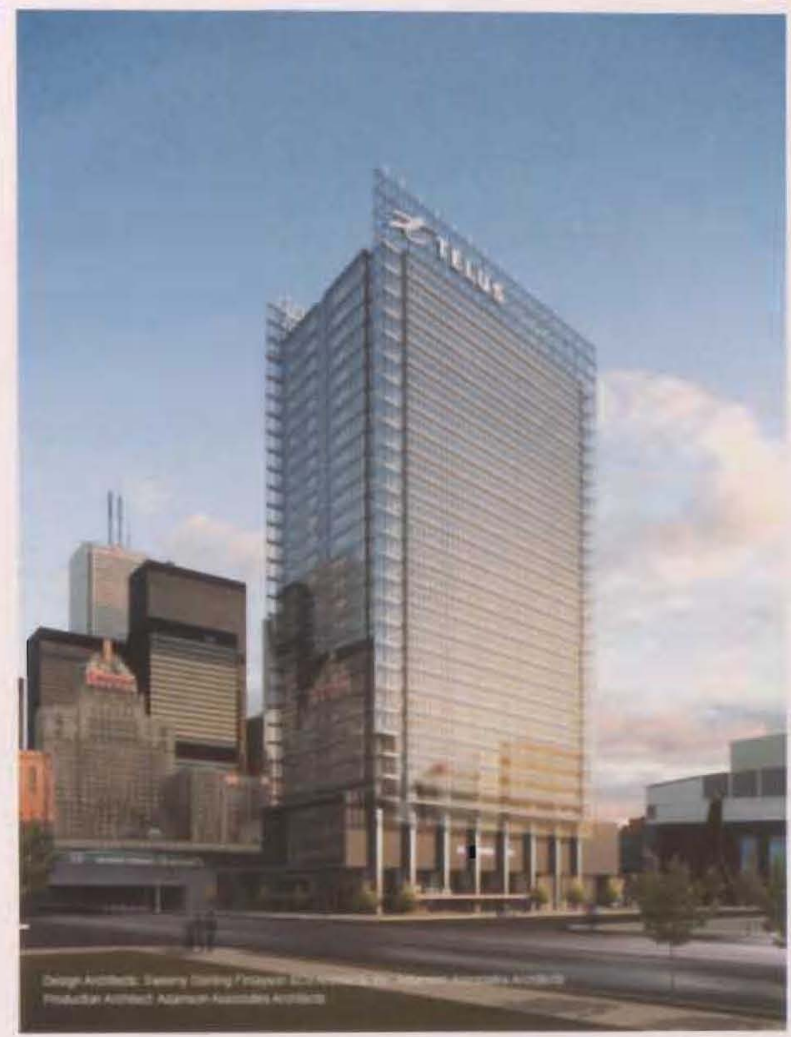

Figure 3.2.5 New Telus building designed by \&Co, currently under construction.

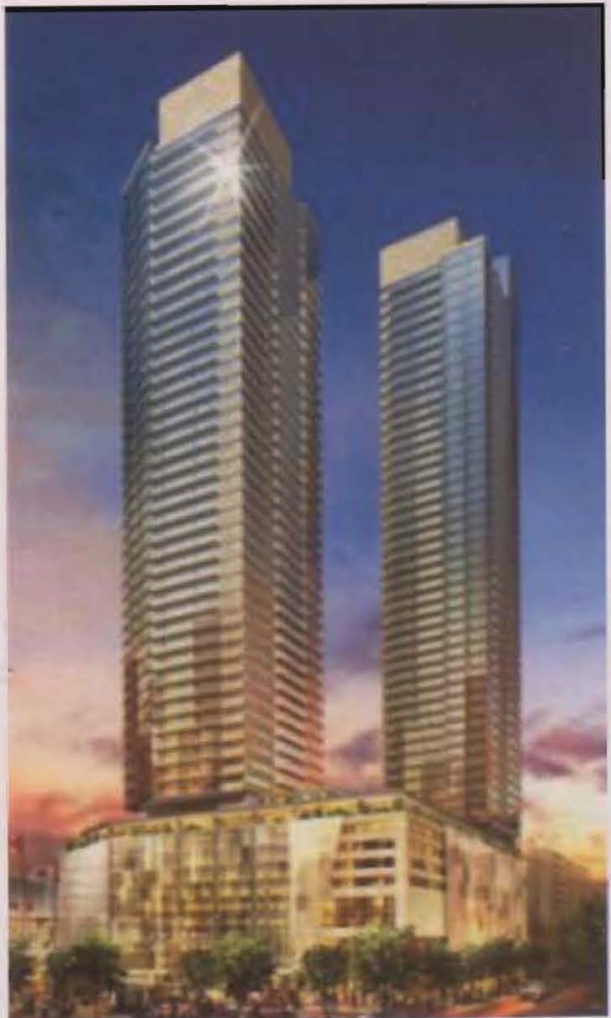

Figure 3.2.6 Proposed Maple Leafs Square, currently under construction. 

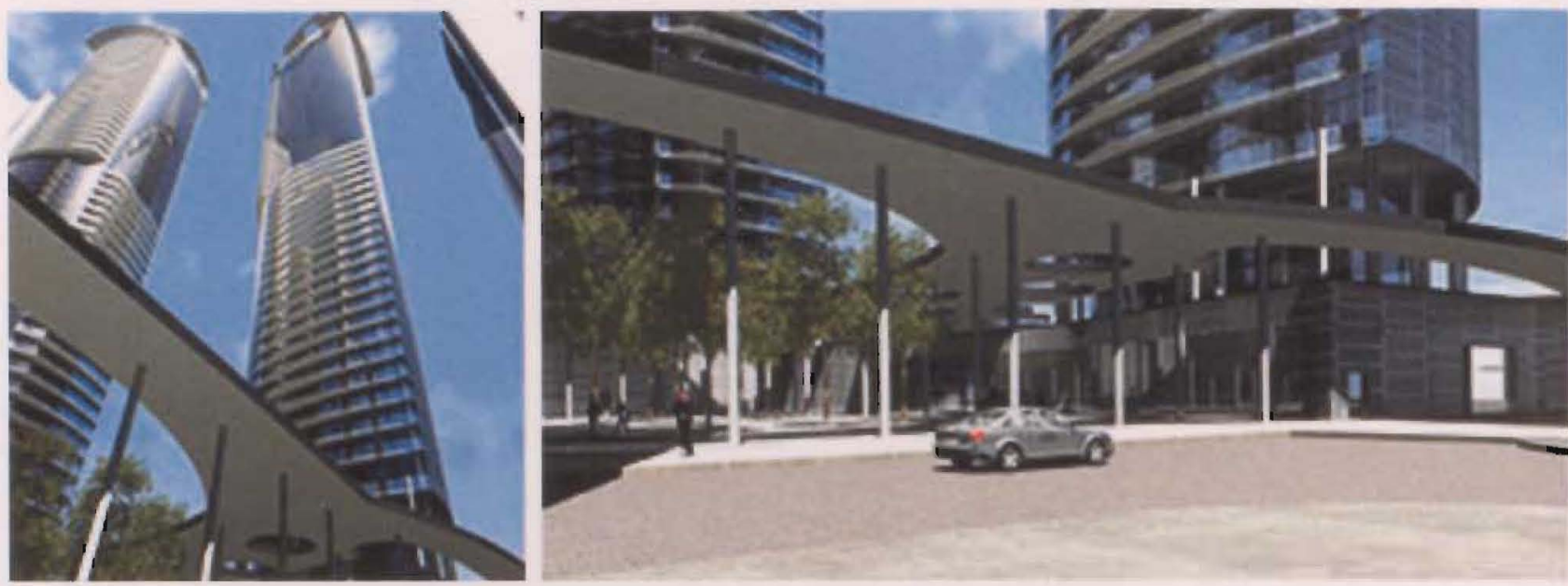

Figure 3.2.7 Initial proposal renderings of ICE Condo's. No relation to surrounding context in renderings.

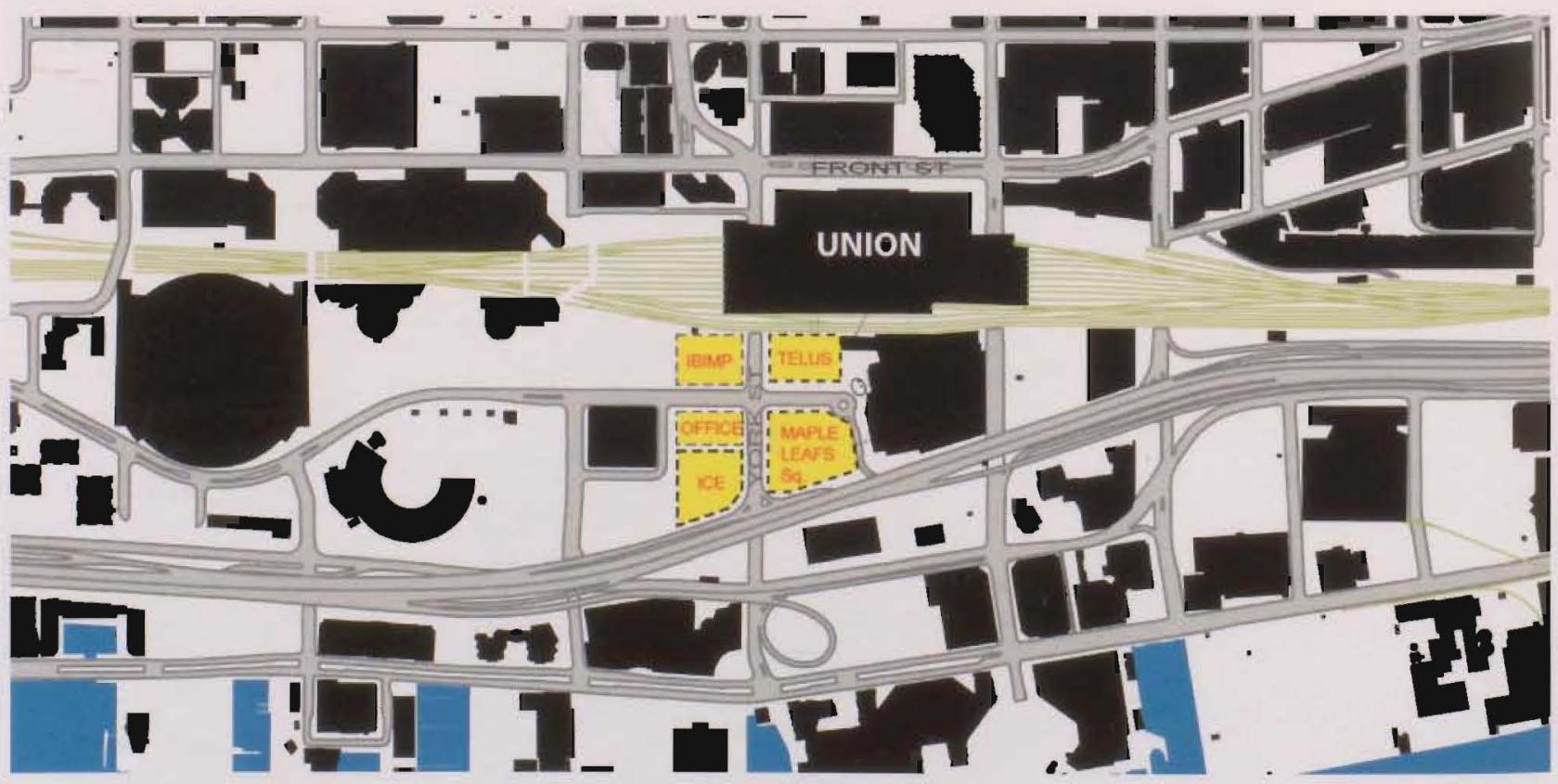

Figure 3.2.8 Locations of new developments defining York Street. 


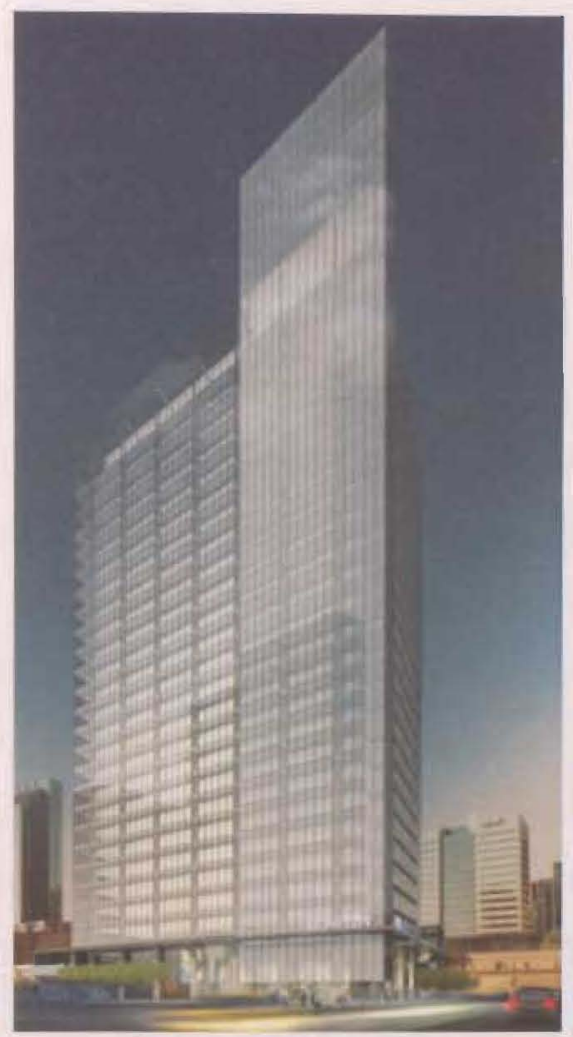

Figure 3.2.9 KPMB designed ibIMC office tower.

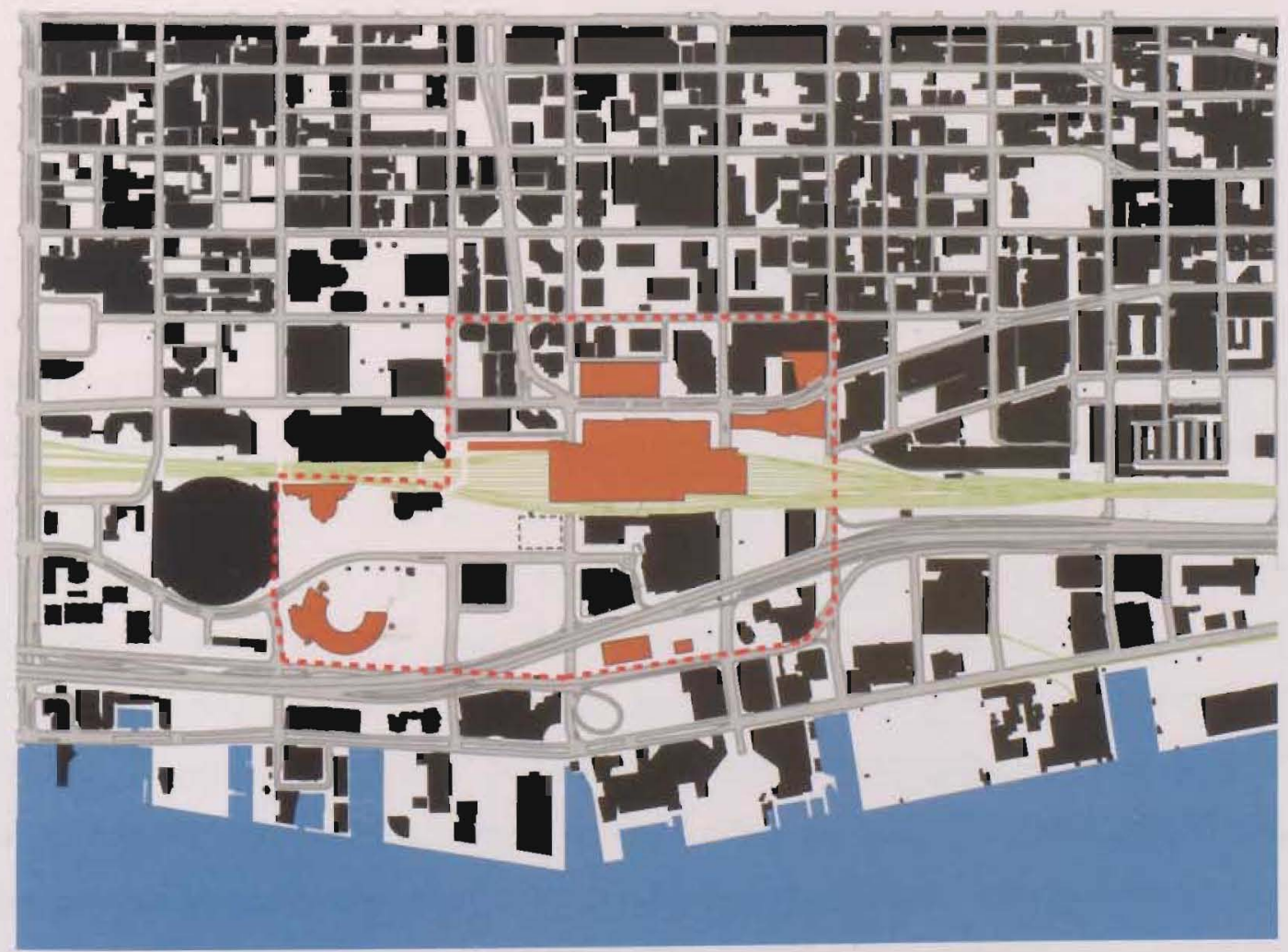

Figure 3.2.10 Union Station District Plan boundaries (dashed red) enclosing historical structures (brown) 


\subsection{So Many Issues ...}

There are as many issues with Union Station, as there are issues with the contextual area of the Central Railway Lands (CRL). Through analysis it has become apparent that Union Station and the CRL must be understood as being in opposition of each other. Opposition has been created by the inability of the City and developers to properly follow through with a singular vision that combines Union Station and surrounding context into an integrated whole. As a result of this opposition, there exists the station, an inflexible stone complex, and the context, a static landscape inflicted with massive infrastructures and developments. The Union Station District Master Plan and the Union Station Master Plan have both proposed superficial methods of combining the CRL and station through a common material pallet and increased north-south connections. While the actions of plans may contribute to defining a district, it will be shown that Union Station and CRL require a much more holistic and complex solution. Currently the CRL is developing into a generic district with no public life, while Union Station sits rotting with poorly integrated services. These polar distinctions have allowed the issues to be grouped into two distinctions: 1) fragmented station and 2) missing identity.

\subsection{Fragmented Station}

When Union Station was constructed in 1927, the designers could never have foreseen the decline of passenger rail travel and the massive rise in commuter rail in the GTA - let alone the concept of the GTA. Changing use has forced Union Station to transform its identity from a passenger station into a commuter hub. The identity change has been performed through a long process of carving out the original function and grafting on new functions, thereby fragmenting the station into isolated parts. When the station opened, passenger rail was the only form of transportation integrated into the design (although automobile access was integrated into the moats, the design never successfully worked). In 1954 the Union to Eglinton subway section of the Toronto Transit Commission (TTC) was completed, providing the first unintentional step towards transforming Union Station into a commuter hub. By 1963 the Union to St. George subway section was completed and GO Transit made its début four years later; officially marking Union Station's shift to a commuter hub (City of Toronto, 2007). A streetcar connection from the Harbourfront to Union Station through an underground tunnel opened in 1990, linking the station 
along a streetcar line to the Spadina subway station. As of 2003 , the GO bus terminal was completed and opened for use behind the Dominion Public Building, adjacent to Union Station (Transit Toronto, 2007). Porter Airlines also started to provide shuttle bus services from Union Station in 2006, linking the station to the Toronto Island Airport (Fig. 4.1.1). Multimodal services at Union Station, apart from GO Transit rail connections, are not physically integrated into the station. GO Transit rail connections are integrated into their own concourse, but the GO bus terminal is separated by a four-lane road and remains independent from the body of the station. The bus terminal does provide access to the GO platforms via the Bay Street teamway, but that remains the closest physical connection to the station (Fig. 4.1.2). The Union subway station is not physically integrated to Union Station, forcing commuters to first exit from Union Station, cross the weather-exposed moats and descend into the subway concourse. The same situation applies for the streetcar service, which can only be accessed by entering into the Union subway concourse. Porter Airline's kiosk for shuttle bus service to Toronto Island Airport is located in the Skywalk adjacent to Union Station, while the shuttle bus pickup is located across the street at the Royal York Hotel (Fig. 4.1.3). The various mentioned infrastructures have been improperly integrated because Union Station was never designed to be flexible, adaptive or upgradeable. Attempts to integrate new infrastructures into the station have resulted in GO Transit readapting old postal rooms or TTC tunneling holes through the station's moats. What presently exists is a clustering of transit infrastructures in and around Union Station - all lacking a coherent connection to each other.

New infrastructures imposed on Union Station have not only caused fragmentation, but have also imposed new spatial programming that corrupts the original station's design. GO Transit has caused the largest programmatic fragmentation due to its 40 years of progressive growth without a singular, coherent vision. Currently, GO Transit has 37 platform access stairs in six areas in and around Union Station. Shinjuku Station in Japan, the world's busiest station, moves nearly three million passengers a day with only 45 platform connections - underscoring the inefficient design of GO Transit's 37 connections for its 200,000 daily passengers (National Geographic, 2008). Connections such as the York Street teamway are divorced from Union Station by a four-lane road (Fig. 4.1.4); while others such as the York Concourse are only recognizable to the most seasoned GO Transit users (Fig. 4.1.5). GO Transit plans to develop the York concourse into another GO concourse, effectively doubling the waiting capacity (Union Station Master Plan, 2004). The unfortunate aspect of redeveloping the York Concourse is the probability that passenger conditions will not improve (Fig. 4.1.6). 
Most passengers using the GO Transit platforms do so by waiting in the GO Concourse below the station's platforms, a space initially designed as a mail sorting room. After waiting in a space never designed for holding commuters, passengers are permitted to leave when the trains arrive. GO Transit commuters are not permitted to stand on the platforms until the trains arrive because the platforms are too narrow (some are six feet narrower) and pose a danger to waiting crowds. This adaptation of leftover spaces is most apparent for disembarking passengers, who are presented with multiple platform exits leading them to underground concourses, pedestrian bridges and exterior teamways. Without the ability to grasp GO Transit's spatial layout holistically, the novice user will find the passenger routes confusing and lacking visual reference points. The inability of GO Transit to make radical alterations has resulted in a cobbling together of spaces to provide an independent commuter terminal. The dispersion of GO Transit services is seen in Figure 4.1.7, which illustrates GO Transit dedicated space, Non-GO Transit space and GO Transit influenced space. GO Transit's programming is causing a ripple effect of destabilizing original programmed spaces.

Go Transit has shifted the station's use to commuter rail, destabilizing the Great Hall's primary role as a passenger ticket lobby. During peak morning traffic, 35 per cent of the flow through Union Station is directed through the GO Concourse Union Subway/PATH connection, which has resulted in bypassing the Great Hall's main entrances, where the peak morning traffic is now only 10 per cent (Union Station District Plan, 2006, App. 5 p. 31). Although the Great Hall continues to function as a ticket lobby for passenger rail, with significantly fewer clientele, it loses its importance as a space for welcorning users. Further program corruption has occurred to the west wing's men's sitting room. The sitting room was demolished to provide a connection to the Skywalk for commuters heading to the Rogers Centre, MTCC and CN Tower. After creating the access to the Skywalk, it must have been apparent to the TTR that the space was too large to function only as a connector, and thus has been filled with incompatible programming. The space contains a unisex barber, candy and confectionery stands, a connection to one GO platform, a link to the Skywalk, washrooms and seating (Fig. 4.1.8). All of these elements combined produce a space without a defined function.

There are many of these types of spaces at Union Station where a program has been added to provide a purpose for a defunct space. The arrivals concourse is another such space that has lost its purpose due to the shift from passenger rail to commuter rail. The intended purpose of this concourse was to separate the arrivals from the departures, but with the decline in passenger rail service, the arrivals concourse has been forgotten. Currently, it acts as an 
interstitial space between the York and Go Transit concourses, filled with as much incompatible programming as the west wing (Fig. 4.1.9). The cause of these purposeless spaces is that the structure of Union Station is not able to provide flexibility for change. Union Station was created for the sole purpose of serving passenger rail - not for providing multi-modal services. When multi-modal services began to function out of and in proximity to Union Station, their programming could only effect minor changes and not a complete reformatting of the spatial functions.

Union Station has developed into a multi-modal hub operating with functionally designed spaces, improperly integrated infrastructure and a structure that does not provide for adaptation. When constructed, it was a temple of stone, signifying the union of competing passenger rail industries, but passenger rail has evolved into commuter rail, which now requires services beyond the intentions of the original design. These new modes of services were grafted onto Union Station through functional connections, which make do with the existing space in and around the station. Functional connections force the 63 million passengers a year to contend with a station 61 times smaller than Pearson International Airport, an airport that can only handle 38 million passengers a year (CBC News, 2007). While airports provide additional services to that of rail services, as infrastructures designed to move people, Union Station moves almost double the passenger volume at a fraction of the space.

Union Station is either a marvel of efficient design or, more realistically, purely functional and provides nothing more than transportation. GO Transit's 37 platform access points are located in concourses, roadside teamways and various other locations, reflecting the functional attempts to integrate commuter services into a passenger station. To meet the needs of a multimodal hub, services are locating away from the station, such as the GO bus terminal and GO Transit teamways. Union Station requires a holistic redesign to accommodate ever-changing infrastructures in a flexible composition that can allow for expansion and contraction of spatial programs. While symbolism was the hallmark of classical train station architecture, designing for the movements of people and changing spatial needs are the new requirements of stations. (Bruinsma, Pels, Priemus, Rietveld, \& van Wee, 2008). 


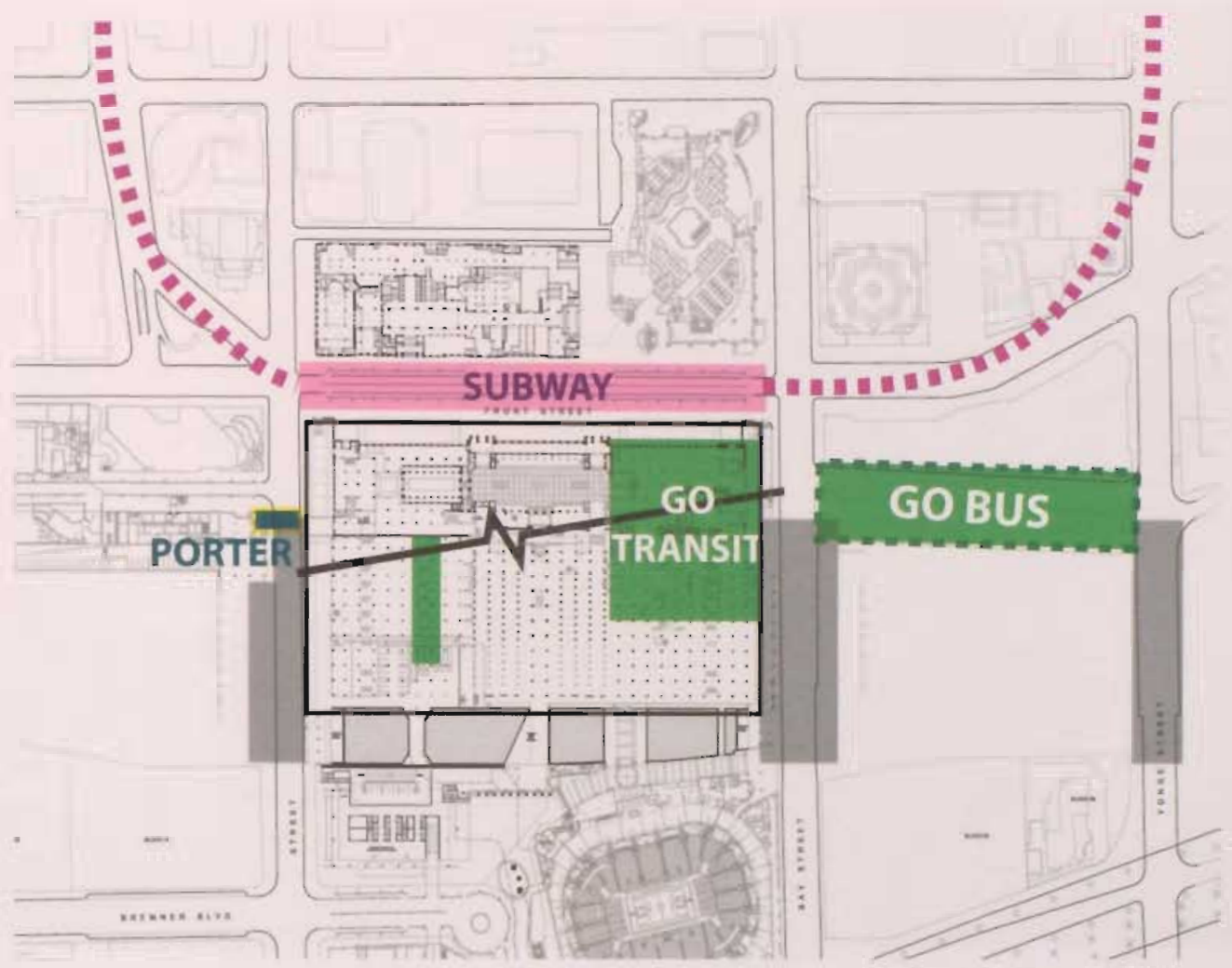

Figure 4.1.1 Layout of infrastructural services, only Go Transit is located within Union Station

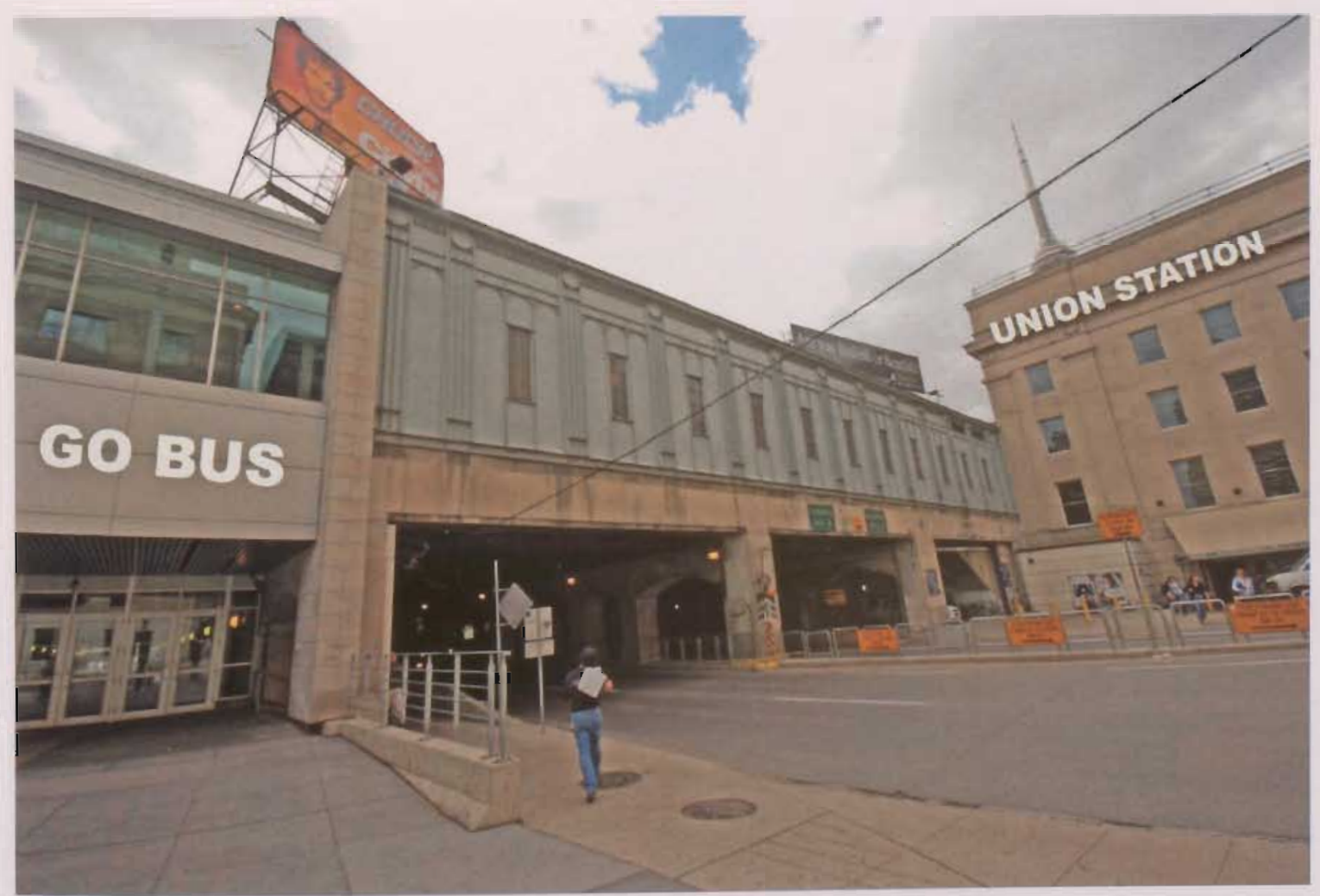

Figure 4.1.2 Go Bus Terminal separated by 4-lane road and pedestrian barrier 


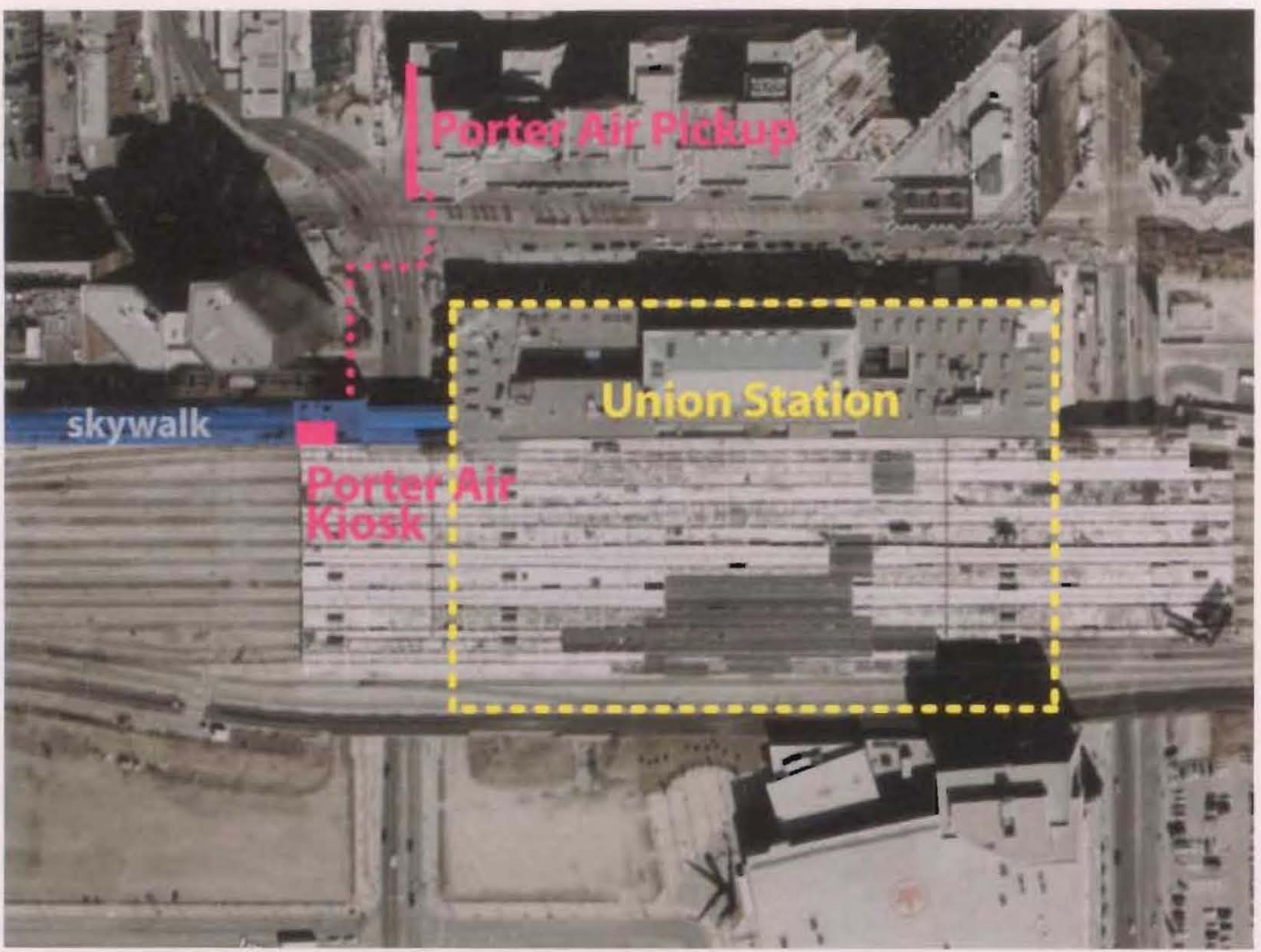

Figure 4.1.3 Porter Kiosk location relative to pictup location

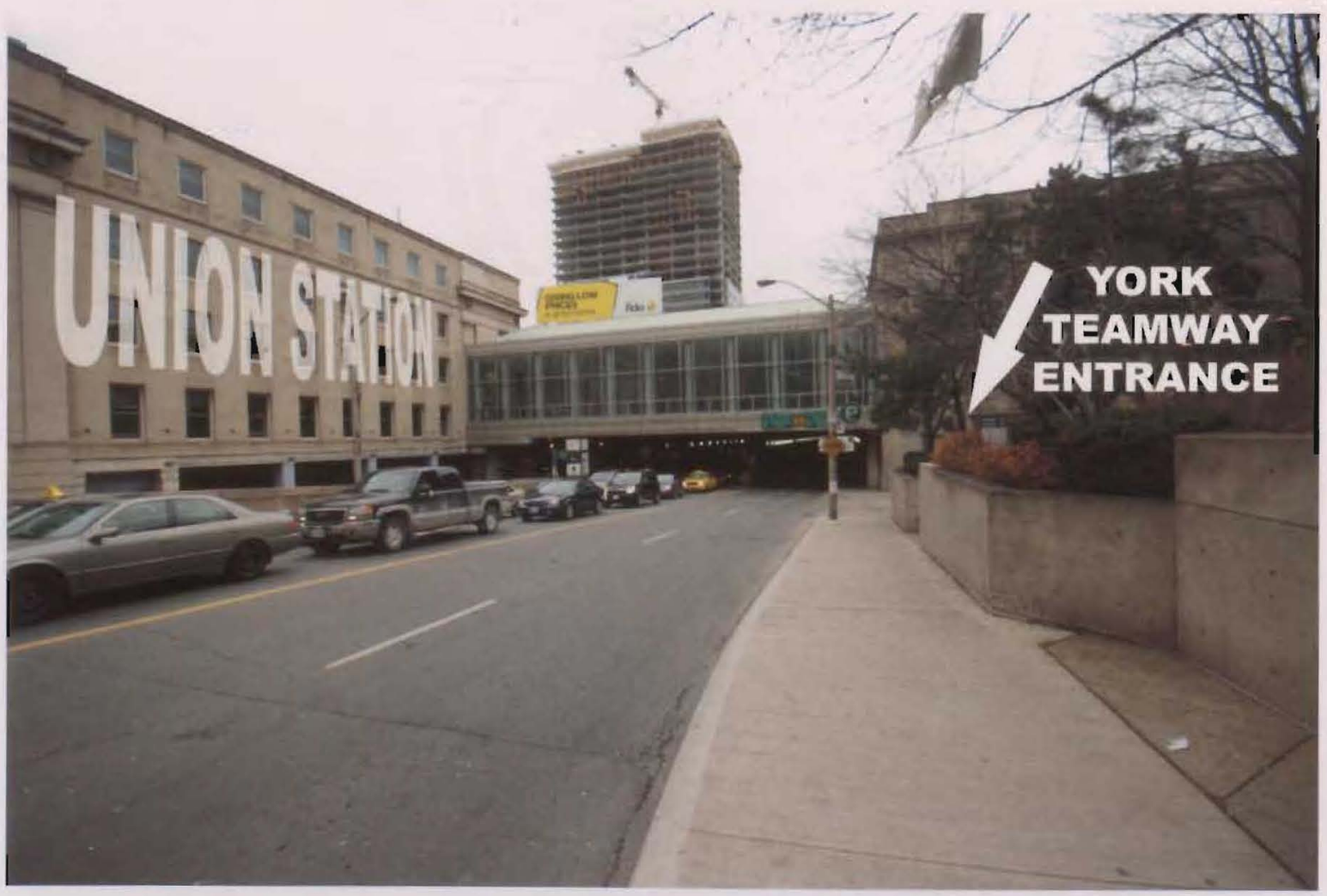

Figure 4.1.4 York Teamway entrance located off from direct pedestrian movement 


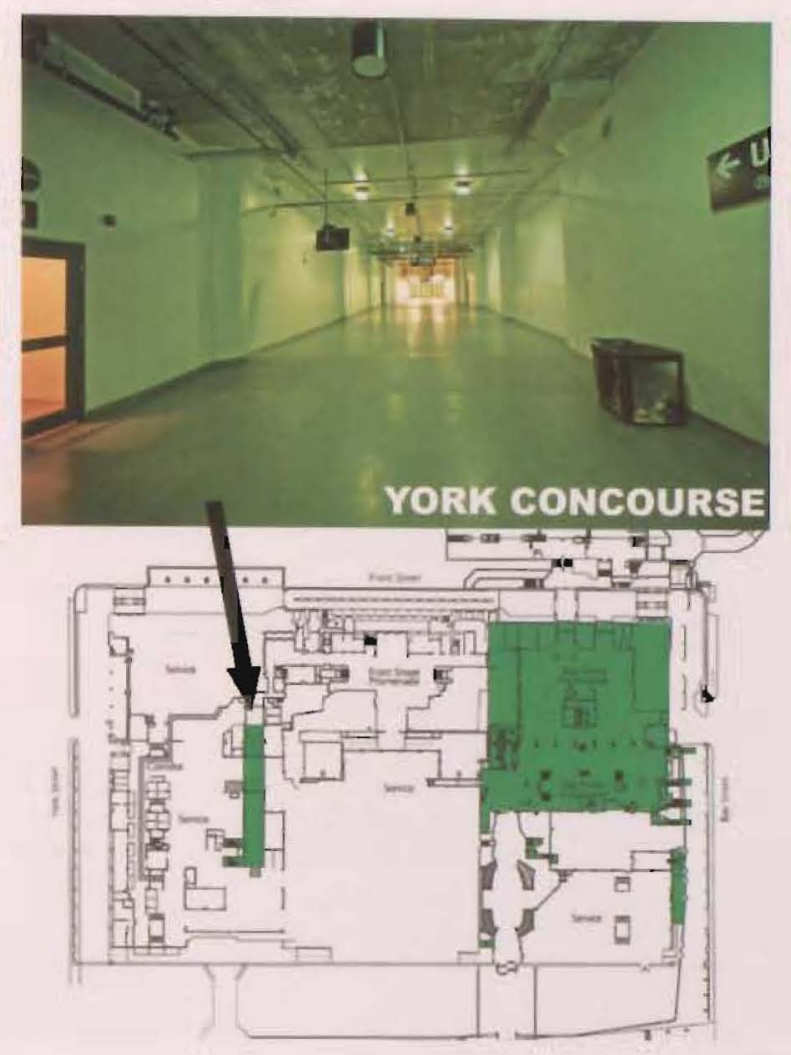

Figure 4.1.5 York Concourse located deep within the terminal

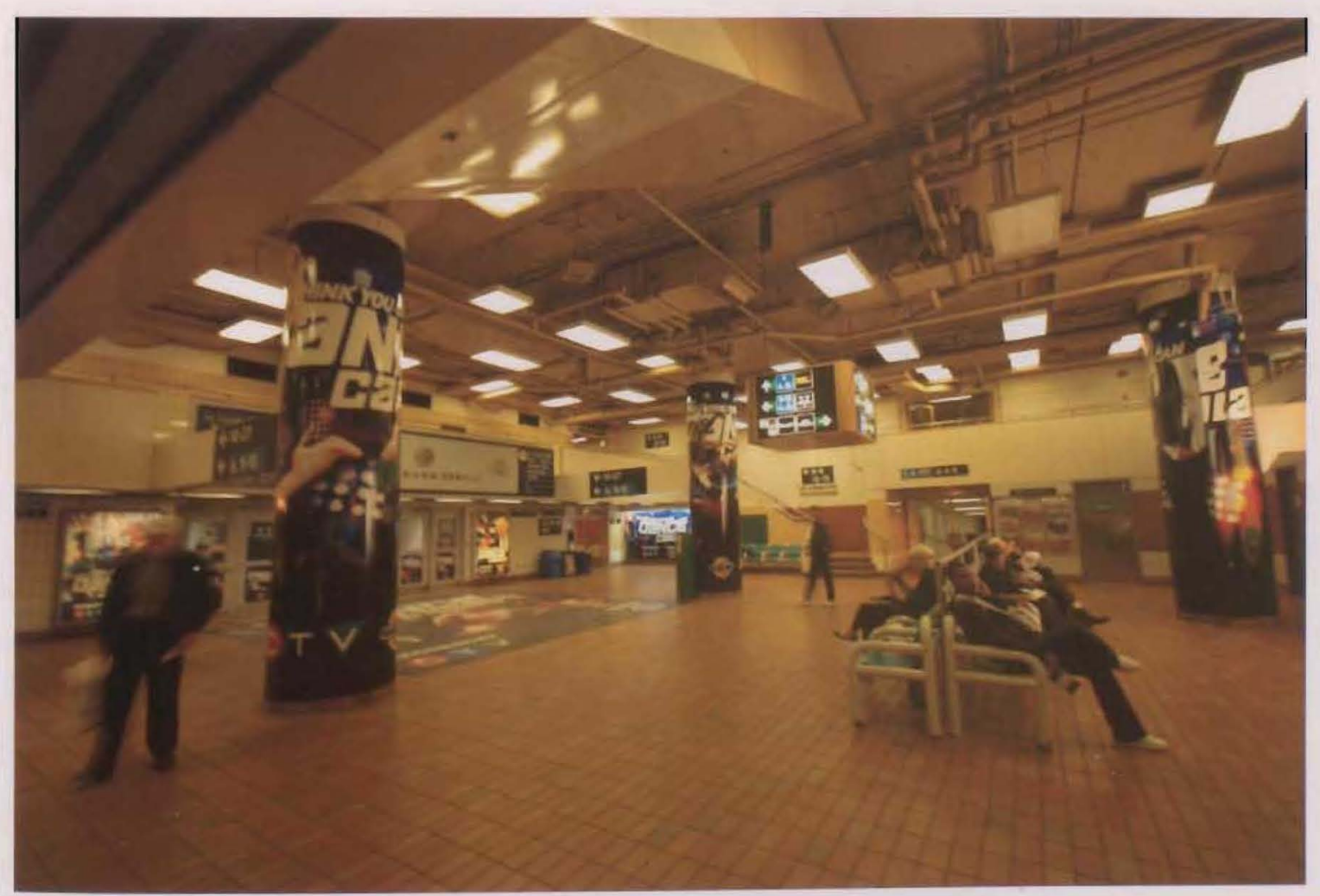

Figure 4.1.6 Converted Postal Sorting Room provides the most basic creature comforts. 

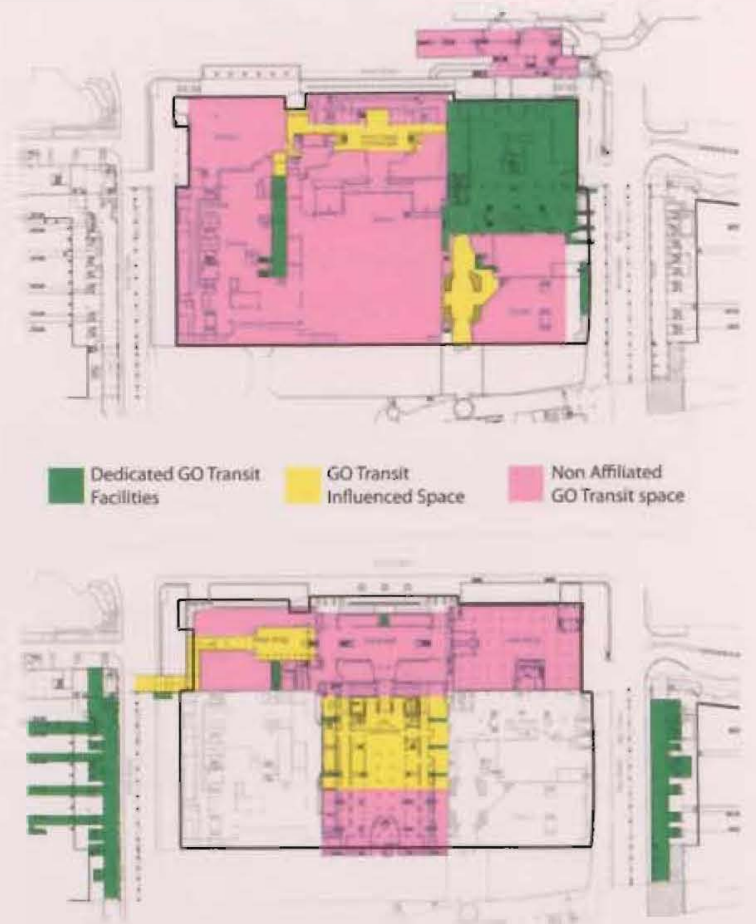

Figure 4.1.7 Dedicated, Influenced and Non Affiliated GO Transit Spaces

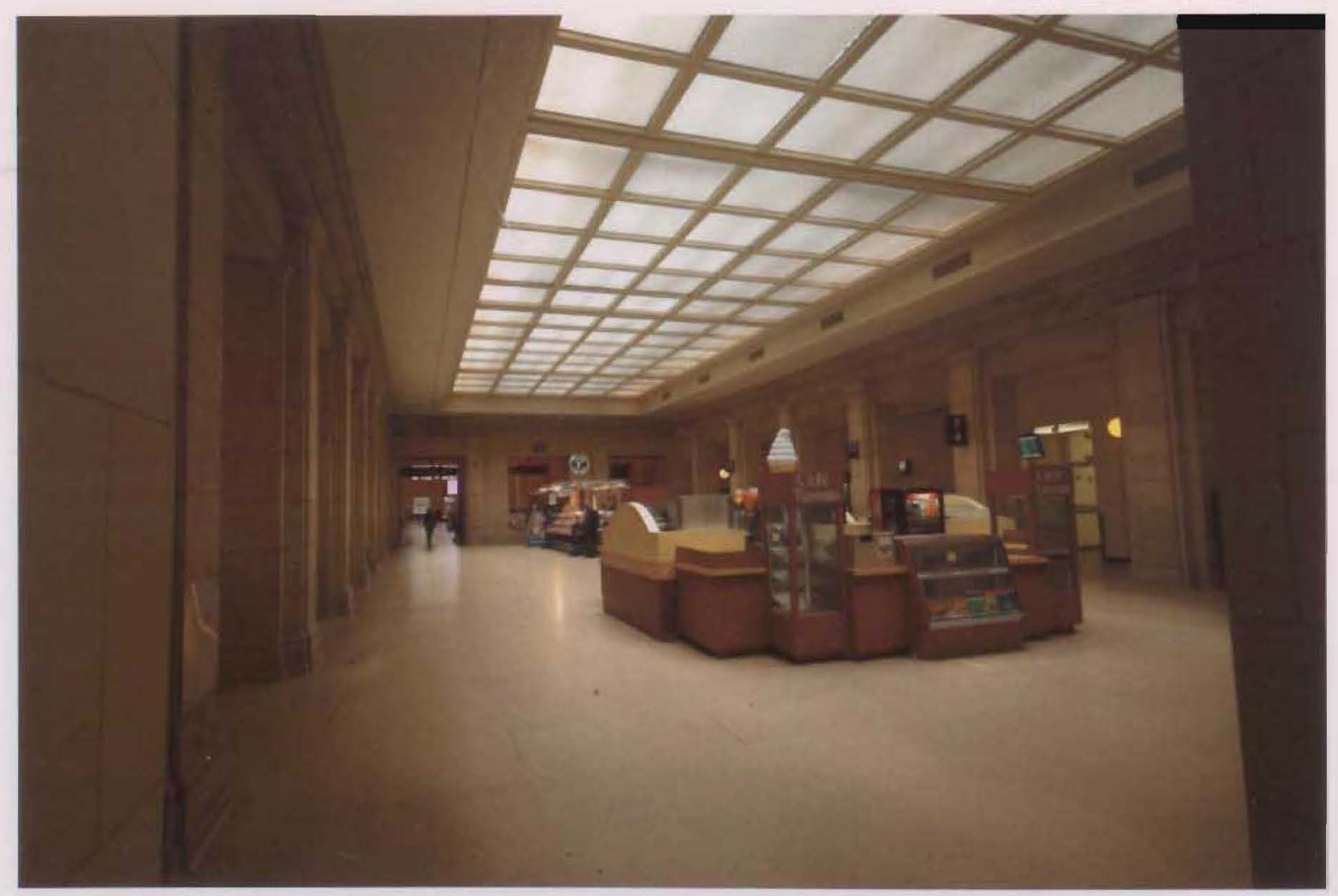

Figure 4.1.8 Former Men's Sitting room converted into an interstitial space 


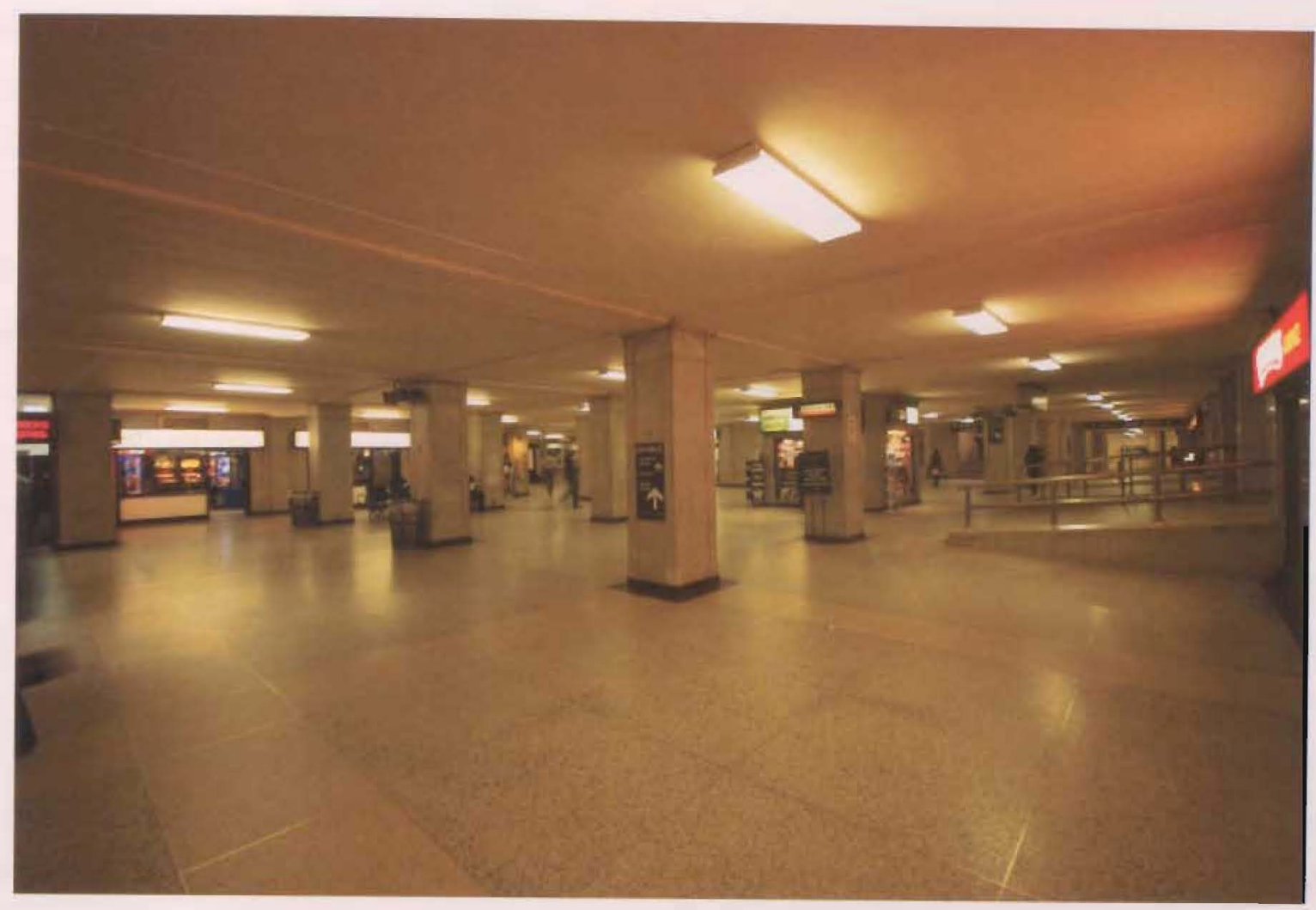

Figure 4.1.9 Current state of the arrivals concourse - barren when GO Transit users are not occupying it.

\subsection{Missing Identity}

Many City of Toronto initiatives are attempting to merge Union Station and its context, the CRL into a singular identity. The Union Station District Master Plan or the Heritage Conservation District Plan are two documents that define the commonly assumed boundaries of CRL, as shown in Figure 3.2.10. While contextual boundaries provide a framework for defining the extent of an area's influence, the implied use of boundaries infers there are elements to be excluded. Union Station's range of influence, determined in Chapter 5.1, will be used to define the contextual area and does not limit elements beyond the defined perimeter. The reason for not defining Union Station's context by rigid boundaries is to provide the recognition that a transit station's range of influence is rather difficult to define, as shown in Chapter 5.0

Before Union Station was constructed, there was no surrounding public space because the station area was previously occupied by built structures. After the Great Fire of 1904, the existing built fabric was burned to the ground and was cleared to make way for a new station. The new Union Station required vast amounts of land for the construction of not only the main 
building, but also rail yards and supporting infrastructure (Carr, 2005). Union Station was to be the public focal point of the downtown and it wasn't the priorities of the designers to set aside public space in combination with the station. Over the years the expansion and contraction of the rail lands has left the contextual area dotted with massive developments and large infrastructural systems. As a result, public space has developed very late in history and is of a poor quality to provide a large public focal point for Toronto. While many large cities in North America, including New York, Chicago and Boston, provide public focal points such as large, intensely programmed parks, Toronto has fairly small public spaces in comparison (Fig. 4.2.1). It is the hope of the Union Station District Master plan to bring the quality level of the few, small public spaces of the station's area to an intensity comparable to other great North American cities (Union Station Master Plan, 2008). However, as Figure 4.2.1 has already showed, Toronto's public spaces are insignificant to other cities.

When Union Station was designed, the architects did not provide for the inclusion of public space in the form of plazas or parks. However, an unattractive setback forming a public plaza in front of the Loggia currently provides a starting-off point for such a space (Fig. 4.2.2). The Union Station Master Plan proposes to increase the plaza by paving a continuous surface from Union Station to the Royal York Hotel (Fig. 4.2.3). The plan further proposes various redevelopments along Front Street to increase the plaza's depth from Union Station by eliminating curbs and the centre street median (Fig. 4.2.4). The master plan states the "Front Street plaza will become one of the great places to linger in the City of Toronto," and while this might be true, it will likely do more to reduce congestion on sidewalks during peak business hours (Fig. 4.2.5) (Union Station Master plan, 2008). Increasing the surface area does not directly imply that more people will make use of the space, as seen down the street at the MTCC where ample sidewalk space is devoid of activity (Fig. 4.2.6).

The master plan further recommends the removal of vendors from the plaza, which would eliminate one of the main reasons for people to currently linger there (Union Station Master plan. 2008). During off-hours, the adjacent financial district is empty, and without evening events at the ACC, the current Front Street plaza is devoid of activity. Much like the MTCC frontage, there is no other programming along Front Street to promote a constantly active environment. Unlike the New York Public Library's grand stairway, which provides what Rivin calls 'a perching area' on which to linger, Union Station lacks even these most basic elements of a good public space (Frank \& Stevens, 2007, p. 47).

Arguably, with its expansive enclosed hall and shelter from the elements, the Great Hall 
could be one of Toronto's great places in which to linger. While the hall provides an enclosed public space, the conditions of the hall conflict with public activities such as events, public gatherings or a general messing-about. It is not conducive as a public space because large noises are amplified and distracting; limited amounts of seating space force people to the floor and corners; and security limits general freedom of play. The Great Hall is primarily a functional space for the sale of tickets and only acts as an unintentional space for people to linger in. The Great Hall was never intended to be a waiting area since these are provided in the departure concourse and the former men and women's waiting rooms.

Immediately south of the train platforms, lodged between the ACC, Maple Leafs Square and TELUS Building, is Union Plaza, the only designed public space connected to Union Station (Fig. 4.2.7). Access to the plaza from Union Station is provided through the $G O$ concourse via the ACC's Galleria tunnel. Currently under construction is a new south entrance that will link the Great Hall to Union Plaza through a tunnel beneath the platforms. To access the new northsouth tunnel, users will first enter the Great Hall, descend into the VIA concourse and proceed south underneath the platforms. Already apparent is that the façade of Union Station does not provide a visual connection from the north to south (Fig. 4.2.8). It is likely that users who are already familiar with the station's layout, such as GO Transit users, will be the only ones who will use the north-south connection. The connection could also bring back fears of ACC patrons undermining the history and character of Union Station by using the Great Hall as an impromptu assembly space before events. These fears were formed prior to the city purchasing Union Station when the Toronto Maple Leafs sought to purchase the station and transform the Great Hall into a new front entrance for a stadium to be built over the tracks (Fig. 4.2.9) (Carr, 2005). With the completion of the north-south connection, there is nothing to prohibit ACC patrons from using the station as an entrance and displacing the passengers using the VIA concourse. However, some have remarked that the GO concourse connection to the ACC already makes Union Station an impromptu front entrance (Transit Toronto, 2007).

Union Plaza's definition as a public space was debatable prior to the construction of the two adjacent developments. Before the construction of the TELUS Building and Maple Leaf Square, Union Plaza was a small, paved, open space adjacent to the ACC's Galleria, which allowed ACC patrons to gather and be picked up and dropped off (Fig. 4.2.10). Since the construction of the two adjacent developments, Bremner Boulevard has been reduced to a semi cul-de-sac, which has extended Union Plaza's reach to Lakeshore Boulevard. However, the ACC has begun to construct a new west entrance lobby in much of the reclaimed space 
that was created when Bremner Boulevard was reduced. The Union Station District Master Plan proposes to transform Union Plaza as a major public destination in Toronto, through cafés, art exhibits and retail space (Union Station District Master Plan, 2006). Two factors potentially upset this desire. First, the new developments will have future connections to the PATH system, bypassing any surface connections through the plaza (Fig. 4.2.11). The negative effect of the PATH system is the diversion of users from the Great Hall directly into the GO concourse. Second, Union Plaza remains in an isolated part of the city, hemmed in by large developments and busy infrastructural routes. Of the large developments, the adjacent building complex of Maple Leafs Square could provide enough programming to re-energize Union Plaza through its inclusion of two residential towers, hotel, office space and a ground plane activated by various amenities. Although, even if Union Plaza provides enough attraction, a direct bridge connecting from the hotel to the ACC could divert some users from Union Plaza. The adjacent TELUS building will have an additional 30,000 square feet of retail space to activate the ground plane at Union Plaza.

The concern is not how much programming these developments will provide, but whether the programming will be enough to draw people to use Union Plaza. Cornmercial spaces in the - surrounding developments currently are not much of an attractor and remain permanently empty or closed when events are not held at the ACC. In the future, two more office complexes and a condo development will be constructed nearby, but are already planned to have a PATH connection with retail below grade (Union Station District Master Plan, 2006). The addition of more condo developments in the area does not guarantee the use of Union Plaza or its amenities, as condo developments are notorious for under-utilizing their own programming spaces (Hume, 2007a). The Union Plaza is relying too heavily on surrounding developments and on insufficient north-south connections to provide stable programming. Due to these deficiencies, until the construction of the TELUS Building, Maple Leaf Square and ACC's new west entrance, Union Plaza's full potential as a public space cannot be known with any certainty. Infrastructural networks, large-scale developments and minor pedestrian connections isolate the few public spaces near Union Station. These underused public spaces consist of the Roundhouse Park, the combined Rogers Centre-CN Tower plaza and the Olympic Gardens (Fig. 4.2.12). The public spaces are too small to be urban parklands for ecological destinations like New York's Central Park and are too large to be activated by the small number of large, mono-programmed developments. The pedestrian connections to these public spaces are both formal and informal. The formal connections from the north include the pedestrian gateway at 
the base of John Street (Fig. 4.2.13) and the Skywalk connection to the MTCC south building (Fig. 4.2.14). The pedestrian gateway starts at the base of John Street with a small park space and continues south to bridge the rail lands and connect with the Rogers Centre's promenade. The promenade continues south, stepping down to meet Bremner Boulevard, while providing connections to the $\mathrm{CN}$ Tower plaza (Fig. 4.2.15). The Skywalk provides the only direct access from Union Station to the Olympic Gardens, which subsequently connects to the adjacent Rogers Centre-CN Tower plaza and Roundhouse Park. While both the pedestrian gateway and Skywalk provide articulated north-south connections, there are no formal south-north connections that would link to the Harbourfront.

As mentioned, with the decline of Blue Jays baseball attendance and the ensuing failure of the Skywalk amenities, motivating elements that will draw individuals from Union Station, along the Skywalk and into the public spaces are lacking. During events at the Roger's Centre and MTCC, the public spaces are rarely used and during the days with no events the public spaces are devoid of human activity. The $\mathrm{CN}$ Tower plaza draws a meagre crowd every day to take in the sights of the tower, but these visitors rarely wander farther than to take a picture of the tower. The completion of the railway display at the Roundhouse may draw more people into the area, but based on the current trends of public space use, it would be foolhardy to think a small railway display would attract a large daily crowd. The Roundhouse is not located near busy pedestrian streets and is surrounded by large developments, wide roads and steep elevation changes (Fig. 4.2.16). Furthermore, the rail museum was drastically scaled down so that a large part of the city-owned Roundhouse could be converted into a Leon's furniture store. The Roundhouse Train Museum can be chalked up to another failed proposal for the rail lands (Hume, 2007b).

In addition to these public spaces, the Union Station District Plan considers sidewalks, roads and transit services in the CRL to be public spaces (Union Station District Plan, 2006). When roads, transit services and interstitial spaces are removed from the district's plans diagram, it leaves only sidewalks and park spaces, reducing the amount of designated public space drastically (Fig. 4.2.17). Roads are public realms, but they are realms reserved for car use and not the casual enjoyment of pedestrians. On the other hand, sidewalks are public spaces reserved for the casual enjoyment of pedestrians. As urban activist Jane Jacob states, a "sidewalk by itself is nothing. It is an abstraction. It means something only in conjunction with the buildings and other uses that border it" (Jacobs, 1961, p. 29). Therefore, using Jacobs' illustration, the majority of sidewalks in Figure 4.2.18 derive their meaning from dead 
programmed commercial spaces of condo developments, perimeters of giant entertainment venues and barren public spaces. To use the Union Station District Plan's notion of streets as public spaces is to completely disregard the surrounding context and only focus on the street as the means of providing public space. The Harbourfront adjacent to the rail lands is an example of a positive relationship of the built environment to the street, provided by the linking together of small, intensely activated public spaces.

Jacobs describes in her book The death and life of great American cities that small, intensely activated public spaces provide a pleasurable journey along a street. She articulates that buildings are perceived in the background, while public spaces are perceived in the foreground. Sidewalks are perceived in the foreground and therefore their existence can be seen as extensions of the public spaces (Jacobs, 1961, p. 106). The Harbourfront's success can be attributed to this relationship of a foreground of intensely activated public spaces, with condo developments disappearing in the background (Fig. 4.2.19). The CRL does not provide intensely activated public spaces along a street's edge, and therefore have no distinguishable foreground and background. Without the ability to differentiate a foreground and background, the area lacks context, leaving developments disconnected.

Another reason for the success of the Harbourfront has been the strong dedication to realizing a holistic approach to unifying a series of public spaces. While the Harbourfront's vision was realized in a three-year period, the CRL has had forty years of proposals by countless high-profile architects, which have amounted to nothing. Ever since the Metro Centre proposal, the former rail lands appear to be haunted by bold initiatives, while the Harbourfront, less than 200 metres away, has completed a bold initiative. The CRL is quickly filling in with piecemeal developments, lacking a holistic vision and organization. The Union Station District Plan is a vain attempt to bring together these unrelated developments through common material pallets in the hope they will provide a cohesive identity. This is a foolish approach for an area that requires a substantial intervention to stitch together unrelated programs into a cohesive identity.

One of the most complex issues of the Union Station context is the longitudinal infrastructural system that creates visual and physical barriers. The major longitudinal barriers include Union Station and its adjacent buildings along Front Street, the elevated rail yard, the Gardiner Expressway and Lakeshore Boulevard (Fig. 4.2.20). A Front Street visual barrier is created by an impenetrable façade of Union Station and adjacent buildings (Fig. 4.2.21). This visual barrier inhibits pedestrians along Front Street from gaining an understanding of what exists on the other side of Union Station. Opening up this visual barrier would allow people to 
first understand that Toronto extends beyond Front Street and second would provide a visual connection to the rail lands. However, if visual connections are opened through Union Station and the surrounding buildings, the elevated rail yard will complicate the situation. The rail yard is a 110 -metre-wide artificial surface rising 4.5 metres above the ground plane. The ground plane further complicates the situation by existing 4.5 metres below the rail yard and rising steeply to Front Street (Fig. 4.2.22). If we were able to remove the train sheds, an individual looking towards the waterfront from Front Street would be unable to see the CRL (Fig. 4.2.23). The visual angle increases the difficulty of providing visual connections to the rail lands from Front Street, and even using a bridge to span the rail yard would be an insufficient method to provide these visual connections, as it would have to rise too steeply (Fig 4.2.24). The barriers of Union Station and its adjacent buildings, combined with the topographical changes of the rail yard, would first have to receive attention to provide visual and physical connections. The Union Station District Plan's present method of providing connections is not substantial enough to encourage individuals to journey south. The methods of the district plan are to increase connections by refurbishing the teamways and providing a new north-south tunnel beneath the platforms (Union Station District Plan, 2006). The issues of the tunnel have already been mentioned, while the teamways' refurbishments do not provide a clear enough distinction of a connection to the south (Fig 4.2.25). Pedestrians use the adjacent sidewalks of the teamways to access the south, bypassing the teamways entirely. In fact, to use the teamways as a connection to the south, one has to pass through two sets of doors instead of using the unobstructed sidewalk (Fig. 4.2.26).

The Gardiner Expressway and Lakeshore Boulevard represent the southern longitudinal barriers to the rail lands. The Gardiner Expressway is an elevated six-lane highway, climbing at the termination of the Don Valley Parkway and descending near Dufferin Street. In the contextual area of Union Station, the Gardiner Expressway raises more than four storeys and has seven ramps, while Lakeshore Boulevard, a six-lane arterial road uses the open space below the Gardiner (Fig 4.2.27). These combined infrastructures develop a physical and visual barrier to the Harbourfront, making it difficult for pedestrians to cross safely while obscuring views.

The Union Station District Plan includes a section of the CRL south of the Gardiner Expressway, but provides no recommendations for connecting across Lakeshore Boulevard. The district's plan of designating streets as public spaces will not help to link across the more than six lanes of Lakeshore Boulevard. The assumed reason for including the southern section of territory 
is to add the Harbour Commission Building to the historic protection list. While the Gardiner Expressway creates dramatic visual barriers, Lakeshore Boulevard creates the most drastic physical barrier. While many urban activists argue for the removal of the Gardiner Expressway, it is my opinion that Lakeshore Boulevard causes the most dramatic separation of the rail lands to the Harbourfront. Other than the intersections, it is impossible for pedestrians to cross Lakeshore Boulevard safely, and even at the intersections it is a mad dash to make the light (Fig. 4.2.28).

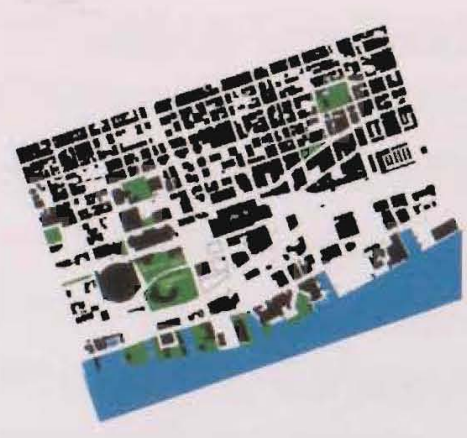

Toronto

2.4 million

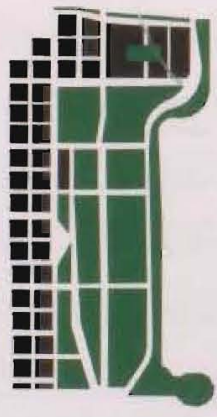

Chicago

2.8 million

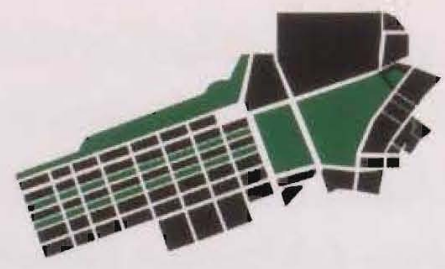

Boston 616,000

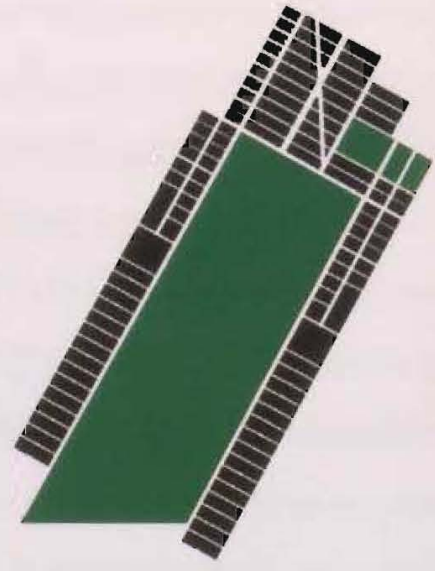

Manhattan $\mathbf{1 . 6}$ million

Figure 4.2.1 Comparably scaled public parks in various American cities with population including Toronto 


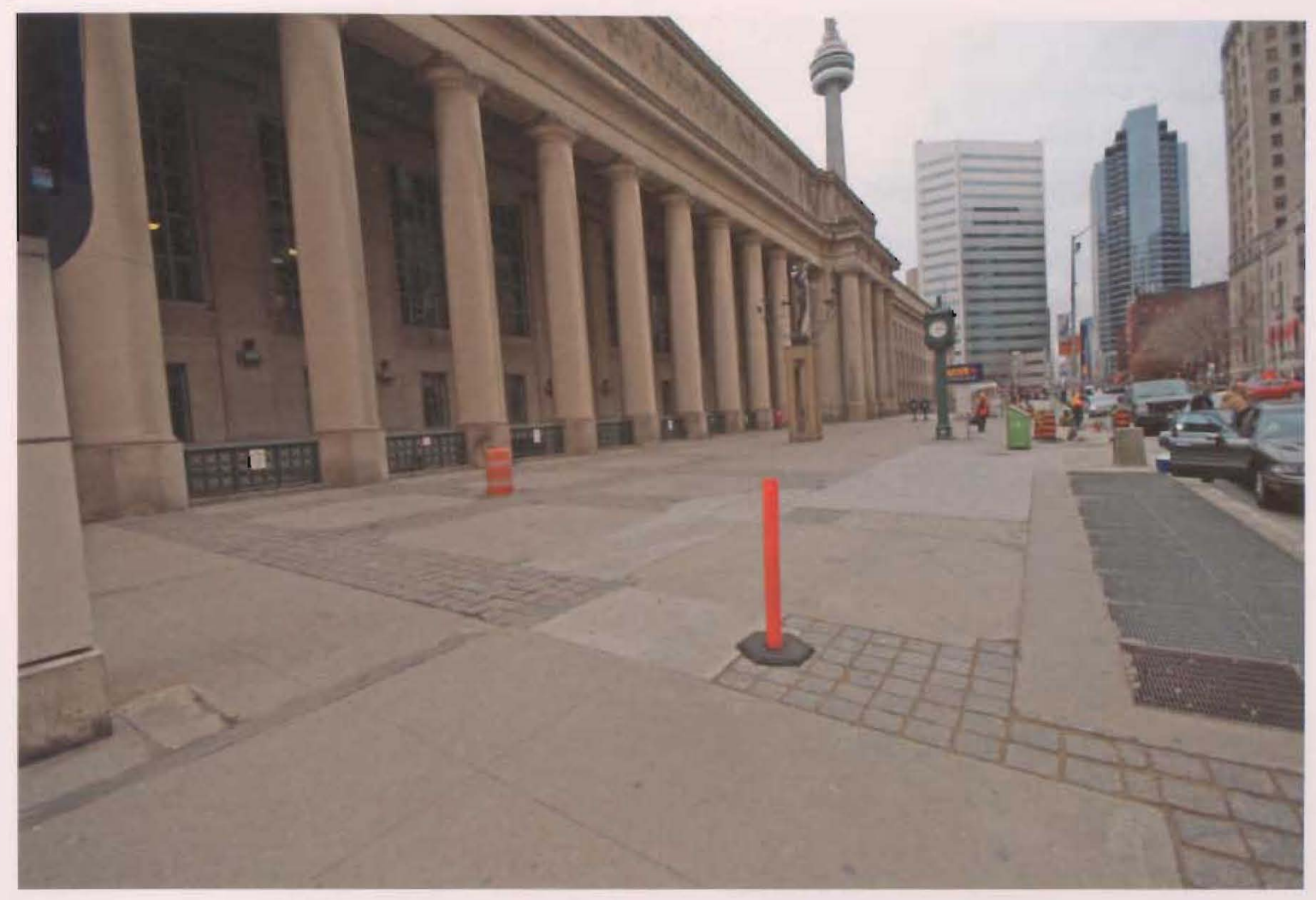

Figure 4.2.2 Front Street Plaza, unattractive and unused.

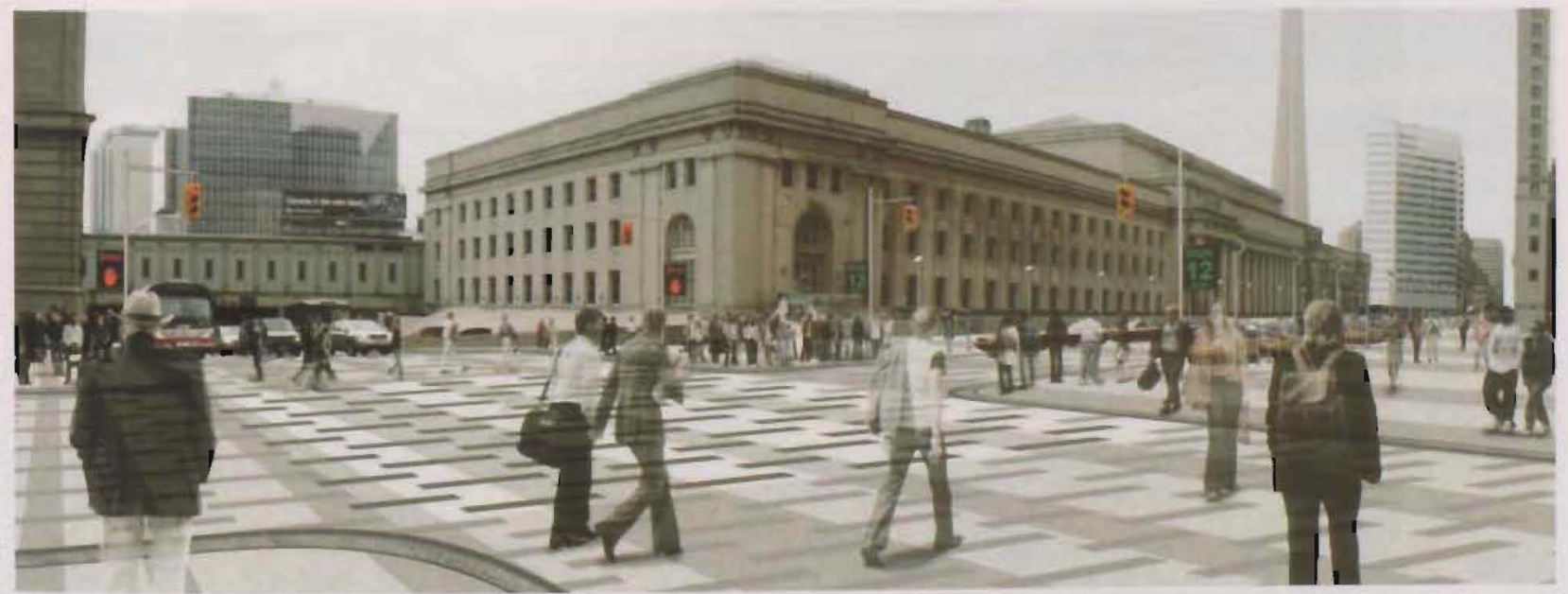

Figure 4.2.3. Union Station Master Plan for a continuous paved surface. 


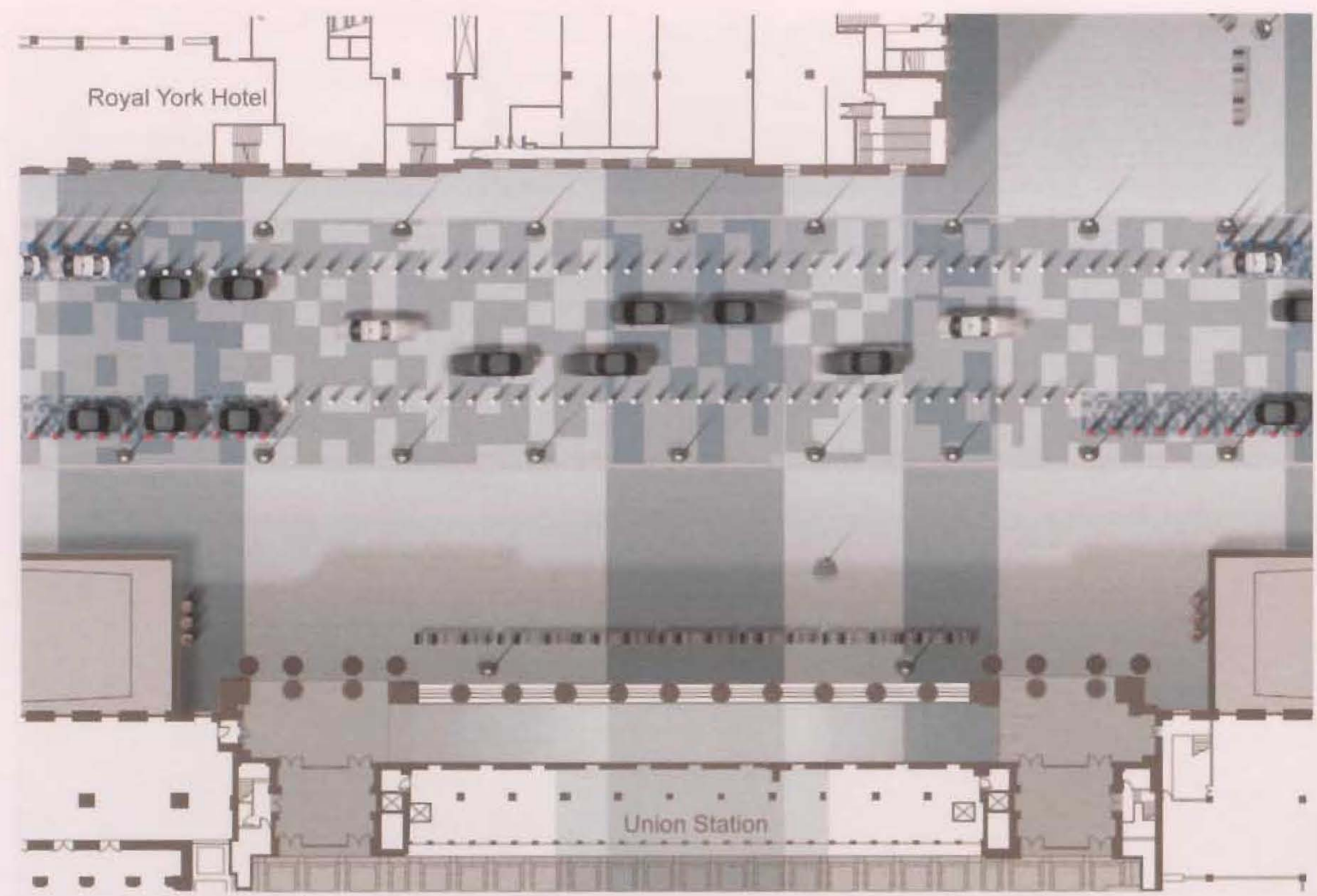

Figure 4.2.4 Union Station Master Plan proposal for removal of centre median

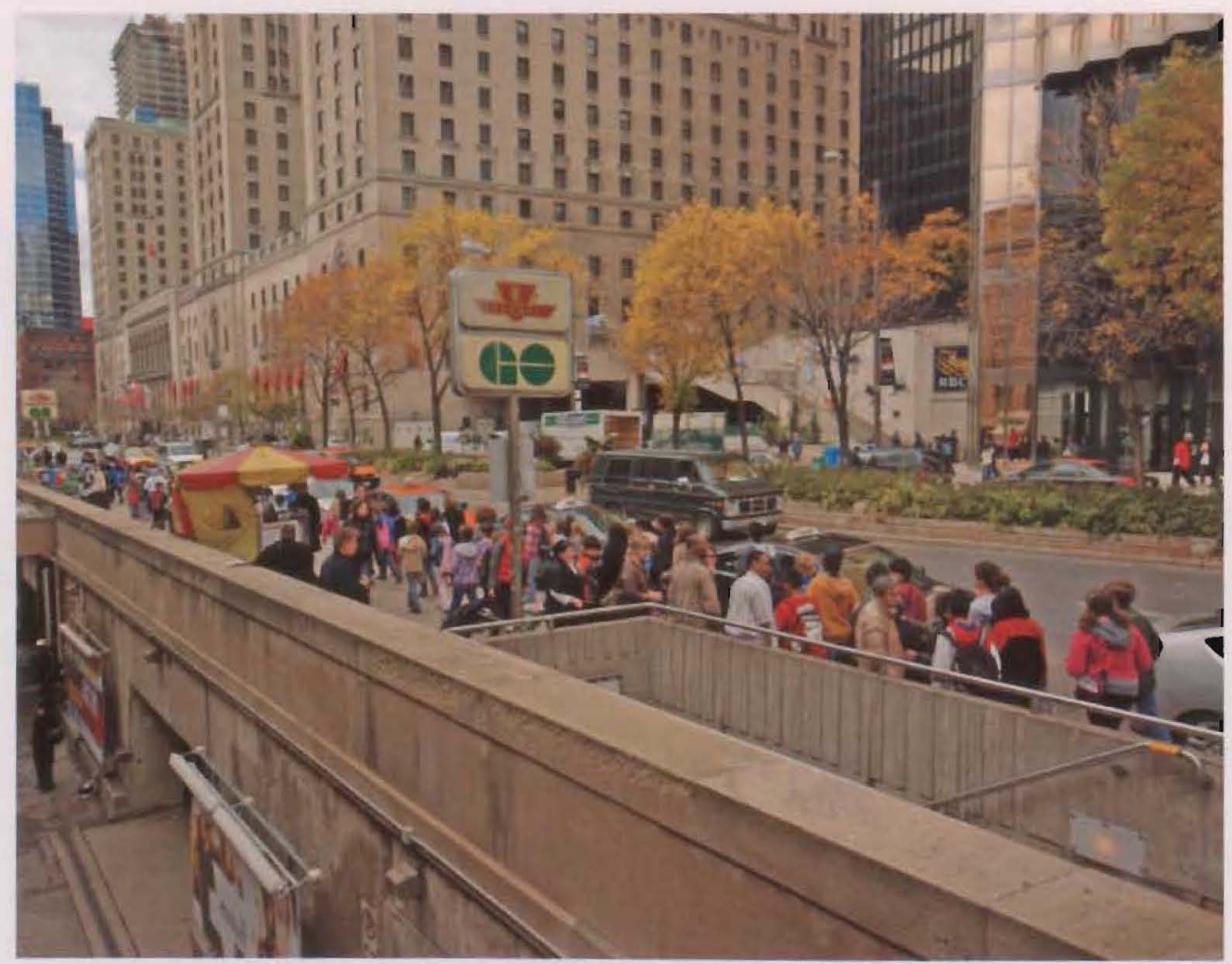

Figure 4.2.5 Congested sidewalk during rush hour. 


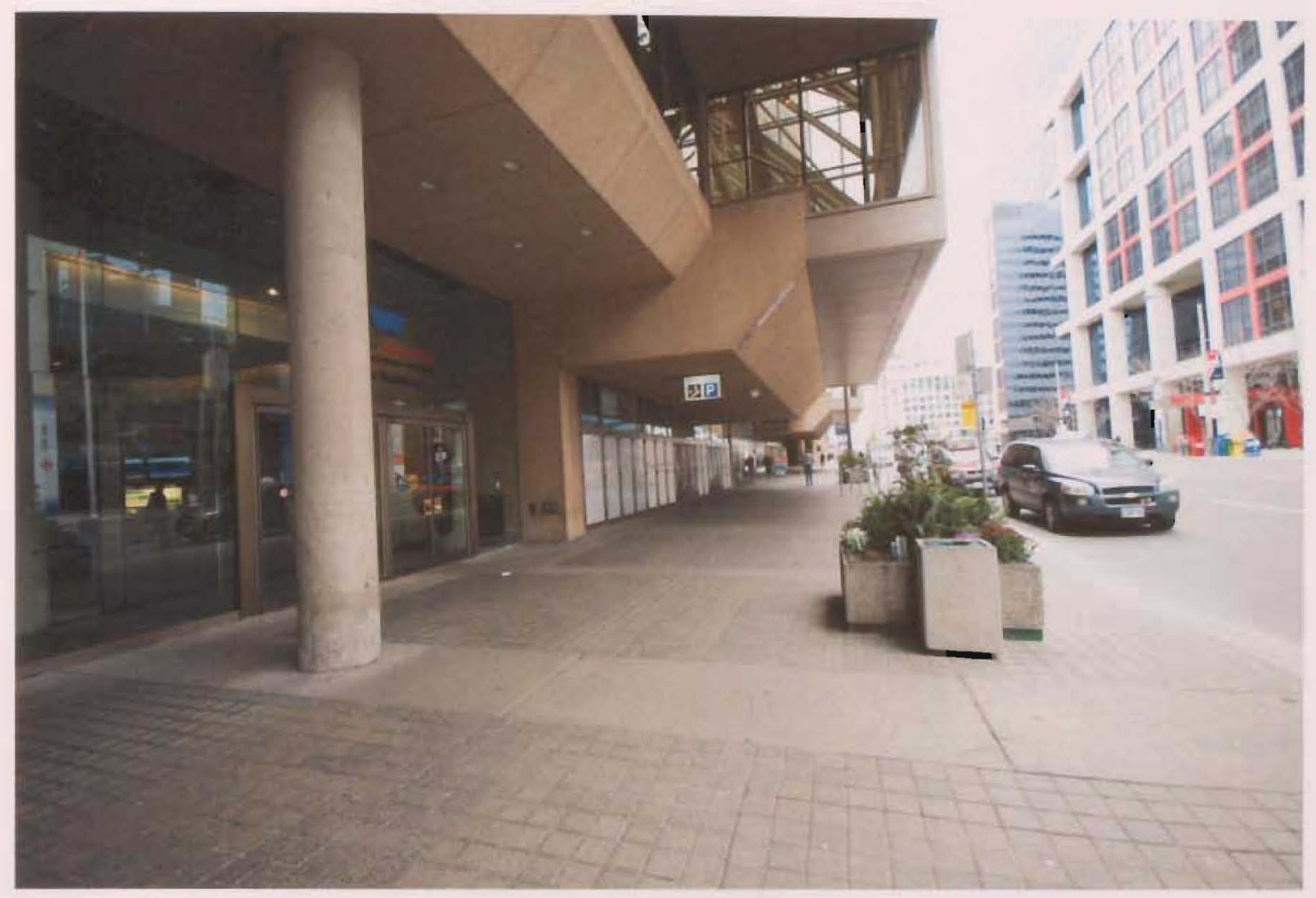

Figure 4.2.6 Typical weekday in front of the MTCC, barren and lifeless.

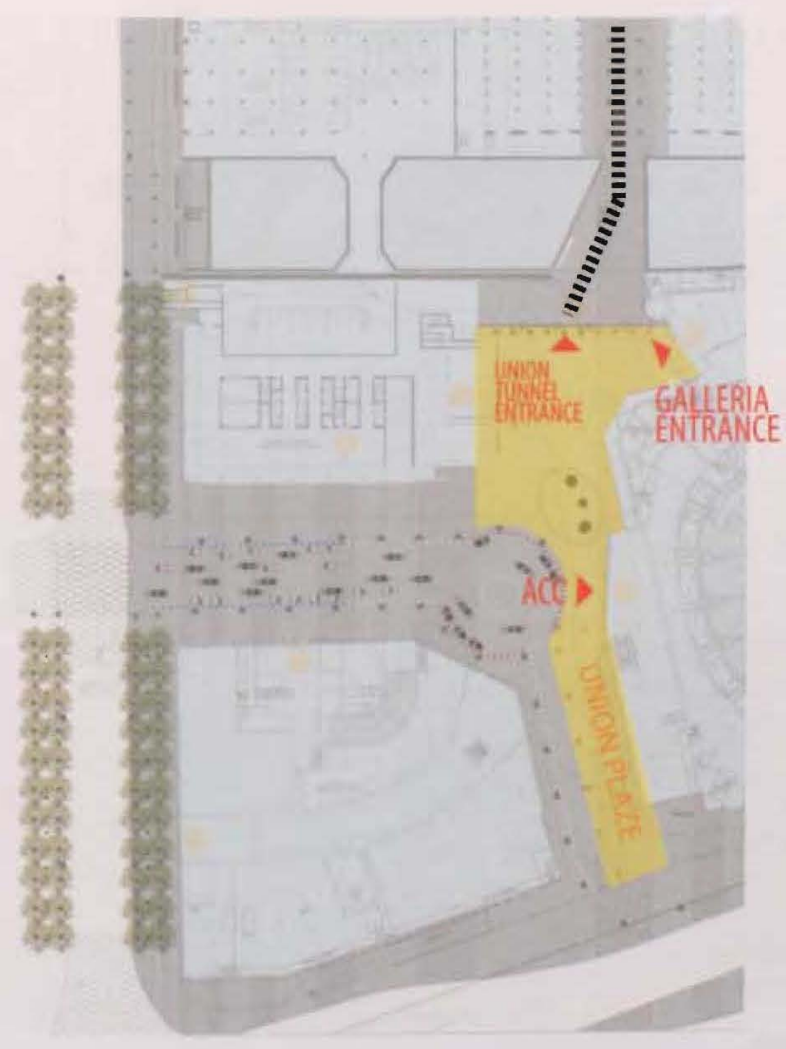

Figure 4.2.7 Union Plaza and major access points = small and compressed. 


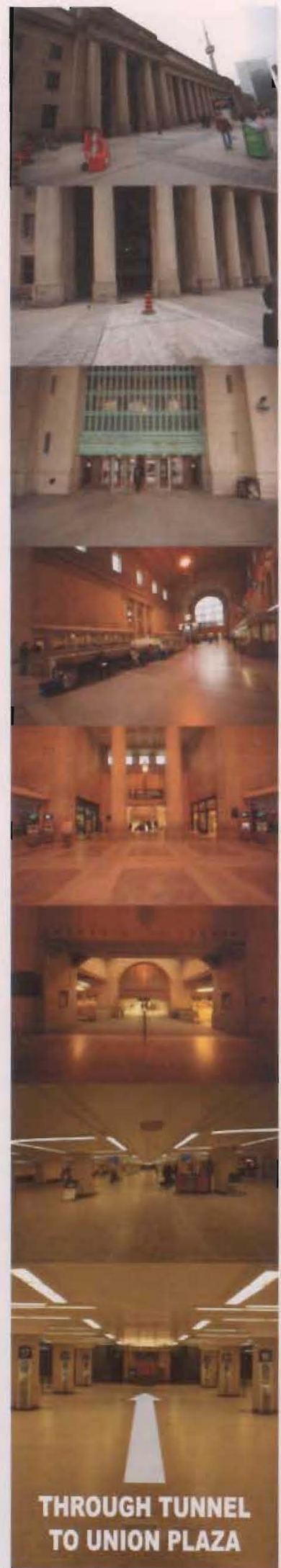

Front Street Entrance

Union Plaza accessed through Departures concourse entrance, far left.

Obscured Visual angle

Route cuts directly through the centre of the VIA Concourse

Figure 4.2.8 Visual journey through Union Station to Union Plaza - not linear and does not provide easy visual cues to target 


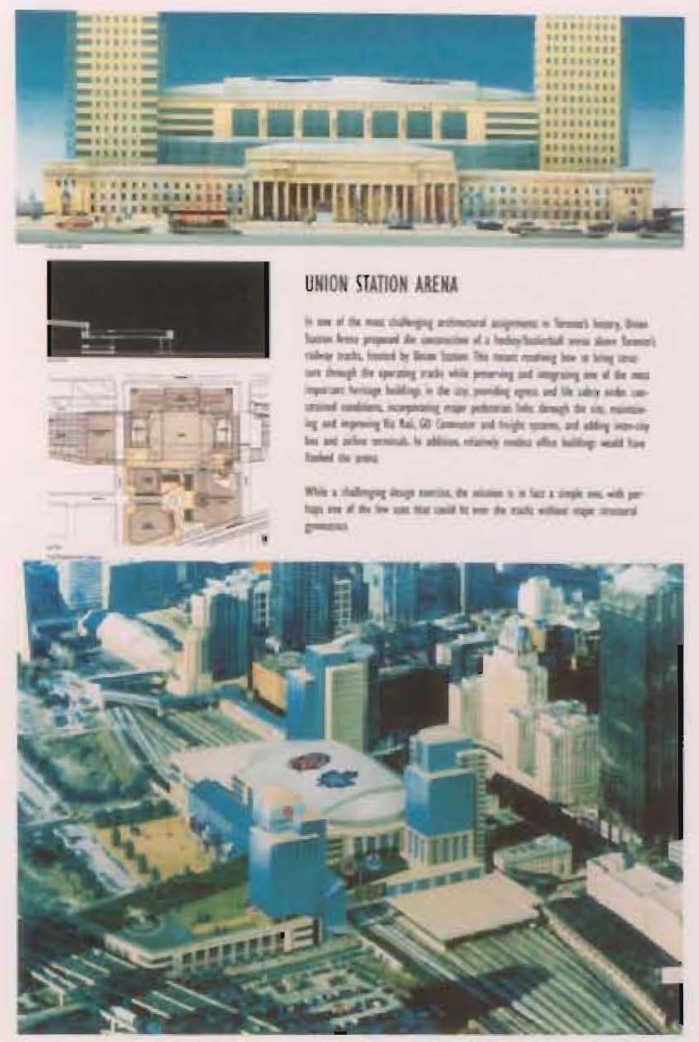

Figure 4.2.9 Toronto Maple Leafs Proposal, images apart of the Unbuilt Toronto display conducted by the Toronto Society of Architects

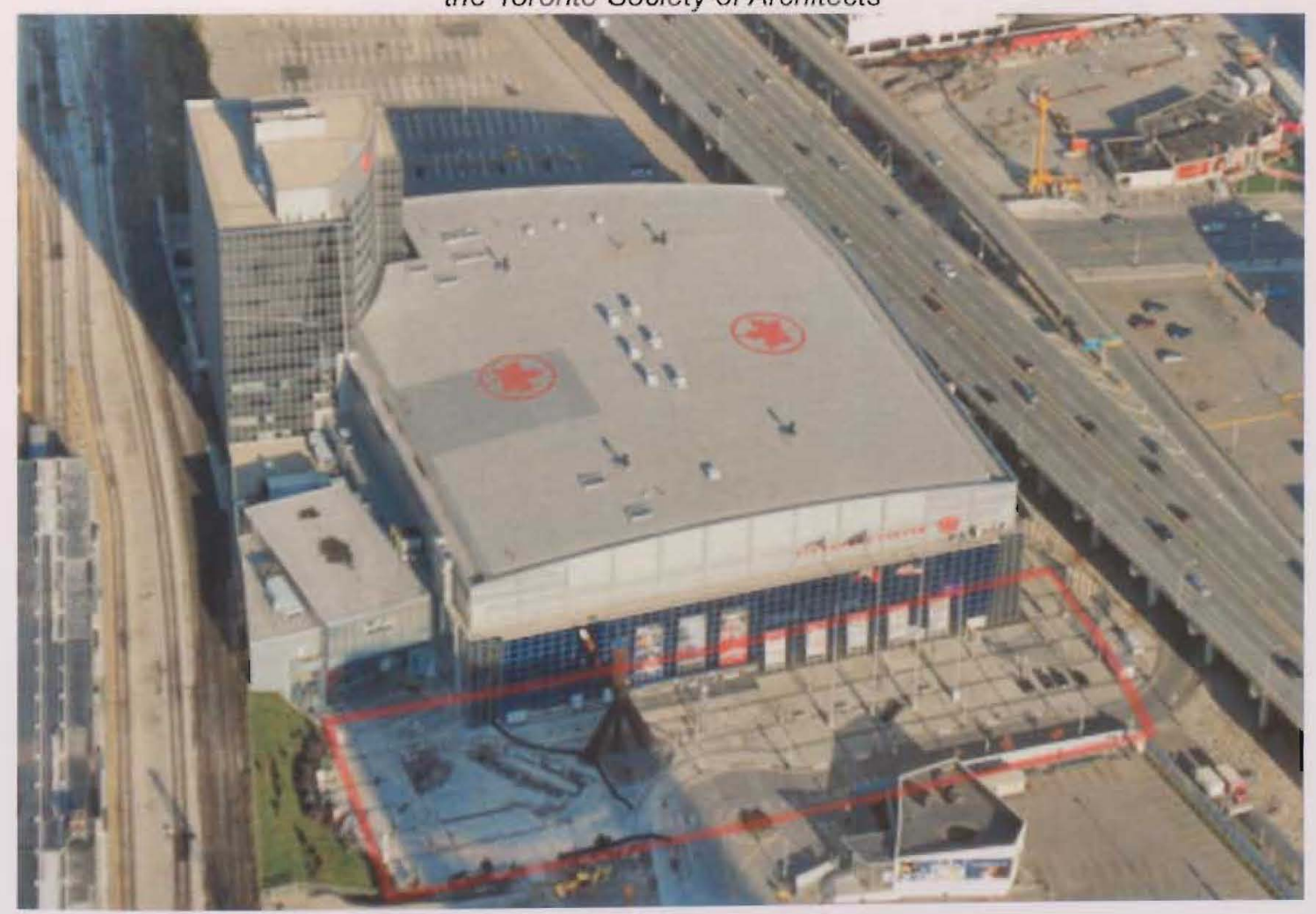

Figure 4.2.10 Original Union Plaza before developments and ACC extension. 


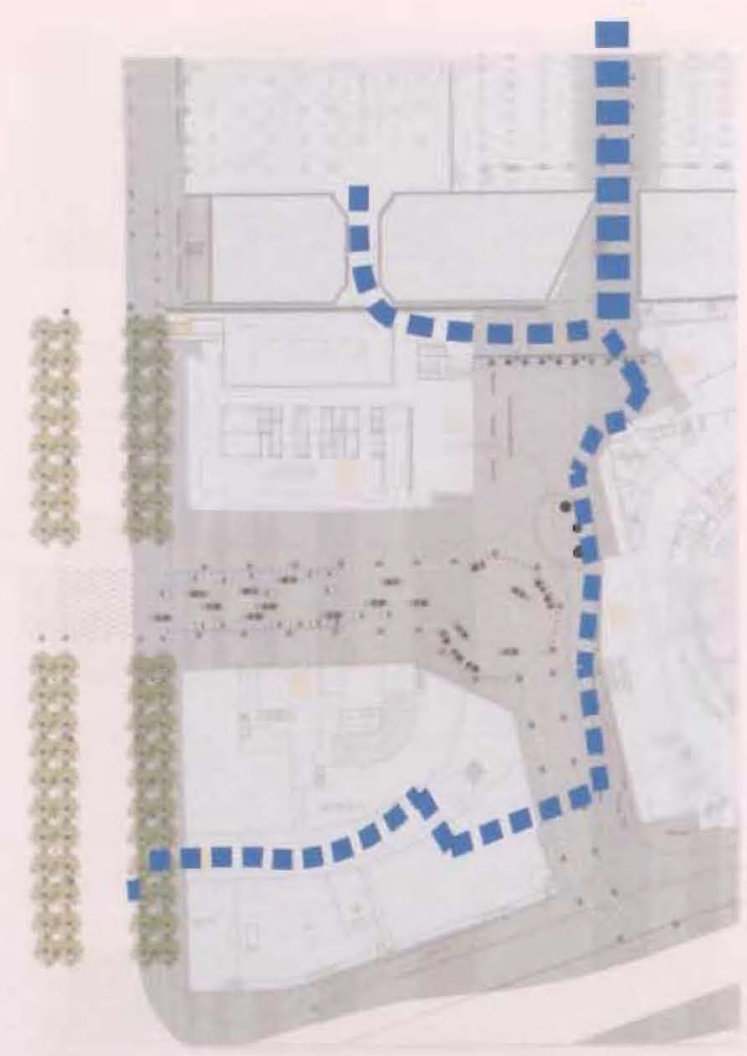

Figure 4.2.11 Future PATH system connections

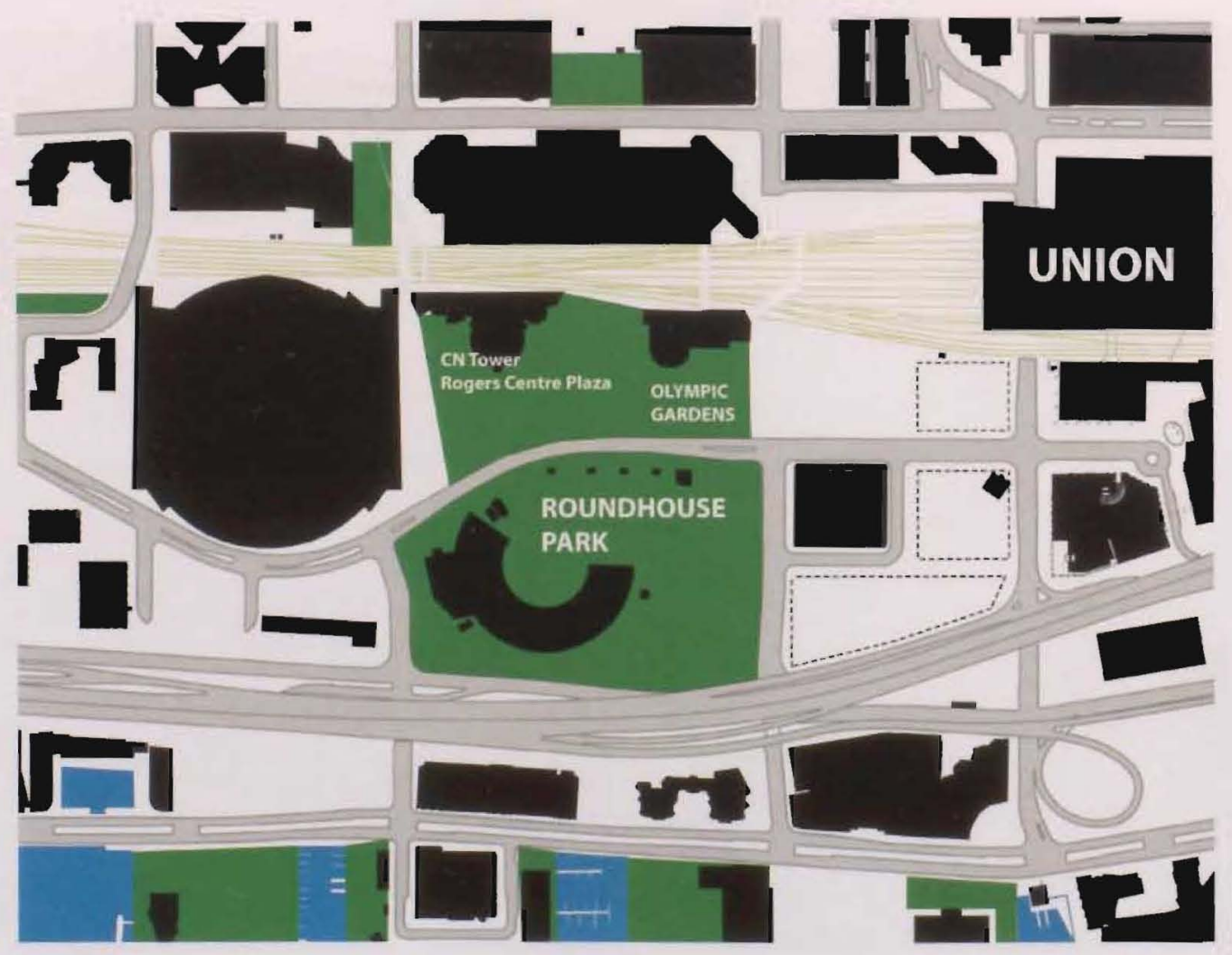

Figure 4.2.12 Park spaces within and surrounding the Central Railway Lands 


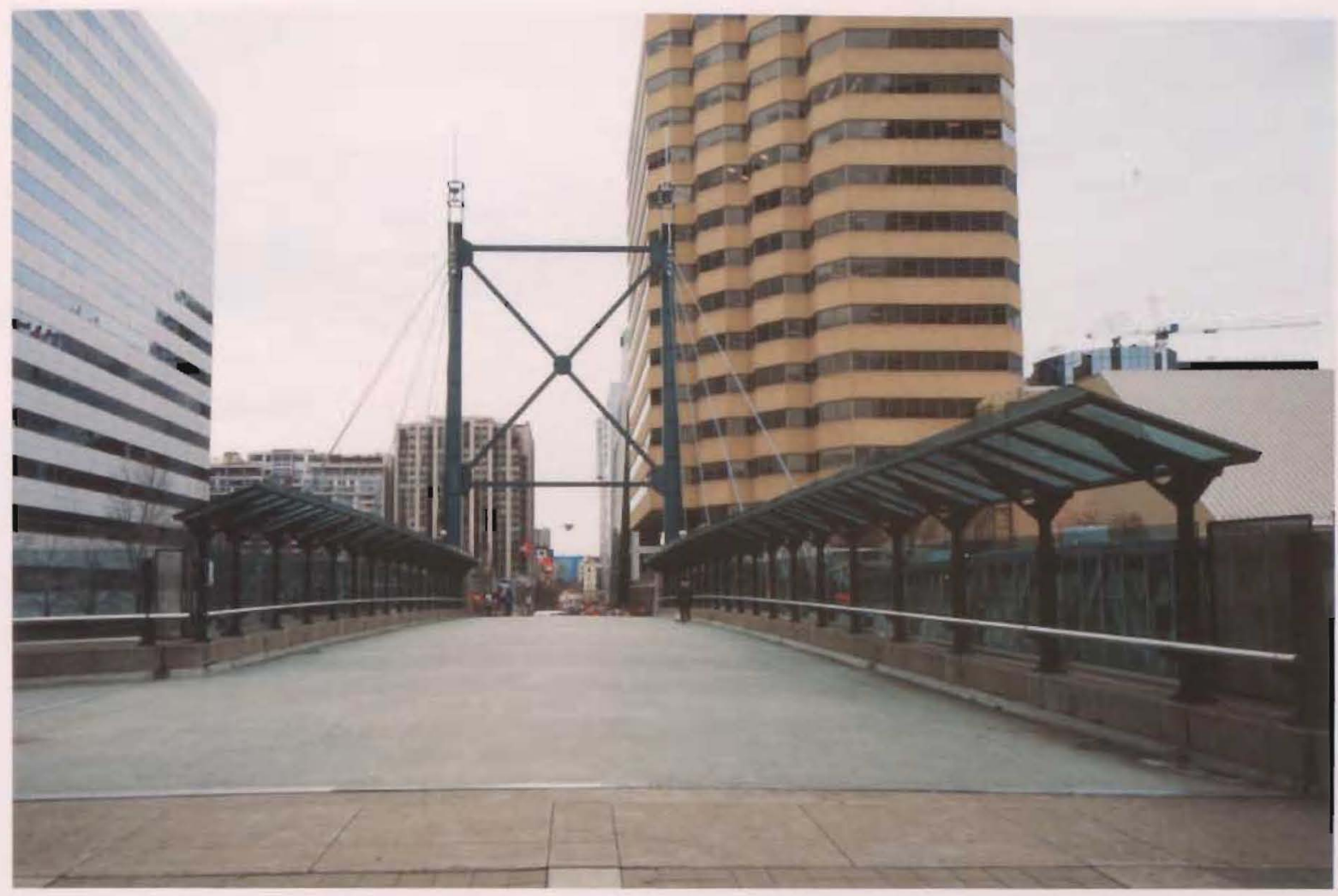

Figure 4.2.13 John Street Bridge connecting over the rail corridor from Front Street to Rogers Centre

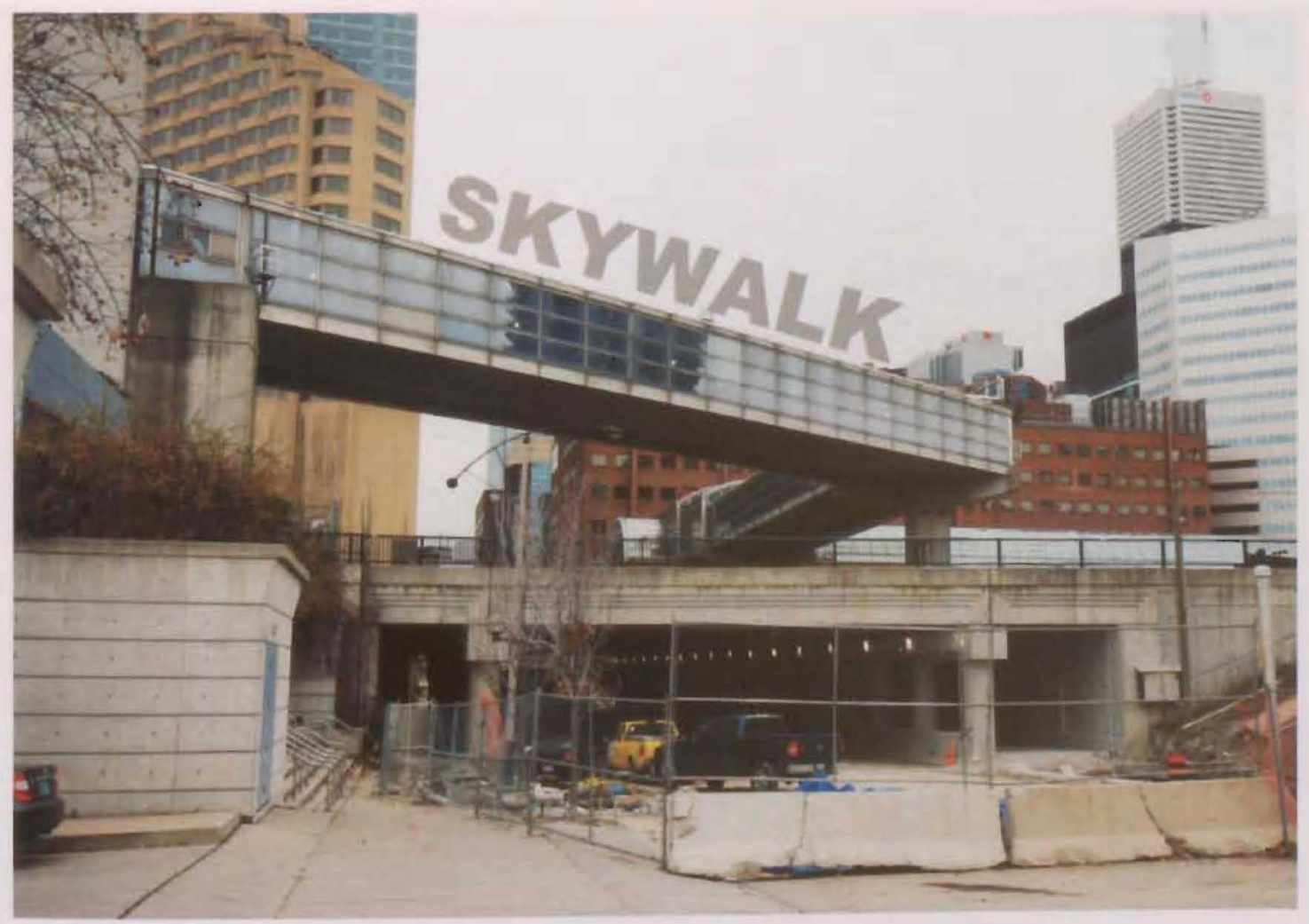

Figure 4.2.14 MTCC Skywalk connection from MTCC South building to Union Station 


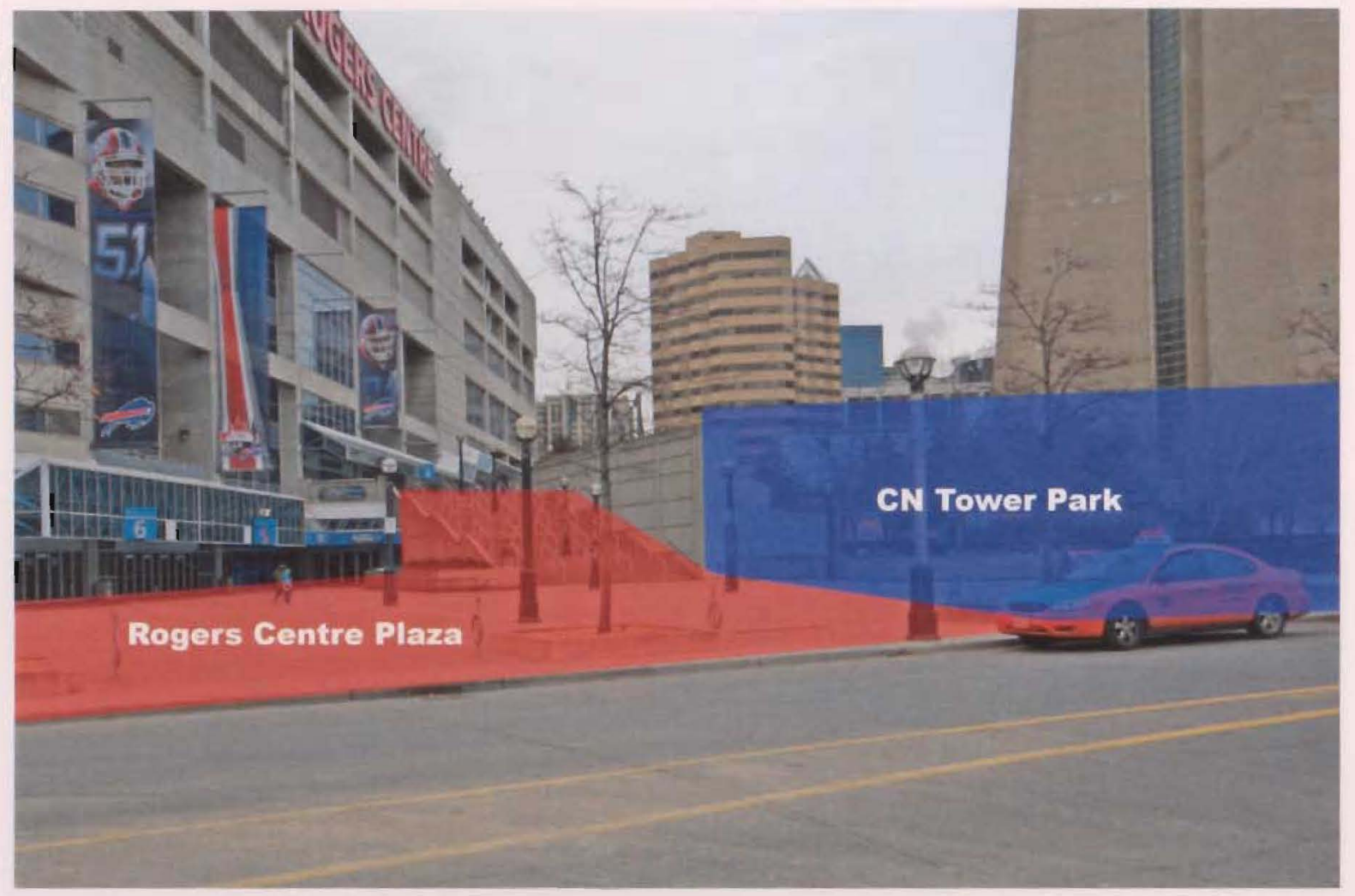

Figure 4.2.15 Rogers Centre Plaza \& CN Tower Park - uninspiring places to visit.

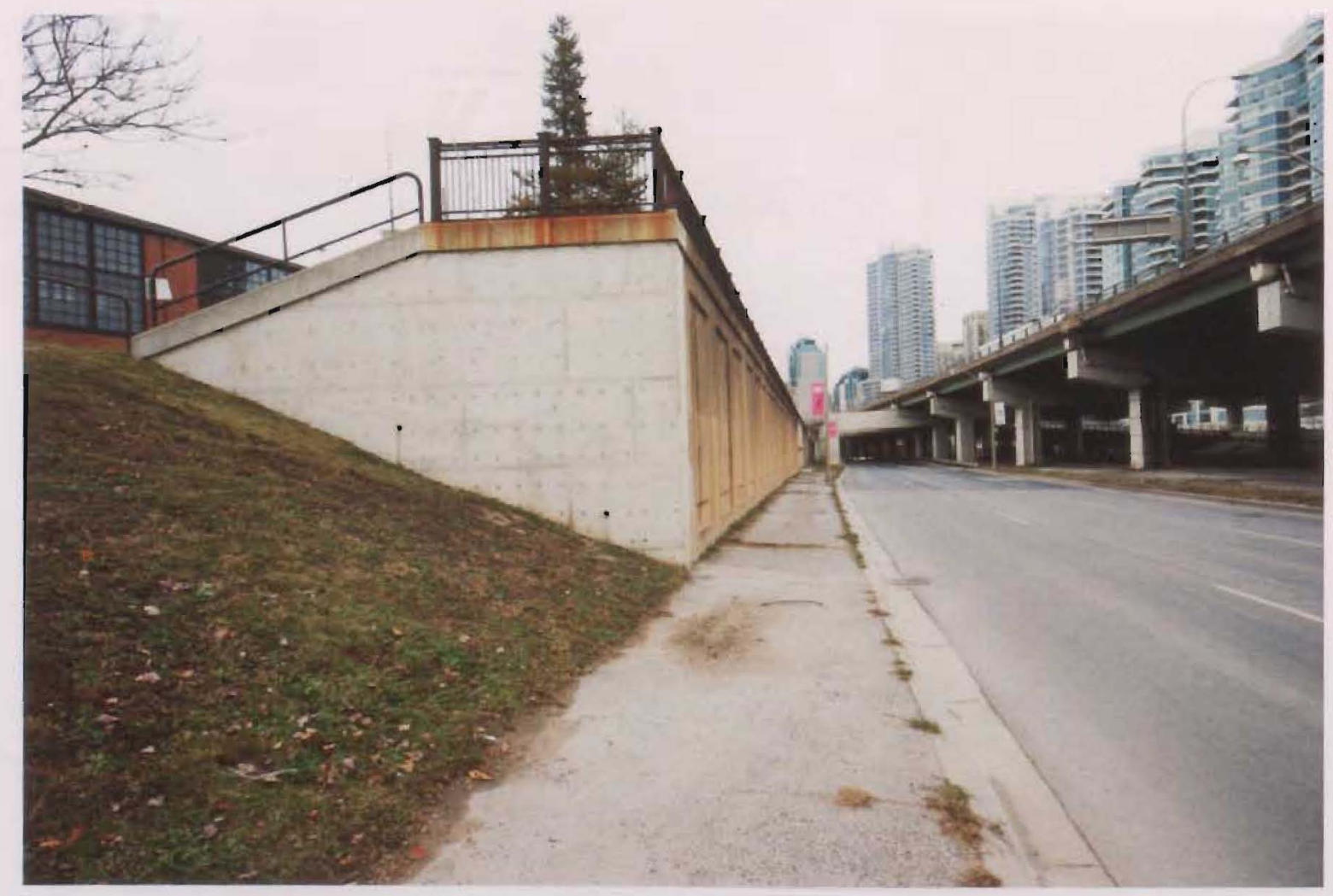

Figure 4.2.16 Steep elevation changes adjacent to Roundhouse. 


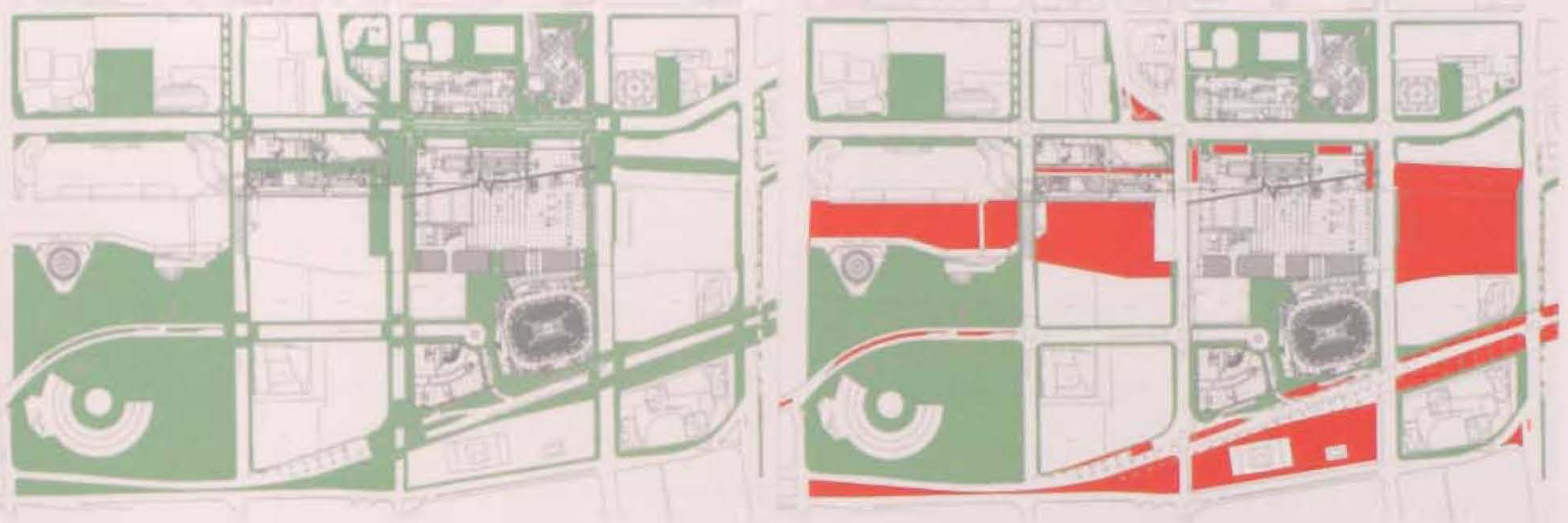

Figure 4.2.17 Union Station District Plan's demarcated public spaces (green) contrasted against areas highly resistant to public space (red).

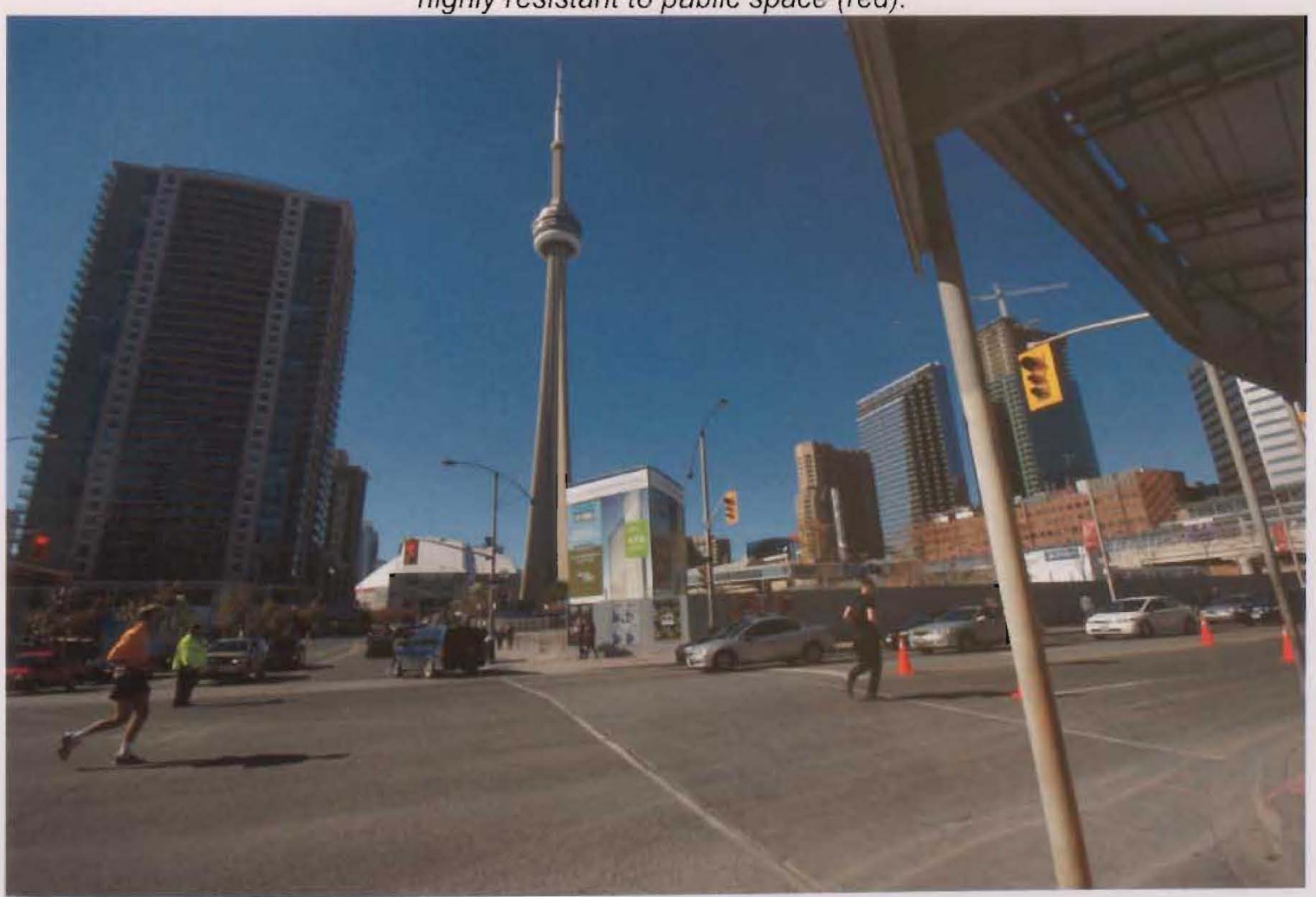

Figure 4.2.18 Difficult to integrate tall buildings visually into the surrounding context. a 


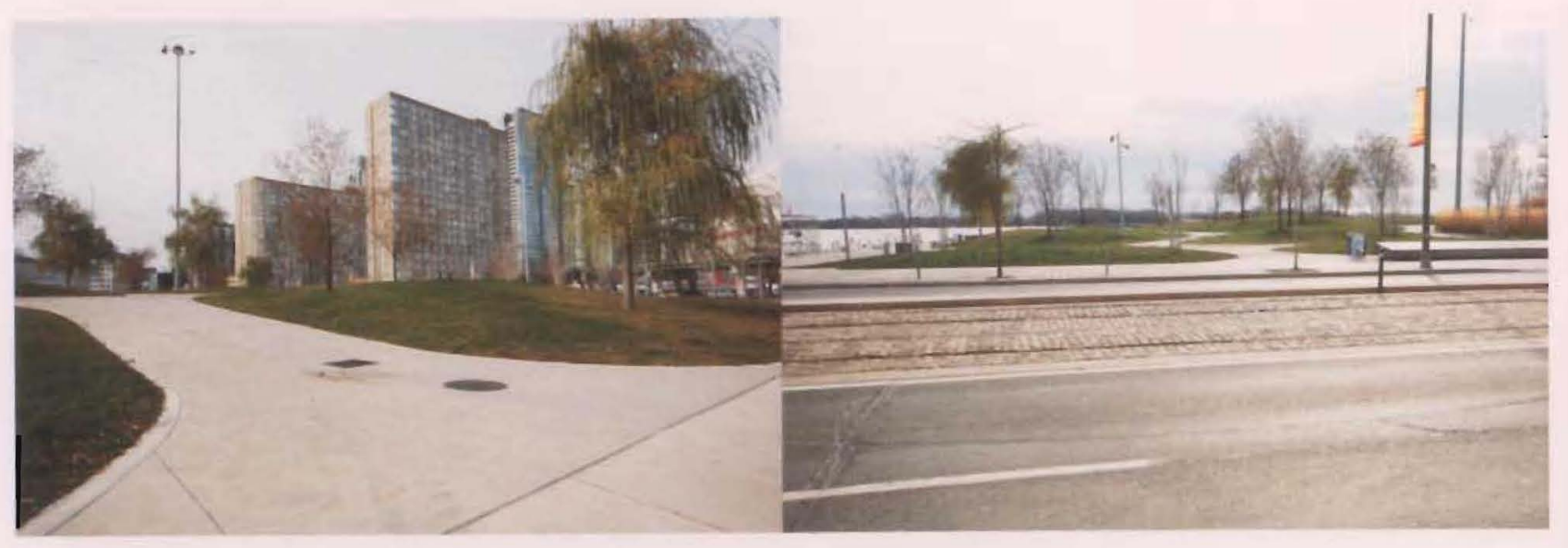

Figure 4.2.19 HtO Park in relation to Harbourfront condos and streets.

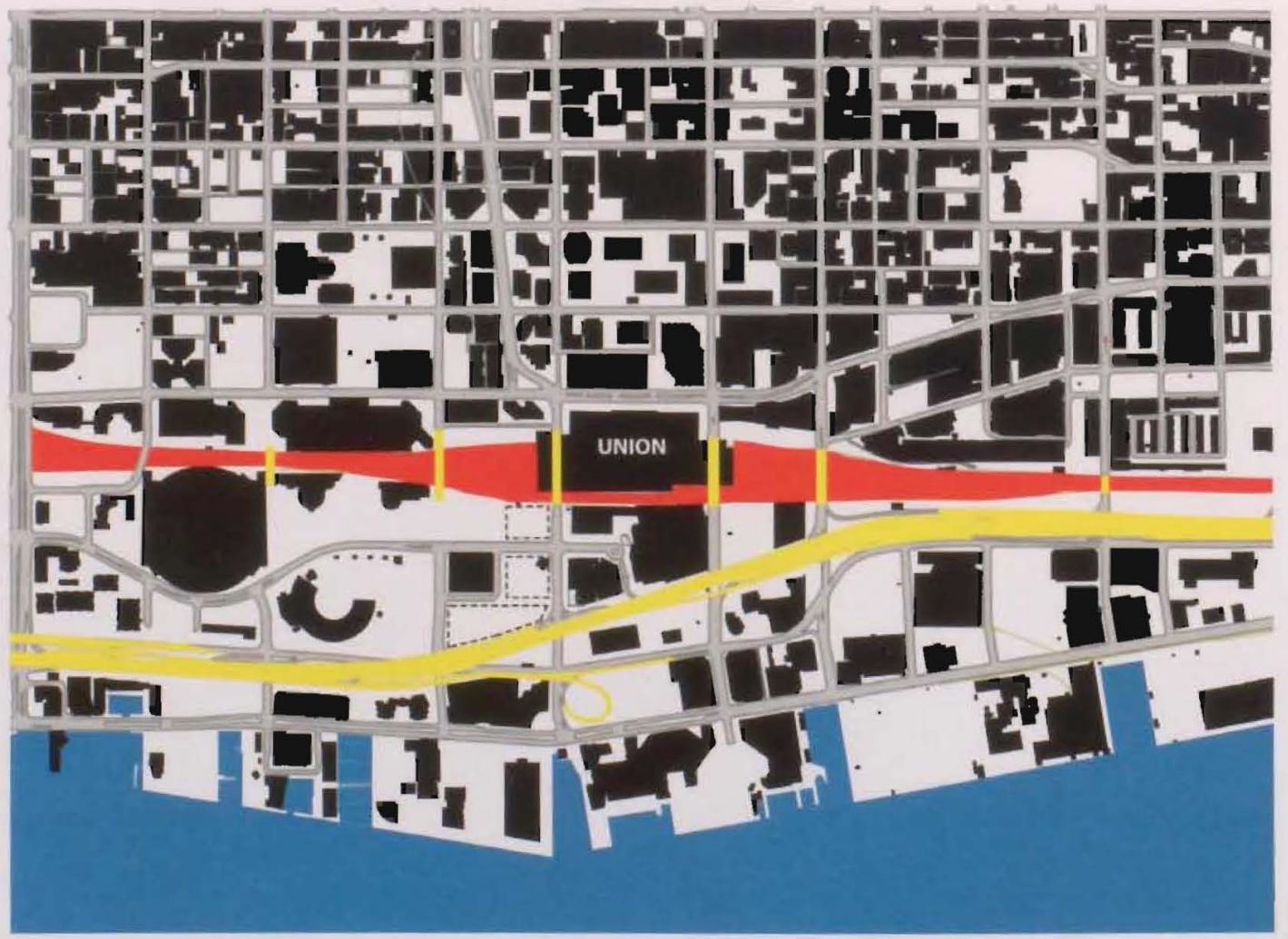

Figure 4.2.20 Yellow: Elevated Barriers, Red: Rail Corridor Barrier. 


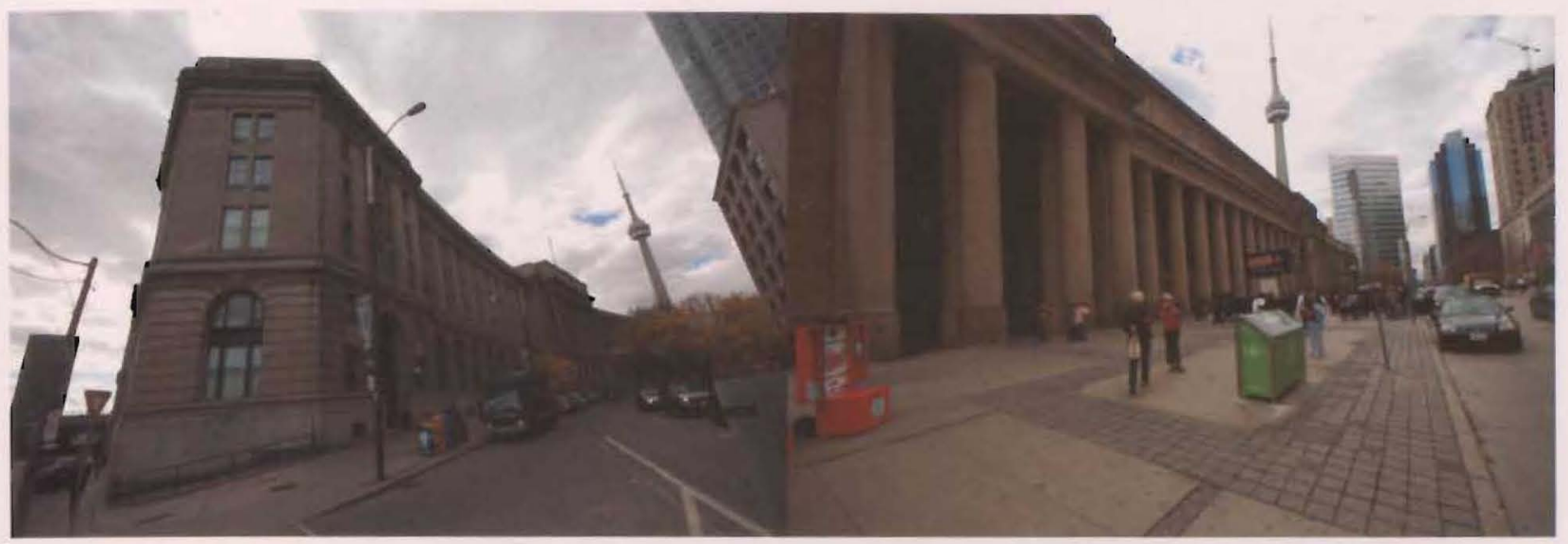

Figure 4.2.21 Impenetrable stone facades along the south side of Front Street.

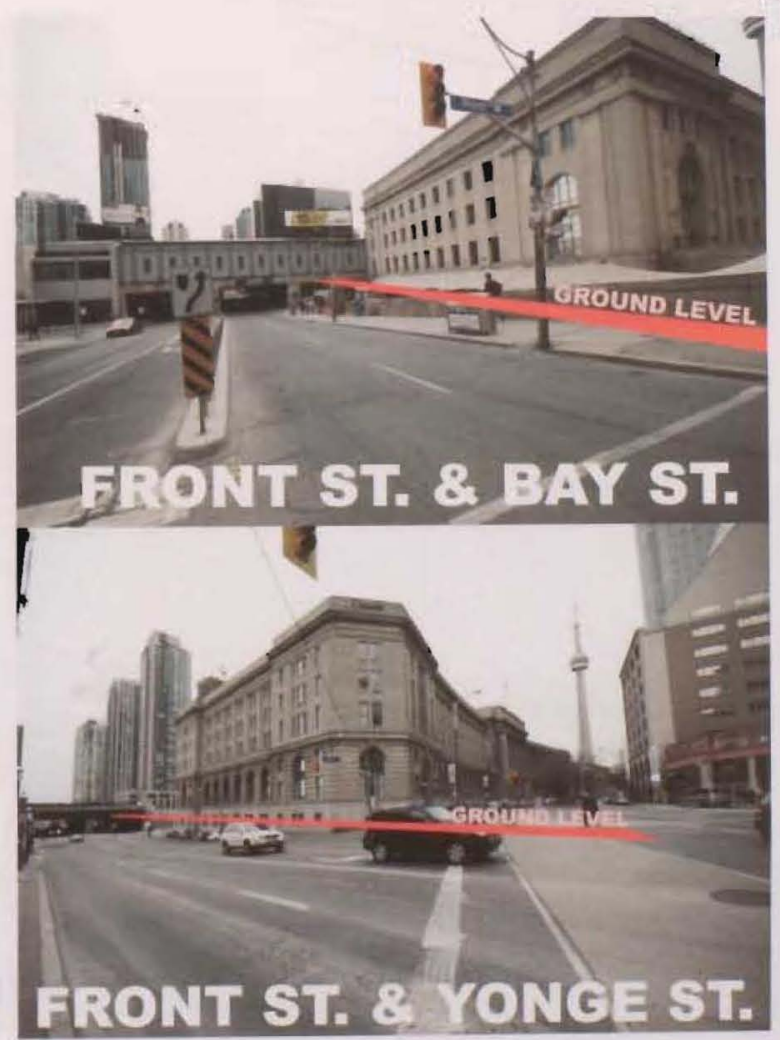

Figure 4.2.22 Elevation Change from Front Street to waterfront. 


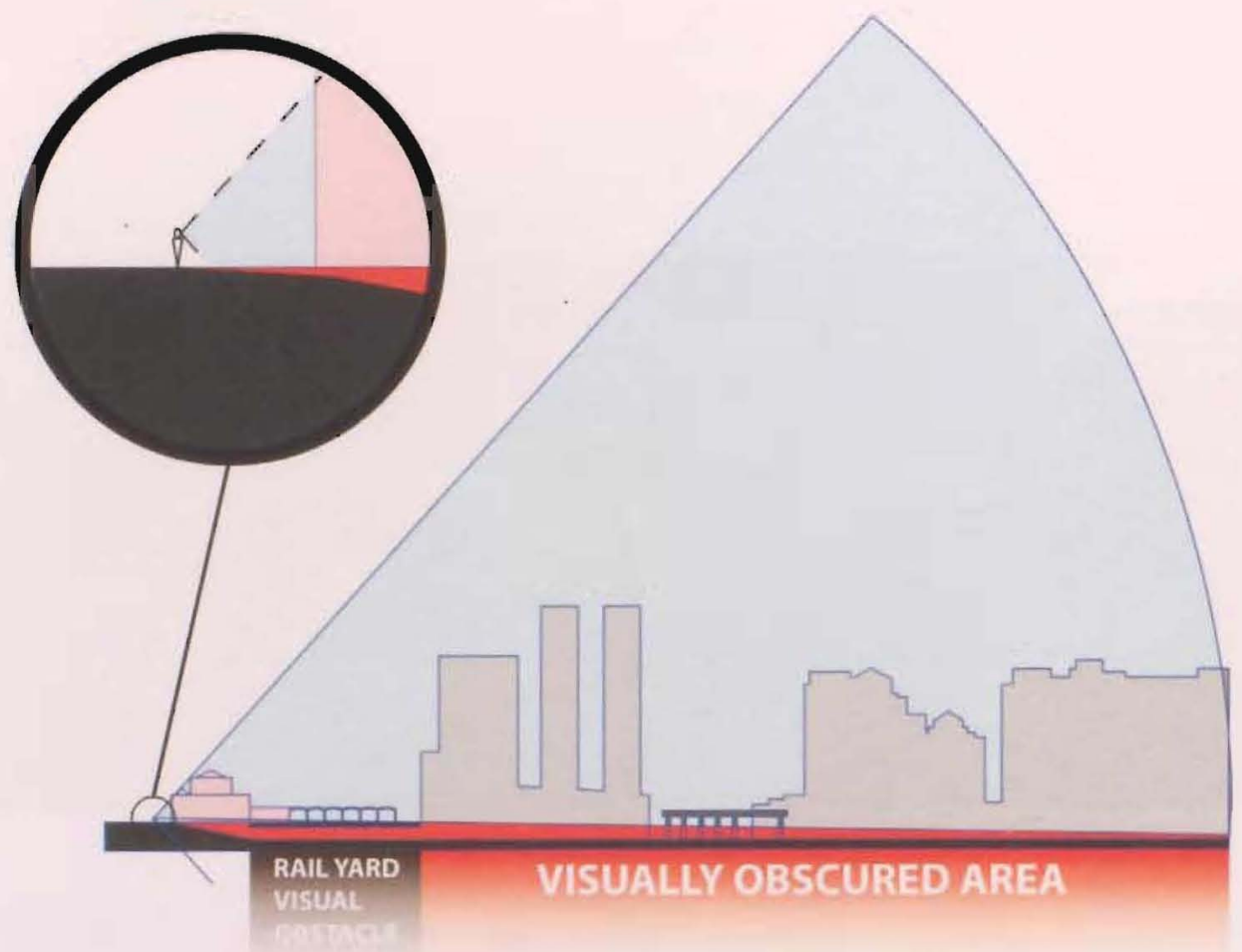

Figure 4.2.23 The rail corridor forms a visual barrier that inhibits a clear view of the CRL an waterfront.

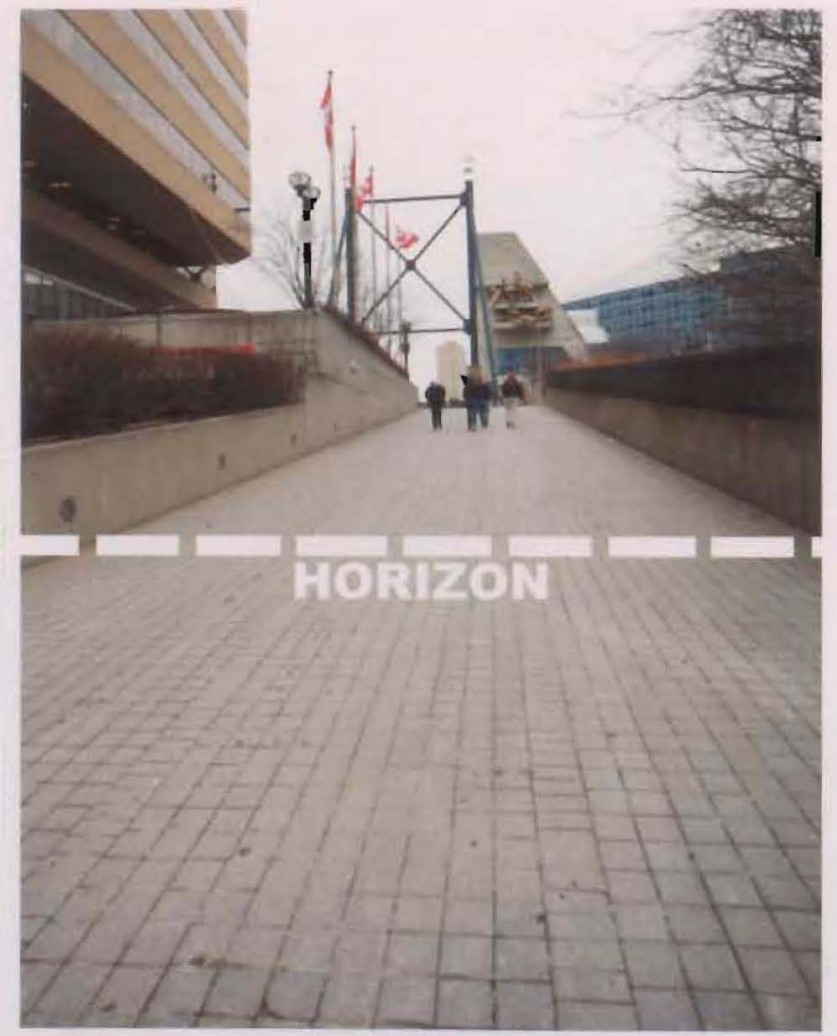

Figure 4.2.24 Steep climb blocks views to the waterfront. 


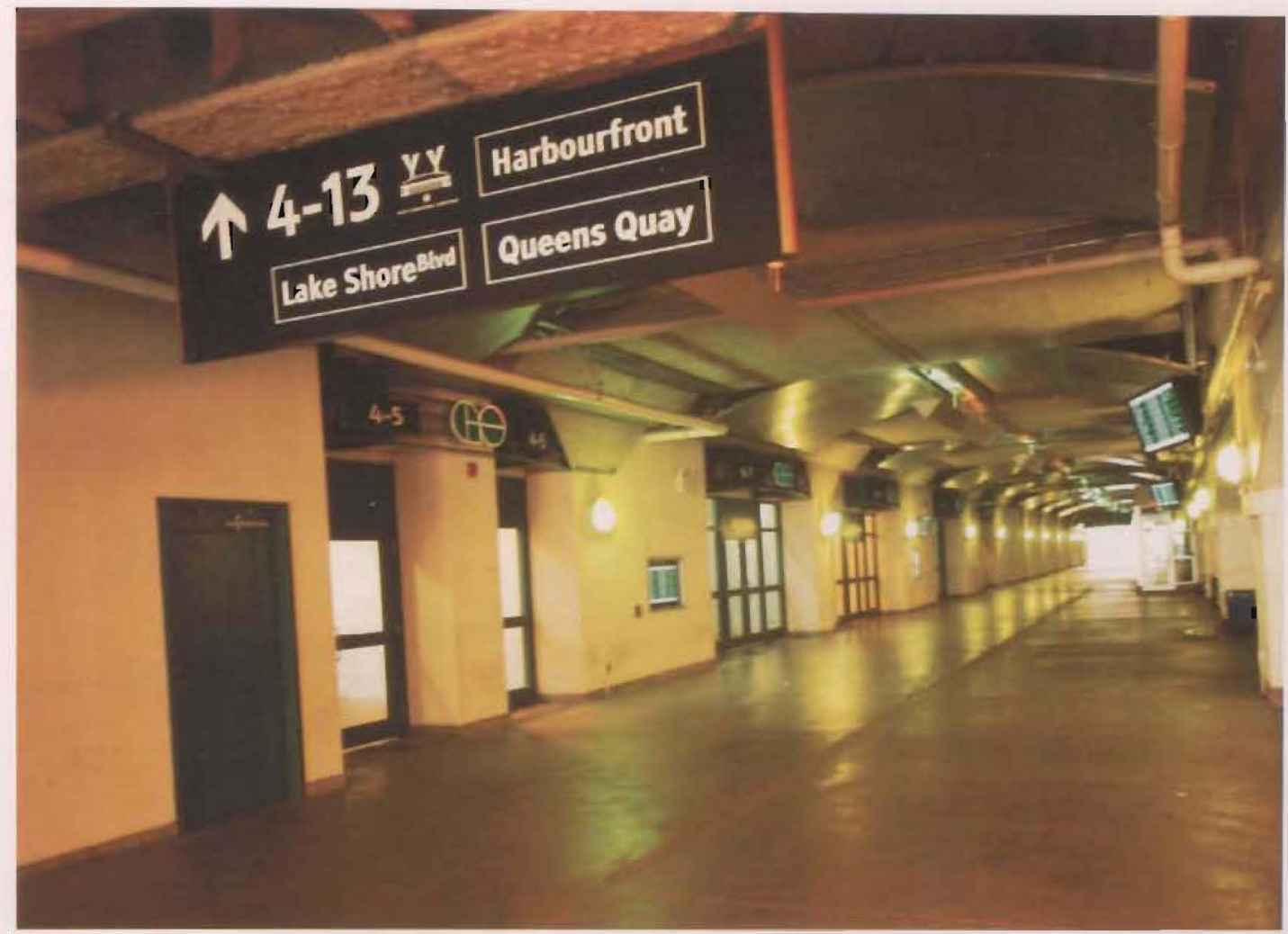

Figure 4.2.25 Go Transit Teamways - signage, colour scheme and doors define the teamways

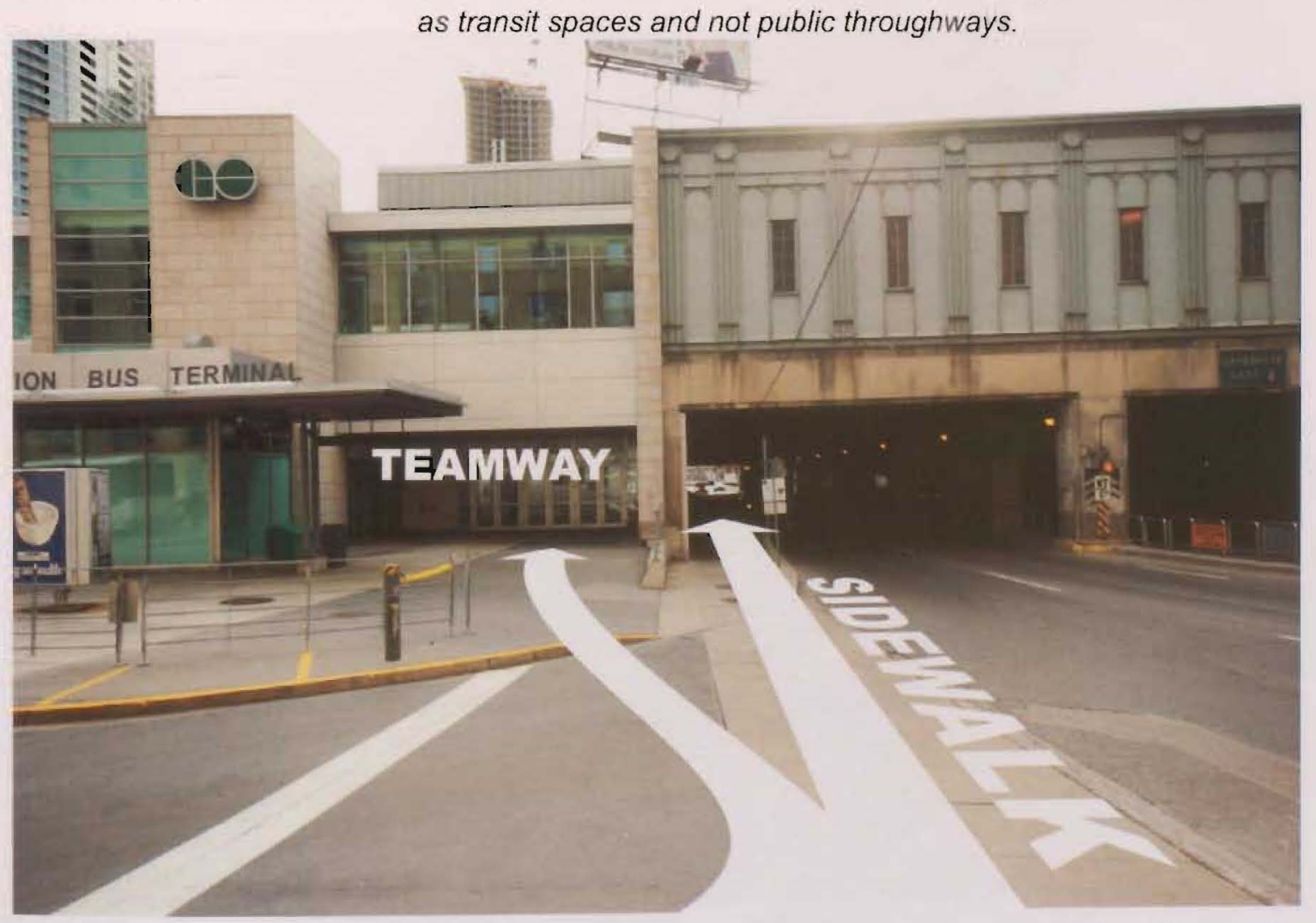

Figure 4.2.26 The sidewalk provides a direct route while the teamway is placed out the direct path of movement. 


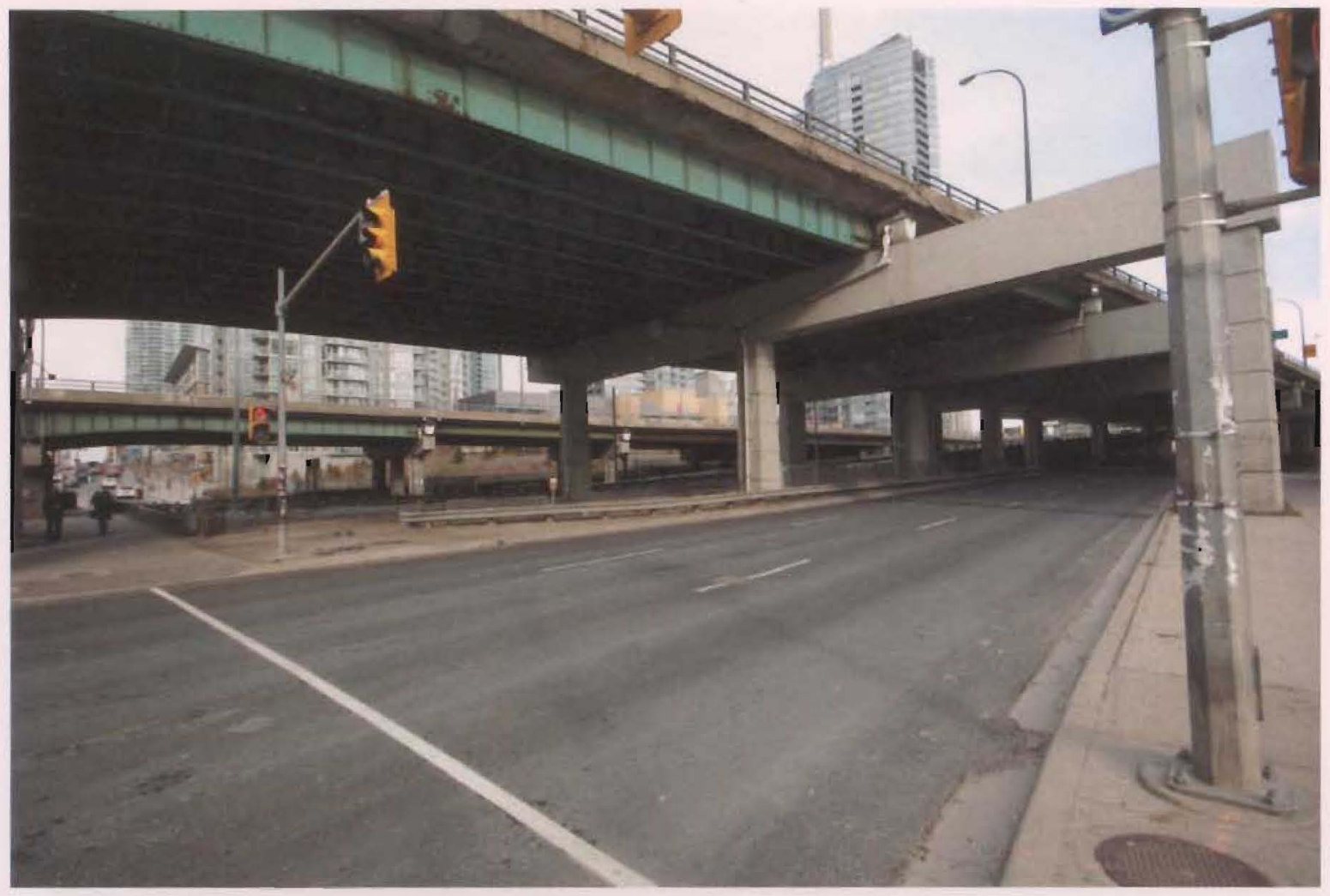

Figure 4.2.27 Elevated Gardiner Expressway with Lakeshore Boulevard below.

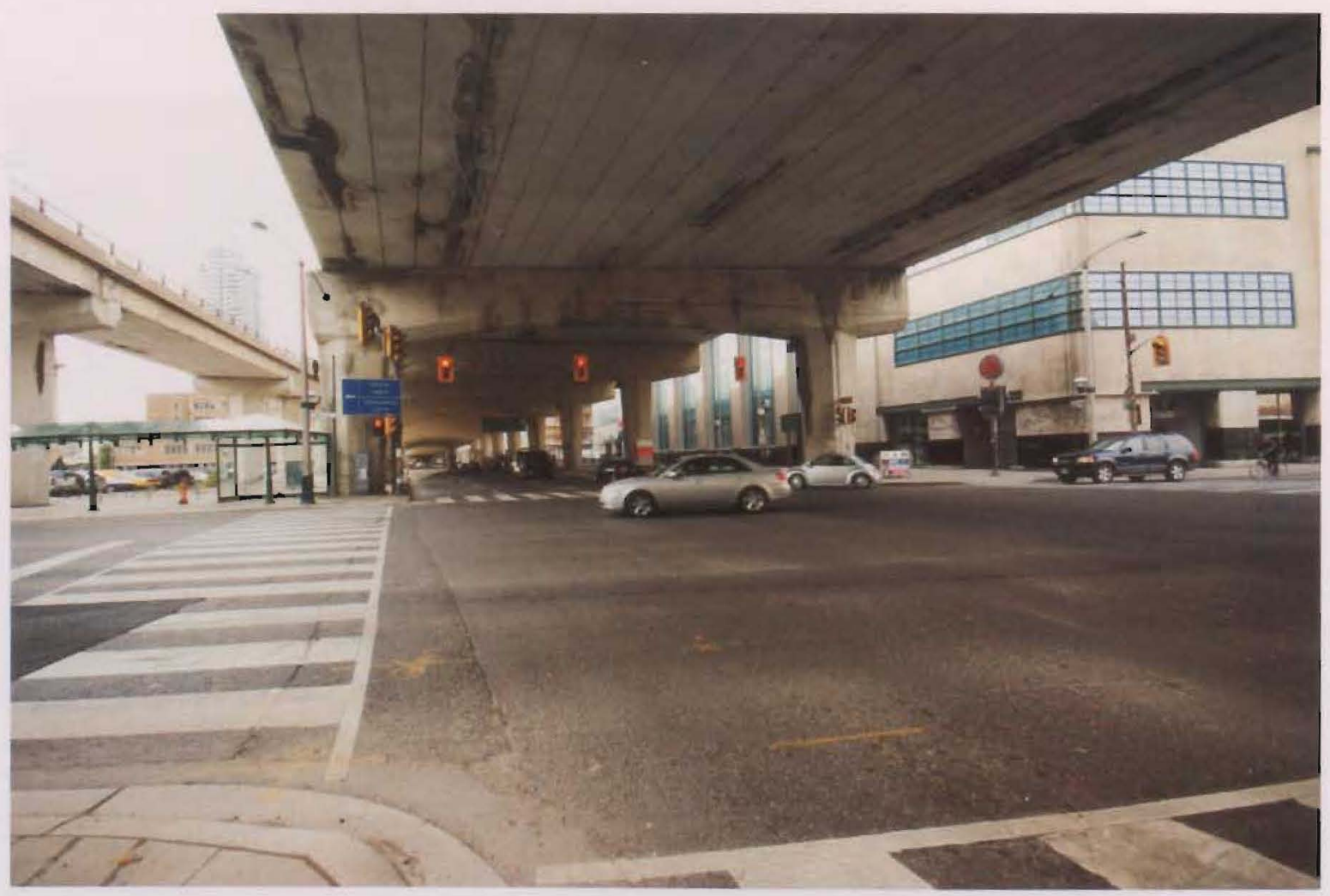

Figure 4.2.28 Intersection of Lakeshore Boulevard \& Yonge Street. 


\subsection{A Solution}

There is an opportunity to address simultaneously the barrier conditions, the lack of functional public space and a poorly integrated multi-modal hub. Toronto has a defined downtown and waterfront condition, but the rail lands exist between these two territories as an interstitial space. As an alternative to the Union Station District Plans' creation for a separate destination, an intervention that redevelops Union Station into a public space could channel and transition the movements of people north and south. If public space became the focus of reprogramming Union Station and the CRL, it could provide both a public focal point within Toronto and the means for encouraging the movement of people - with the public focal point obviously not the primary destination. 


\subsection{What is Union Station?}

What is Union Station? Is it an infrastructural node, a destination or both? With Union Station's fragmented spaces providing a functional means for moving large volumes of passengers every day, it can be said that the station is a structure for transferring people. But this definition does not offer a sufficient understanding of the station's potential — or even if there are potentials to be exploited. In their book Cities on rails, Bertonlini and Spit provide a framework for defining a station as both a place and a node. The framework of a node-place allows the station to be conceptualized as a "node of networks and place in the city" (Bertonlini \& Spit, 1998, p. 9).

A node of networks generally refers to a station's convergence of infrastructural systems, such as rail, subway and bus lines, but also relates to more abstract references such as "socioeconomic networks" (Bertonlini \& Spit, p. 11). Socio-economic networks can be regarded as activities that tend to form groups in proximity to stations, such as business headquarters or regional city-to-city business links. The obvious networks of Union Station are its infrastructural networks, but less obvious are its socio-economic networks. Union Station does not provide high-speed commuter connections to other Canadian cities, and not being connected to other economic centres reduces its socio-economic influence. This situation is different than in Europe or Asia where high-speed rail services provide rapid connections to other socio-economic centres (Dawes, 2001). VIA Rail does provide connections to major Canadian centres, but with a yearly ridership of 2.4 million passengers through Union Station, it fails to compete with GO Transit's 48 million passengers a year (Union Station Master Plan, 2008). On any given weekday morning, thousands of commuters disembark at Union Station, destined for the Financial District or TTC. By the end of the day, all these commuters return to Union Station, bound for their suburban homes.

Union Station provides the socio-economic ability for people to live in the suburbs while working in the city core. So does this mean Union Station is a transition point? This question cannot be answered until we understand what a node is or what a place is in relation to a station. 


\subsection{Space and Atmosphere}

Bertonlini classifies place as having co-existing meanings of space and atmosphere, where "a place is a physical environment and a synonym of space, or the physical surroundings and a synonymous of atmosphere" (Bertonlini \& Spit, 1998, p. 11). The Union Station 'space' can be associated to the physical building complex, including the rail yards, GO Bus and TTC services, while the immaterial qualities of its 'atmosphere' is less concrete. It is hard to distinguish what constitutes the atmosphere of Union Station, as there are varying conditions inside and outside the station. Along Front Street the historical facades of Union Station, Royal York and adjacent buildings provide an atmosphere that relate the station to its roots as a passenger terminal, but to the rear of the station the atmosphere is less connective to any sort of place.

As mentioned, the district plan is attempting to unify the old rail lands into a cohesive whole in order to provide a 'pedestrian sphere' for the station area (Union Station District Plan, 2006, p. 2). The Union Station District Plan (2006) rigidly defines the boundaries of the station area as the limits of place, but Bertonlini states that a station's extent is less concrete and has developed four factors to define a station's limit. First, a station's extent can be determined by the limits of a walkable radius - usually 500 metres. A 500-metre radius from Union Station borders onto four other districts and encompasses most of the Financial District (Fig. 5.1.1). However, walking radiuses do not account for the actual walking distance determined by physical or psychological barriers (Bertonlini \& Spit, 1998, p. 12). Union Station's actual walking distance must include the extent of the PATH system (Fig. 5.1.2) and factor in the barriers at the north and south ends of the rail lands. When these are accounted for, we find that Union Station's walking radius is much larger to the north than the south, where the large physical and psychological barriers inhibit movement (Fig. 5.1.3).

Second, the station's extent can be a factor of its 'functional-historical elements,' which are determined by the various structures constructed in relation to the station. These elements can include structures that are or were connected to the station, and structures that have associative links to the station (Bertonlini \& Spit, 1998). At Union Station, this would include all buildings associated with the terminal and all structures having a historical significance to the station, such as the Roundhouse, Royal York Hotel and the Dominion Public Building. Defining a station's physical extents based on functional-historical elements provides concrete examples for defining the area (Fig. 5.1.4). A drawback to using this method is the focus on past and 
present elements and a restriction on an ability to provide potentials for progress (et al., 1998, p. 13). Much of the Union Station District Plan is plotted against the extents of the historical fabric and does not include the significant relationship of major structures to the station such as the Roger's Centre.

Third, the topography of the station can be a factor of its physical boundary or by the surface area covered by the station (Bertonlini \& Spit, 1998). This extent does not provide an accurate representation of the station's boundaries because the rail infrastructure could be in layers and even submerged below grade. If rail is submerged, the visual boundaries of a station are reduced, but connections could extend much farther than is visually apparent. This is obvious for subway stations whose visual surface extent may only be a head house, which is not representational of the complex that exists below grade. Figure 5.1.5 takes into account Union Station's elevated rail yards as the topographical extents and reveals that the boundaries are sharply longitudinal. However, the topographical extents of the Union Station complex are largely not accessible to the public.

The fourth issue for determining a station's boundary is the perimeter of the development, where a specific initiative defines the boundaries. In the case of Union Station, the Union Station District Plan defines the boundaries of the new district (Fig. 5.1.6). The issue with a development perimeter is that either the elements outside the initiatives area are neglected or the district itself is neglected if the initiative does not provide enough attention (Bertonlini \& Spit, 1998). If all four factors of Union Station are overlaid and mapped out, the result shows that the station's 'place' has varying degrees of influence (Fig. 5.1.7). The strongest overlaps occur obviously within the 500-metre walking radius; however, to the south the influence is less obvious due to poor pedestrian connections and barrier conditions. 


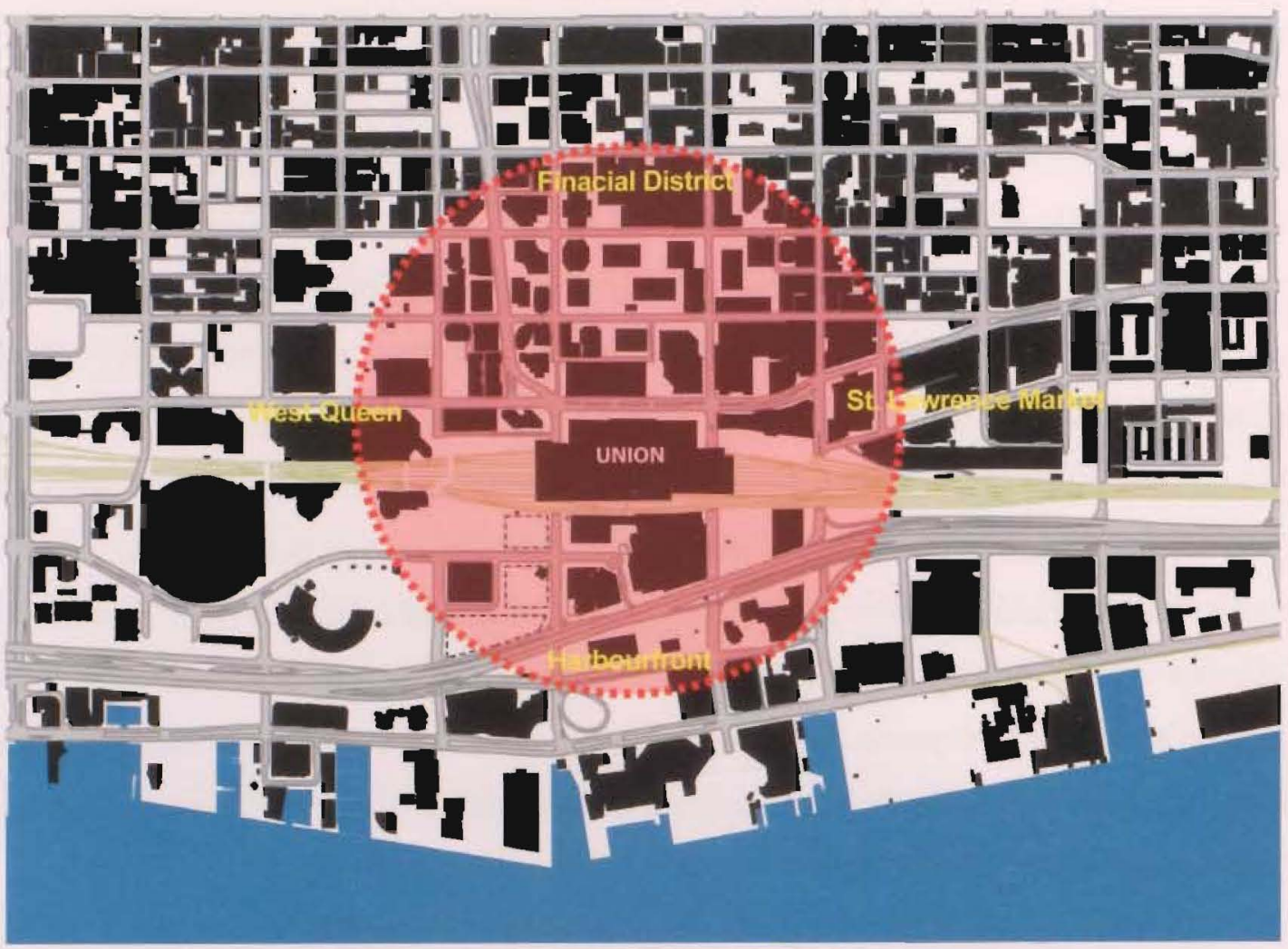

Figure 5.1.1 500m walking radius from Union Station

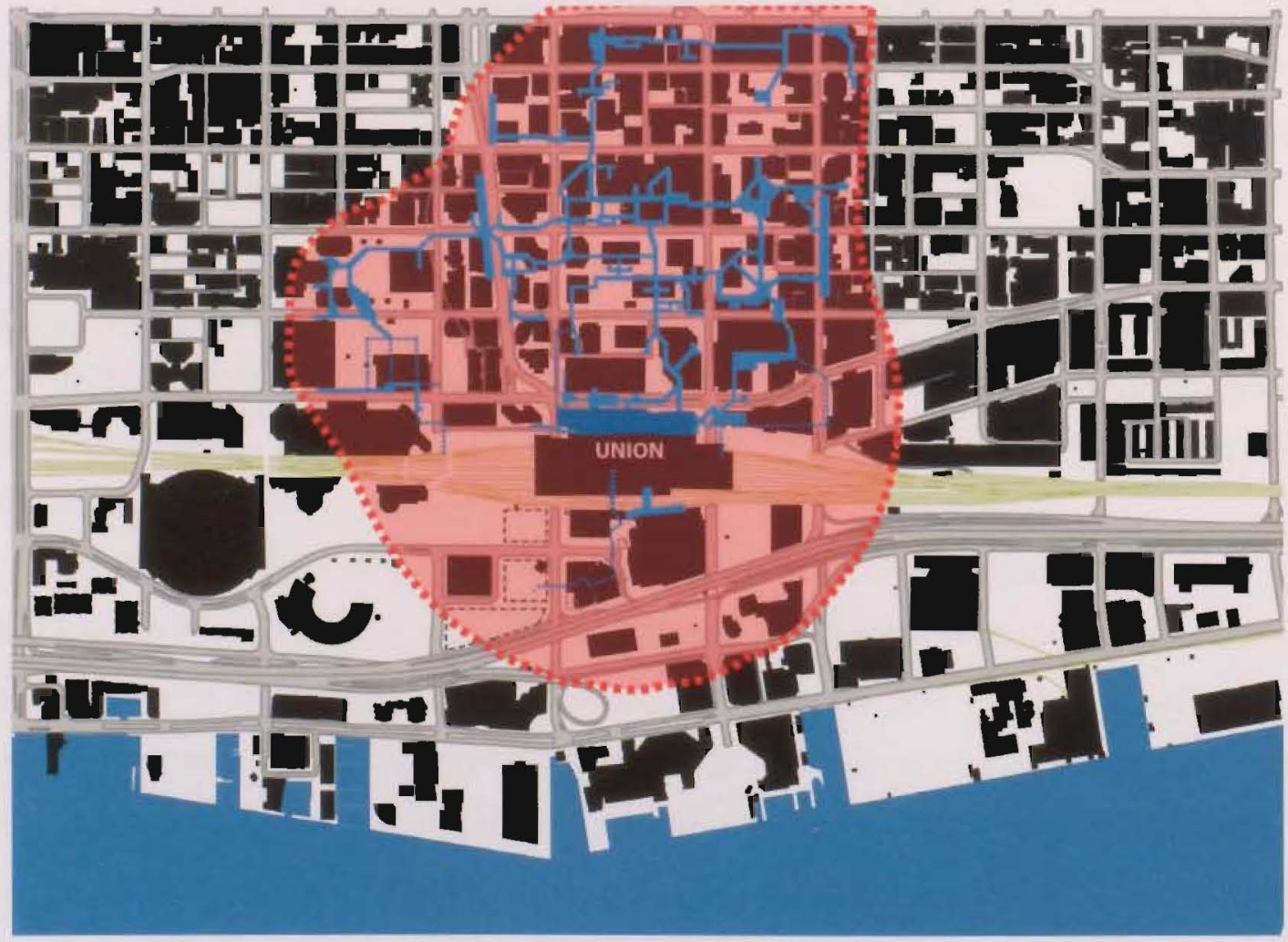

Figure $5.1 .2500 \mathrm{~m}$ radius augmented by PATH system 


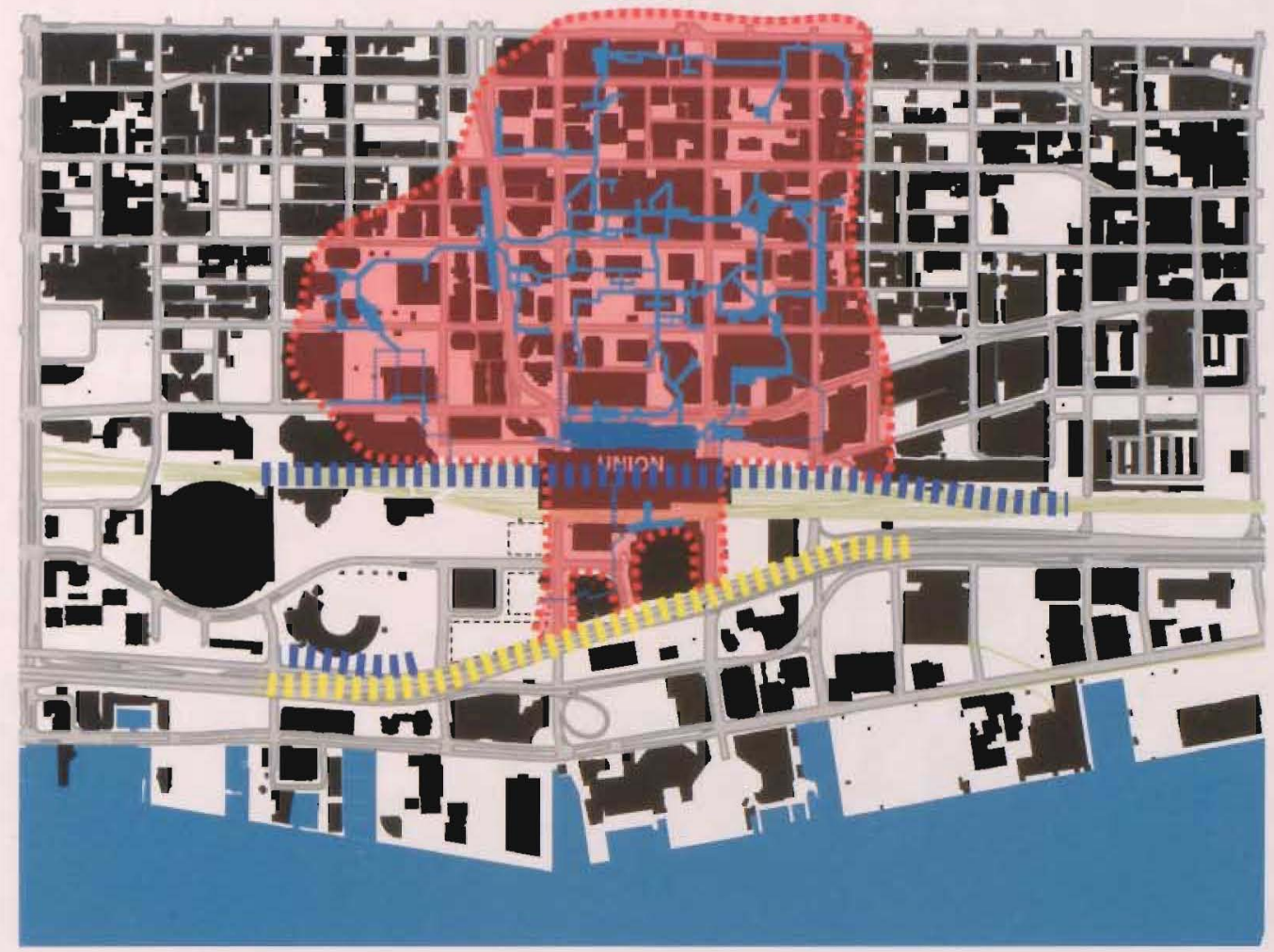

Figure 5.1.3 Walking distance based on PATH system and restricted by barriers.

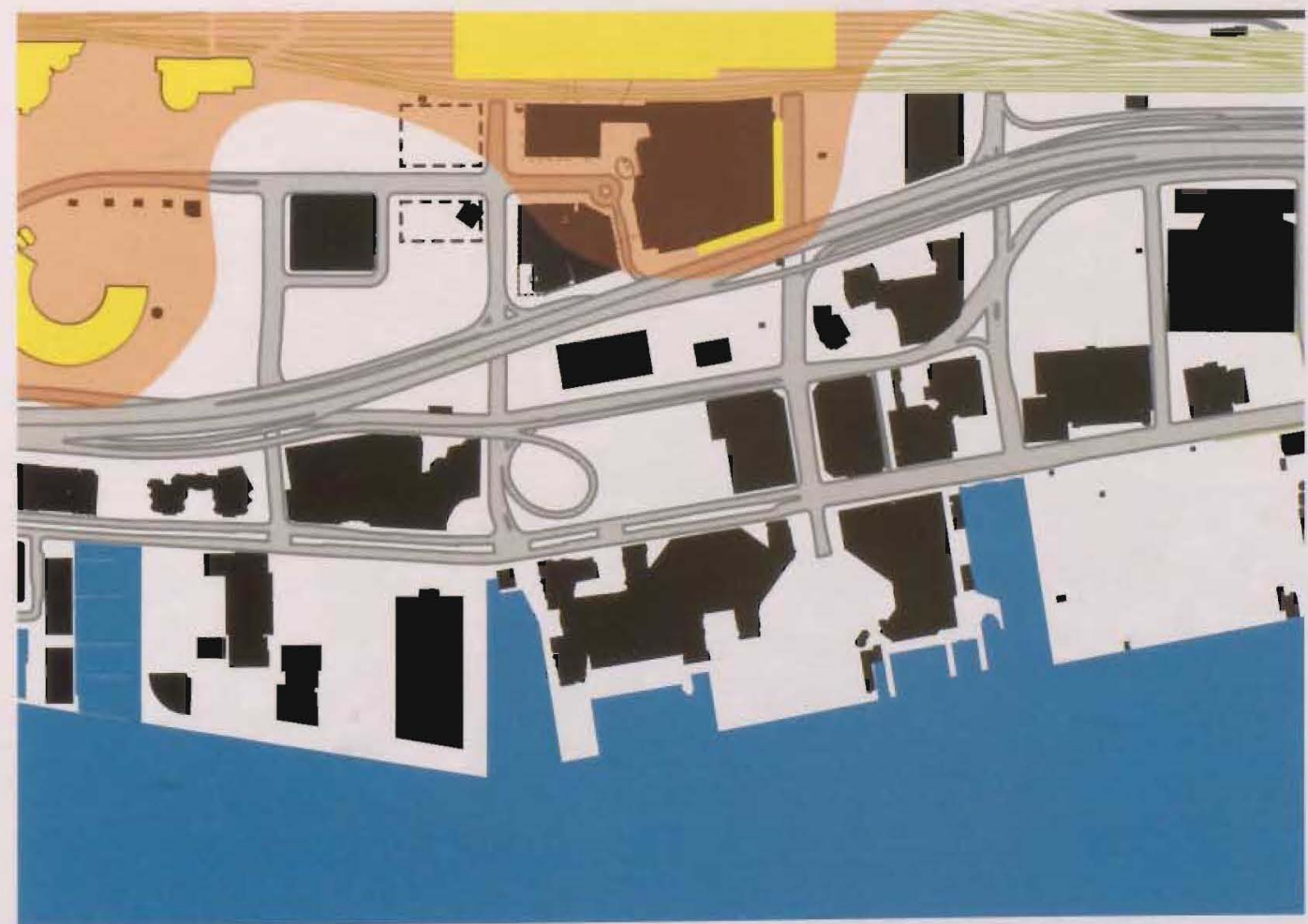

Figure 5.1.4 Historical Boundaries defined by historical structures related to Union Station 


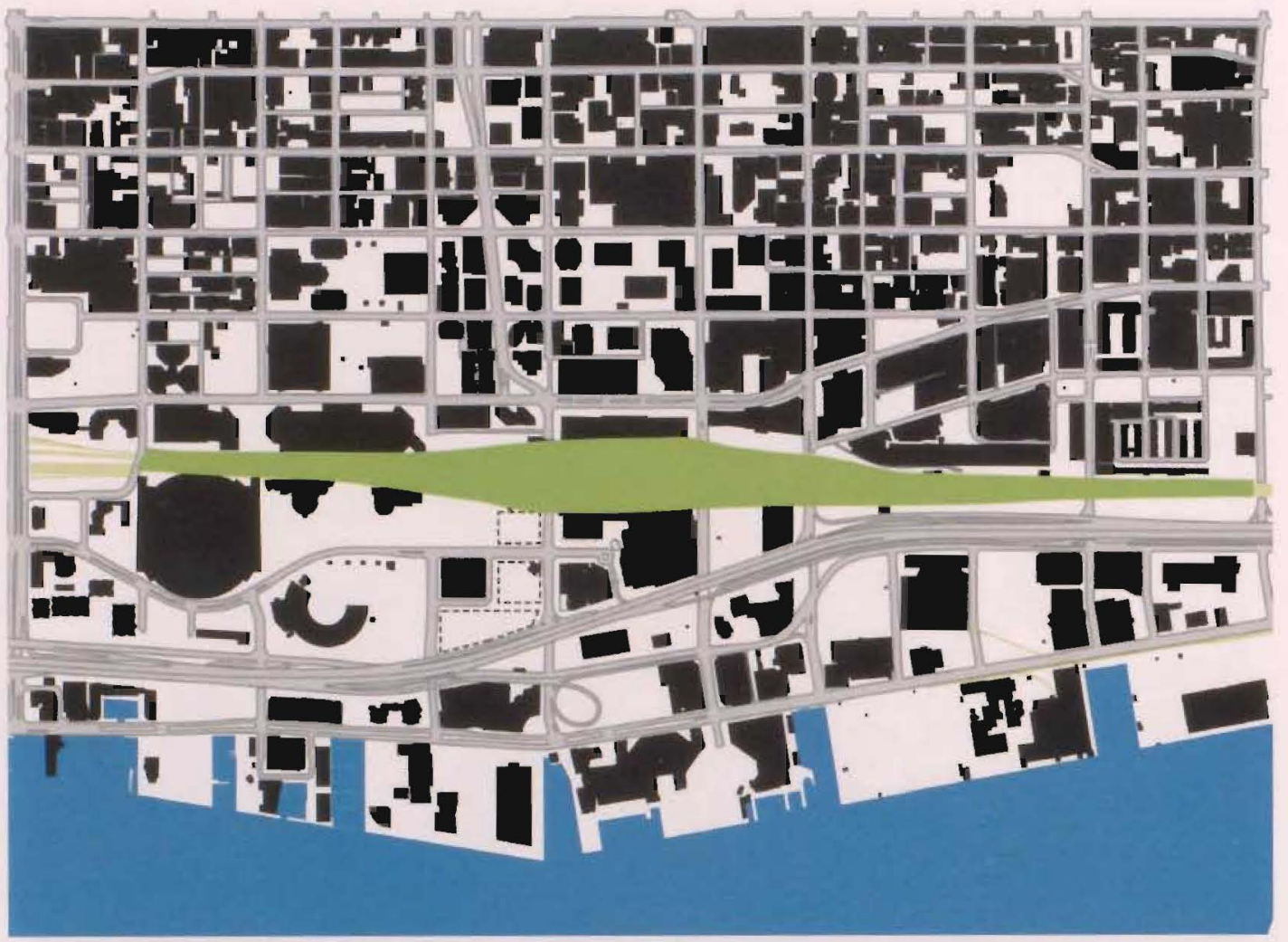

Figure 5.1.5 Topographical extents are primarily formed by the elevated rail corridor.

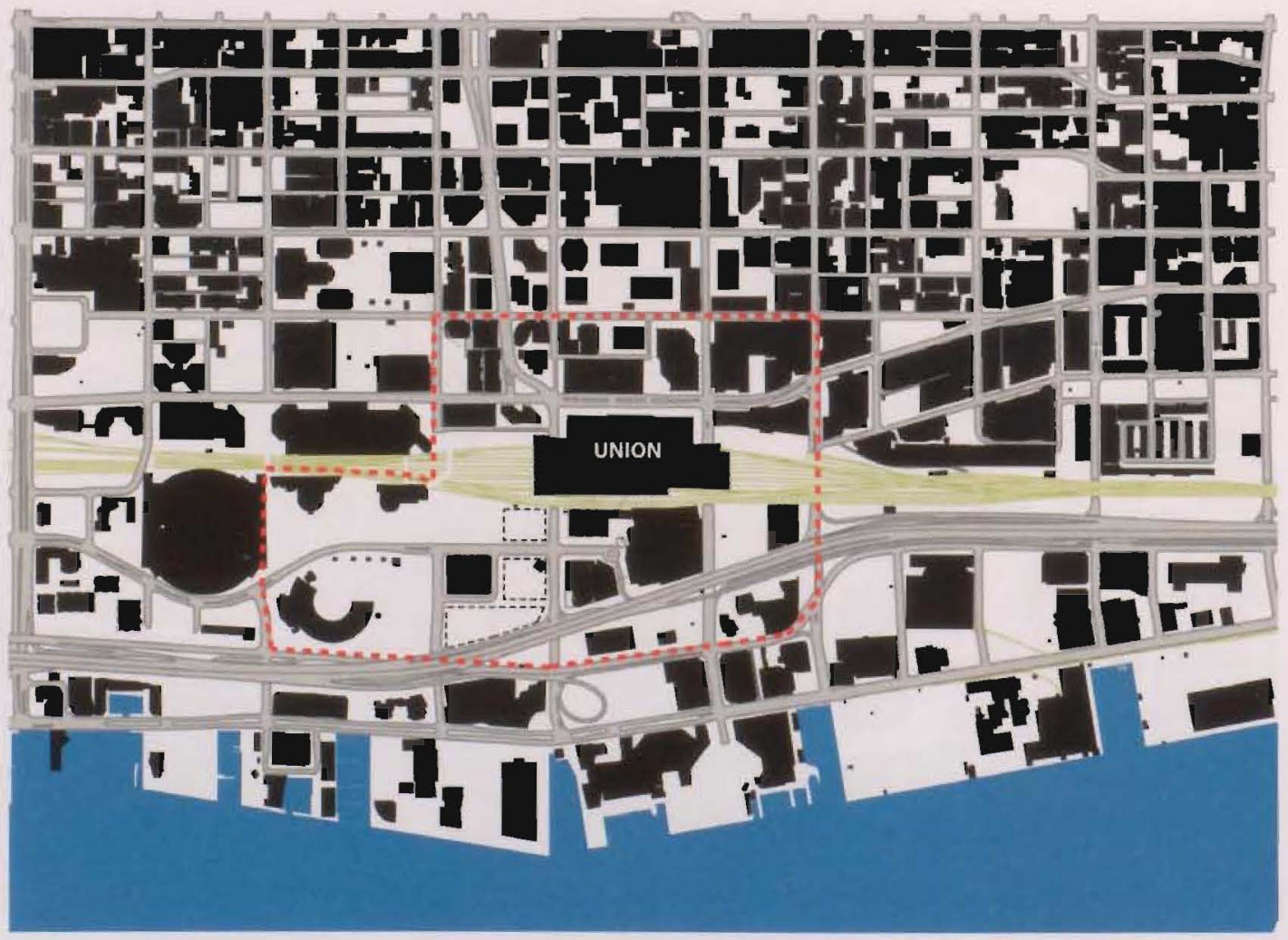

Figure 5.1.6 Defined Union Station District Plan Boundaries. 


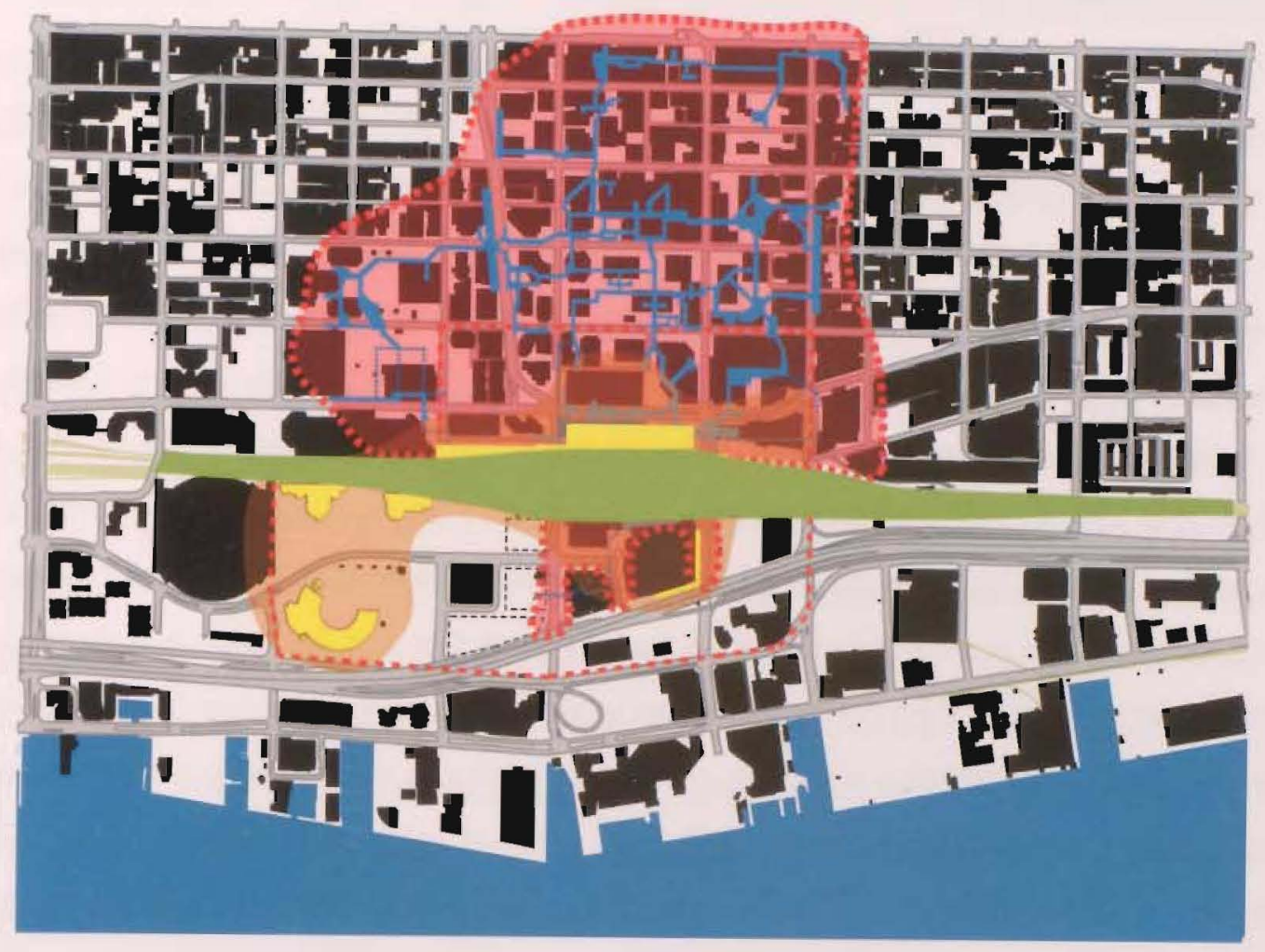

Figure 5.1.7 The strongest overlap that defines the extent of Union Station is north of the rail corridor.

\subsection{Urban Exchange Complex}

Once the varying boundaries of 'place' have been mapped, what exactly is the place of Union Station? Bertonlini and Spit propose that a station's place has become an 'urban exchange complex, 'where a station is no longer a juxtaposition of separate elements but is an integrated whole (Bertonlini \& Spit, 1998, p. 35). Urban exchange complexes are defined by their integration of hard essentials (infrastructure) and soft essentials (services). There is a desire to organize the infrastructure and services in a way to provide "a place to be, not just a place to pass though" (et al., 1998, p. 35). Bertonlini and Spit consider a station location's attractiveness through many factors, which include accessibility, livability, security, identity, liveliness and even property investment. Property investment is important because it evaluates how much available space is left for development and if the station location has reached its maximum development potential (et al., 1998, p. 35). Union Station is a condition of juxtaposed infrastructure and services, and there is an obvious attraction towards organizing these elements into an urban exchange complex. 
If Union Station were to become an urban exchange complex, what would the development potentials be?

Development potentials immediately around Union Station are quickly becoming consumed by condominium and office developments. Given the current financial crisis, it is possible that development around Union Station could cease, providing a chance for the city to capitalize on the land's potential as a large civic renewal project. Bertonlini and Spit have developed a node-place model to define the potentials of a station location using five key factors: dependence, balanced, stressed, unbalanced node and unbalanced place (Fig. 83) (Bruinsma, et al., 2008 p. 38). Stations aspire to reach a balanced node, but the strongest development potentials for a station is as an unbalanced node or an unbalanced place where the imbalances provide opportunities to grow nodal connections or enhance a station's 'place' of importance in its surrounding context. The node-place model only shows development potentials, and actual realization is dependant upon a station's conditions beyond transportation and land use (that is, city policy) (Bertonlini \& Spit, 1998). Applying Bertonlini's node-place model on Union Station can help to refine what type of urban exchange complex it has the potential to become.

A dependant station is a condition where both demand for nodal connections and development are so low that the station is reaching a critical point where its existence may become an issue. When a station location is an unbalanced node, such as a newly opened suburban station, nodal connections are fully developed with strong potentials for land use development. Ten years ago Union Station was an unbalanced node, with plenty of opportunity for land use development. This condition has changed, with development filling out most available lands. A station under stress occurs when the development potentials of node and place have been maximized. At this point a station under stress has little ability to expand or adapt to changes. Union Station is beginning to reach a point where it will be under stress, if it is not already. Easy development potentials are diminishing and nodal connections are already maximized, but even though there are few cheap and easy development potentials left for Union Station, there are still potentials for more development and increased nodal connections. When a station is an unbalanced place, such as a historical area where development potentials are saturated, there are potentials for increasing nodal connections or developing a new functional mix of programming in the area. (Bruinsma et al., 2008, p. 39). Union Station is currently at the cusp between a station under stress and an unbalanced place where its historical fabric restricts new expansions; new developments have saturated land use; and is in need of a new 
functional mix of programming. The potentials of Union Station as an unbalanced place are the redevelopment of nodal connections into an integrated complex and providing a new functional mix of programming to activate the contextual area. These redevelopments would ease the stress on the nodal connections through seamless transfers, while a new functional mix can provide programming for an urban exchange complex.

Despite the fact that the Bertonlini model provides an easy way to reference a station's potential, it is not an accurate method of analysis because it lacks ways to assess if development will be successful or if the station location is a pleasant place to be. Under the model, the development around Union Station shows it is successful at promoting property investment, but does not provide methods to understand if property investment provides a benefit to the station. Also, the model does not state what makes for good and bad nodal connections. Union Station's multi-modal connections would point to it being a strong node, but these connections are fragmented and improperly integrated. The model provides a standard framework identifying various potentials of the station area, but it requires the researcher to delve deeper into specific issues of the station location.

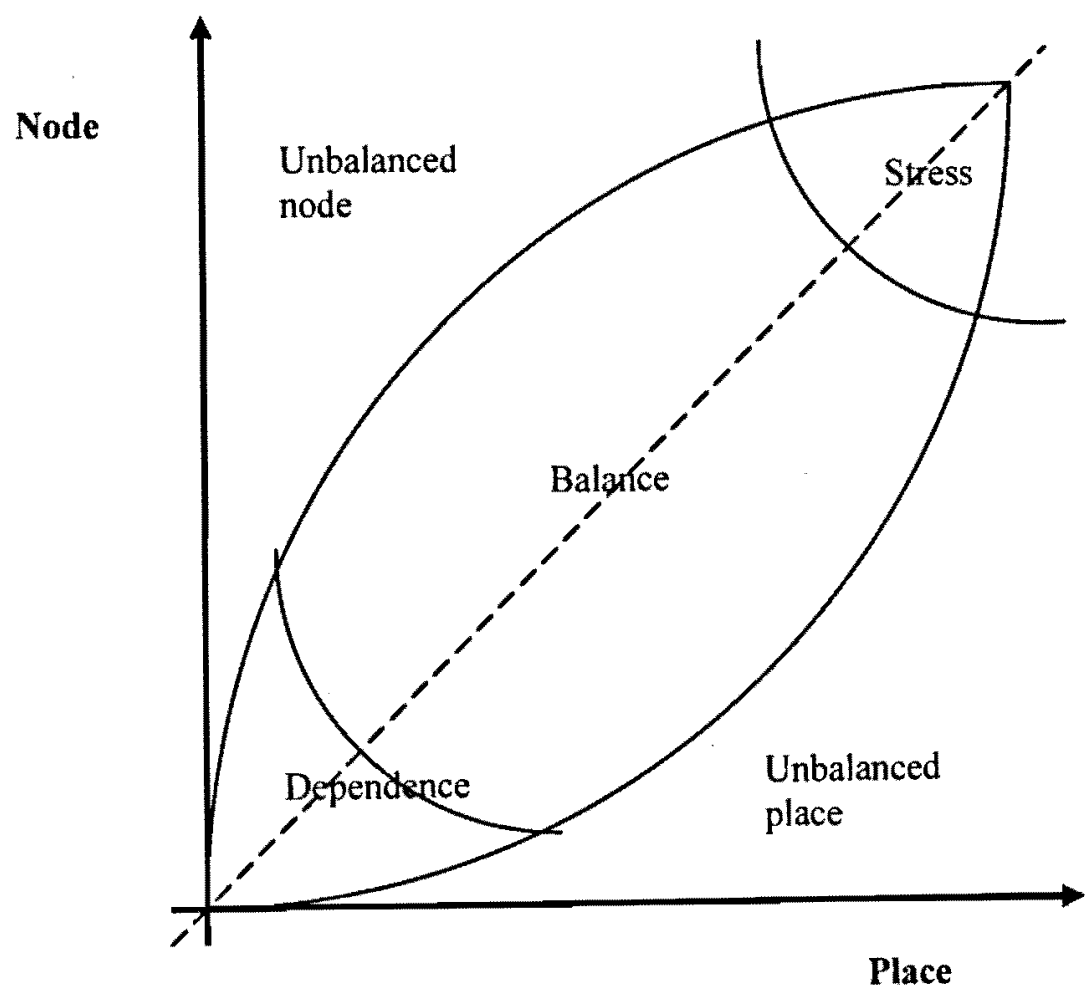

Figure 5.2.1 Bertonlini Node-Place Model 


\subsection{An Ideal Station}

Peek, an economist and researcher at Delft University, has developed a similar nodeplace referencing system as Bertonlini, but provides a more defined framework to understand the relationship of node and place as an ideal station conditions. Peek's method of assessing an ideal station condition is through four approaches he calls connector, transportation node, meeting place and urban centre (Fig. 5.3.1) (Bruinsma et al., 2008, p. 127). Using his method helps to fill in the gaps the Bertonlini and Spit model could not do by narrowing the requirements of an ideal urban exchange complex.

The first method of evaluating an ideal station - one that Peek characterizes as a connector - is that it is primarily concerned with the nodal connections of a station and secondarily concerned with the connections to the location. An ideal connector functions by providing "the connections as smooth as possible ... [and] transferring should be safe, reliable, fast, hasslefree, comfortable, and pleasant, thus corresponding with travellers' demands" (Bruinsma et al., 2008, p. 128). Obviously, Union Station does not provide an ideal condition of a connector, providing an ad hoc means of moving people through an improperly designed station for commuter traffic. Peek also elaborates that ideal connectors should make provisions for including indoor and outdoor space as well as public and private space, for the benefit of the two main transferring activities: "moving between stops and staying within the connector, which includes collecting information and ticket, shopping and waiting" (Bruinsma et al., 2008, p. 128). While Front Street plaza and Union Plaza provide public spaces, they are treated as separate entities and should instead be made into a condition where public space is throughout the station, urging users to linger even as their train arrives.

The second method of evaluating an ideal station is characterized as transportation node, which primarily treats the station as a node of infrastructure and secondarily as a network of systems. The ideal condition for a node of infrastructure is to create an optimization of the infrastructural systems at one station, which in turn contributes to the performance of the greater network. Transportation and traffic planners are typically responsible for the optimization of transit systems (Bruinsma et al., 2008). Transit services at Union Station are not ideal, but they appear to be coping for the time being. However, there are congestion problems when dealing with freight trains that share the VIA and GO Transit corridors. It appears that freight uses the Union Station corridor to provide a more direct route to the city of Hamilton and the USA border instead of the longer northern route (Fig. 5.3.2). Dedicated freight and passenger lines through 
the south of the city could provide unencumbered rail service for both systems, or a zero use policy for freight trains would prevent congestion along the Union station corridor.

Peek defines the third trait of an ideal station as a meeting place where the station is "a modern market place where people are still confronted with urban life in all of its multiplicity." He goes on to state that "the combination of accessibility and public space offers opportunities for planned and spontaneous encounters of individuals" (Bruinsma et al., 2008, p. 129). Peek's statement can be linked back to a hybrid form of Foucault's third principle of Heterotopia, where it "is capable of juxtaposing in a single real place several spaces, several sites that are in themselves incompatible" (Foucault, Info, 2007). The railway station as a market place is a heterotopotic concept because it allows incompatible elements such as ticket lobby, train platforms, public spaces and shopping to have a relation to each other in a single structure. Therefore, an ideal station would allow for greater public interaction through a design that would provide more than just transit. Japanese train stations are often examples of heterotopic station complexes that can contain theatres, offices, public spaces, shopping arcades, institutional buildings, residences, hotels and more (Bruinsma et al., 2008). Kyoto station is one of Japan's largest stations and contains a multitude of functions in a single complex (Fig. 5.3.3), with the main axis of the station a large public arcade (Fig. 5.3.4). In fact, the railway component of the station only takes up a small fraction of the floor area, with the rest dedicated to other services not directly related to rail. Union Station fairs less favourably as a market place with its homogenous programming providing little services other than transportation services. Amenity spaces in the GO Concourse merely take advantage of trapped commuters, and while the Great Hall does provide a meeting place, it lacks added programming to retain people in the space. If Union Station was programmed and designed to mimic the happenstance nature of the market place, it could provide a realm where people waiting for a train are not isolated in silence and unable to experience other things.

The fourth method for evaluating an ideal station is the urban centre, where the location can "stimulate the urban economy" through concentrations of development and transit services. Peek elaborates on this theory, which he states follows closely the concept of transit-oriented development (TOD) found in the US (Bruinsma et al., 2008, p. 130). TOD is the concept of integrating transit into a dense concentration of development in a larger constellation of transitorientated developments (Fig. 5.3.5). TOD is comparable to Europe's High-Speed Train (HST) because both concepts typically create dense nodes of mixed programming around a transit terminal in a larger network of terminals (Bruinsma et al., 2008). Toronto is taking steps towards 
a transit orientated-development through the provincial Metrolinx initiative to increase nodes of mixed programming around existing GO Transit terminals. With the development of the outlying GO Transit stations, it could be postulated that commuters from the downtown would travel to outlying suburban centres for employment. Anyone who has tried to board a GO Train at Union Station during morning rush hour knows that Union Station can only support a single direction of traffic. If a growing ridership begins to commute in an opposite direction to current traffic, commuters would be confounded by traffic congestions in the terminal. If Union Station were to become a proper urban centre, it would have to first cope and promote multidirectional traffic. Currently it has become a weak urban centre, but is still capable of strengthening development to the adjacent financial district. There are presently three office towers under construction within a 500-metre radius of Union Station, with plenty of more real estate opportunities for future growth (Fig. 5.3.6).

Bertonlini's node-place model and Peek's four approaches to an ideal station can be grouped into two parts: 'node' and 'place,' where each defines the best condition for a station. The two models approach the station's infrastructure as a multi-modal hub, with many layers of integration providing not only smooth operation of transit services, but also smooth movements for people. Furthermore, nodes are viewed as places where development is concentrated, providing for conditions beyond transit use, such as places for enjoyment and activities. Union Station has failed to meet the basic conditions of a node with poorly integrated transit services, irregular spaces causing poor transitions, and development created independent from Union Station.

Four approaches to railway station development

\begin{tabular}{lll}
\hline Primary focuslSecondary focus & Location & Network \\
\hline Node & Connector & Transportation Node \\
Place & Meeting place & Urban centre \\
\hline
\end{tabular}

Figure 5.3.1 Four approaches to railway station development. 


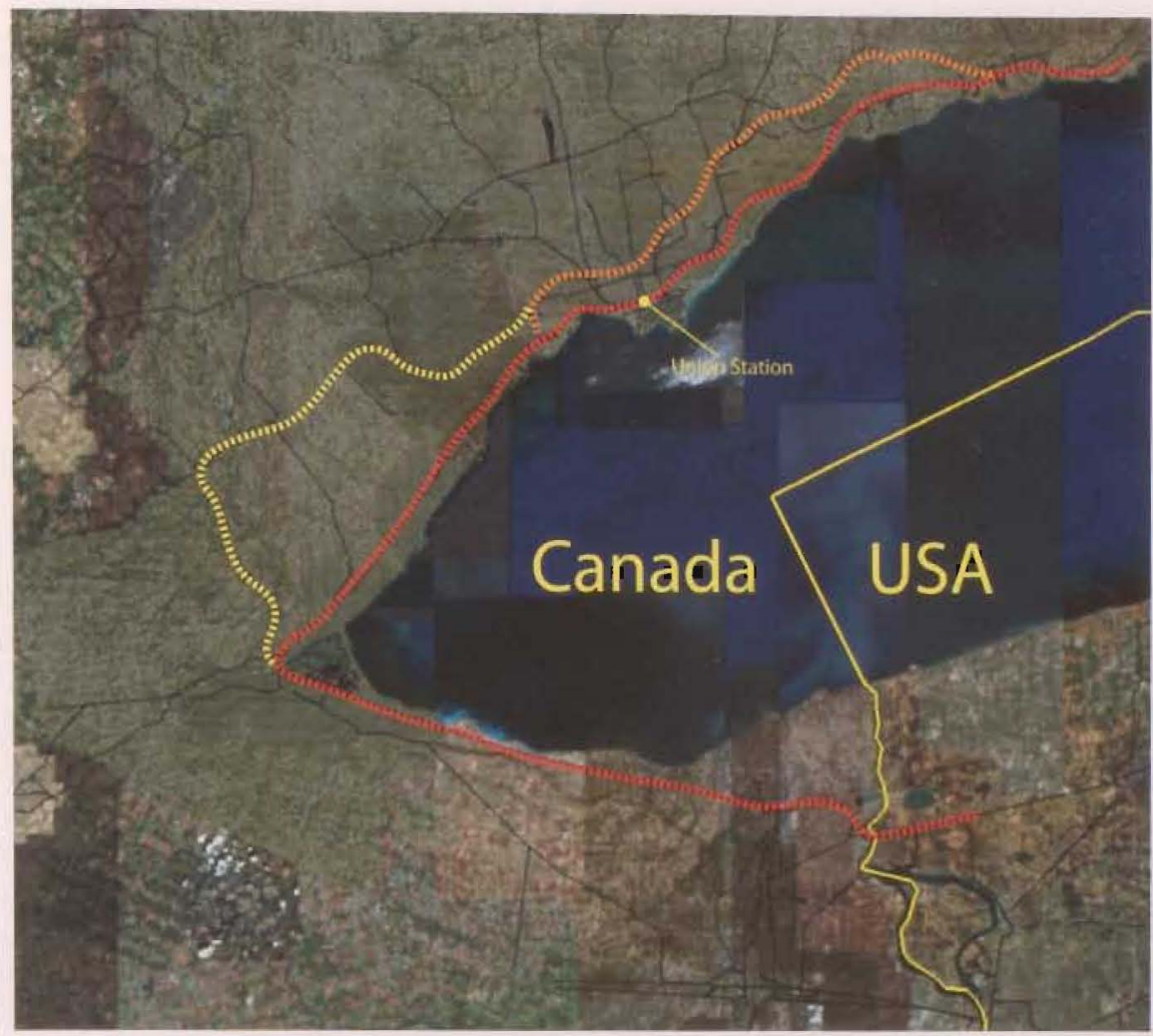

Figure 5.3.2 Red: Shortest route to the US Border. Orange \& Yellow dashed lines are the next shortest rail routes to the US Border

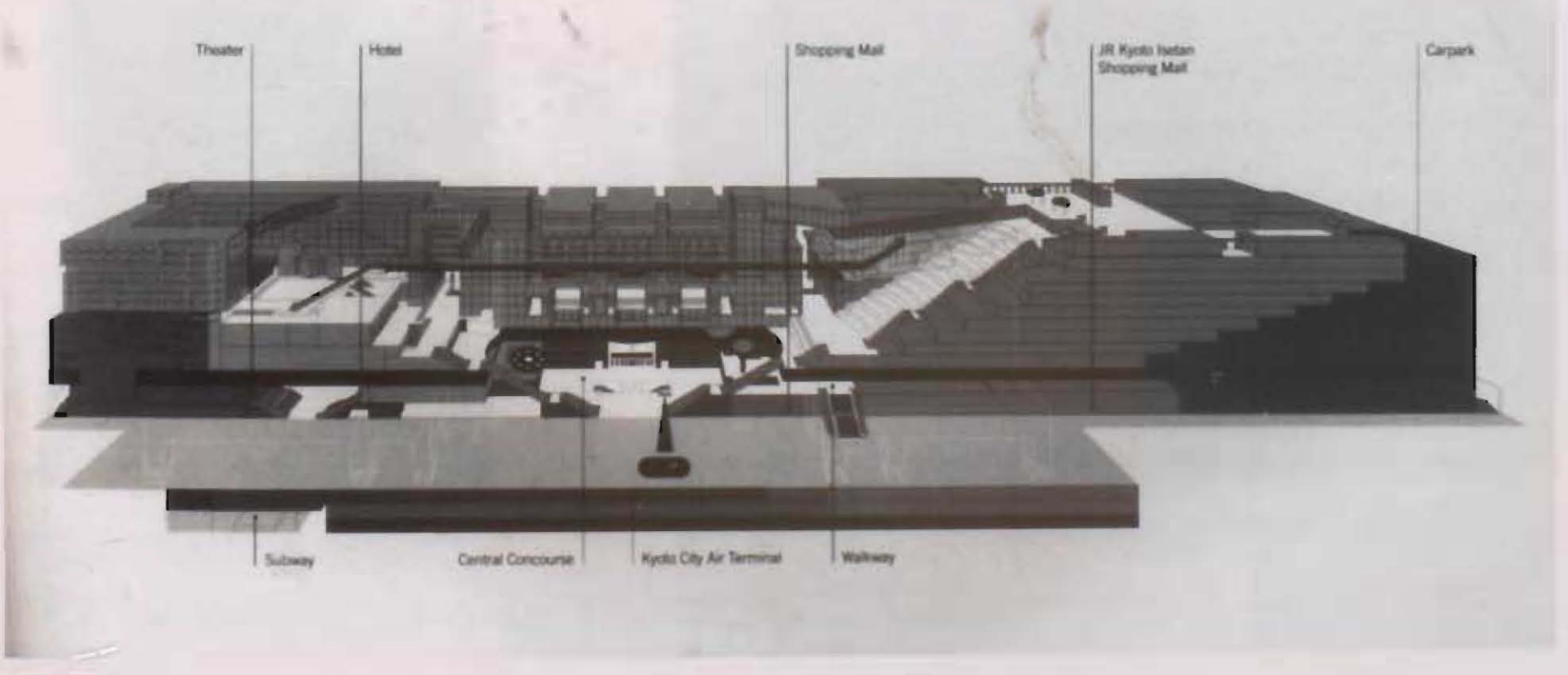

Figure 5.3.3. Kyoto Station, a multilevel complex with various amenities and services 


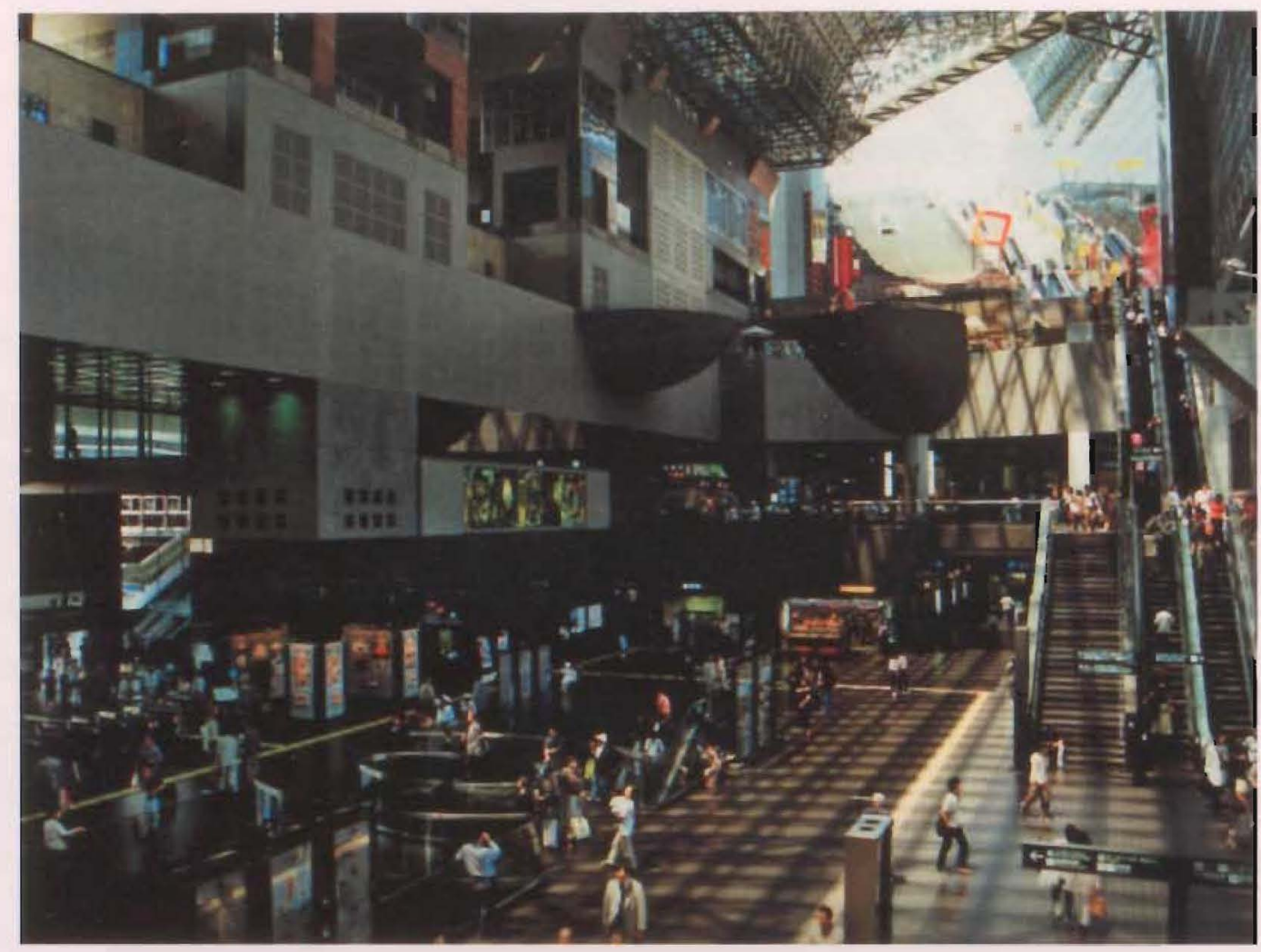

Figure 5.3.4 Kyoto Station central atrium space

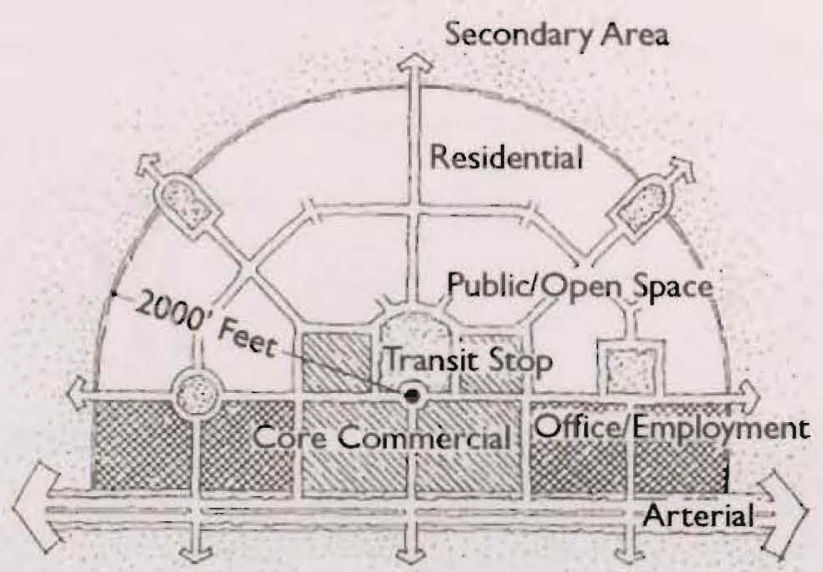

Basic TOD Diagram.

TOD's are mixed-use

districts within a comfortable

walking distance of a transit

stop and core commercial

area (about $2,000-$ feet). A

watkable environment makes

it attractive for residents,

visitors, and employees to

travel on foot to transit and

conveniences.

Figure 5.3.5 Calthorpe Associates Transit Orientated Diagram 


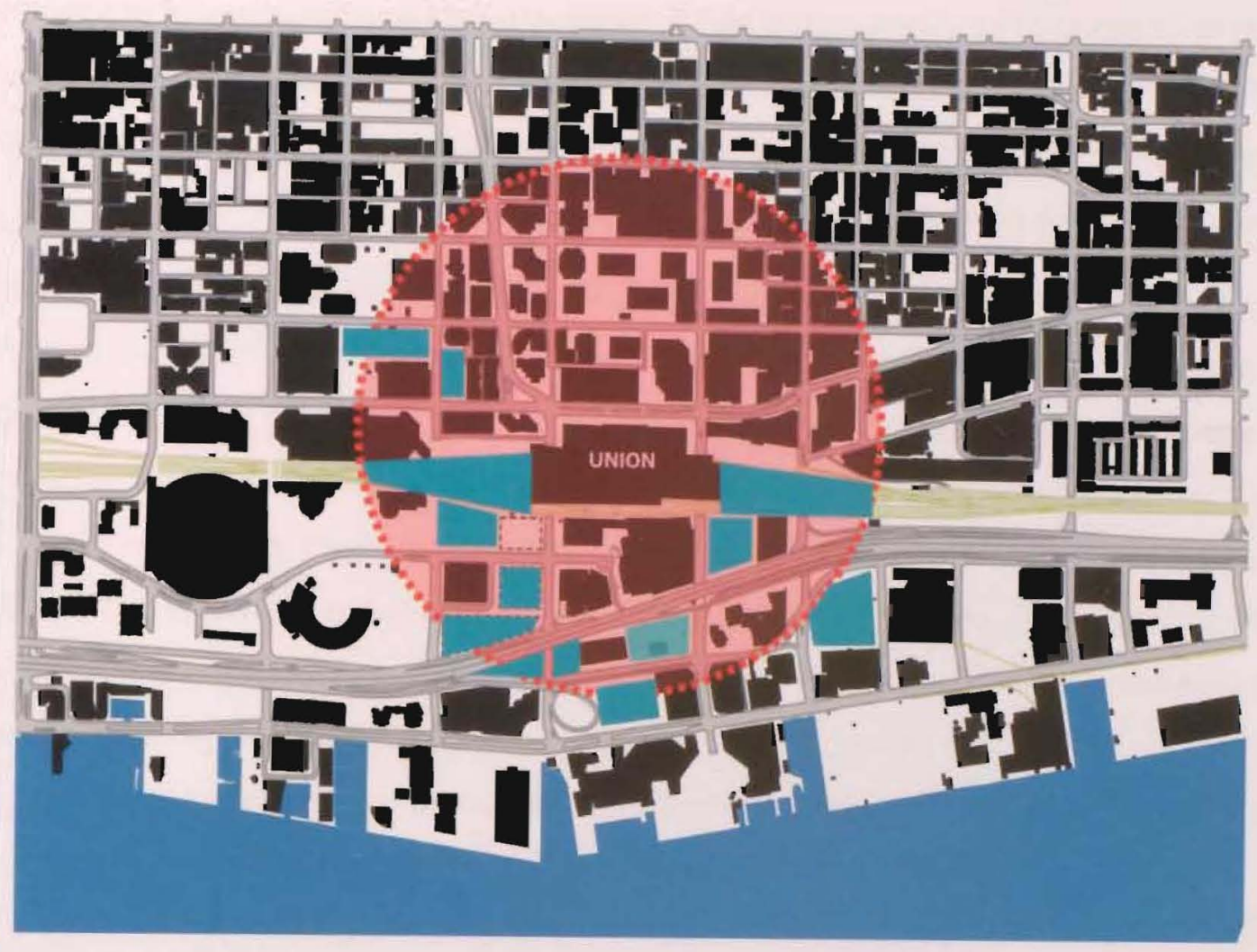

Figure 5.3.6 Available areas for development in a 500m radium of Union Station

\subsection{Not Important}

Bertonlini and Peek's definitions of place are similar concepts as they both define a station as having a significant civic duty for providing locations that are mixed use, highly attractive and more than just transit. Attractiveness and civic duty vary for different station conditions, but for a centrally placed station in a large city, attractiveness and civic duty must be at the highest level. Union Station is not only centrally placed in Canada's largest city, but it is also Canada's largest transit terminal. Unfortunately, Union Station is not treated with the importance that is required of a station with such regional and national importance. Even as development pops up around the station and attempts are made to define the area, the station still lacks a concept of 'place.' A proposal for Union Station needs to take into account all the factors that Bertonlini and Peek have outlined in order to truly represent both Toronto and Canada's most important transit terminal. The first steps for Union Station to become an urban exchange complex is to understand its potentials as an unbalanced place that requires an 
intensive re-ordering of its infrastructure and to develop a new functional mix of programming. These two factors can contribute to defining Union Station as a proper node with suitable transit services for smooth operation and conditions for transportation, work and play. But how would these factors shape a new Union Station? 


\subsection{Porous vs. Smooth}

Many aspects of the Union Station Master Plan and Union Station District Plan seek to recreate Union Station as a modern terminal by readapting many of the existing spaces. A component of the Union Station Master Plan is to define the place of Union Station by expanded connectiveness through increased porousness. What does it mean to be porous and how would this define a place? That master plan's definition of porousness is the maximization of connectiveness through "extended pedestrian connections" (Union Station District Plan, 2006, p. 33). The Collins Essential English Dictionary defines the root of porous as 'pore' or a 'passage' and to be porous is to have many pores or passages (Collins Language, n.d.). By combining the two definitions of porousness, we see the desire of the master plan involves increasing connections (passages) through the various existing spaces (pores) to create an unobstructed space (porous). Is increasing the porousness of Union Station going to generate a place and subsequently help it to become an ideal station?

Looking at the existing condition of the station, it becomes apparent the act of increasing porousness is not an effective way of connecting spaces. In fact, it is the route of degrading the condition of Union Station. When the construction of the TTC's Union Subway Station began in the 1950s, there was an obvious need to connect the subway station to the train station. To connect the two stations together, a tunnel was constructed in the northeast corner of the arrivals concourse (Fig. 6.0.1). For the first and most important connection to the subway line, Union Station did it in the least obvious manner possible, which was to only benefit the train passengers leaving from the station. People catching trains using the TTC would leave the subway, enter into the arrivals concourse and either make their way into the Great Hall or, if burdened with luggage, enter into the departure concourse before ascending into the Great Hall. The path of journey was in the opposite direction of the circulation principles on which the station was designed (Fig. 6.0.2).

When GO Transit converted the Post Office space for the new GO Concourse in 1978, there was a need to increase the porousness of the station yet again. The original subway connection was semi-convenient for GO Transit users who utilized the VIA Concourse, but when GO Transit facilities moved, a more convenient subway connection was created. The old connection was abandoned and a new connection was made directly through the Go Concourse, across the moats and down into the Union Subway concourse (Fig. 6.0.3). The old subway connection was not grand, but it protected users from the elements, while 
the new connection forces users into the weather-exposed moats before they enter the subway connection. GO Transit also realized in the 1970s that an ever-expanding ridership would require more access to platforms. Thus began a phase of constructing new platform connections. The new connections contributed to increasing the porousness of the station by creating new passages from existing spaces in the most invasive way. Like a termite, GO Transit passages are boring their way through the station, forming porous connections wherever they are needed. There are 37 passages in six parts of the station complex that provide no hierarchy or coherency for GO Transit facilities. Walking through the station, one is confronted by a dizzying array of GO Transit access stairs and secluded concourse spaces.

Go Transit has not been the only contributor to increasing the porousness of Union Station; increased porousness has been created by the Skywalk, PATH connections through the moats, ACC tunnel, teamways and soon the new south entrance. These passages have been created to make the station more porous to its surrounding context, with an emphasis on opening the station to the south. However, the means of making the station more porous seems to be nothing more than a brutish process of punching holes through an existing form. Has increasing the porousness benefited Union Station and the contextual area? The quick answer would be yes, the connections have provided the means to move large numbers of passengers through a station. But the means of connection have been done in the most functional and utilitarian ways possible. All these connections are removing the station's place in favour of direct, functional connections. The porous condition provides direct methods of unifying spaces and lacks an articulation of the threshold to signify the connection. Articulations of passages, such as the Loggia of Union Station, have been historically used to declare the passage through symbolism and form, announcing blatantly 'this is a passage.' As more and more unarticulated connections are made through the station, the more the station loses its place within the city and becomes a hollowed-out mass. If connectiveness is causing Union Station to lose its place, what could provide connections while reaffirming itself as a place? There is a growing trend of transportation terminals that are abandoning traditional spatial connections and beginning to use the shape of traffic flows to define a station's form. This is called smooth space. 

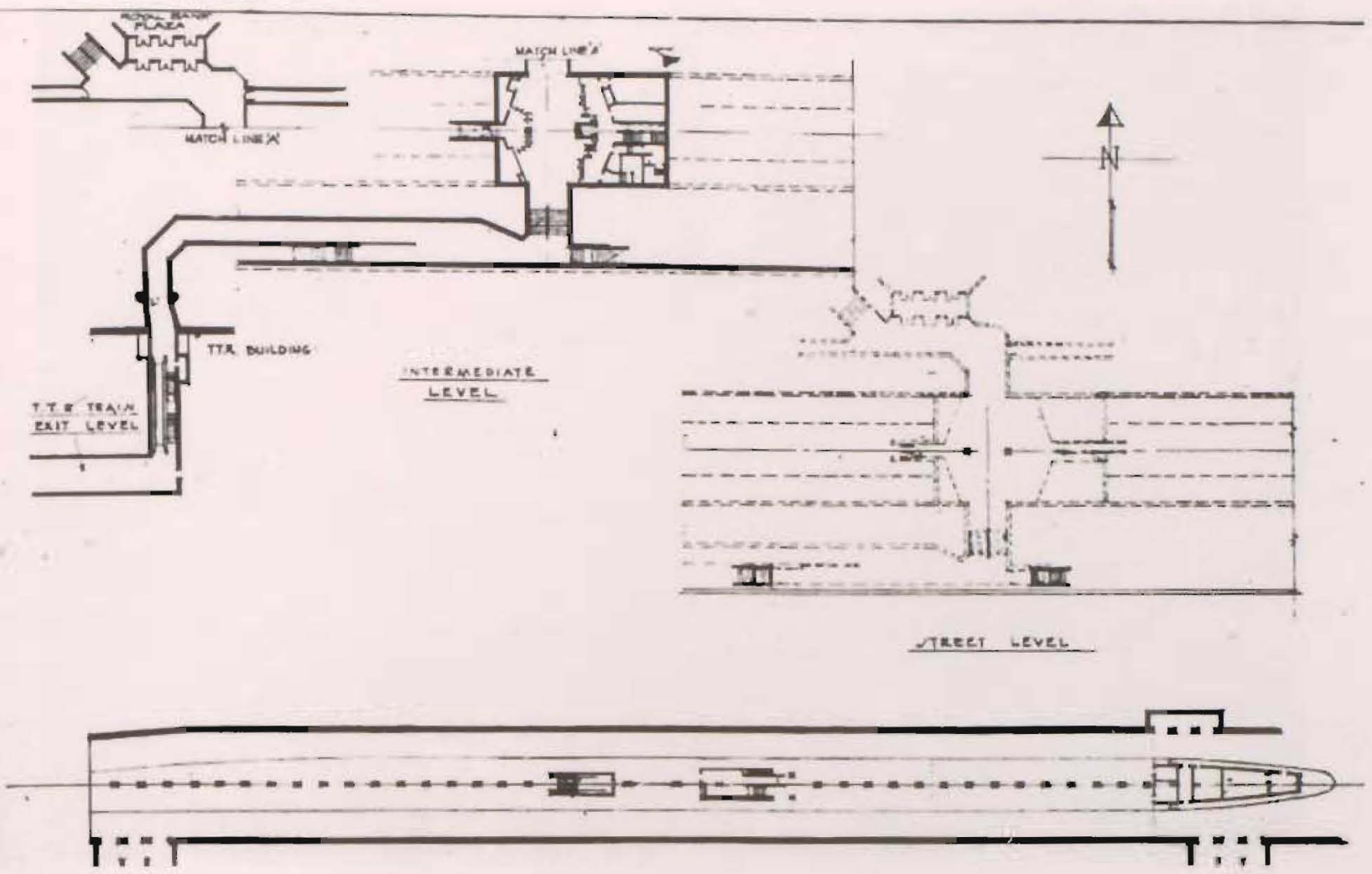

Figure 6.0.1 Original plans for the subway connection from Union Station to Union Subway Station

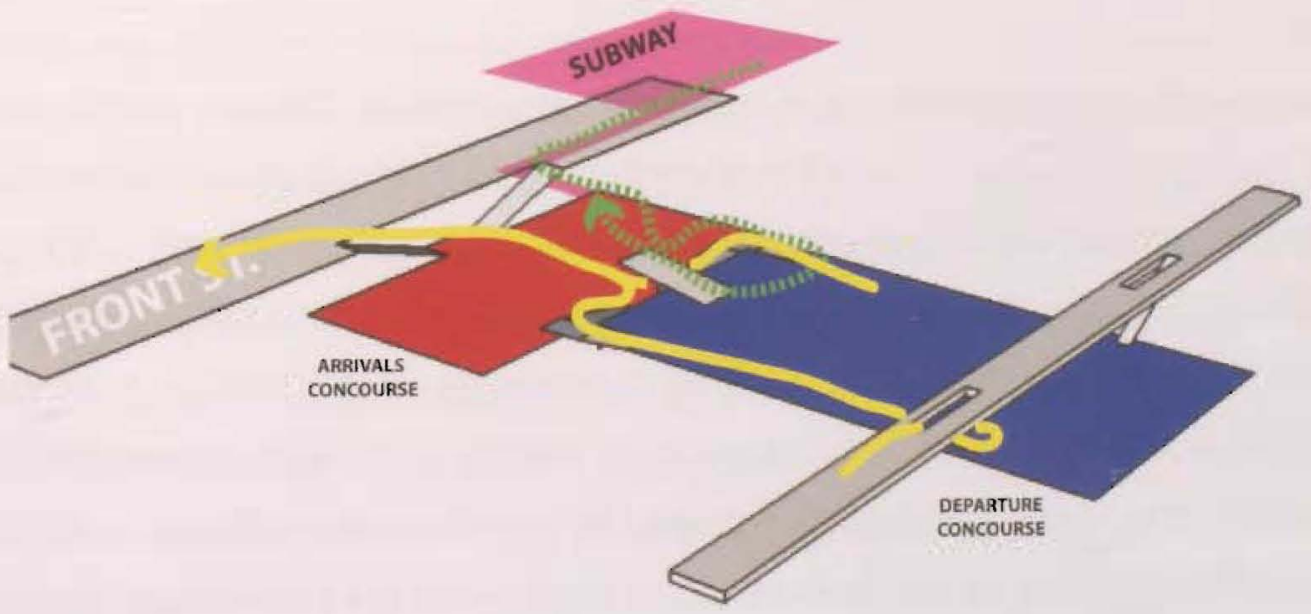

Figure 6.0.2 First Subway connection interrupted the original flow patterns of the station 


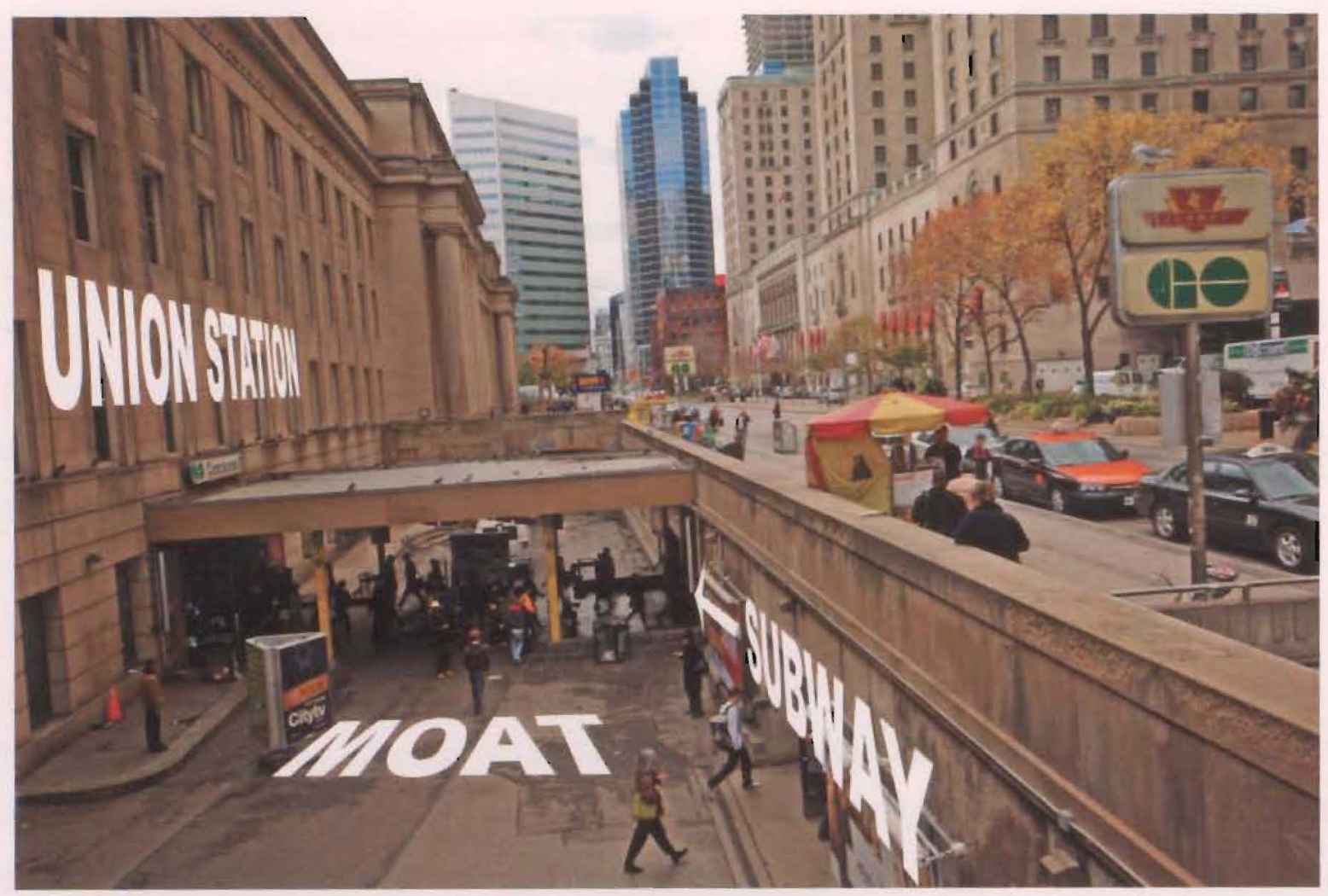

Figure 6.0.3 New Subway connection from GO Concourse-functional convenience.

\subsection{Striated vs. Smooth}

The meaning of 'smooth space' is commonly referenced by Deleuze and Guattari in their book Mille plateaux, v. 2 of Capitalisme et schizophrénie, where they differentiate two kinds of spaces, striated space and smooth space. Deleuze and Guattari view striated space as the realm of the sedentary, of the State, of gate and wall, of cultivated fields, where space is activated by formed and objectified things. Smooth space comes in opposition to striated space, where smooth space is the realm of the nomadic, of deserts, of ice fields, of steppes, where movements are trajectories and space is activated by events and intensities (Fig. 93) (Deleuze \& Guattari, 1987). Stickells, an architectural theory professor at the University of Sydney, has developed a narrowed theory of smooth space called 'Flow Urbanism' or 'Urbanism by Flow;' which relates directly to terminals (Dehaene \& de Cauter, 2008). While Landscape Urbanism postulates many theories of smooth space, the shear amount of varying theories from land formation to architecture does not provide a narrow enough understanding of smooth space as it is applied to transit terminals. Stickells' theory of Flow Urbanism (heterotopias of flow) 
narrows the meaning of smooth space to the typology of a transportation terminal, providing a understanding of smooth space to traffic flow. By understanding the potentials of smooth space, it can possibly provide new solutions for Union Station (Dehaene, et al., 2008).

Stickells uses FOA's Yokohama terminal and UN Studio's Arnhem Central Interchange to frame three concepts of Flow Urbanism: mobility, intensity and infrastructure. OMA's Souterrain Tram Tunnel in The Hague will be used to contrast Stickells three concepts of Flow Urbanism. FOA and UN Studio's projects will be discussed in Chapter 7.0. The Souterrain Tram Tunnel was apart of The Hague's initiative to increase the Dutch capital's density while minimizing car traffic on the street level. The project has gone on to win the 2005 Dutch Design Prize for Public Space and the 2007 Netherlands Building Award. The Hague initiative restricts road traffic to local cars and creates the 'parking road,' a loop of parking garages that are largely underground (Cecilia \& Levene, 2007, p. 46). OMA takes the concept of the parking road and creates a 1250-metre long, multi-storey subterranean 'tunnel-building' that utilizes infrastructural systems to formulate a space based on movements of people, automobiles and trams (Fig. 94) (Cecilia, et al., 2007). Using systems of movement as the means to define space falls into Stickells' first concept of Flow Urbanism, which was Mobility. The concept of mobility uses systems of movement through a 'non-representational structure' to create an architecture of 'indeterminate form' (Dehaene \& de Cauter, 2008, p. 248). Designed as subterranean structure, the Souterrain tunnel-building lacks the ability to be objectified, relying completely on the internal programming to delineate space. By using the tunnel walls as structural support, the Souterrain tunnelbuilding is free from a structural grid and is almost completely free of vertical barriers (Fig. 95). Mobility is not about creating a objectified point of entry, it is about creating an 'experiential' moment 'to the point at which the subject feels the sense of propulsion' (Cecilia, et al., 2007, p. 250). Stickells formulates the experiential idea by the ability of users to navigate freely and not be encumbered by physical and visual barriers. By not using a structural grid, OMA was able to reveal the different layers of Souterrain and permit users to identify programmed spaces from afar. Souterrain achieves spatial clarity by using glazed partition walls and weaving together various modes of movement, allowing a user to perceive at a single moment the tram line, pedestrian routes, parking garage and outdoors (Fig. 96). Unfortunately, Stickells does not elaborate greatly on the ability to perceive multiple spaces at once, which in my opinion is a very important feature of buildings that exhibit Flow Urbanism. It is much more convenient to see your destination without the use of signage or maps. Union Station lacks exactly this clarity, therefore causing a confusing array of passages and exits. 
Stickells' second concept of Flow Urbanism, intensity reconsiders fixed, determined use with intensity and flexibility of use. Using Deleuze and Guattari's analogy, programs on smooth space become an event (intensity) where the event has a ternporal value (flexibility) (Deleuze \& Guattari, 1987). A key factor of smooth space is the ability of a program to change over time and not change the integrity of the space. Like the nomadic event, programmed functions are typically objects on smooth space, which can move, disappear and reappear as desired. Stickells realizes that when programming is treated as an event, "the impact of the formal strategies and spatial dynamics [of smooth space] remains ambivalent: much depends on the process of programming and ... continual reordering," of program (Dehaene $\&$ de Cauter, 2008, p. 251). OMA's Souterrain may not appear to have a flexible program, but this is not to say it cannot or does not have flexible programming. OMA has enhanced the experience of moving through a connector by installing a poster museum along the walls and Chinaware displays in glass-topped floor wells (Fig. 97). Incorporating the display of art into the space creates the ambivalent nature of smooth space that Stickells was remarking about. At one moment the Souterrain can be a gallery; at the next moment when the tram arrives, it's a terminal. This sort of juxtaposition by flexible programming allows smooth space to take on different characteristics over time.

Flow Urbanism's third concept, infrastructure reconsiders architecture's formal attributes with the 'possibility of an architecture of weak form - dissolved into infrastructure.' Stickells formulates that flow urbanism develops "architecture as public infrastructural construction rather than symbolic, figurative object." Therefore, architecture of flow urbanism cannot be removed from infrastructure because the articulation is "rooted in the flow of program and movement patterns" (Dehaene \& de Cauter, 2008, p. 252). Unlike Brentwood Station by Busby \& Associates in Vancouver, B.C., where the station exists as an object, OMA's Souterrain tunnel-building cannot remove itself from its infrastructure because the architecture has become one with the infrastructure (Fig. 98). Stickells becomes critical of Flow Urbanism in that "without a critical approach to programming itself, Flow Urbanism would seem to be less a means of supporting heterogeneity than of normalizing the potential of the interstitial" (Dehaene, et al., 2008, p. 253). This criticism is hard to apply to the Souterrain tunnel-building where the sitespecific programming influenced the spatial layout and is difficult to replicate somewhere else. To merely state that the Souterrain tunnel-building is a homogenous space is, in my opinion, to ignore all the infrastructural systems that give rise to a heterogeneous complex. As architecture is dissolved into infrastructure, it develops program relations to those systems that cannot be 
divorced.

Stickells elaborates by stating that these three concepts of smooth space for terminals can provide an "alternate spatial ordering for urban places based on qualities of fluidity, changing programmatic intensity, rhythms of use and their aesthetic possibilities." He goes on to say that "heterotopian spaces ... become tools for imagining other modes of public occupation and encounter" (Dehaene \& de Cauter, 2008, p. 255). It is this elaboration that connects with Bertonlini's idea of the urban exchange complex where Stickells' theory can provide the complex's spatial ordering for a new form of 'public occupation and encounter.' Flow Urbanism can provide the potential for Union Station to redevelop into a public space based on traffic to benefit not only the station's functional use, but to provide connections to other parts of the city. The ability to have changing 'programmatic intensity' that responds to demands can help to reduce Union Station's present inflexible condition. The new Union Station can be created as an urban exchange complex based on movements and not the present condition where porousness has eroded the station's meaning. As mentioned earlier, Union Station and the surrounding area can become a place of transition from downtown to the waterfront, and the indeterminate nature of smooth space can achieve this without struggling to create the station area as a separate entity from the city. To realize the formal potentials for Union Station, case studies that present various aspects of smooth space design need to be analyzed.

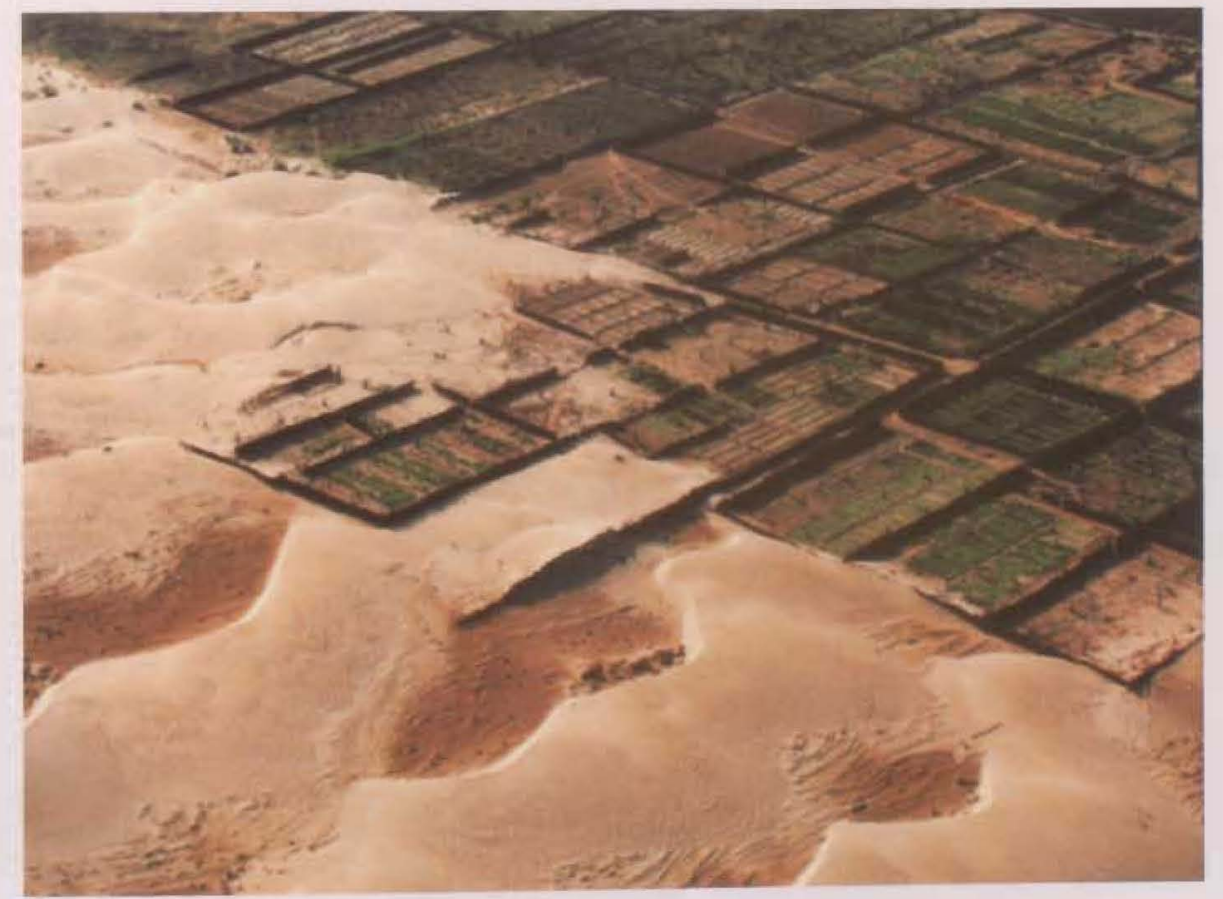

Figure 6.1.1 Smooth Space of the Desert Meeting the Striated Space of the cultivated field. 


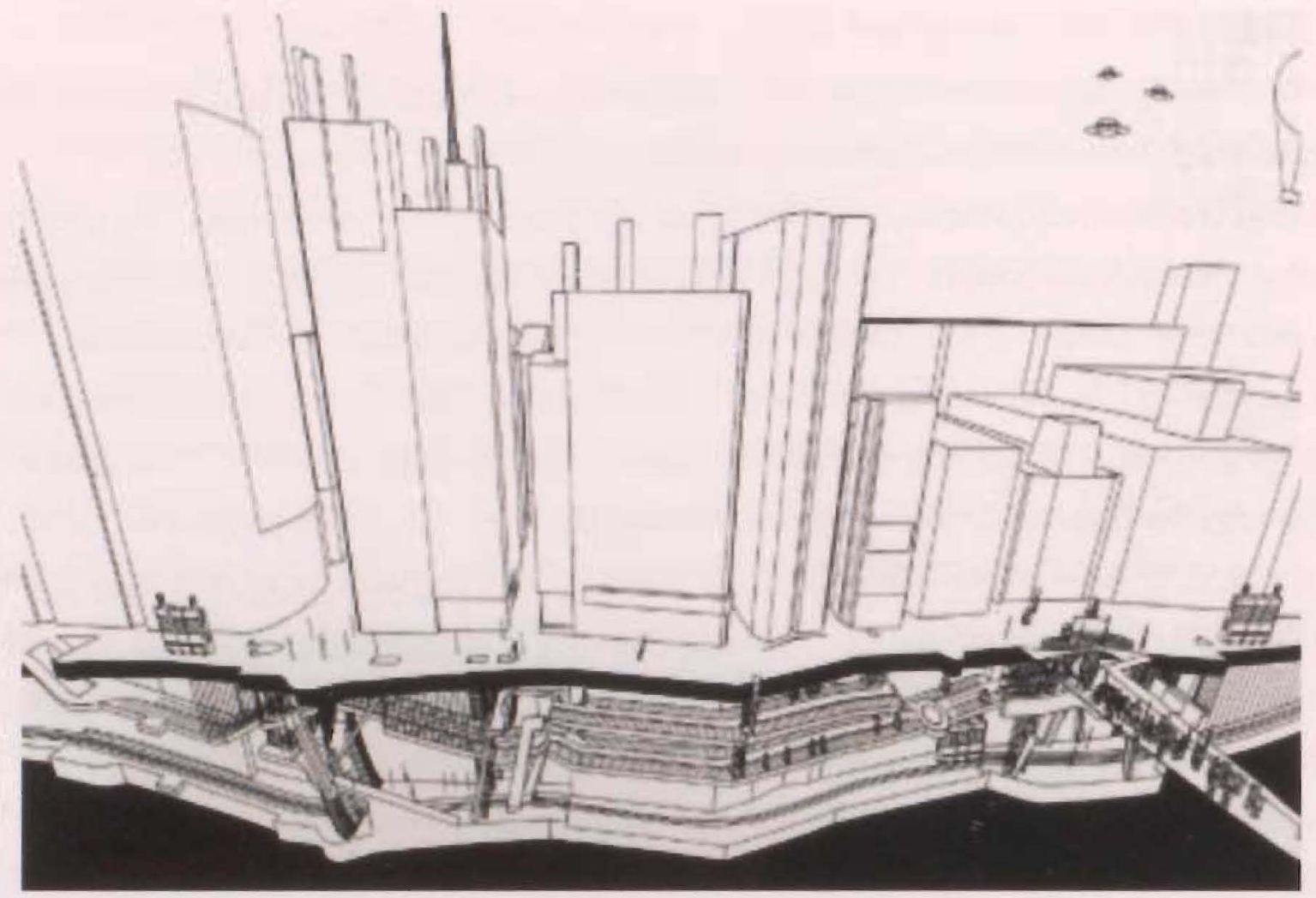

Figure 6.1.2 Sectional Perspective of OMA's Souterain Tunnel-Building

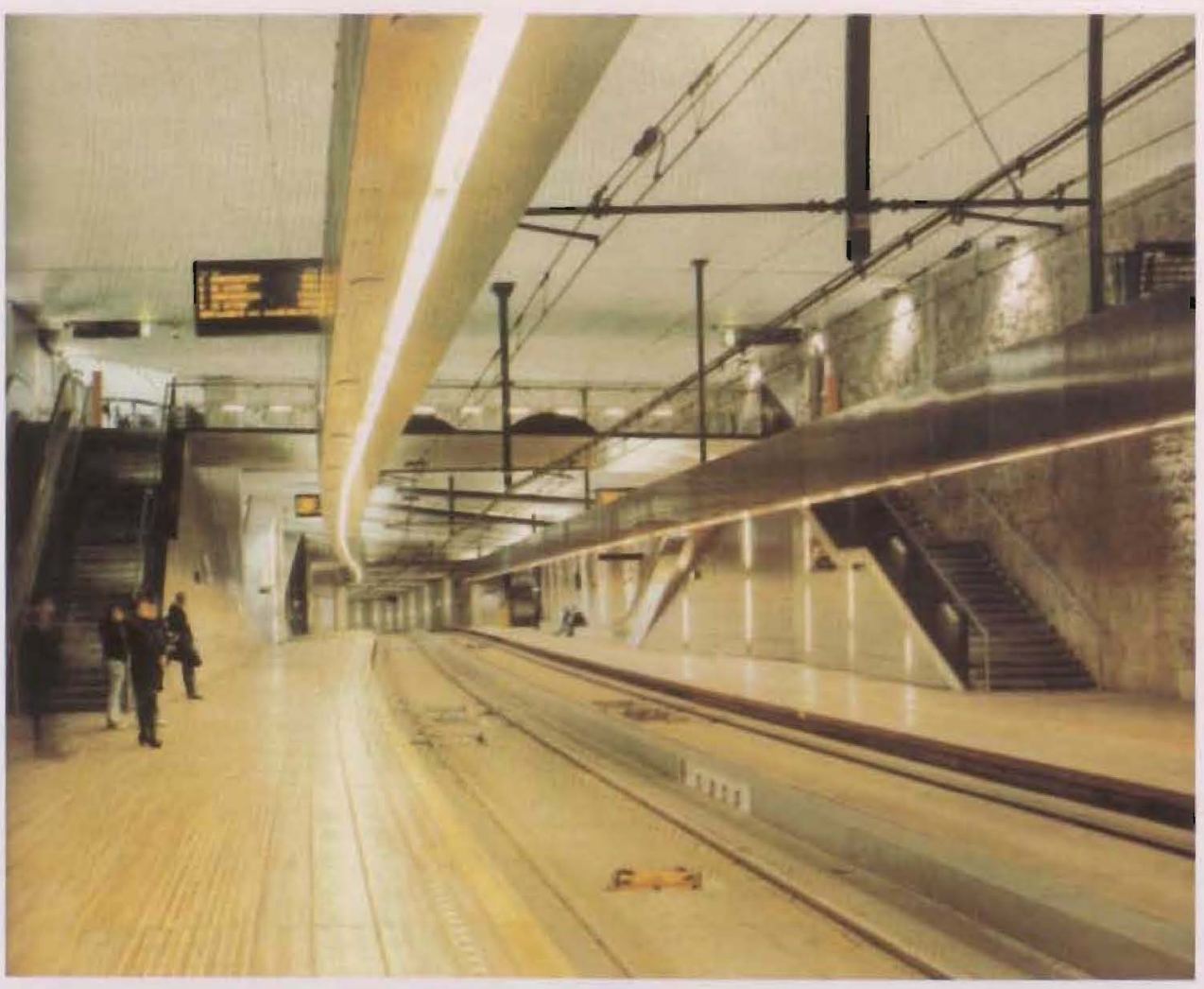

Figure 6.1.3 OMA's Souterrain-Clear Span space 


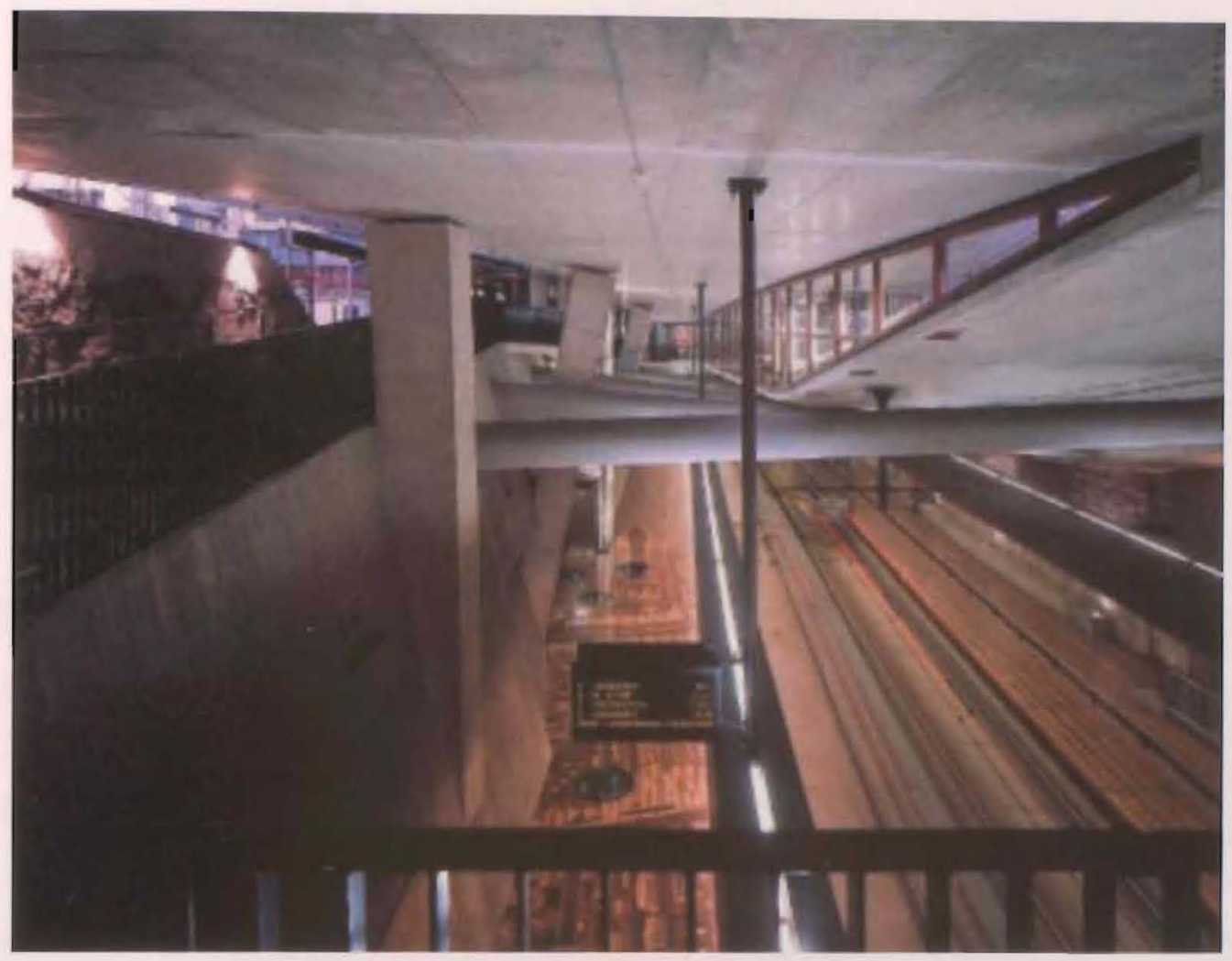

Figure 6.1.4 OMA's Souterrain - in the instance the exterior street, parking garage and Tram platforms

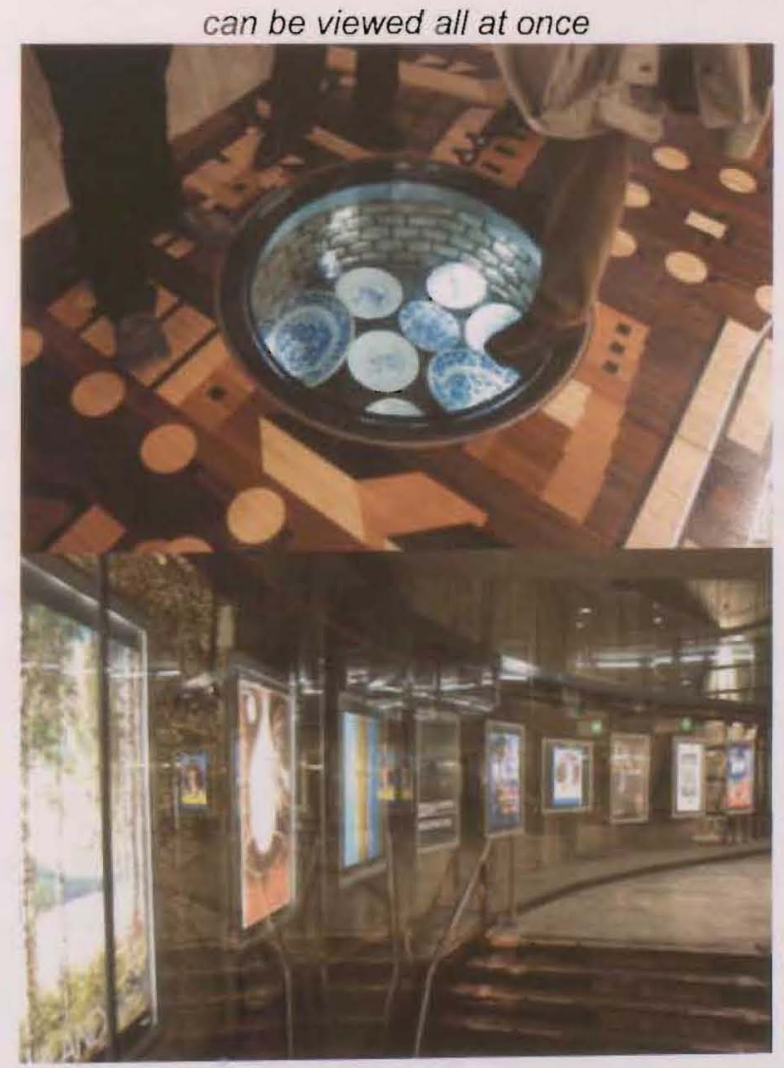

Figure 6.1.5 OMA's Souterrain - Glass topped floor display cases and Poster Museum wall displays. 

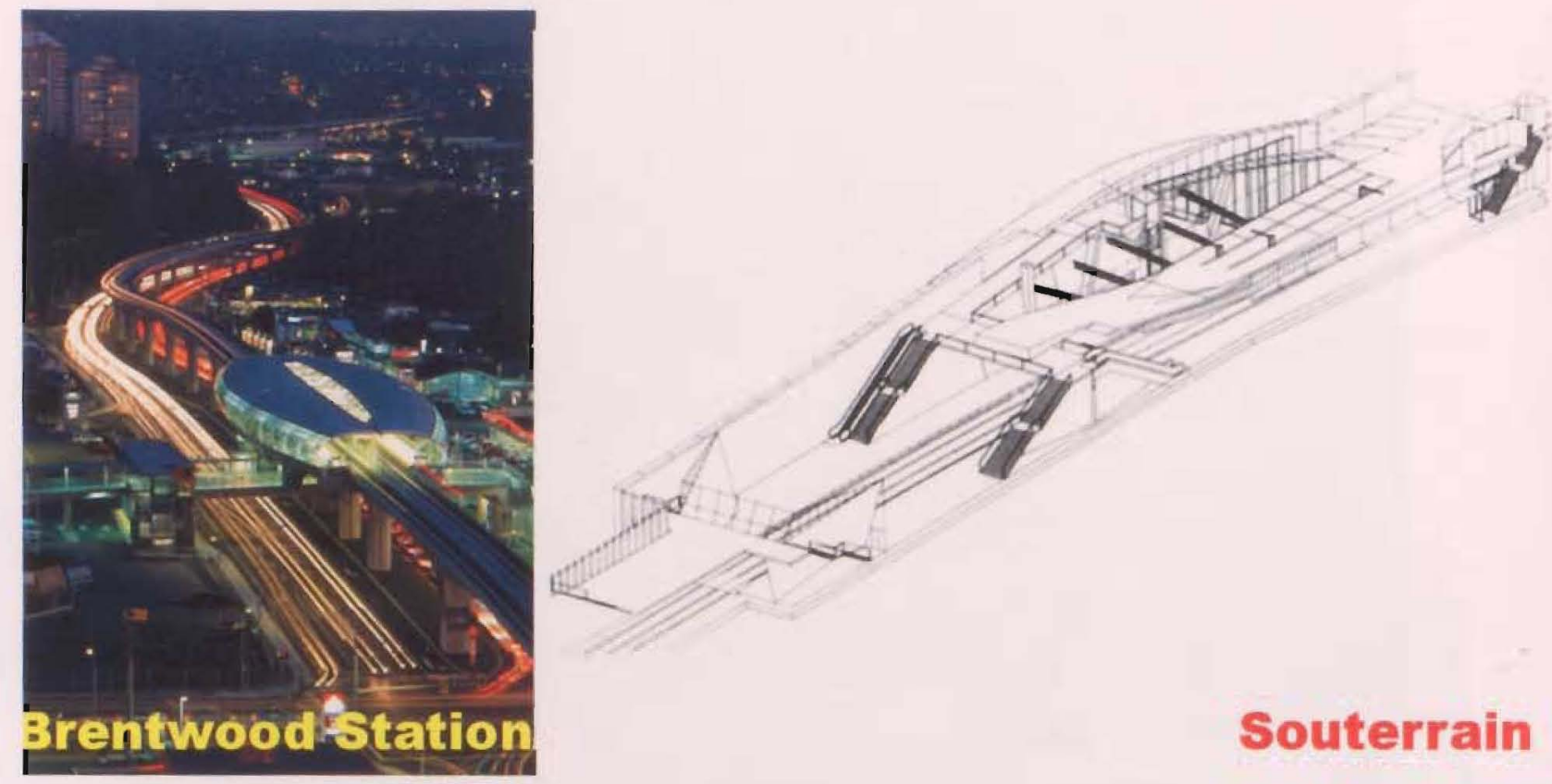

Figure 6.1.6 Brentwood Station (floating station) vs. Souterrain (design is infrastructure). 


\subsection{Case Studies}

The following case studies analyse two contemporary transit terminals that were designed using flow urbanism, as documented by Stickells, and are followed by two examples of public spaces that interact with infrastructure. The first two case studies look at the formulation and properties of smooth space terminals, contrasted against Union Station, to gain an understanding of the station's deficiencies and the benefits of smooth space design. These case studies focus on traffic flows, structural layout, material choice and integration of public space throughout the design. The terminals include Yokohama's International Port Terminal by Foreign Office Architects (FOA) and Arnhem Central Interchange by UN Studio. The remaining two projects are examples of public park spaces that connect fragmented city spaces while interacting with infrastructural systems. The first example, Stuttgart's new Underground Terminal by Ingenhoven Overdiek \& Partners, merges a green roof with the city's castle garden system, blending the old terminal with public space. The second example, Weiss/Manfredi's Olympic Sculptural Park in Seattle, Washington, is a park intervention that stitches Seattle's urban fabric over infrastructural barriers to connect with the waterfront. All of the case studies are meant to show the potentials of public spaces for blending and merging infrastructural systems to form a public landscape.

\subsection{Warped Lasagna - Yokohama International Port Terminal}

Yokohama International Port Terminal by Foreign Office Architects (FOA) is considered by many to be the clearest example of architecture as smooth space. The port terminal design was chosen from a 1995 competition won by FOA for a new gateway on Yokohama's Osanbashi Pier (Fig. 7.1.1). FOA's concept for the terminal was to create the "possibility of generating organization from a circulation pattern [where] ... circulation can literally shape space" (Kubo, Sakamoto \& Ferre, 2002, p. 11). Realizing that traditional transportation buildings work as 'inputoutput' devices, FOA became more "interested in exploring the possibility of a transportation infrastructure that could operate less as a gate, as a limit, and more as a field of movements with no structure orientation." The circulation pattern for the terminal was created through FOA's 'no-return diagram, ' creating a "structure of interlaced loops that allow multiple return paths" (Kubo et al., 2002, p. 11). Using the no-return diagram as an organizer freed people to move around the terminal in multiple self-intersecting trajectories without ever encountering a 
permanent barrier condition (Fig. 7.1.2).

Unlike FOA's terminal, Union Station was designed rigidly as an input-output device with separate departure and arrival paths. The division of flows functioned smoothly until the station began to alter its role from a passenger station to an ever-evolving multi-modal hub. To respond to the growing need of increased connections, Union Station has become more porous by puncturing the existing form. Becoming more porous has allowed users to choose their own trajectories through the station; in this way, it is similar to FOA's. Unfortunately, Union Station cannot truly achieve what FOA has done because the rigid design of Union Station does not provide an easy translation of free movement. New circulation systems imposed on Union Station have disrupted the existing programs that have been rigidly laid out along circulation paths. FOA avoided disrupting program by not integrating programmed elements into the structure; elements were left as free-moving, adaptable elements that can meet the needs of changing circulation patterns. An example of a free-moving element is the Custom Booths, which are mobile checkpoints, able to freely change the internal programming and circulation of the terminal. The flexibility of changing program and circulation is far more advantageous than Union Station's porous model that only allows users to choose a destination in a rigidly programmed environment.

FOA sought to avoid the objectification of the terminal and proposed to create a very flat building that turned 'the building into a ground,' avoiding the terminal from becoming an object statement. As a result of avoiding objectification, FOA maximized the useable site area and developed the building as a ground by layering a three-dimensional version of the noreturn diagram, which resembles "a kind of lasagna of warped surfaces" (Fig. 7.1.3) (Kubo \& Ferre, 2004, p. 230). The warped surfaces create a space that fluctuates in size and shape to guide and modulate the flows of people. Rigid programming was avoided as much as possible, giving spaces the ability to take on different functions for various occasions. The main internal space can be adapted for various functions such as baggage check-in and checkout, customs processing, waiting area, greeting space and an area for entertainment venues, Fig. 7.1.4 Comparably, Union Station does not provide any means of adaptable spaces other than removing permanent program and replacing it with another (Kubo et al., 2002). The Great Hall is the closest space at Union Station that provides a flexible environment, but only because of its shear size but because its various programs allowed to function. Large spaces such as the Great Hall are defined by FOA as classical modes of program flexibly by "conventional programmatic distribution [that] is fundamentally related to an extensive use of space and time: 
programs are allocated in particular extension of space and time with well-defined limits" (Kubo et al., 2002, p. 17).

FOA wanted to create a structure "literally out of the circulatory diagram" and not default on to classical modes of structure, like the column "deployed on the [circulatory] diagram a posteriori" (Kubo et al., 2002, p. 13). The main ramps of the terminal became main structural members, integrating circulation directly to the formation of structure (Fig. 7.1.5). Steel sheets resembling the cross-section of cardboard formed the warped and bifurcated surfaces, while folded steel sheets resembling origami formed long-span vaulted spaces. As structural systems changed in relation to the demands of the circulation diagram, "loads could flow in unison with the architectural form" (Kubo et al., 2002, p. 105). While Union Station's stone structural elements appear to form a Beaux Arts compilation, the elements in reality are mostly symbolic and provide no internal structural support. The structure is made out of steel and concrete and clad with stone elements (Carr, 2005). This is not an inherently bad structural system: it serves the design purpose of symbolizing rail infrastructure, but it is highly counter-productive for alterations and adaptations. The designers of Union Station did not foresee change to occur to the station and rigidly locked structure and program together. Since becoming a National Historic Site and protected under a Heritage Easement Agreement, the station cannot be structurally adapted, freezing the current form (Toronto, 2007). Yokohama terminal structurally cannot be altered, but because the programming acts independently from the structural layout, the terminal does not share the same limitations as Union Station.

An important feature of FOA's Yokohama terminal and other 'smooth space' designs is the avoidance of vertical elements such as walls and partitions. Vertical elements would break the continuity of smooth space and limit the continuous navigable surface. Spaces become ambiguous without vertical elements to divide and capsulate the environment, connecting spaces together without thresholds (Dehaene \& de Cauter, 2008). Where a 'lateral enclosure' is required in the Yokohama terminal, glazing is utilized so as not to interrupt the continuity of the surfaces (Kubo \& Ferre, 2004, p. 234). Where heights would require millions in glazing, FOA corrugated the glazing to provide the structural stability (Fig. 7.1.6). Using few vertical elements not only retains the continuity of the space but also gives users the ability to navigate the space by seeing the destination. Union Station relies completely on formalistic expression and signage to allow a user to navigate the station. While the main building's formalistic expressions provide an unsubtle means of navigation, the GO Concourses and much of the VIA Rail concourse rely completely on signage (Fig. 7.1.7). The thick, rigid vertical elements of Union Station impede 
users from perceiving where particular destinations are and to gain an overall understanding of the layout of the station.

One would suspect that with a minimalist material pallet the Yokohama terminal would suffer aesthetically from undifferentiated spaces that are commonly seem in airport terminals (Stringer \& Barber, 1999, p. 88). FOA avoided stagnant aesthetics by defining the ground surface with only wooden planks and grass, while the ceiling surfaces express the structural system. As one travels through the terminal, different structural demands augment the ceiling condition providing an ever-changing visual experience. The ground surfaces use wooden planks that conform to the warping surface demands of the terminal. As a result of the warped surfaces, the wooden planks provide way-finding for users, offer a rich visual experience and create a non-differentiated surface (Fig. 7.1.8). Stickells views that FOA "repositioned the city's spaces of flow as key contemporary public spaces, superseding the static, representational space of the town square" (Dehaene \& de Cauter, 2008, p. 248). The terminal does not use thresholds to state what is or what is not a public space, allowing the terminal to shed static representation of public spaces. While the top of the terminal functions as a dedicated public space, the bifurcated nature of the structure weaves the top surfaces with internal surfaces, blending public space throughout the terminal. Stickells understands the Yokohama terminal as "an aspiration of the flexible occupation of public space," changing its use from being dependant on the program to a use of the space (Dehaene et al., 2008, p. 251).

Yokohama terminal produces a form of public space that urges the user to explore the changing landscape of the building. On the contrary, Union Station isolates public spaces as static, classical representations. Stickelis elaborates, citing Paul Virilio's theories, on the fact that public spaces today need to match the "increasing sensorial sophistication" of users by the rise of technologies (Dehaene et al., 2008, p. 253). Yokohama terminal has increased the sensorial sophistication by merging public space with the form and flow of the terminal - not as a gimmick; but as a method to meet the sophistication of present-day users. 


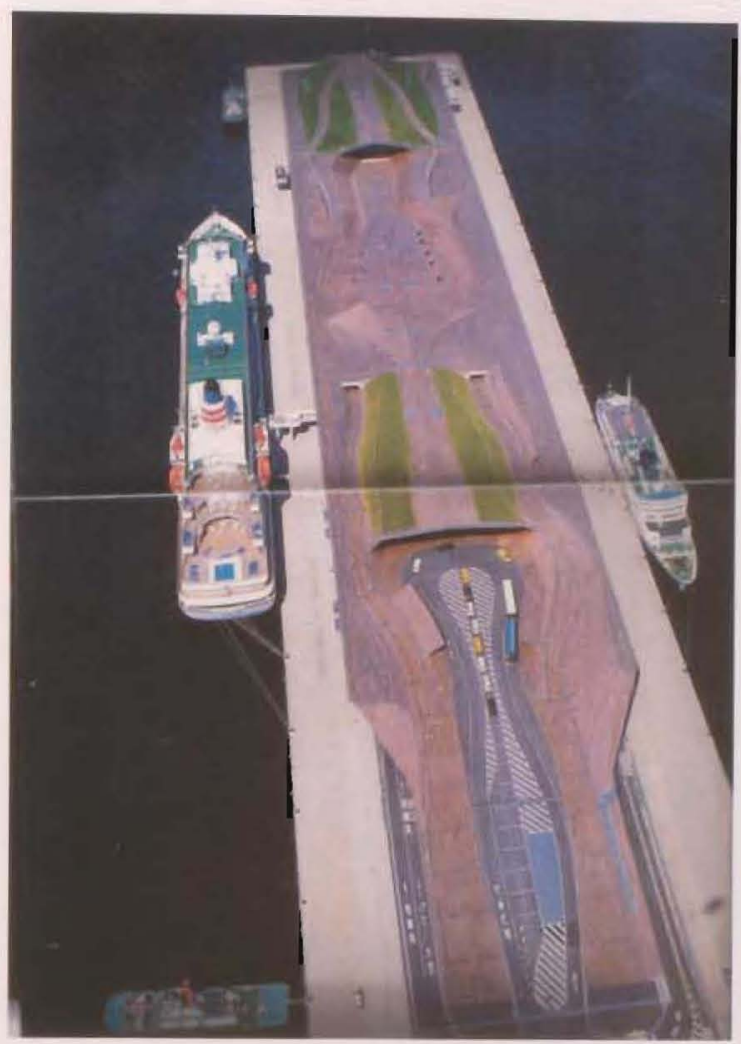

Figure 7.1.1 Yokohama International Port Terminal

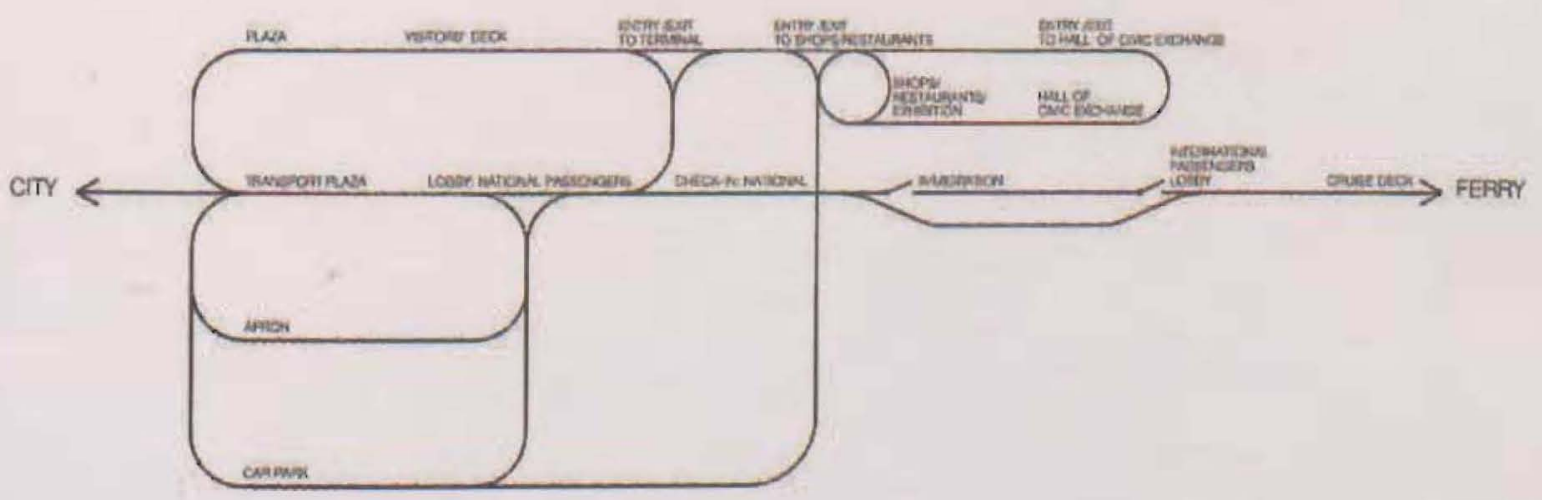

Figure 7.1.2 No-Return Diagram-interlaced loops 


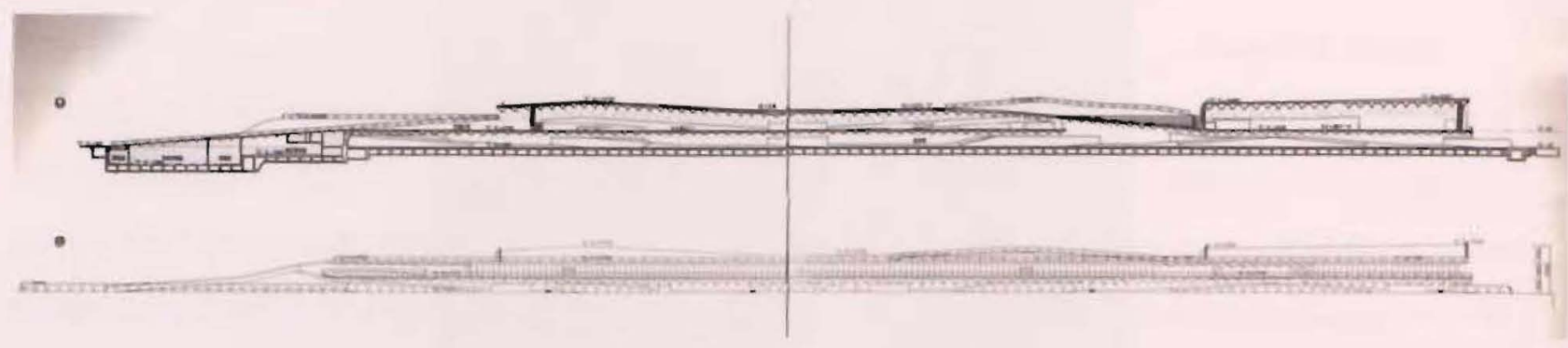

Figure 7.1.3 Longitudinal Section and Plan - lasagna effect.

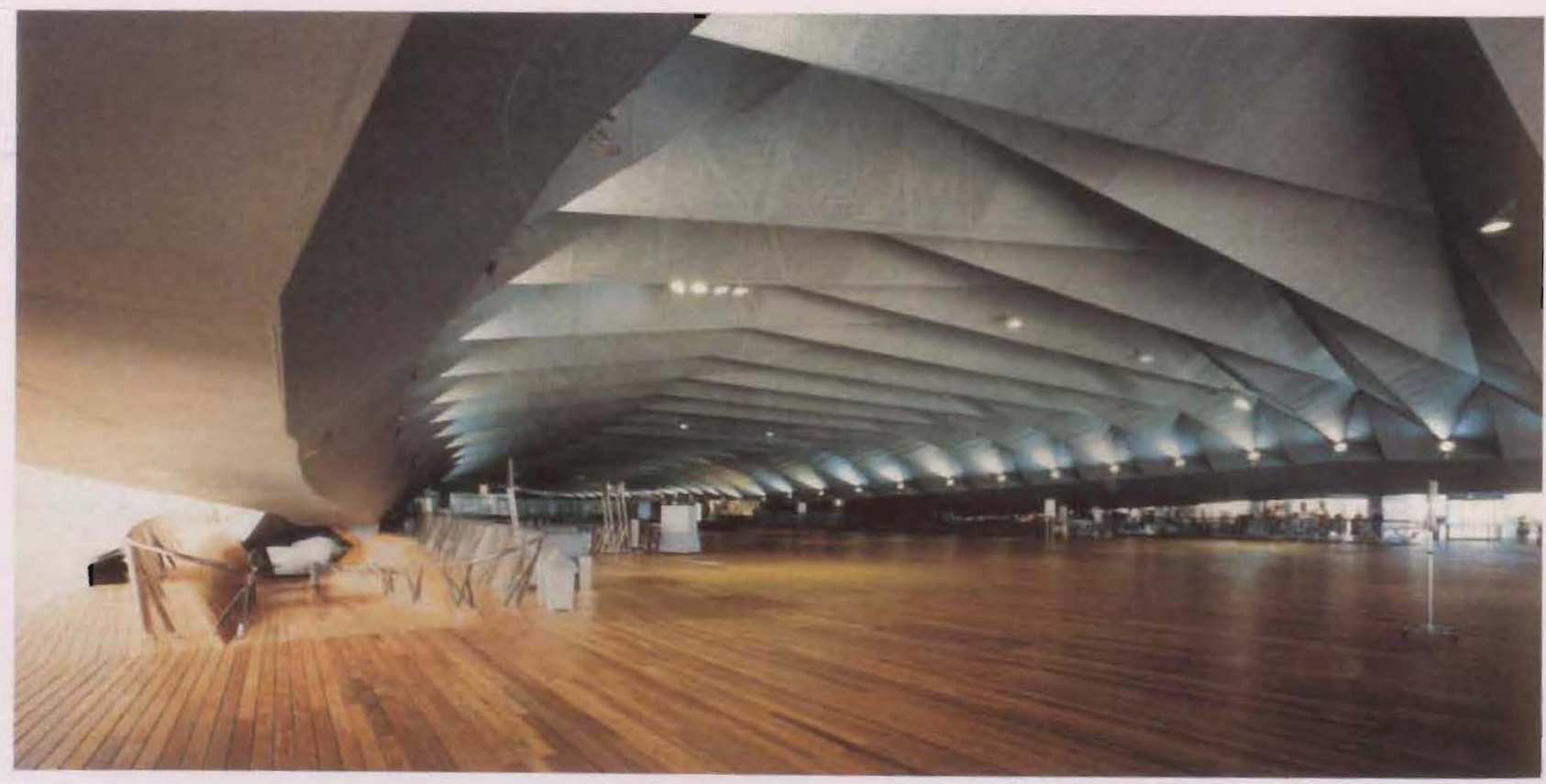

Figure 7.1.4 Interior of the main gathering space. 


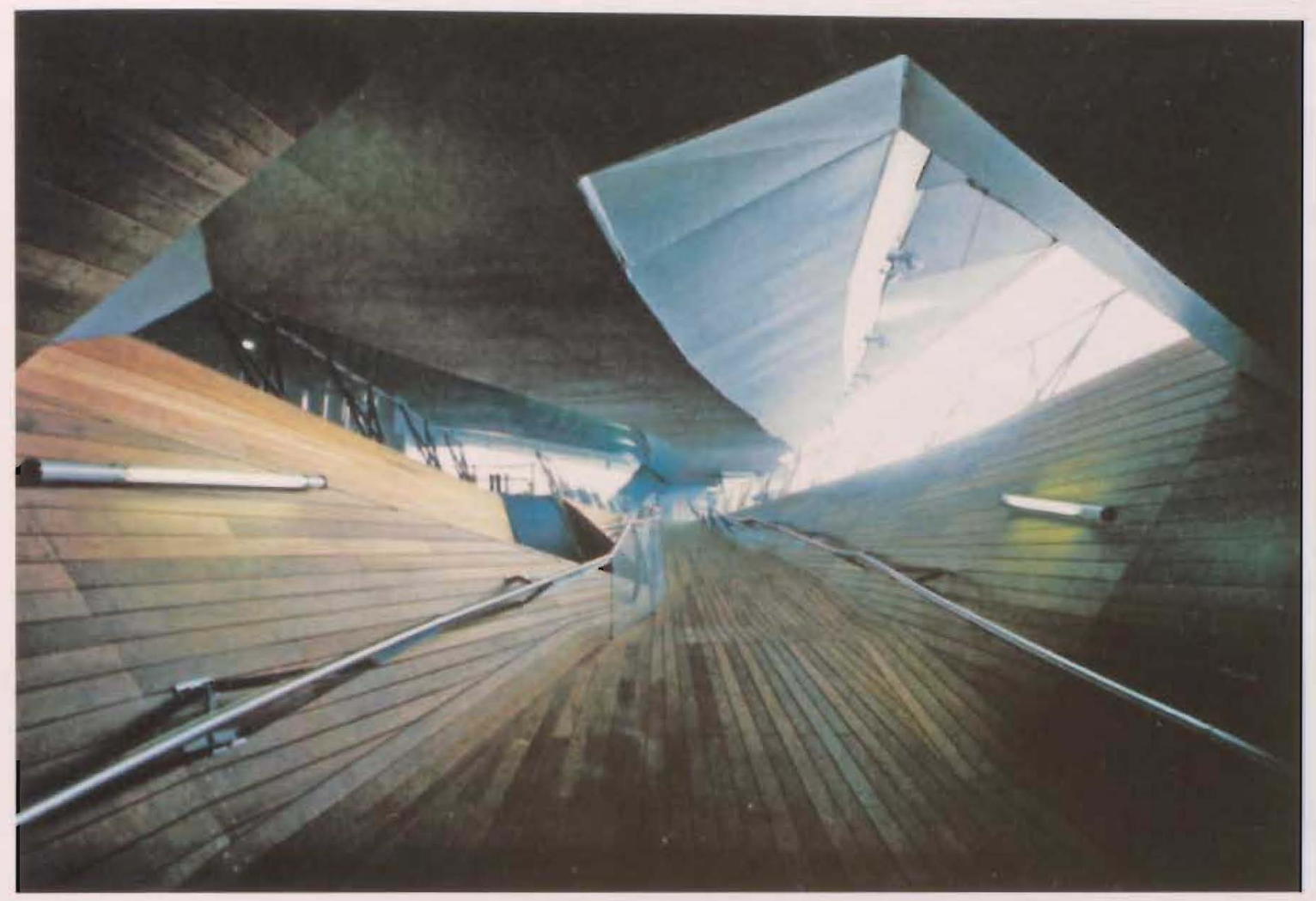

Figure 7.1.5 Circulation influencing structural layout

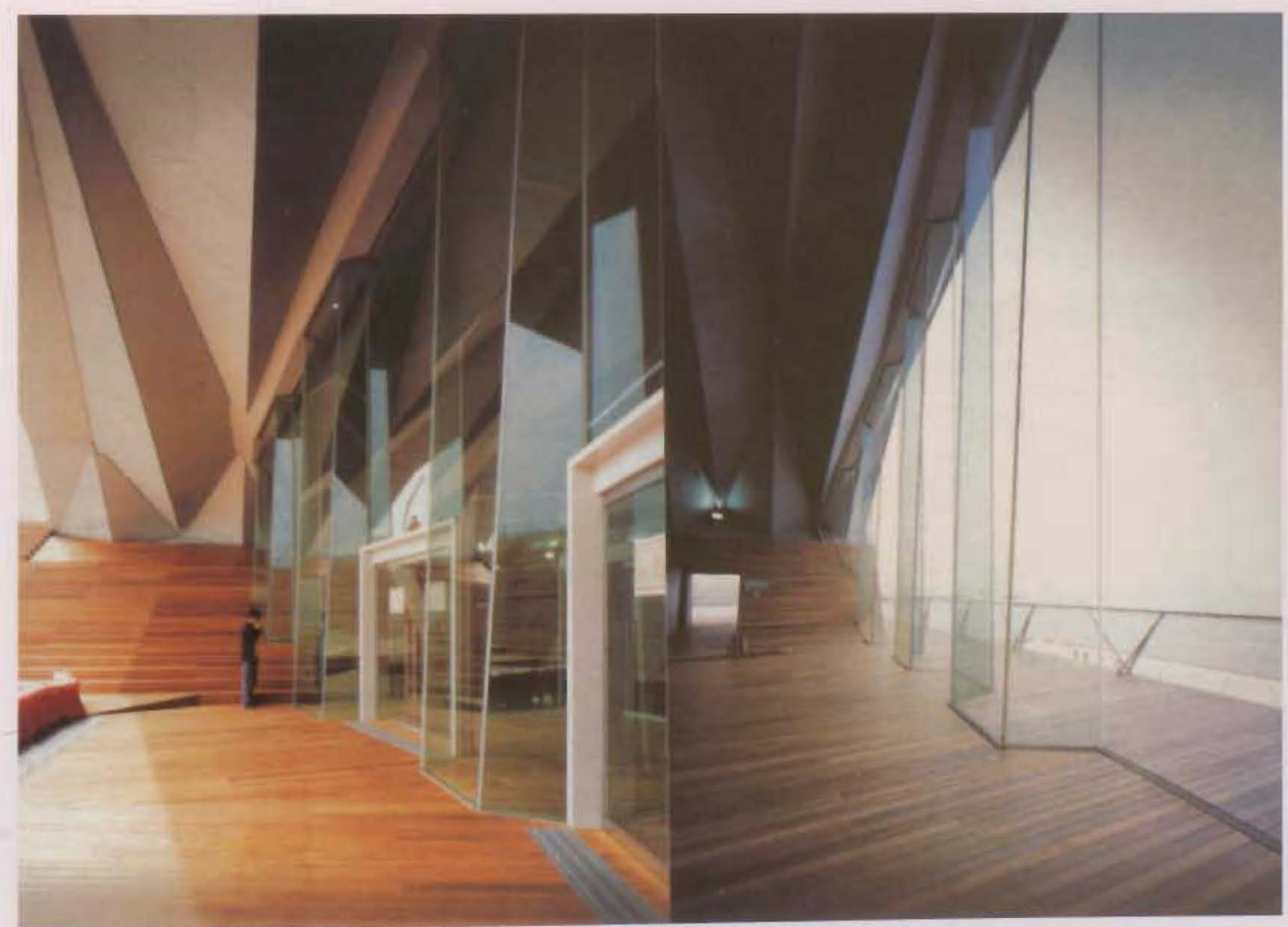

Firgure 7.1.6 Corrugated Glass with buried mullions. 


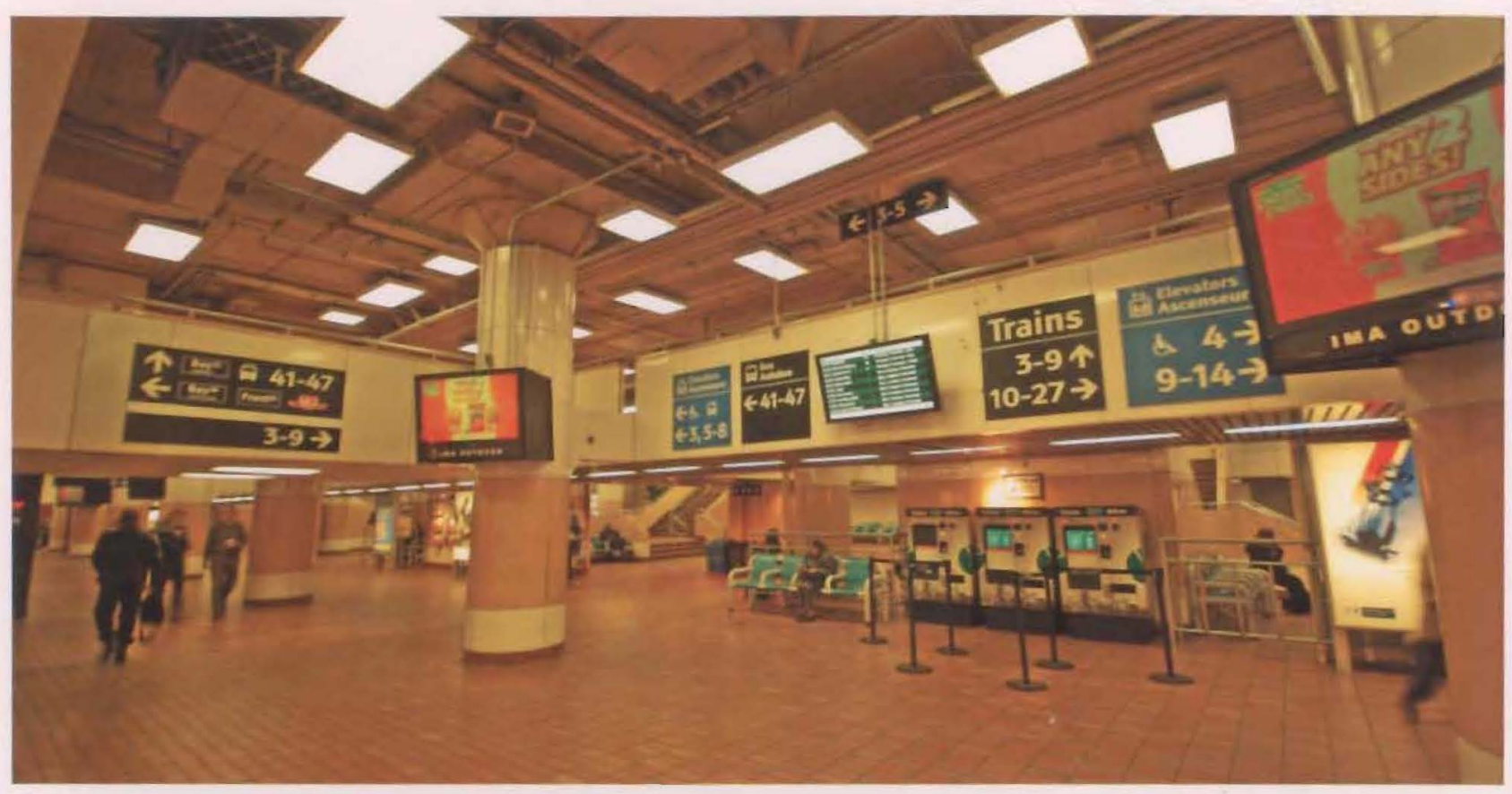

Figure 7.1.7 GO Concourse Signage - over stimulation.

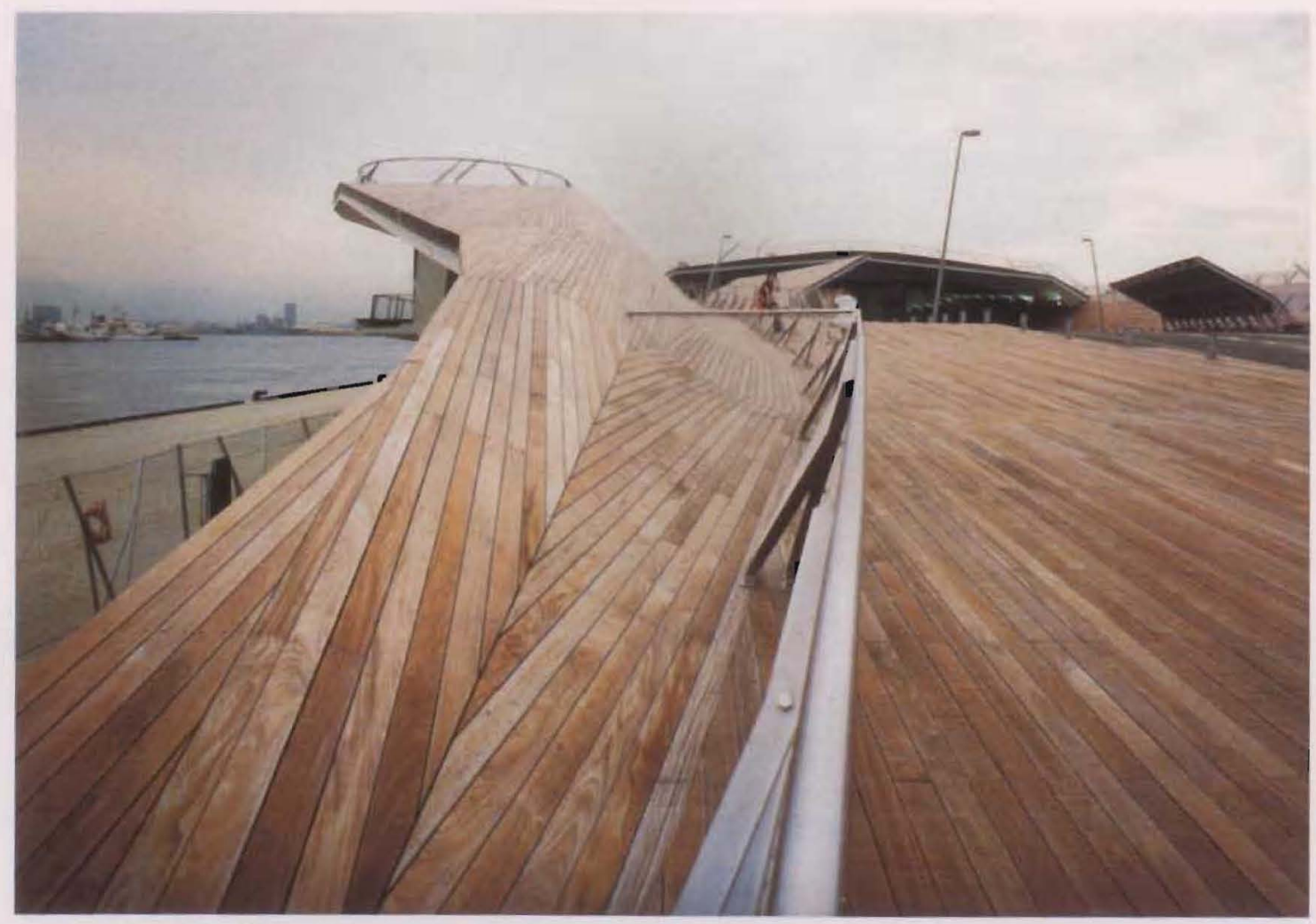

Figure 7.1.8 Warping wood deck surface of Yokohama terminal. 


\subsection{An organ, like the heart or a kidney - An Arnhem Central Interchange}

The Arnhem Central Interchange by UN Studio in collaboration with Balmond (Arup) is a transfer station hub incorporating railway platforms, transfer hall, storage for 5,000 bicycles, parking for 1,000 cars, bus terminal, retail, offices and housing units (Fig. 7.2.1) (UN Studio: Arnhem Central, 2006). UN Studio's starting point was to map out all the traffic flows with an emphasis on the movement of people. UN Studio's leader, van Berkel, calls the emphasis on the movement of people "a new approach to making design, one in which people are central," elaborating that UN Studio designs "bottom up instead of top down" (cited in Burmanje, 2006, p. 5). Van Berkel associates the top-down approach as the creation of a formalistic design where people's movements are rationalized after the fact. The bottom-up approach is the same method used by FOA for the Yokohama terminal, where traffic patterns are paramount to developing the architectural form (Fig. 7.2.2). Traffic flow was scrutinized for Arnhem Central with computer simulations calculating the "directions of the various trajectories, their prominence in relation to other forms of transportation on the site, duration, links to different programs, and interconnections" (UN Studio: Arnhem Central, 2006, p. 46). These calculations optimized the connections to transportation systems and formulated much of the spatial dynamics of the terminal. UN Studio used its Klein bottle model - a self-intersecting closed curved volume - "as an organizational model for passenger movement" and is similar to FOA's no-return diagram (Dehaene $\&$ de Cauter, 2008, p. 248). Both concepts provide a self-intersecting diagram in which an architectural response can be synthesized from the trajectories (Fig. 7.2.3). Union Station was designed classically as a station to be an input-output, a gateway and a controller for passenger rail, and as a result disregarded making connections to itself beyond formal entranceway and train platforms.

Only now is Union Station beginning to create connections to the surrounding area. Unlike Union Station, Arnhem Central's movement model incorporates connections to the surrounding area, which changes Arnhem Central's role from a station to an organizer of urban movements. Burmanje, editor of Archldea, a biannual architectural magazine, contrasted the form of Arnhem station to be akin to "an organ, like the heart or a kidney ... that feeds people into the city and then draws them out again." He goes on to say that "the building is an ensemble of organic forms, connections and spaces that flow into one another" (cited in Burmanje, 2006, p. 5).

Structurally, Arnhem Central Interchange is far more complex and intensive than Yokohama terminal, which has a fairly symmetrical structural layout. UN Studio decided to merge 
its 'V-model' structural system with its 'Klein bottle' diagram to create a form of 'uninterrupted transformation' (Swerling, 2004, p. 198). The V-model structural system does not disrupt the organization of the Klein bottle diagram by creating large clear spans that works sympathetically to create free forming traffic flows. The $\mathrm{V}$-model system also allows for average clear spans of 16 metres to 25 metres, with the largest, the transfer hall, spanning 40 metres column free. Not only does the large clear span limit the amount of intrusive structural elements, but it also allows for natural light to penetrate into the lowest levels of the parking garage. As noted earlier, Union Station's rigid design and inflexible programming contributes to its failure as a terminal, and because of this the station cannot become an organ for movement like Arnhem Central. So far it is unclear if Arnhem Central's programming will be handled the same as Yokohama terminal or if the programming will be integrated into the station as a whole. From published images of the station, there appears to be no movable programming like at Yokohama terminal (Fig. 7.2.4). Another component that complicates Arnhem Central structurally more than the Yokohama terminal is the requirement to include office and retail sectors. Structural systems for office and retail require repetitive and cost-effective layouts, demanding Arnhem to modulate from a flow-dependant structure into a cost-effective, Cartesian grid structure. UN Studios solved this problem by applying its 'box to blob' model where an orderly, 'unit-based' structure warps into a fluid space (van Berkel \& Bos, 2006, p. 216). This modulating approach allows Arnhem Central to respond to traffic flows and generic space requirements; a condition that Yokohama terminal or Union Station cannot replicate. UN Studio also realized that societal demands fluctuate over time and for this reason made sure the structural grid of the office towers could support standard residential layouts (Burmanje, 2006, p. 6).

Arnhem Central does not include public space in the traditional sense, nor does it have public space set aside like Yokohama terminal's roof-scape. UN Studio has chosen to create instead a 'social condenser' by taking advantage of the unique nature of pedestrian movements (Swerling, 2004, p. 198). The terminal allows for spaces that UN Studio calls 'fast flow; that are trajectory-driven and that are programmed for fast interaction, such as 'run shopping.' Calmer areas allow for 'slow flow' and are adjacent to fast-flow trajectories, permitting a leisurely interaction of programmed spaces without interrupting fast flow (imagine a race car pit stop versus the race track) (Dehaene \& de Cauter, 2008, p. 248). These two classes of spaces create a social condenser by permitting a wide range of programs and movements in a singular complex, Fig. 7.2.5. Union Station is striving to reach a sort of social condenser by providing multiple access points and varying the types of programmed spaces. Unlike Arnhem Central, 
where traffic flows create the connections and become the public spaces in and of themselves, the connections at Union Station are unable to unify spaces cohesively. A cohesive terminal is a very important feature of Arnhem Central as it allows a continuous public space to influence a greater area. The Arnhem Central design emphasizes the interior as a "climate-controlled plaza that interconnects and provides access," blurring the threshold between the exterior and interior public space (van Berkel \& Bos, 2006, p. 272). Without emphasizing the threshold, public space appears to wrap and fold into a knot at the transfer hall of Arnhem Central (Fig. 7.2.6). No matter how porous Union Station becomes, in its present form the station cannot blur the distinction between exterior and interior public space; the Beaux-Arts architecture will not allow it to occur. The only solution is to reject the current station as a terminal in favour of developing an intervention that can draw together the contextual area as social condenser. Using Arnhem Central as a model, a new Union Station can utilize the blending ability of smooth space to connect the various conflicting conditions of entertainment venues, parks, offices and residential towers.

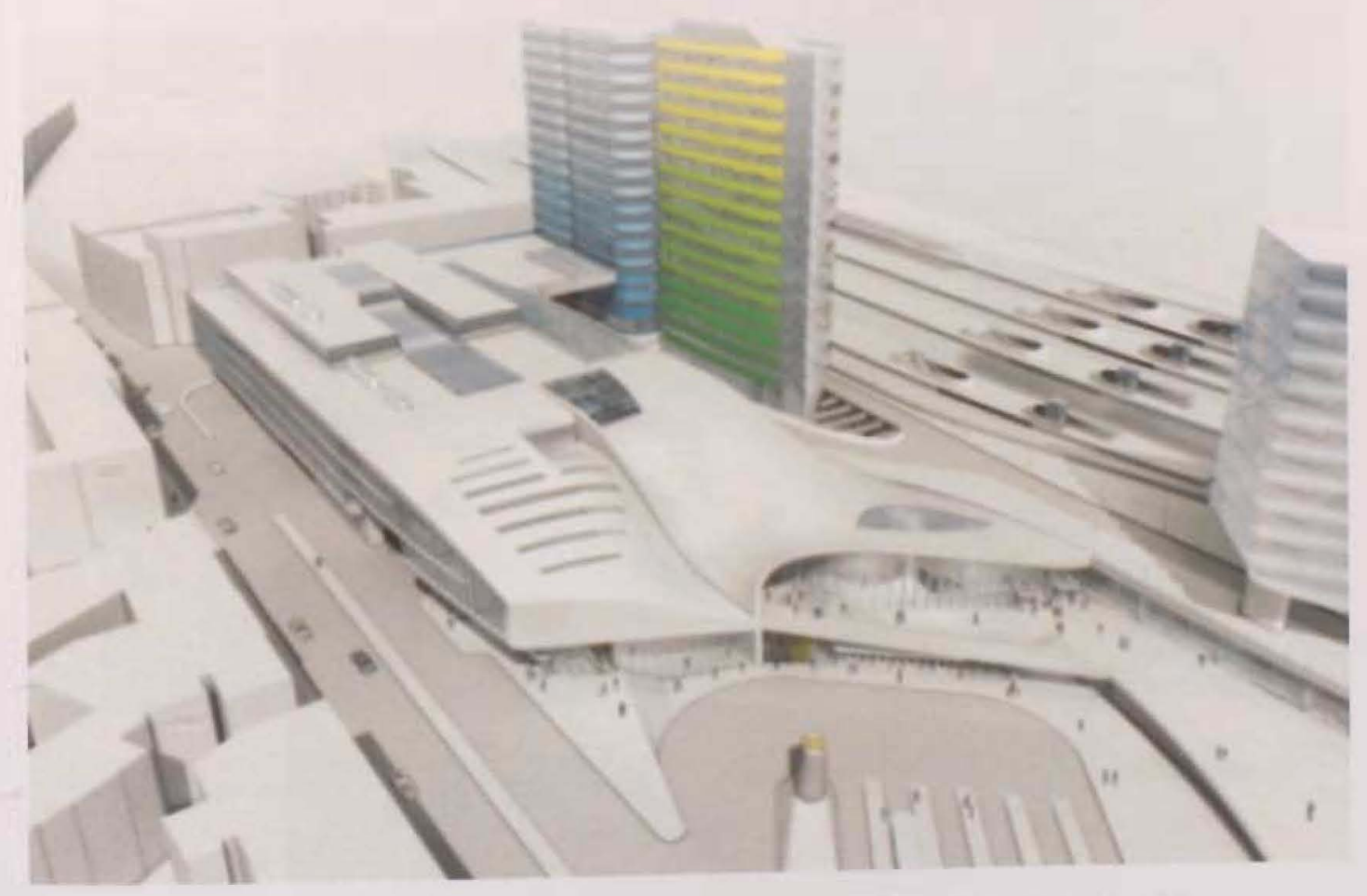

Figure 7.2.1 Arnhem Central Interchange-Mixed Use Terminal 


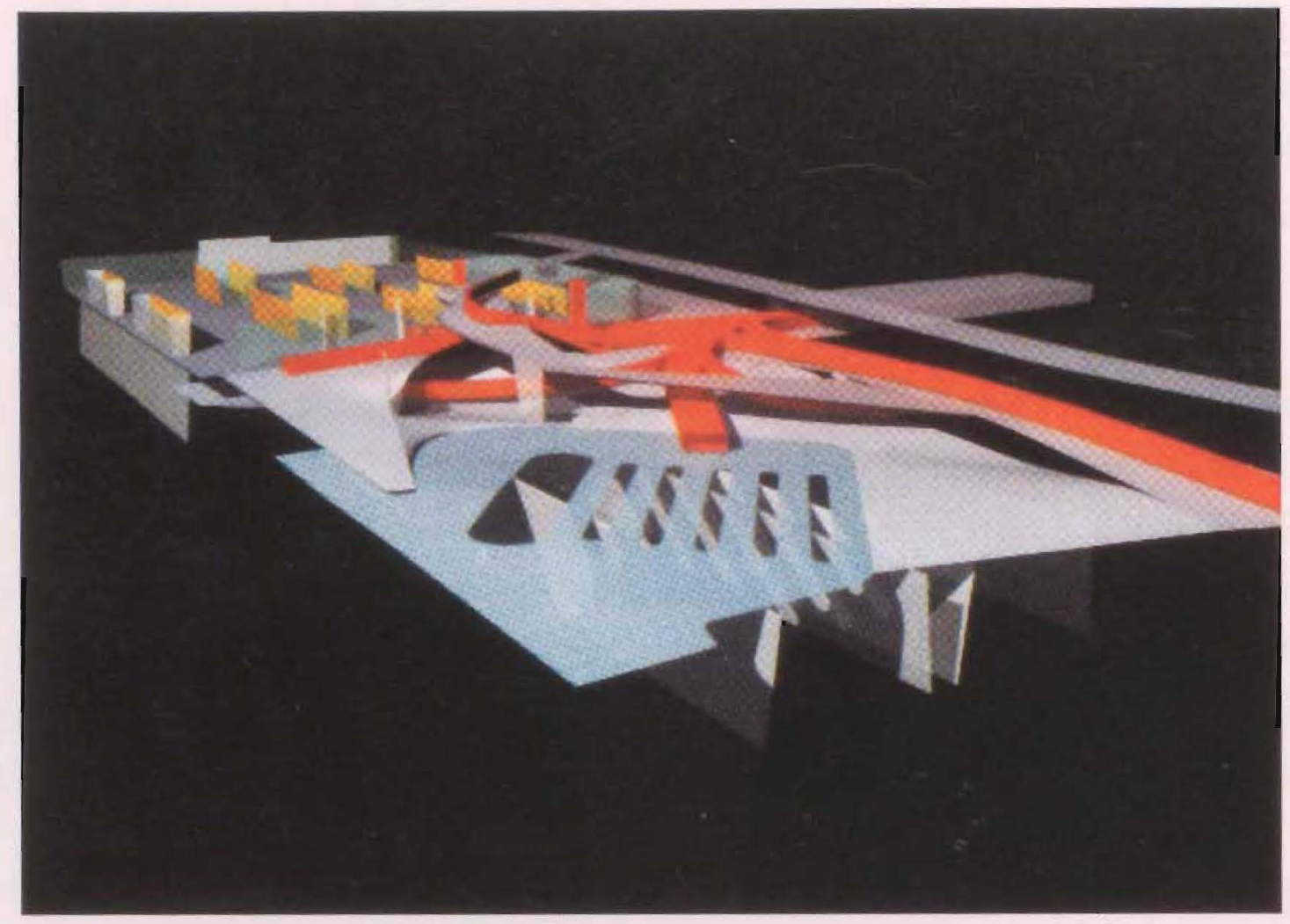

Figure 7.2.2 Traffic Trajectories in three-dimensions.
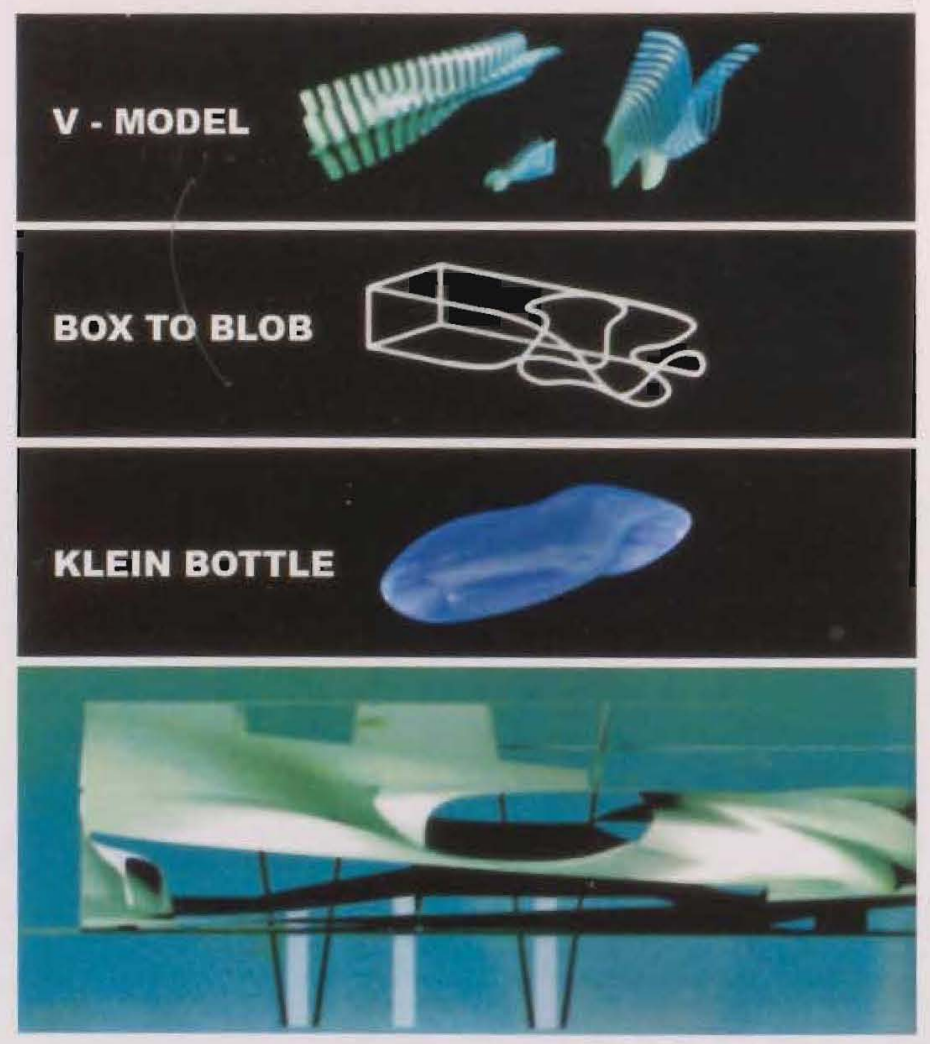

Figure 7.2.3 The 3-Models Used to form the resultant structural form. 


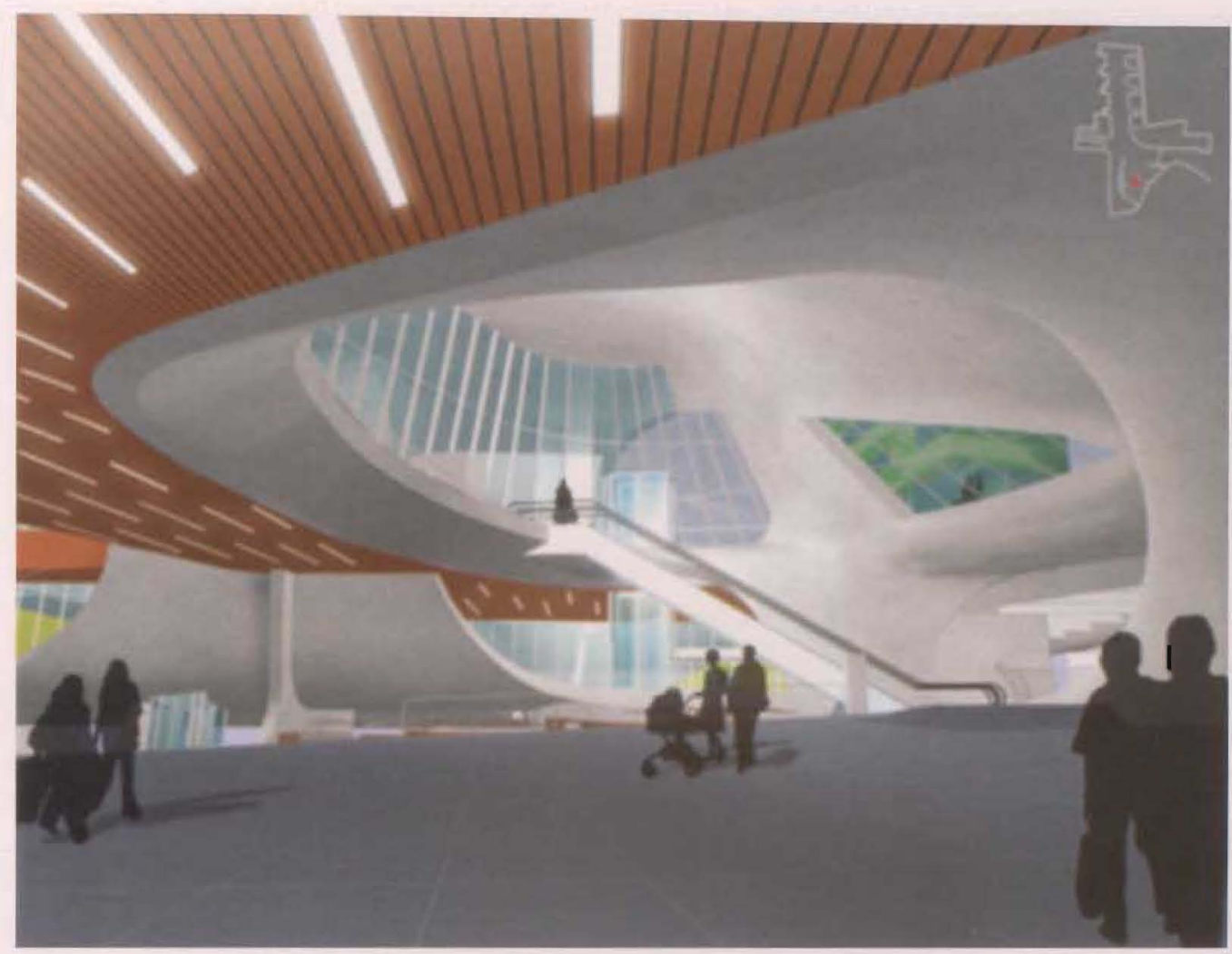

Figure 7.2.4 Arups (structural engineer( rendering of interior, expansive and few programmed elements.

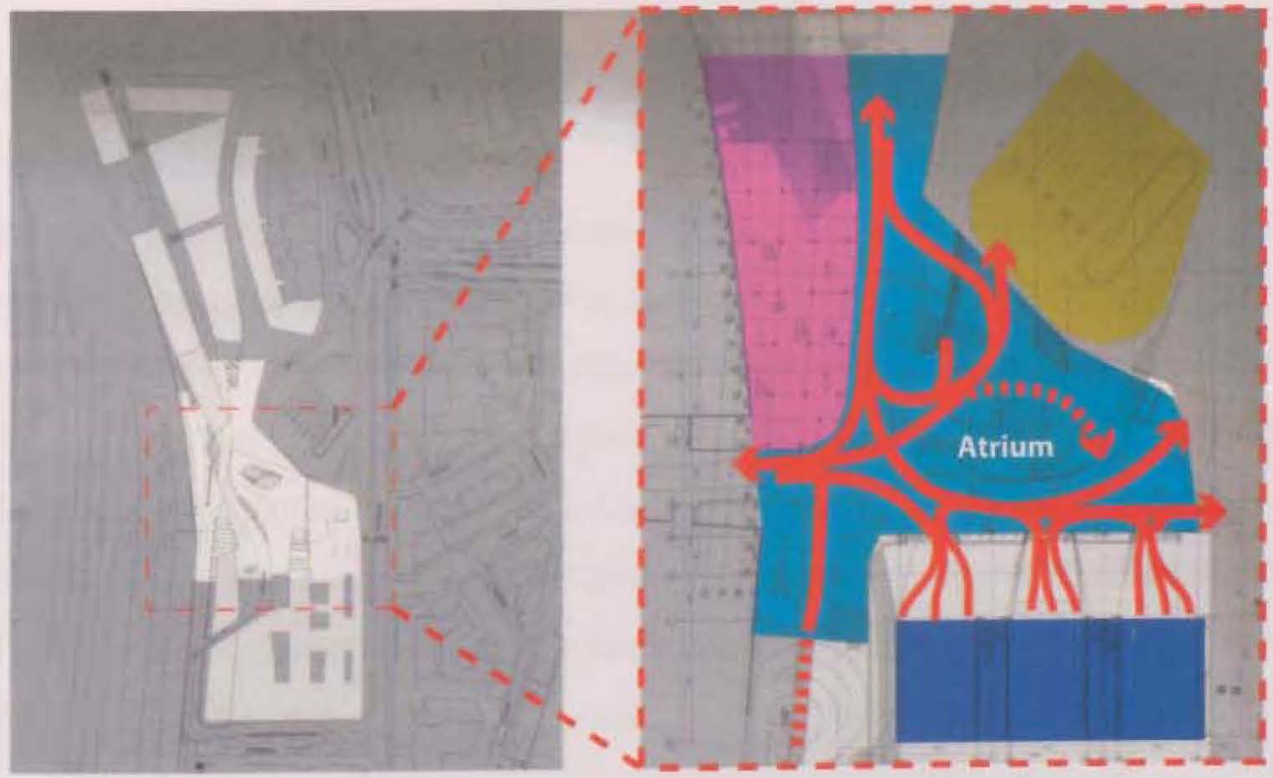

Slow Flow Fast Flow Shopping Platforms Bus Platform

Figure 7.2.5 Public Space slopping and converging at the knot, the interchange. 


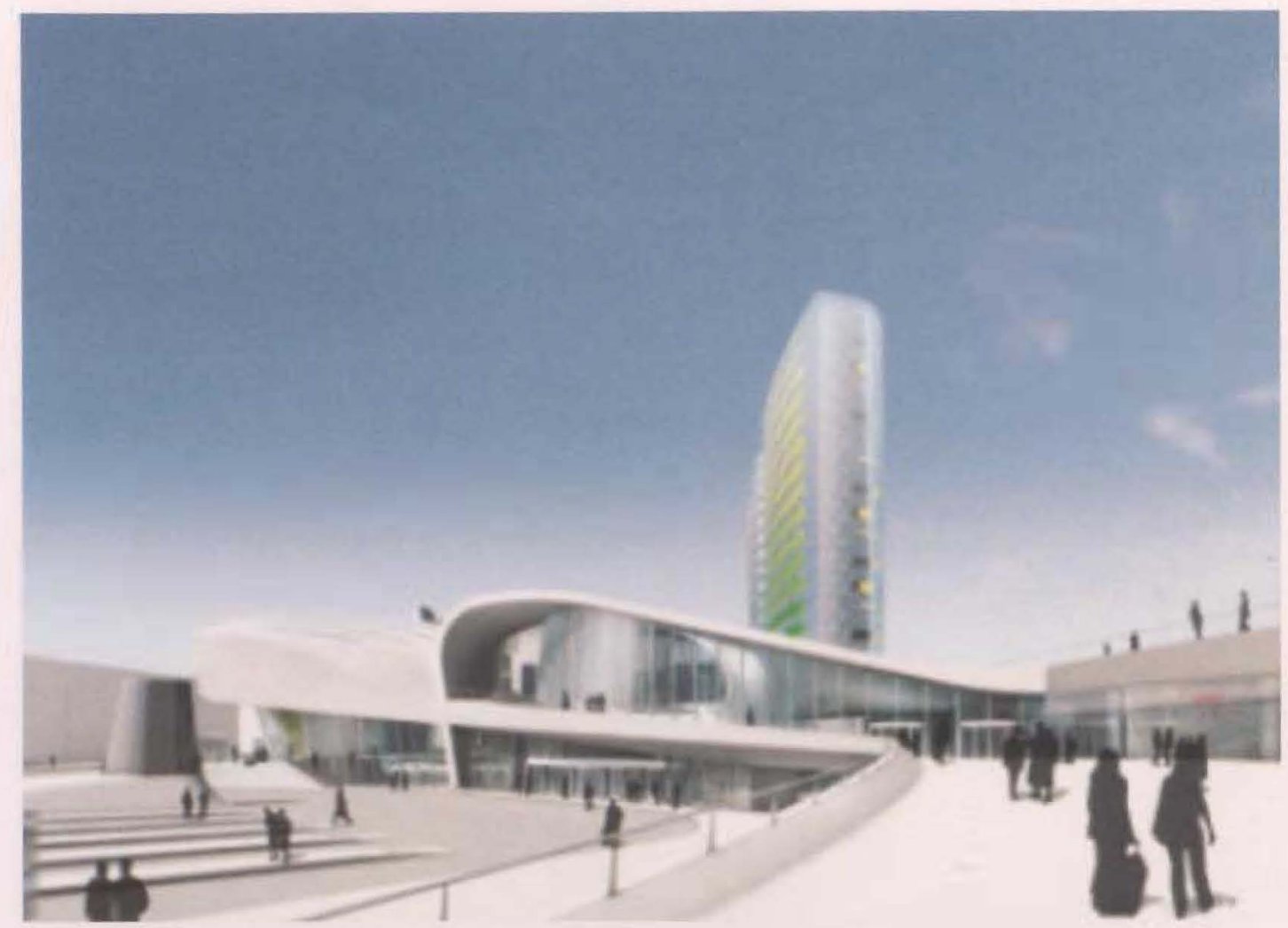

Figure 7.2.6 Public Space slopping and converging at the knot, the interchange.

\subsection{Hard-to-Find Examples}

Yokohama Terminal and Arnhem Central are the clearest examples of smooth space seen through a transportation terminal. In fact, it is hard to find examples of architecture exhibiting smooth space conditions that are not associated with transportation interchanges. A reason for the lack of Flow Urbanism case studies could be attributed to the long period of time - upwards of 10 years - to design and construct transportation interchanges. Much of the merits of Arnhem Central are speculative because only phase one, the parking and office towers, are complete, with the terminal building scheduled for completion in 2010. While Flow Urbanism provides a useful medium for traffic flows, the merging of public space with design is a very important factor for providing a progressive social role. The combined nature of traffic flows, public space and an adaptable program creates an ideal condition for terminals that are sensitive to these principles. It would be presumptuous to assume that terminals designed with smooth space principles would be continuously flexible forever, but it is my opinion that with a design emphasis on traffic flow, a terminal could be buffered from alterations much longer than a traditionally designed input-output terminal such as Union Station. 
Programming like that of Yokohama terminal, where elements are scattered on the surface of the station as independent points of intensity, appear to provide enough flexibility to allow the building to change with the needs. However, there is little documented evidence to corroborate this statement. Stickells warns that programming such as Yokohama Terminal's 'risks normalization' of the spatial layout (Dehaene \& de Cauter, 2008). In his article Turbulence in smooth space, Stringer also warns that terminals that use characteristics of smooth space would be 'undifferentiated in their aesthetic logic,' becoming homogeneous with all other terminals (Stringer \& Barber, 1999, p. 88). However, Stringer was speaking more about airport terminals around the world, which are all currently using a fairly common aesthetic logic. As Arnhem Central and Yokohama terminal have shown, their aesthetic logic and layouts are completely different from airports or from each other. Stickells and Stringer's concerns of the normalization of spatial layout should not be feared because terminal design is sited on specific infrastructural systems and must meet site-specific constraints, whereas airports are typically sited on green field developments.

\section{4\$7 Billion Station - Stuttgart Main Station}

Stuttgart's Main Station is soon to witness a massive rejuvenation that will submerge all the rails with an addition of a High Speed Train (HST) terminal. The original station was designed by Paul Bonatz in 1910 and is said to be "a grand, austere stone structure that in its Spartan way links 19 th-century eclecticism and both the sparseness of Modernity and Albert Speer's scraped monumental Classicism" (Fig. 7.4.1) (Davey, (2003, p. 66). The new Stuttgart Main Station by Ingenhoven Overdiek is part of the Stuttgart 21 proposal to redevelop the existing rail lands by submerging all the old lines and building over top. The plan also includes the construction of new tracks to convert the terminus station into a through station and to incorporate a HST. The new HST terminal and redevelopment of the existing terminal will be below grade, with the roof structure incorporated into the Schlossgarten (public castle gardens (Davey, 2003).

The Schlossgarten performs as the new public focal point for Stuttgart Main Station by the continuation of the gardens over the old rail lines. The old station will be readapted for the new terminals' point of departure with three new arrivals entrances constructed into the Schlossgarten. The public space is dotted with dunes that perform as skylights and natural ventilation for the terminal below. The dune effect breaks up what would have been a 
monotonous flat space. The subtle dips and rises of the new park space will cause pedestrians to weave back and forth through the space. Instead of the Schlossgarten terminating awkwardly on the northern edge against an eight-lane road, the new extension over the station frames the garden with classical and contemporary architecture (Fig. 7.4.3). Restaurants added to the old station and along the adjacent office complex will activate the edges of the Schlossgarten extension (as seen in Fig. 7.4.2) (Davey, 2003).

The new through terminal will be 12 metres below the Schlossgarten, with regional rail connections below the through terminal. The structure of the new terminal is the most important feature of the design, incorporating a roof top garden, skylights and a structural system of the most minimum of thicknesses. The reduced mass of the structure allows for narrow columns on the platforms and reduces the possible visual barriers that can be produced by subterranean structures (as seen in Union Station's subterranean concourses, Fig. 7.4.2). So sophisticated is the structure that the depth of concrete is to be no more than a hundredth of the span, making the thinnest point 90 millimetres thick (Davey, 2003, p. 66). The structure works sympathetically with the garden space by creating a dynamic terrain with the teardrop skylights. These skylights not only augment the roof's surface condition, but also provide a seamless integration into a structural column support (Fig. 7.4.4). Stuttgart Main Station shows how a structural system can work sympathetically with public park space without causing the structural system to outshine the public park.

Stuttgart Main Station reveals to Union Station how the submergence of rail lines below grade can open up huge potential for expressing public space and generating new development potentials. Boles, a historian for the Toronto Railway Historical Association (TRHA), has mentioned that it would be impossible for Union Station to submerge its rail lines, which is quite true if the City of Toronto and investors are willing to spend the bare minimum on interventions and avoid disrupting service as much as possible; in comparison, the Stuttgart 21 project from proposal to completion is forecasted to take 16 years and will obviously cause disruptions (Davey, 2003, p. 69). If Union Station wants to proceed into the 21st century, the City of Toronto must provide a bold statement to show its dedication to rail transportation, or in Boles opinion, give up on Union Station and build a cheaper, more useful station elsewhere. With a submerged terminal, Union Station could readapt the existing terminal to provide a gateway to a new public space built over a new terminal. A new public space could interconnect the fragmented public spaces in the rail lands and tie them together into a much large public park network. Stuttgart Main Station is also an important case study for Toronto because it shows the 
dedication and desire of a city to construct a terminal that not only provides new transportation services, but also gives back to the community by increasing public park space. Stuttgart Main Station may lack the intricate and flowing complexity of Arnhem Central or Yokohama Port terminal, but it makes up for this through a very bold initiative to rejuvenate the station area with public space at a focal point. This is not a timid project for the city of Stuttgart, costing well over $\$ 7$ billion CAD (Verband Region Stuttgart, 2007), which pales in comparison to Toronto's \$1 billion to upgrade Union Station, $\$ 400$ million of which is badly needed just to rehabilitate Union Station (Transit Toronto, 2007).

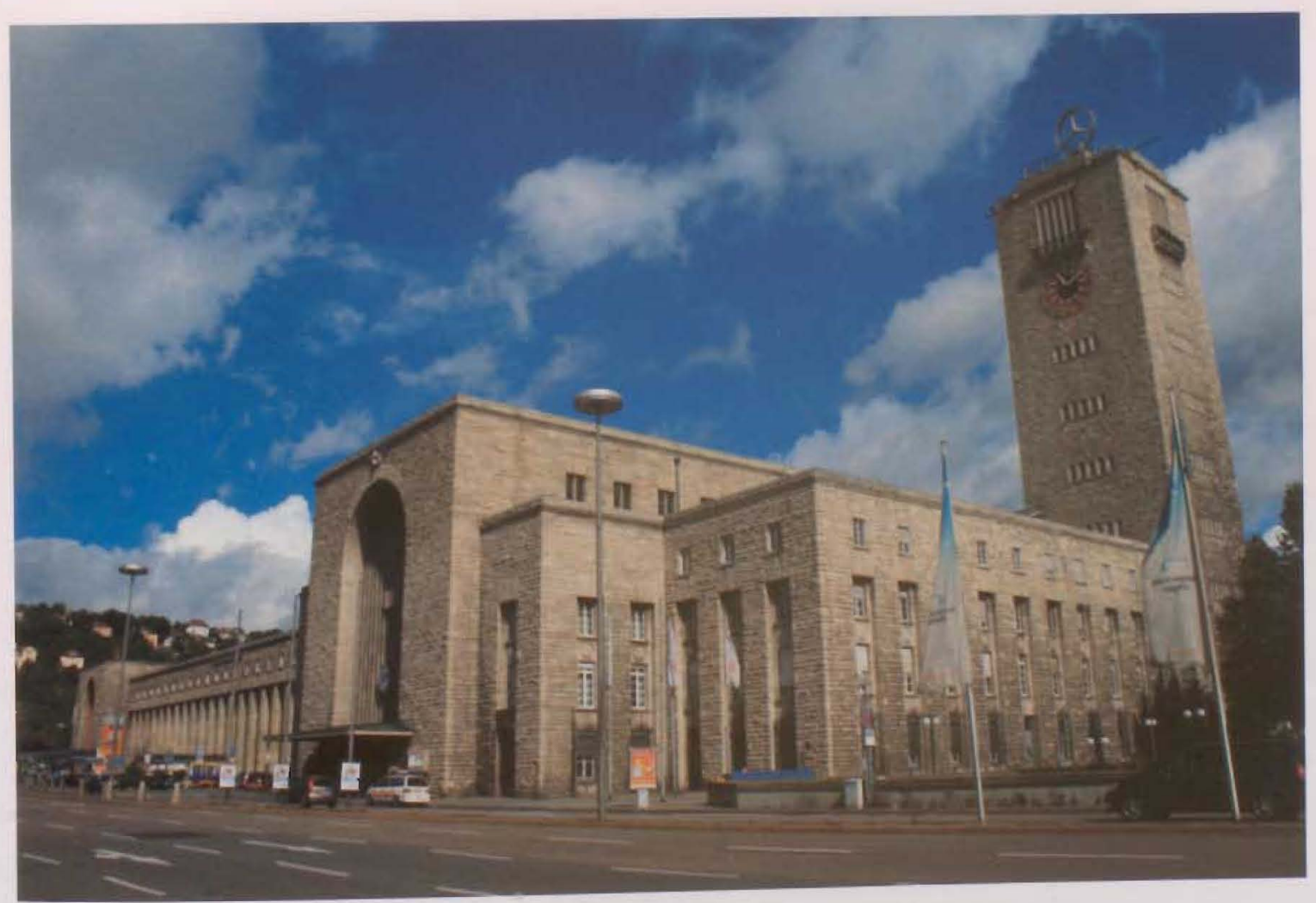

Figure 7.4.1 Stuttgart Main Station-original terminal 


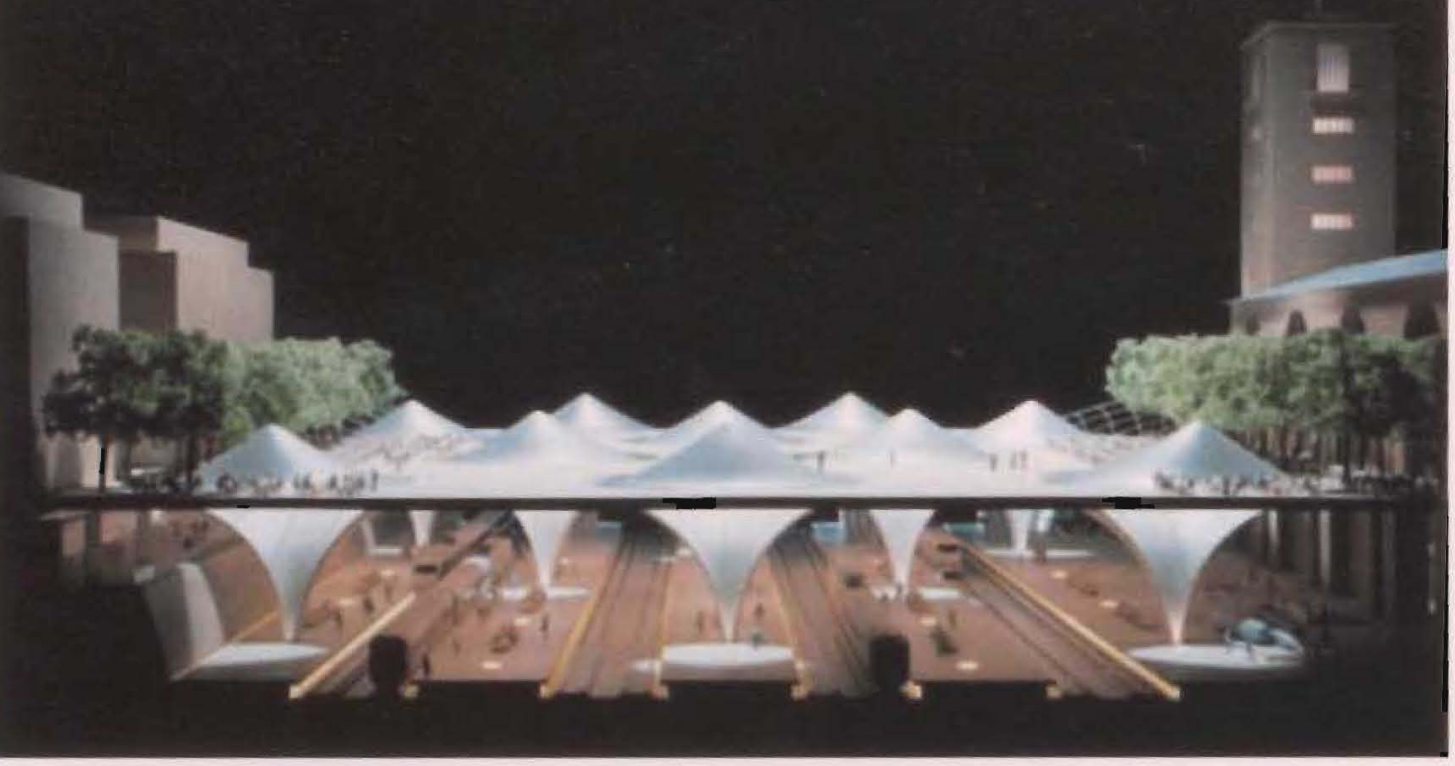

Figure 7.4.2 Model of Ingenhoven Overdiek's new Stuttgart Station terminal.

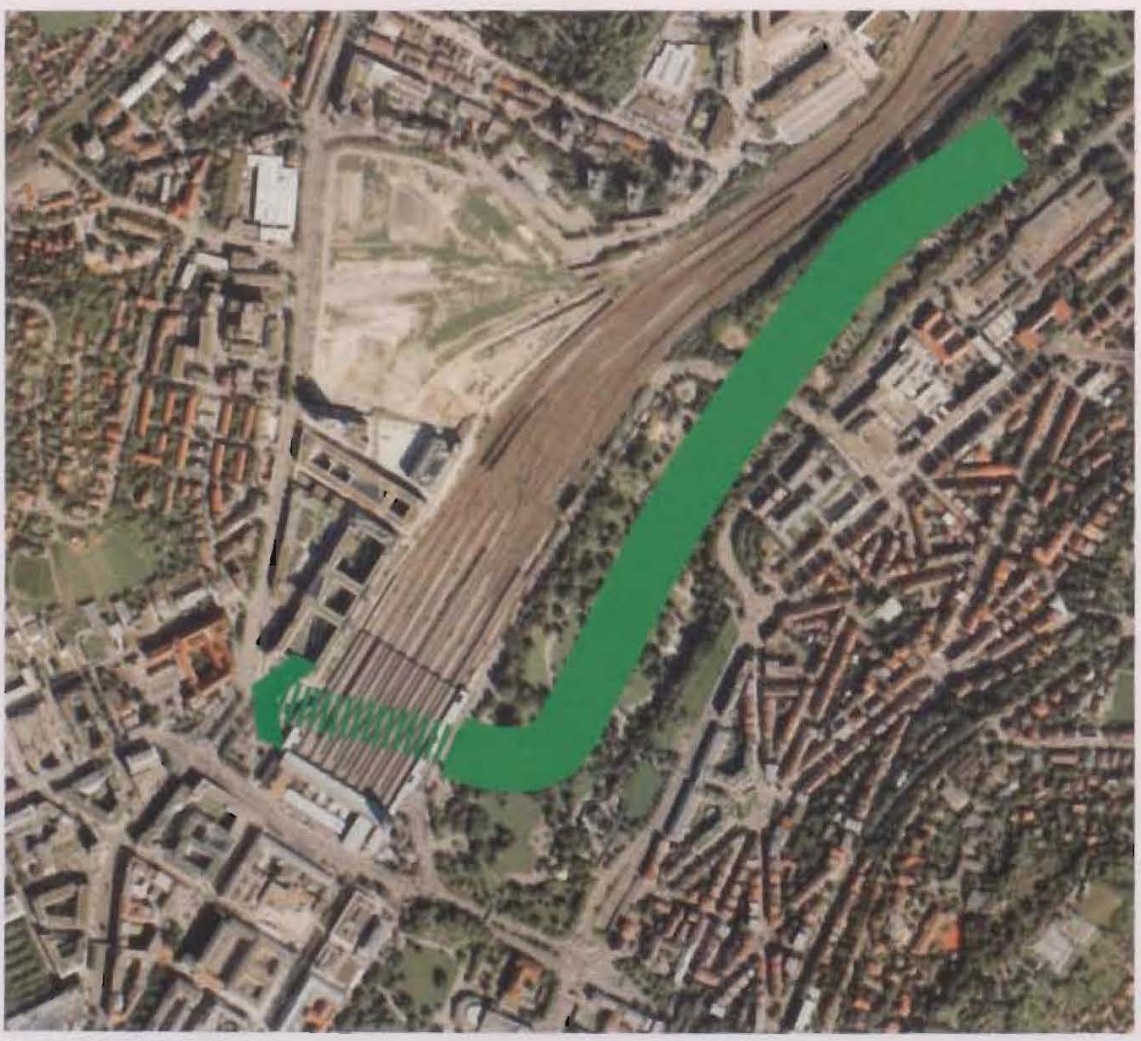

Figure 7.4.3 Diagram of where the new park space is located (dashed). 


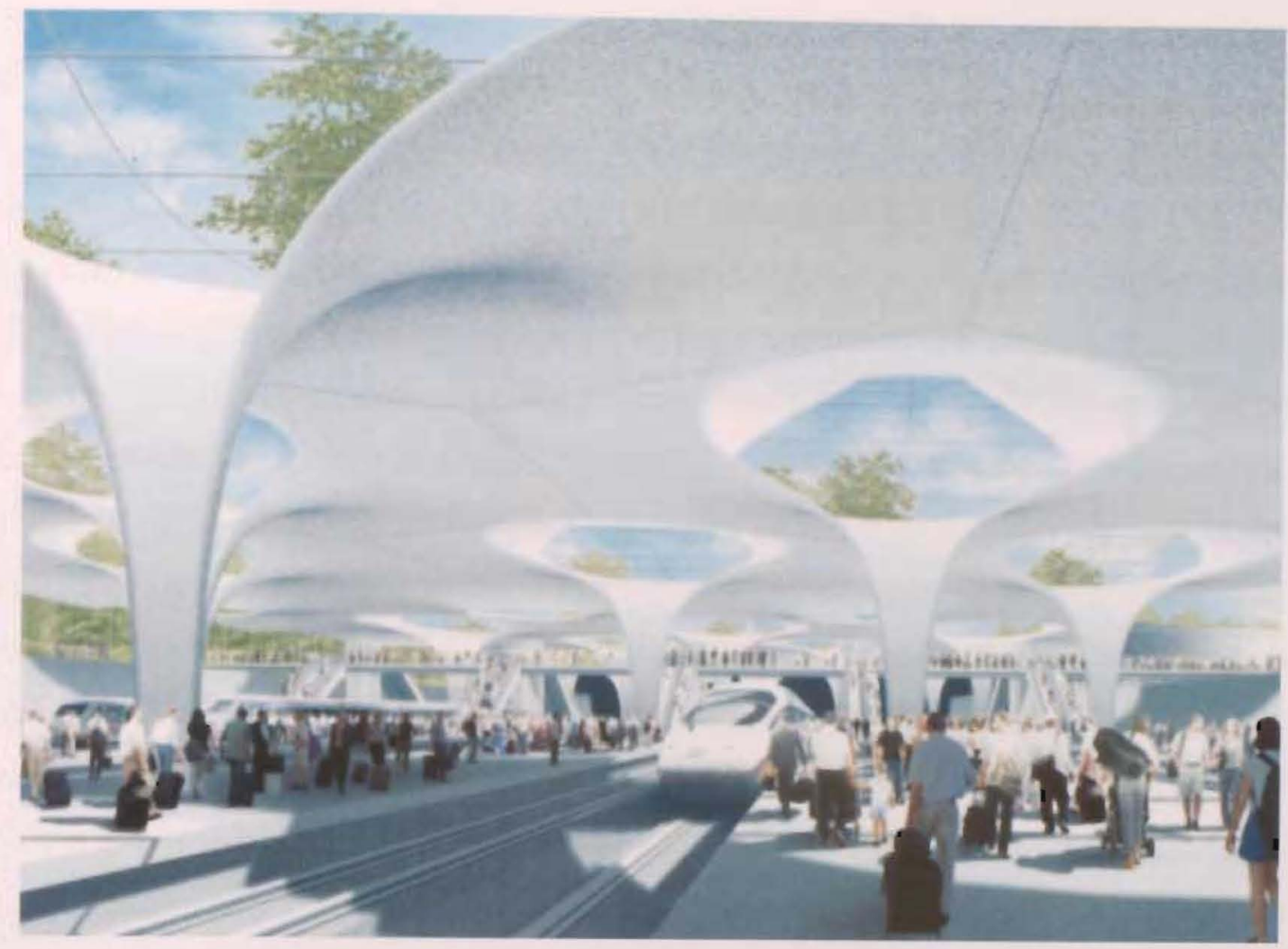

Figure 7.4.4 Structure becomes one with skylights and park space.

\subsection{Z-Shaped - Olympic Sculpture Park}

Weiss/Manfredi's design for the Olympic Sculpture Park for the Seattle Art Museum is an example of a continuous public landscape that does not bridge infrastructure but works in conjunction with infrastructure to stitch together fragmented spaces (Fig. 7.5.1). Like most North American waterfronts, the Seattle waterfront was displaced from the city by industrial factories and harbour industries (Busquets, 2008). In many regards, the history of the Seattle waterfront followed closely that of Toronto's waterfront. The 1960s and 1970s saw a decline of waterfront industries. This created a vacuum, leaving both waterfronts empty and forgotten. Due to the interstitial nature of the devalued waterfronts, 'specialized transport infrastructure' positioned themselves on the waterfront to take advantage of the open and cheap lands. During this time of devalued waterfront, Toronto saw the construction of the Gardiner Expressway and Seattle the Alaskan Way Viaduct - both elevated expressways. After the 1970 s land speculation increased the worth of the abandoned waterfront and both cities returned their focus to the water's edge. Now the real estate markets took to the waterfront and both cities saw a boom in high-rise residential development that has continued to this day (Busquets, 2008). While Toronto 
has chosen to define the waterfront's edge as a public space through initiatives like the HtO Park and Jarvis Slip, Seattle has chosen to merge the waterfront with the city (Busquets, 2008).

The Olympic Sculpture Park was initially the last remaining parcel of land adjacent to the waterfront and was divided into three chunks by a road and train tracks (Fig. 7.5.2). The Seattle Art Museum put up a competition to not only find designs to increase the museum's space, but to unit the three fragments and connect the city to the waterfront. During the competition for the park, the firm of Weiss/Manfredi knew it was not a choice to cover or bridge the infrastructures, but to embrace their presence. To deal with the infrastructure and change in elevation, Weiss/ Manfredi created a "Z-shaped topography that wandered from the city to the water's edge ... without denying the energy of the existing infrastructure" (Busquets, 2008, p. 30). The Z-shaped land functions as a 2,200-foot-long public art landscape that uses its tilting planes to provide "micro-settings for diverse ecological environments" (Busquets, 2008, p. 30). The topography was created by tons of infill and reinforced with concrete retaining walls to raise the northern parcel of land high enough to bridge the road and tracks (Fig. 7.5.3). The earthworks are an important feature, transforming the park space from a mere pedestrian bridge into an extension of the landscape. The earthworks provide a natural appearance and a sense of permanency that integrates the park directly to the site. Varying micro-ecosystems mimic natural ecosystems found near the water's edge, thus increasing the park's sense permanency (Busquets, 2008).

The Z-shaped park space does not restrict pedestrian movement to one direction and provides the ability for pedestrians to access the park space at different points along its span to the waterfront (Fig. 7.5.4). The park is not a traditional 'contemplative' public space, but is what Leers calls a "setting for art, it is an active pathway" that provides more than a link to the waterfront, but a sensorial experience (Busquets, 2008, p. 62). The park's success can be attributed to the active pathway of sensitively placed micro-ecosystems and art installations. The vegetation will evolve over time, as well as the art installations, which have special platforms that provide digital hookups for newer generations of interactive artworks (Busquets, 2008, p. 36). The ability for a sensorial experience to change over time is a very important feature of Olympic Sculpture Park, one that provides an interesting potential for a redevelopment of Union Station

If Union Station were to follow the lead of Stuttgart Main Station and bury the platforms to provide a public space, it would require an intervention like Wiess/Mandfredi's to provide connections to activate the public space. The contextual area of Union Station lacks sensorial experiences to draw people into the area and requires experiences like the Olympic Sculpture 
Park to draw in users. Furthermore, an intervention like the sculpture park could facilitate in bridging the various infrastructural systems that divide up the contextual area of Union Station. If done properly, a public space could extend from Union Station to the waterfront, finally linking the city formally to the waterfront.

\subsection{Last Two Examples}

The last two examples have shown methods of bridging and interacting with infrastructural systems to provide new forms of public space. Stuttgart Main Station's public space interacts with the structural skylights of the new terminal, giving the public park space a dimpled surface, while the Olympic Sculpture Park zigzags over infrastructural systems to knit together the city's fragmented sections. To create a new public focal point for Union Station one need merely to follow the examples of Ingenhoven Overdiek \& Partner and Wiess/Manfredi, who both demonstrate how to handle an attractive and functional public space in an urban setting.

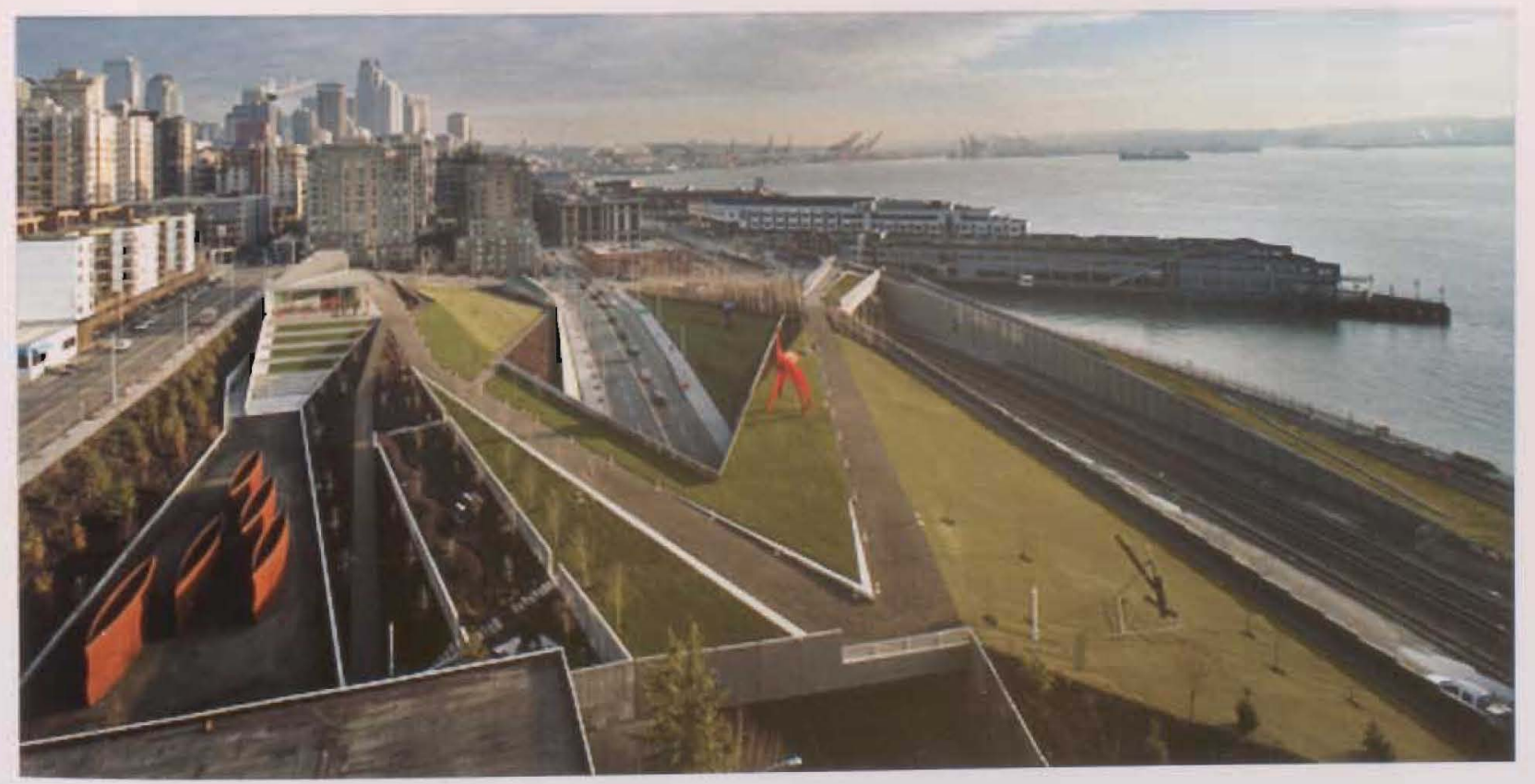

Figure 7.5.1 Olympic Sculpture Park by Wiess/Manfredi Architects. 

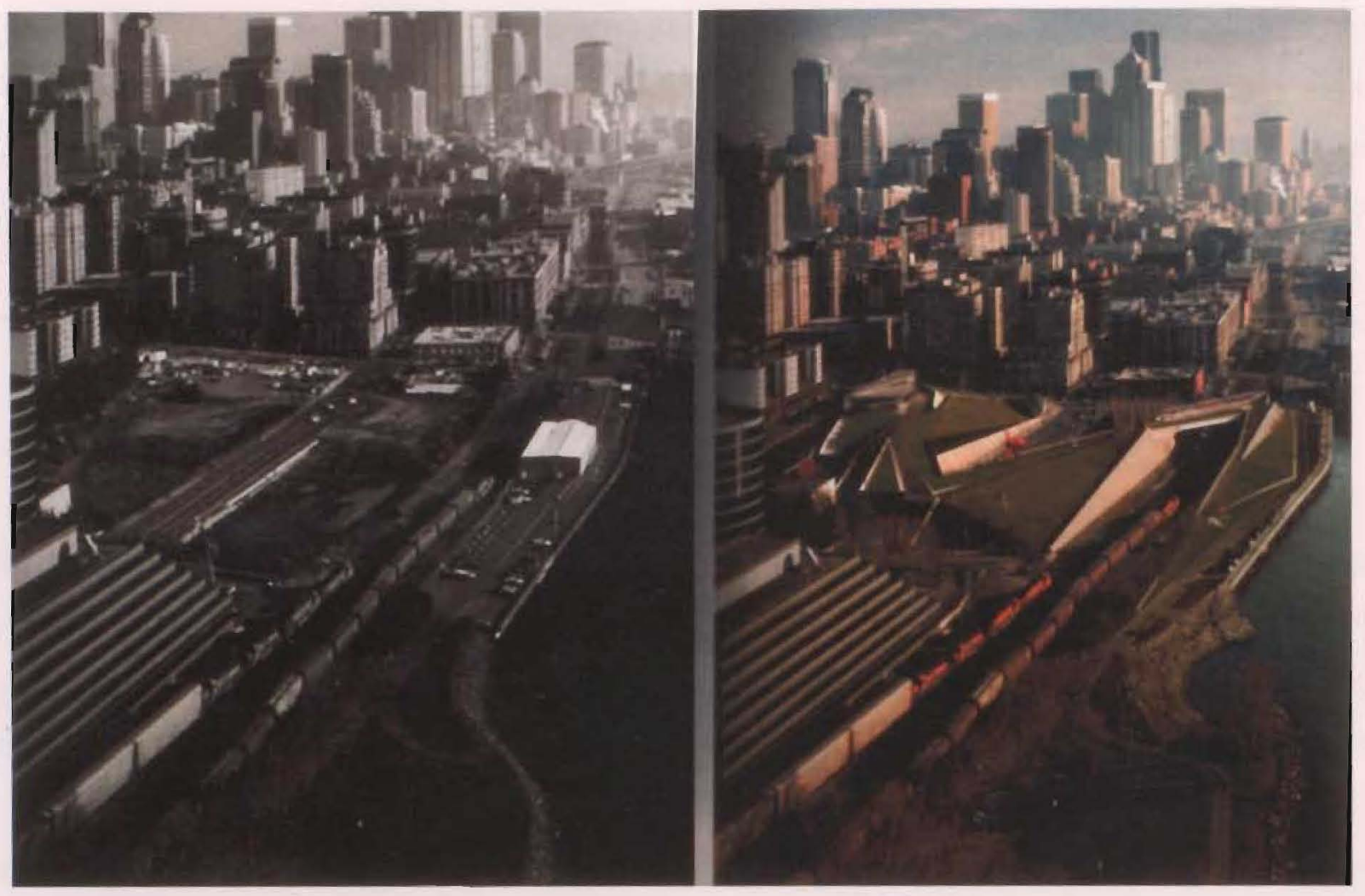

Figure 7.5.2 Before and After the addition of the Olympic Sculpture Park.

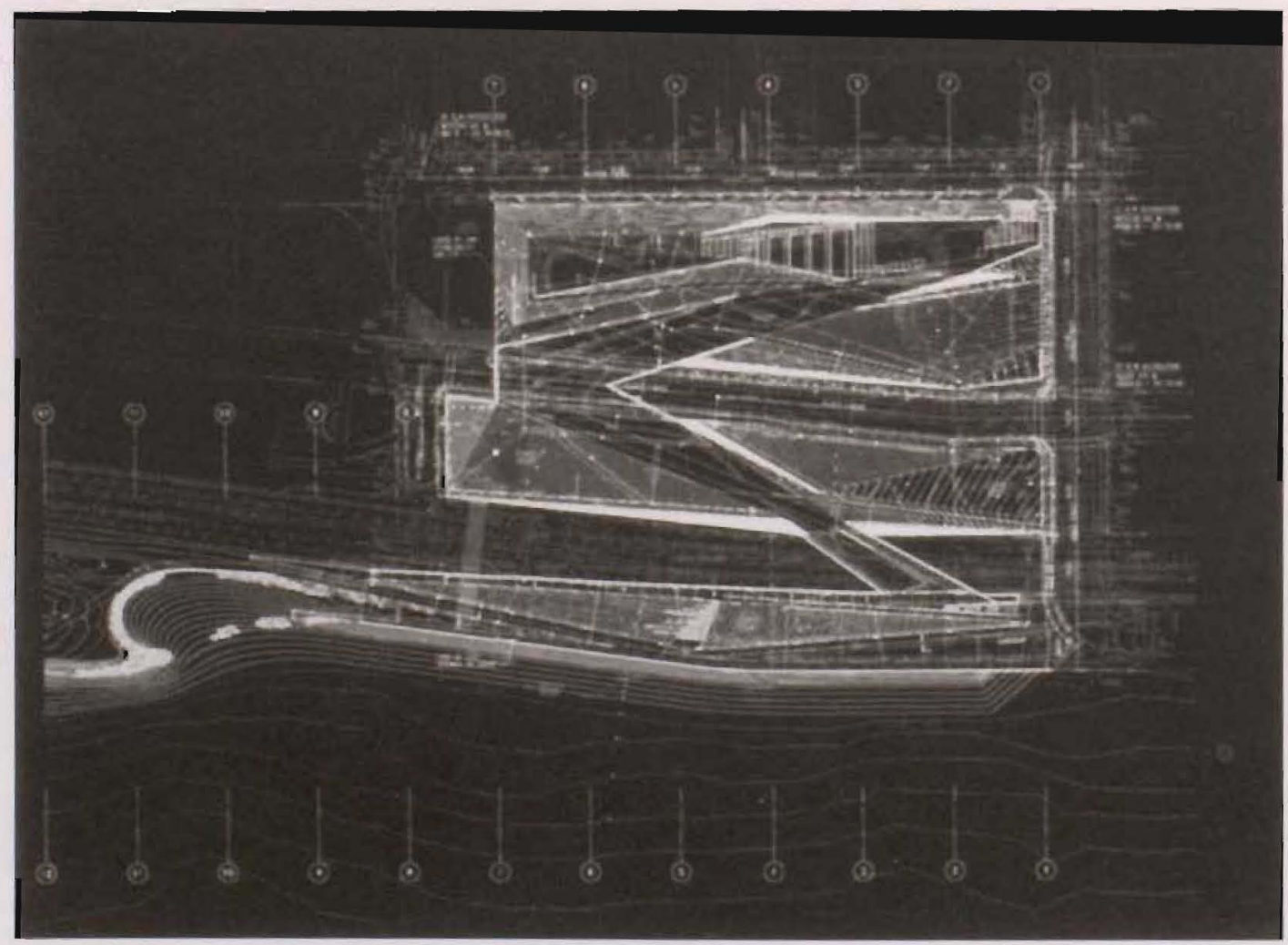

Figure 7.5.3 Olympic Sculpture Park Topographical Plans. 


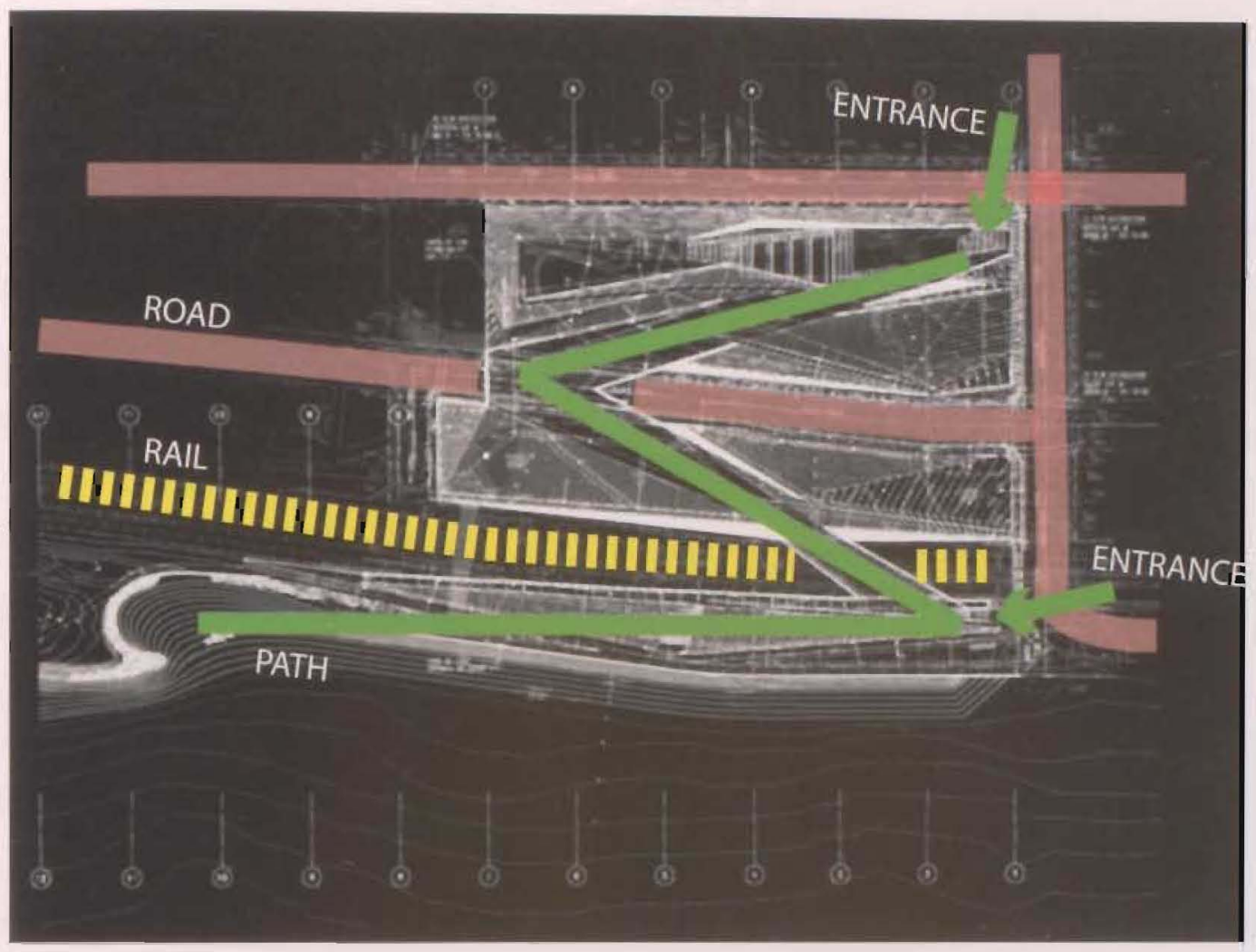

Figure 7.5.4 Mapped routes and entrances to the park. 


\subsection{Proposal for Union Station}

Union Station is insufficiently designed to handle modern commuter demands, resulting in a utilitarian-designed transit facility of uninspiring quality. Union Station's newer commuter facilities, including the subway and regional rail service, have forcefully imposed themselves onto a station never designed for these forms of infrastructure. The rigid layouts and homogeneous functionality of the passenger station cannot cope with new modes of transit. The current Union Station Master Plan and GO Transit Master Plan are not bold enough in vision to completely reinvent Union Station into a proper 21 st-century facility. Further issues include the inability of initiatives to define the surrounding contextual area and integrate the station, Central Railway Lands (CRL), barriers and waterfront into an urban fabric. As a result of this lack of vision, these elements remain juxtaposed against the rest of Toronto - providing no greater return to the city.

\subsection{What Did We Learn From Node-Place?}

Bertonlini's node-place model has revealed that Union Station and CRL are an Unbalanced Place, requiring redevelopment of nodal connections and a new functional mix of programming. Union Station's nodal connections are currently set apart from each other and need to be brought together in a central complex. A new functional mix is required to generate new activities and destinations, and to define the station as a place and not just a train station. Peek's node-place model finds that Union Station lacks all four guidelines required for an ideal station. As a Connector, Union Station and area provide no ideal conditions for 'safe, reliable, fast, hassle-free, comfortable, and pleasant' travel, resulting in poor conditions for the two main commuting activities. Although the Transportation Node qualities of Union Station are satisfactory, the poor Connector conditions mean that people cannot be moved efficiently enough. As a meeting's place, the station and area fail completely, providing nothing for a modern market place where people are exposed to urban life. The subterranean concourses and lack of urban destination provide little more than a functional sevice for people coming and going from Toronto. The station provides a functional means to connect a workforce to their source of employment, but does not provide an urban centre that creates a focal point for the public. 
What can be understood from the issues and node-place conditions is that Union Station and area requires a redevelopment to meet three conditions: first, a modern terminal that can adapt to changing commuter needs while providing the best conditions for travel; second, an activated public space that merges fragmented urban elements together in a civic focal point; and third, a master plan that seamlessly integrates both a modern terminal and civic focal point. From this response, Union Station and CRL can reach Bertonlini's ideal condition of an urban exchange complex, where the station area is a place to be and not a place to pass through (Bertonlini \& Spit, 1998).

\subsection{New Characteristics}

What would be the characteristics of a new station area? All of the case studies revealed methods of using public space throughout the design to act as a medium to which infrastructure and services are attached. Yokohama International Port Terminal and Arnhem Central Interchange are two examples where smooth space is used to provide public space throughout the design. A proposal for Union Station using smooth space could potentially piece together the CRL with a continuous public space surface, blurring the distinction of the terminal as a strictly functional space. Olympic Sculpture Park used a public landscape to bind infrastructure to architecture, proving that infrastructural systems do not have to be blights on a city and can provide a dynamic relationship to public space.

Stuttgart Main Central provides a potential that would completely change the relationship of Union Station to the urban context by burying the terminal and creating a continuous public landscape. Such a proposal for Union Station would not be done to hide the rail lines, but to provide new potentials for an urban landscape that would define the Union Station area and generate a focal point for the city. Union Station could provide a large public space for Toronto like so many over North American cities (Fig. 4.2.1). Such a proposal has wider implications of connecting to the Harbourfront parks and providing a much-needed public connection to the waterfront. 


\subsection{Final Thoughts}

In his essay A land of promise: The future of train travel in the United States, Phillips asserts that "there is broad agreement among rail historians and futurists that the history of the passenger train in the 20th century makes a persuasive argument that it will be around at the end of the 21 st" (Dawes, 2001, p. 43). If this fact is to remain true, Toronto's Union Station has a minimum of nine decades of service left. It is an imperative that Union Station be first transformed into a 21 st-century terminal to provide enjoyable commuter services and, second, be transformed into a public landscape for the people of Toronto to enjoy into the 22nd century. 


\subsection{Design Introduction}

The initial requirements of the research document called for three initiatives: first, a modern terminal that can adapt to changing commuter needs while providing the best conditions for travel; second, an activated public space that merges fragmented urban elements together in a civic focal point; and third, a master plan that seamlessly integrates both a modern terminal and civic focal point. However, during design analyses these initiatives have been reworked to take into account larger issues that arose. Union Station's failures are not inclusive to just the station, but plague much of the Central Railway Lands (CRL). Isolated programmed elements, poor circulation, and improperly scaled and designed public spaces are issues found to be in common with both the station and the CRL. Therefore an appropriate response was to include both the CRL and Union Station into a initiative that would properly unite various programmed elements through a cohesive circulation network of paths and public spaces. The original initiatives have since been reworked through design analyses into: first, a grand terminal hall that provides open sight-lines, easy pedestrian access, and direct connections to park spaces and venues; second, an activated public park space with a functional mix of uses, merging together scattered nodes surrounding Union Station; and third, a consistent topographical form that physically and visually unites the programmed and circulatory elements of the park space with the urban fabric of Toronto. These new initiatives help to envision a new relationship of Union Station and the CRL to the urban context by creating a continuous public landscape in and around the station, uniting station to venues through a medium of park space. These parameters infer the need for the redevelopment of Union Station and the CRL to provide the city of Toronto with a proper Urban Centre for transit and public activity.

Research of Bertonlini and Peek's ideal station conditions found that the CRL had become an "Unbalanced Place", requiring redevelopment of nodal connections and a new functional mix of programming. Nodal connections are all points of destination within a transit complex which include, but are not limited to transit gateways, lobbies, amenities, points of egress, leisure space, transit modes, and city destinations. A functional mix of programming can be considered the connective medium on which nodal connections are dispersed upon. An unbalanced place therefore is a condition when well developed nodal points are improperly connected through a functional mix of programming. Union Station's poor functional mix of programming provides inadequate connecting trajectories to navigate and merge with the CRL's largely monotone entertainment venues, underutilized and isolated parks, and downtown. These 
poor nodal connections created by an insufficient functional mix of programming lead design research to analyze the $C R L$ for its potential of becoming a large public space that could unify the various fragmented nodes and create a cohesive functional mix of programming across a large area. The intervention would have to provide a medium that can navigate various conditions including a transit hub, existing buildings, rail lands, roads and public entertainment venues. Not only does the intervention have to deal with the aspects of the immediate context, but account for the connective links that the transit system provides for the Greater Toronto Area (GTA). From a GTA perspective, Union Station is the central hub for all regional connections

\subsection{Regional Importance}

Regionally the CRL's importance is derived through its direct transportation links with Go Transit, Go Bus, Via Rail, TTC, expressways, and minor links with Toronto Island Airport and Toronto Island Ferry. Figure 9.1.1 produced by Graham Stewart for the artist/architect ran website, Reading Toronto reveals that Toronto's public transit network converges at Union Station. The diagram visually reveals Union Station as the most important hub in the entire GTA with all the lines radiating from the station. However, the map does not include connections outside the GTA such as Go Transit's regional links into Barrie and Niagara Falls or VIA Rail's intra-regional links, Figure 9.1.2.

Connections to Union Station provide services to more than 65 million users annually and keeps 1.5 billion $\mathrm{km}$ from being driven through the GTA annually; providing the population of the GTA easy access to the downtown from suburban locations \{Union Station Master Plan, 2005\}. Union Station complex's GTA importance is further increased by containing the regions 2nd largest convention centre, the Metro Toronto Convention Centre (MTCC); the Rogers Centre entertainment and sports venue who is home to the Toronto Blue Jays Baseball Club and Toronto Argonauts Football Team; and the Air Canada Centre (ACC) entertainment and sports venue who is home to the Toronto Maple Leafs Hockey Club, Toronto Raptors Basketball Club, and the Toronto Rock Lacrosse Team. In total the Union Station complex provides entertainment seating for more than 76,000 patrons and more than 750,000 sq. $\mathrm{ft}$ of exhibition space (Figure 9.1.3).

Located within the densest region of Toronto, the CRL as a hub is further enhanced by its characteristics as a transition point between downtown and waterfront, Figure 9.1.4. Originally CRL's northern edge, Front Street was defined as Toronto's original shoreline in 1850. 
Progressively since the 1850's Toronto's shoreline has been artificially expanded by infilling the lake and by the 1930's formed a bustling railway and shipping industry (Figure 9.1.5 \& 9.1.6).

The new shoreline continued to grow until the 1970's where the collapse of the rail and shipping industries in Toronto halted any further expansion into Lake Ontario. As the shipping and rail industries collapsed Toronto's world image as a metropolitan city grew. As a result of this the former railway lands were targeted for new development and services for the downtown core. The Gardiner Expressway was added in the 1960s through the railway lands to facilitate direct vehicle access to the downtown (Figure 9.1.7) and with large parcels of land abandoned by the railway industry, mega scale entertainment and sports projects including the $\mathrm{CN}$ Tower, Roger's Centre (formerly the Skydome), Metro Toronto Convention Centre (MTCC) and various large-scale condos of the Harbourfront 2000 initiative were added (Baird \& Sampson, 1987). Rather than locate these regional scale venues at the edge of the city Toronto intentionally located them in the City core as a means to boost activity in the largely vacant former rail lands. However, even through these large venues were created to increase the vibrancy of the downtown, they have had an opposite effect.

Without an appropriately programmed context around the venues and transit hub the area between the CRL lacked the ability to capture a constant populous. As a way to correct these programming issues the left over territories of the CLR were infilled in with condos, offices and more venues. By 2009 the remaining parcels of land are slated for near future construction leaving the Union Station complex in a disjointed mess of massive venues, miscellaneous service roads, office and condo complexes (see Chapter 3.0 Contextual Evolution). The addition of condo's and offices have not alleviated the issues of entrapping an active population around the CRL.

Primarily the venues and Union Station are occupied at specific time frames created by either commuters day movements or patrons of events at the venues. During non business hours and unscheduled venue events the CRL lacks a purpose for people to inhabit. Furthermore, like most condominium developments, the condominiums of the CRL are poor at activating the ground plane and are no better than the offices to provide use after hours. The proposed addition of underground mall space to Union Station, Telus Building and Maple Leaf Square are in trouble if they cannot capture a large enough population of users. Much like the PATH system of the business district, there is no evidence that these new subterranean shopping spaces will provide any use during the off hours. 


\section{TTC GTA TRANSIT MAP}

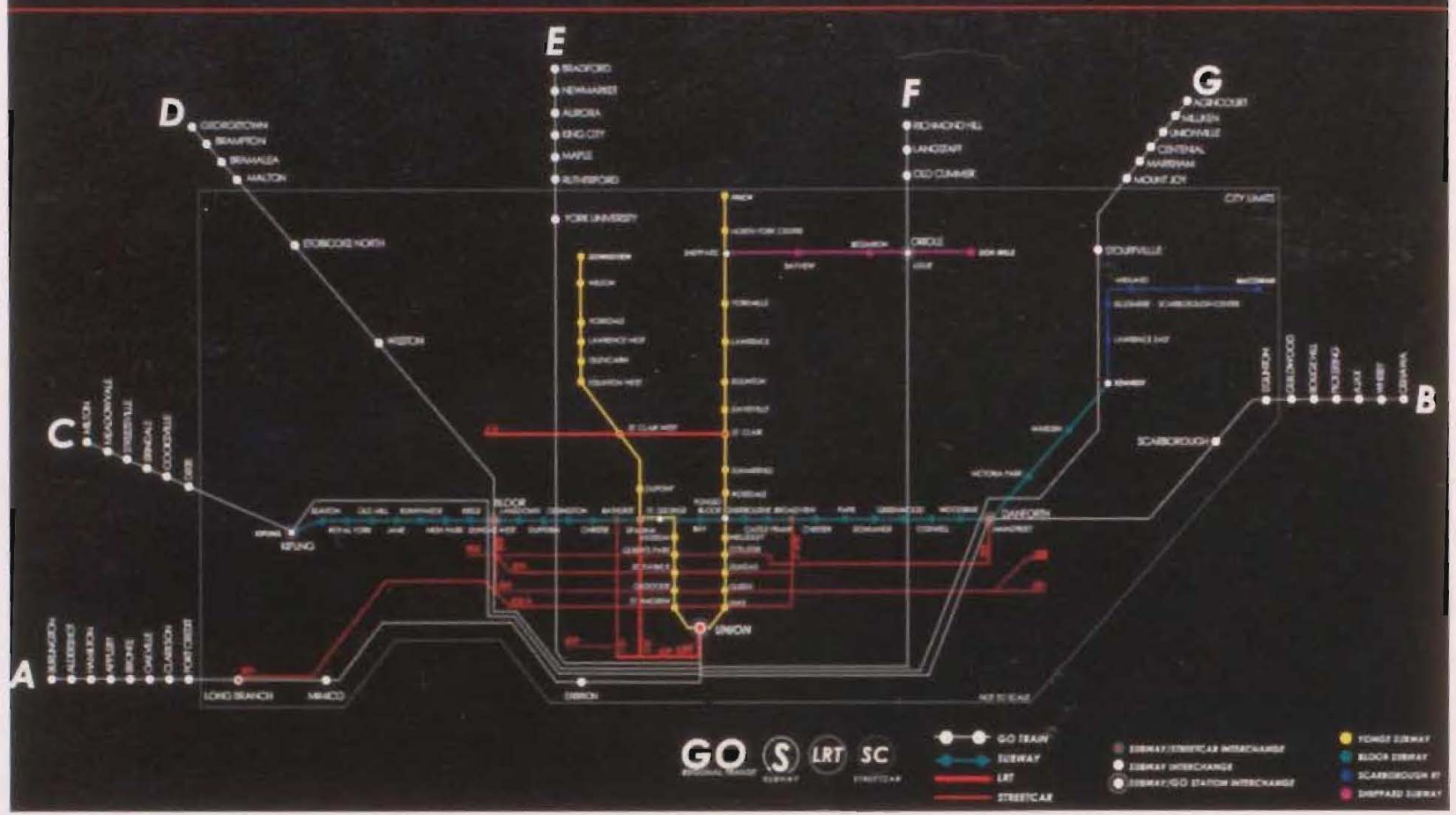

Figure 9.1.1 Graham Steward's TTC map,

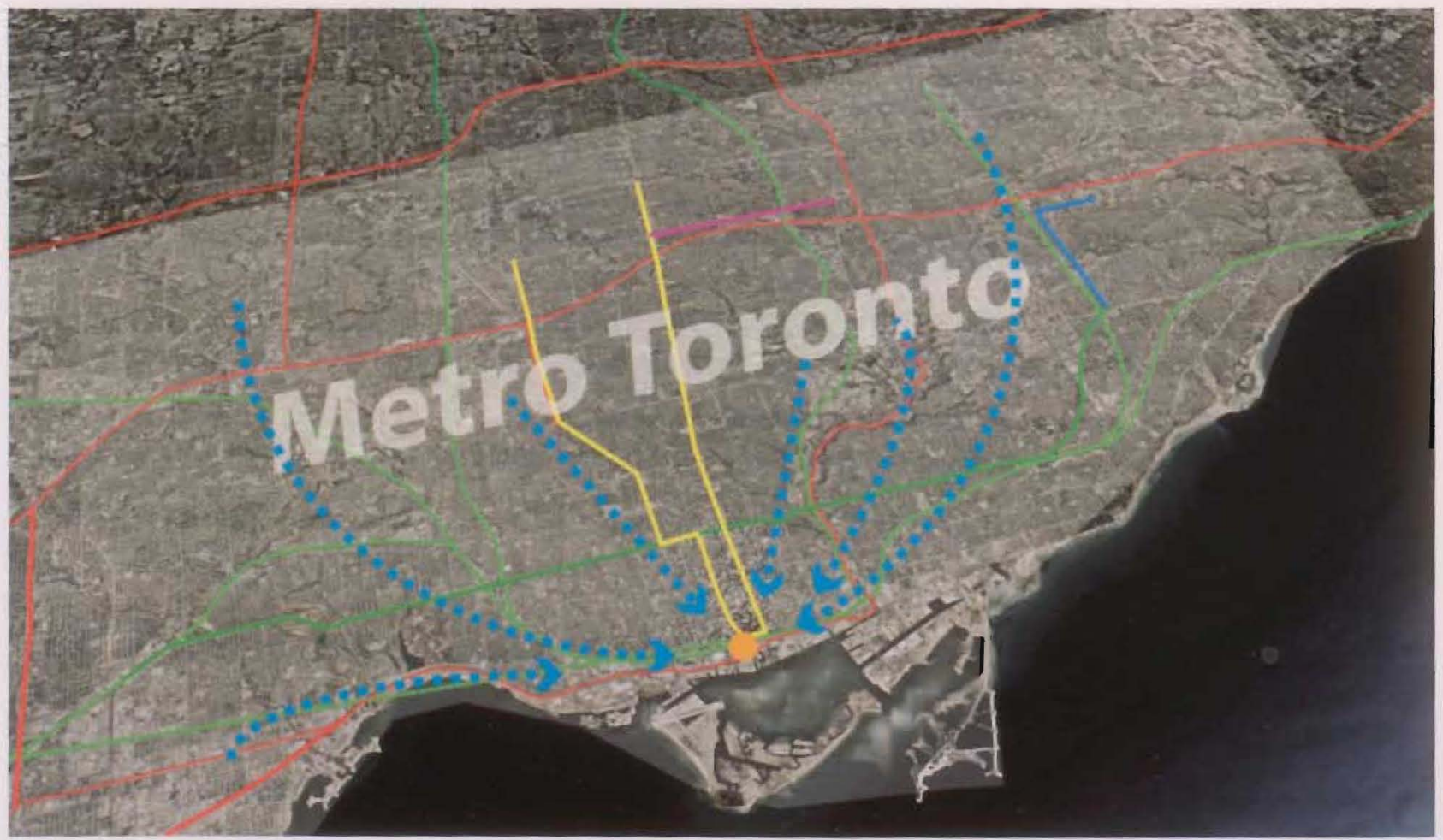

Figure 9.1.2 Convergent Infrastructure Systems - RED: Highway, SOLID GREEN, YELLOW, BLUE. PURPLE: Subway, and DASHED GREEN: GO TransitVIA Links 


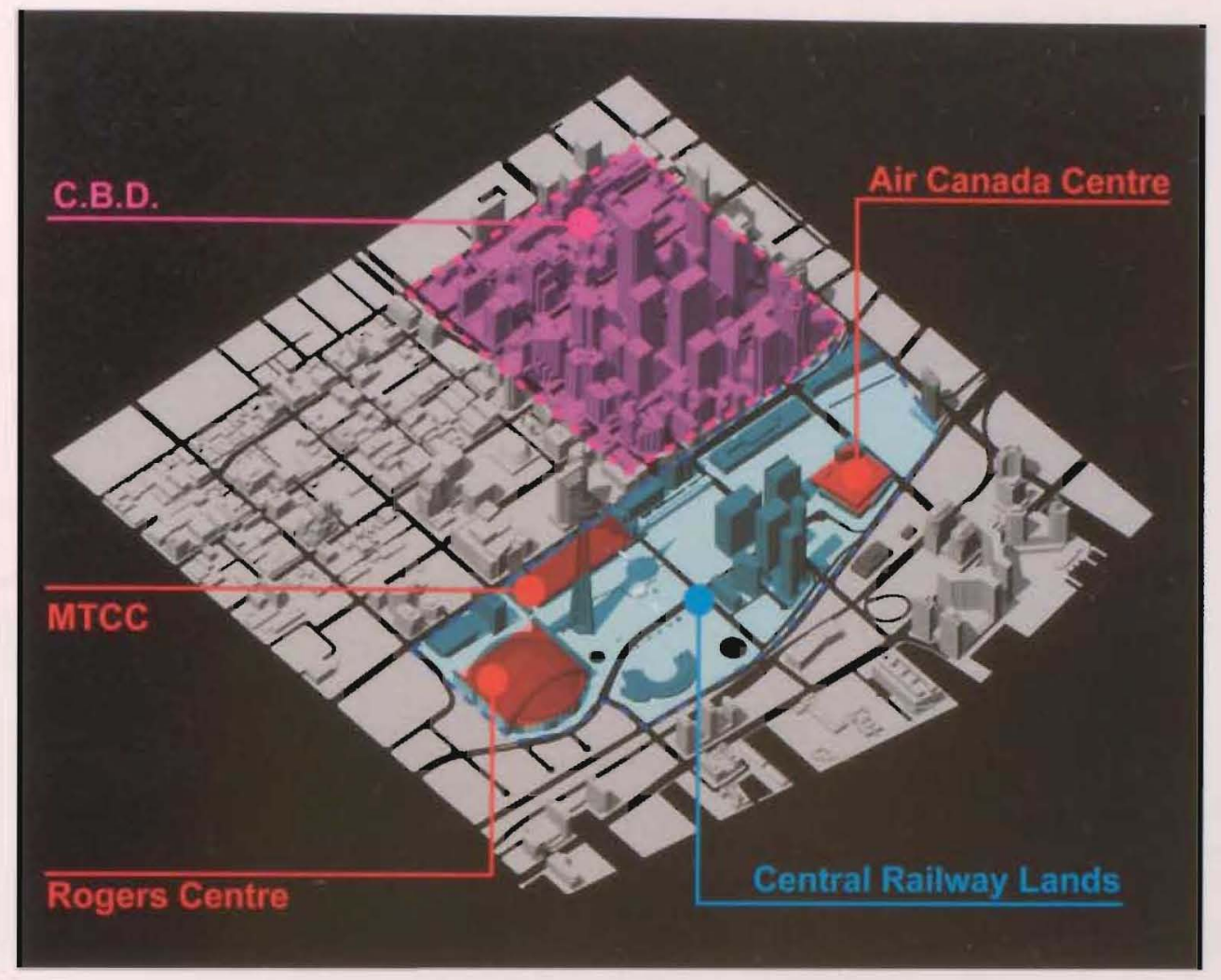

Figure 9.1.3 Venues and districts

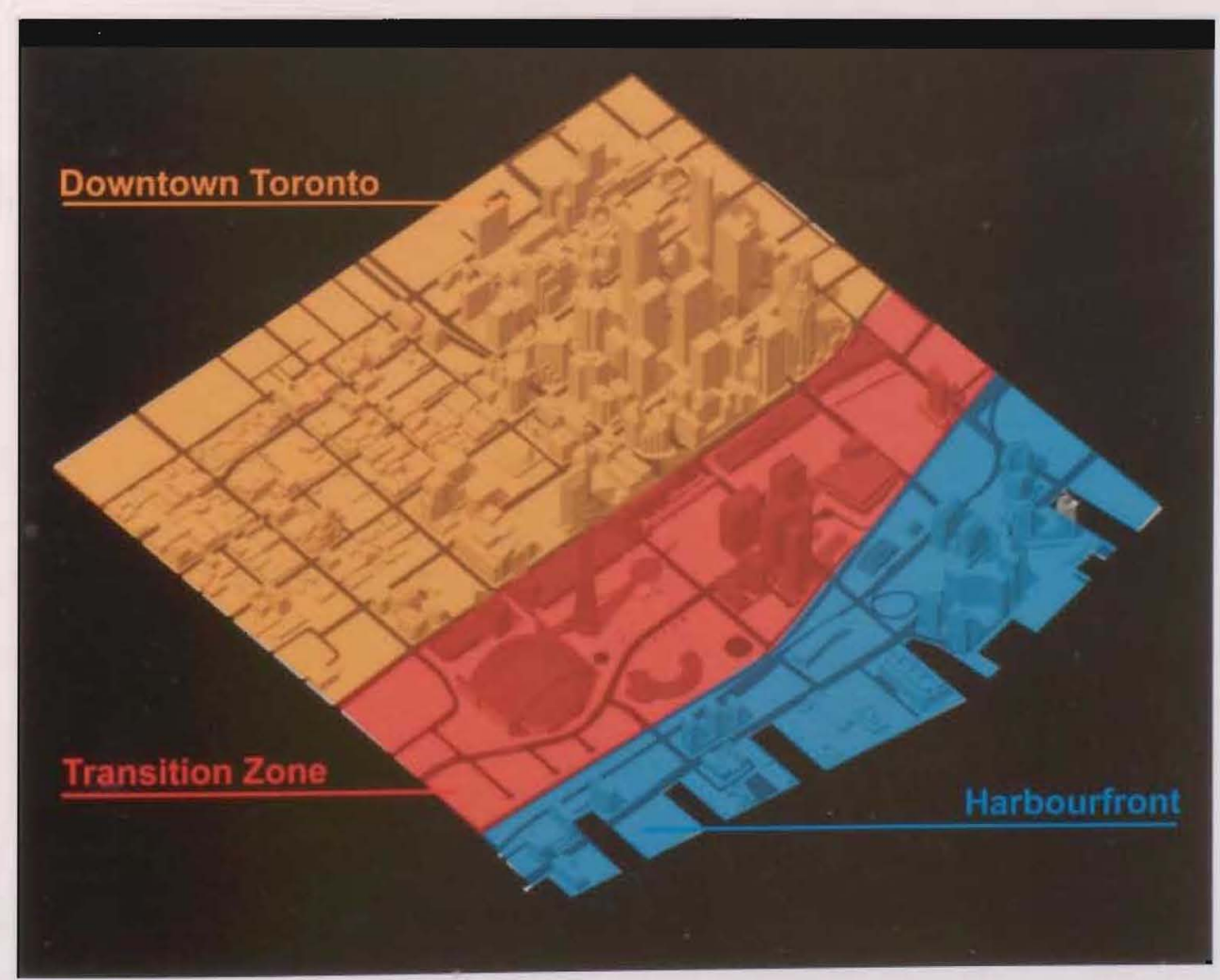

Figure 9.1.4 Transition Zone 


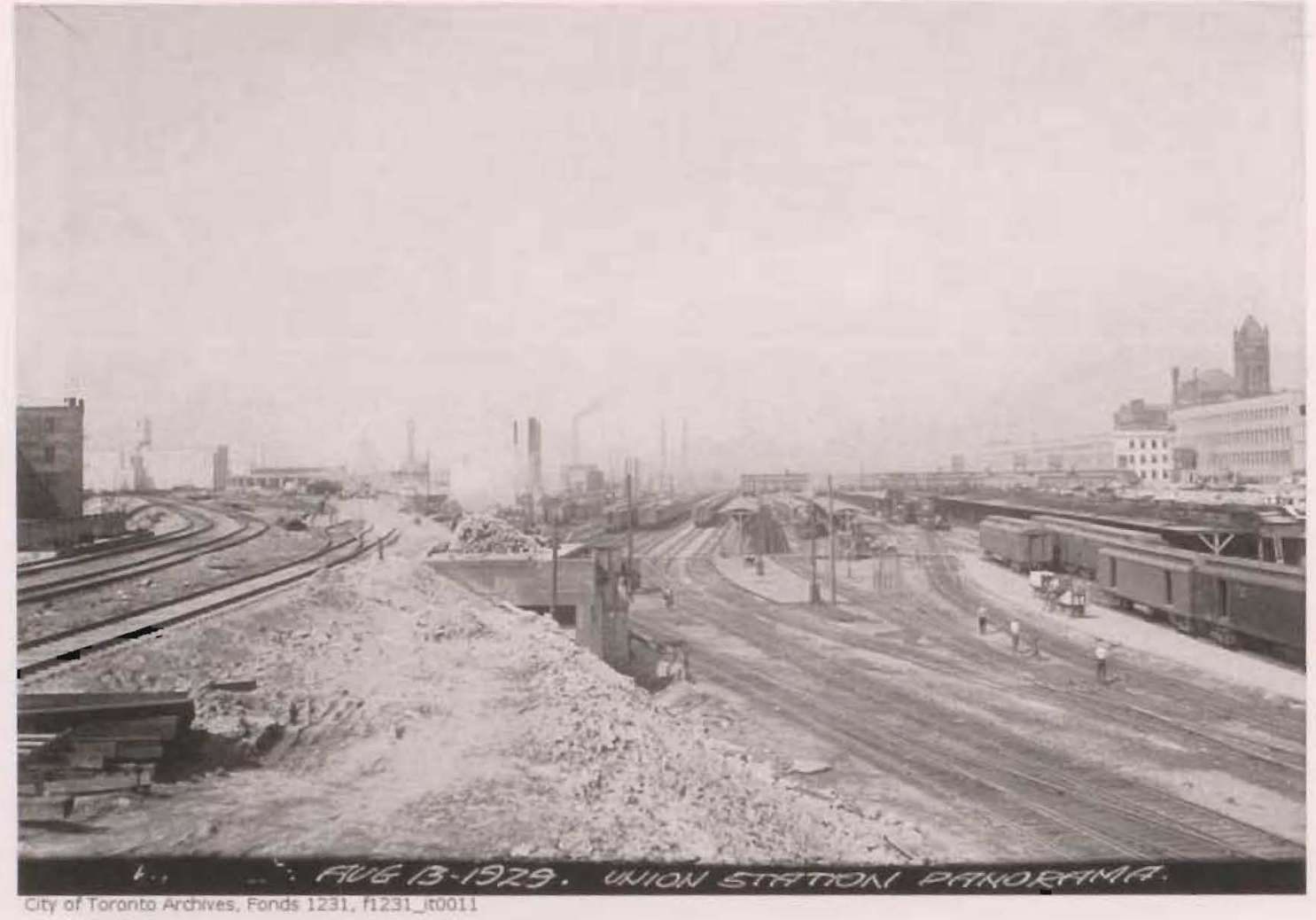

Figure 9.1.5 Shipping and Rail Industry, Union Station to the RIght, 1929.

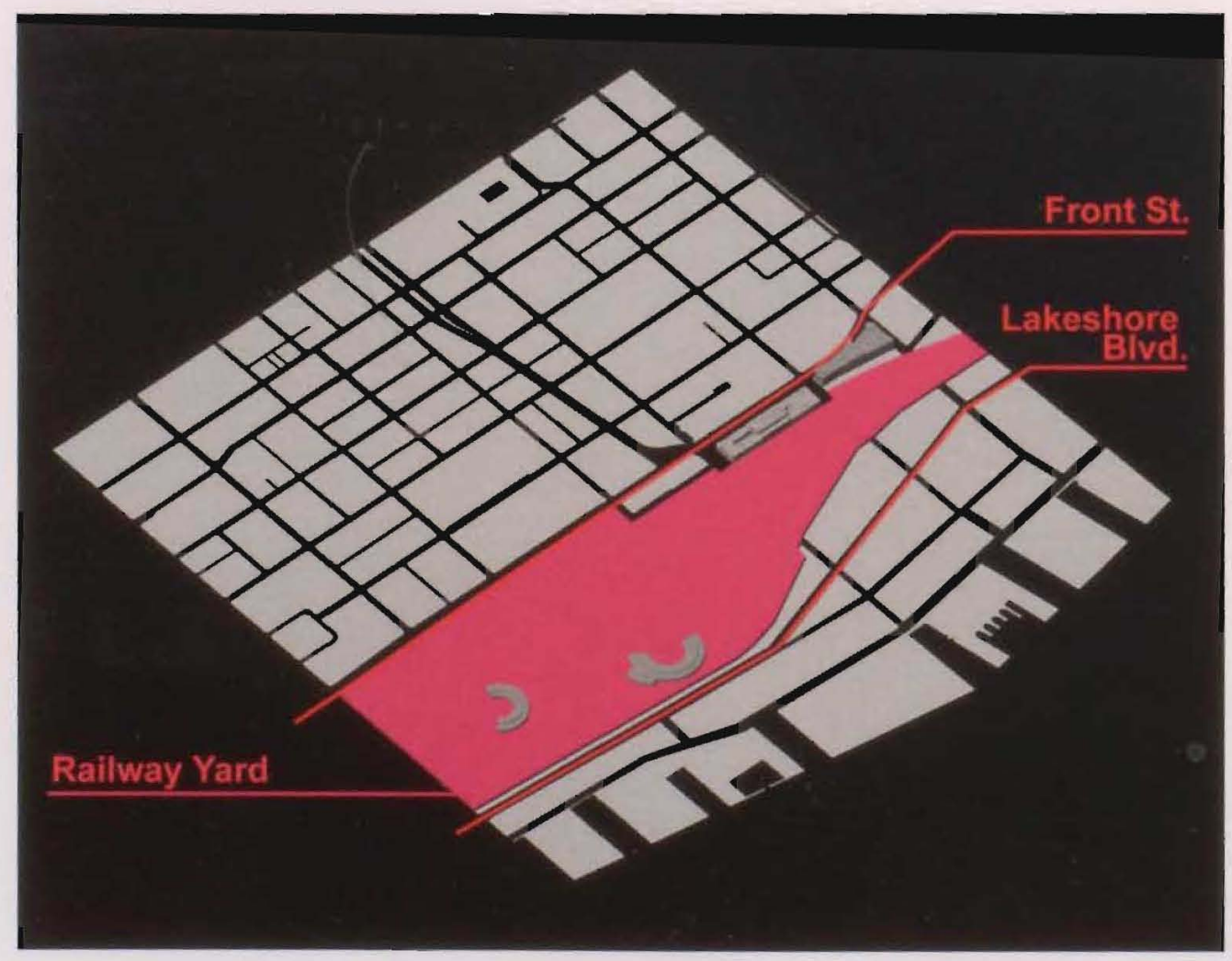

Figure 9.1.6 The extent of the railway yards and their peak usage. 


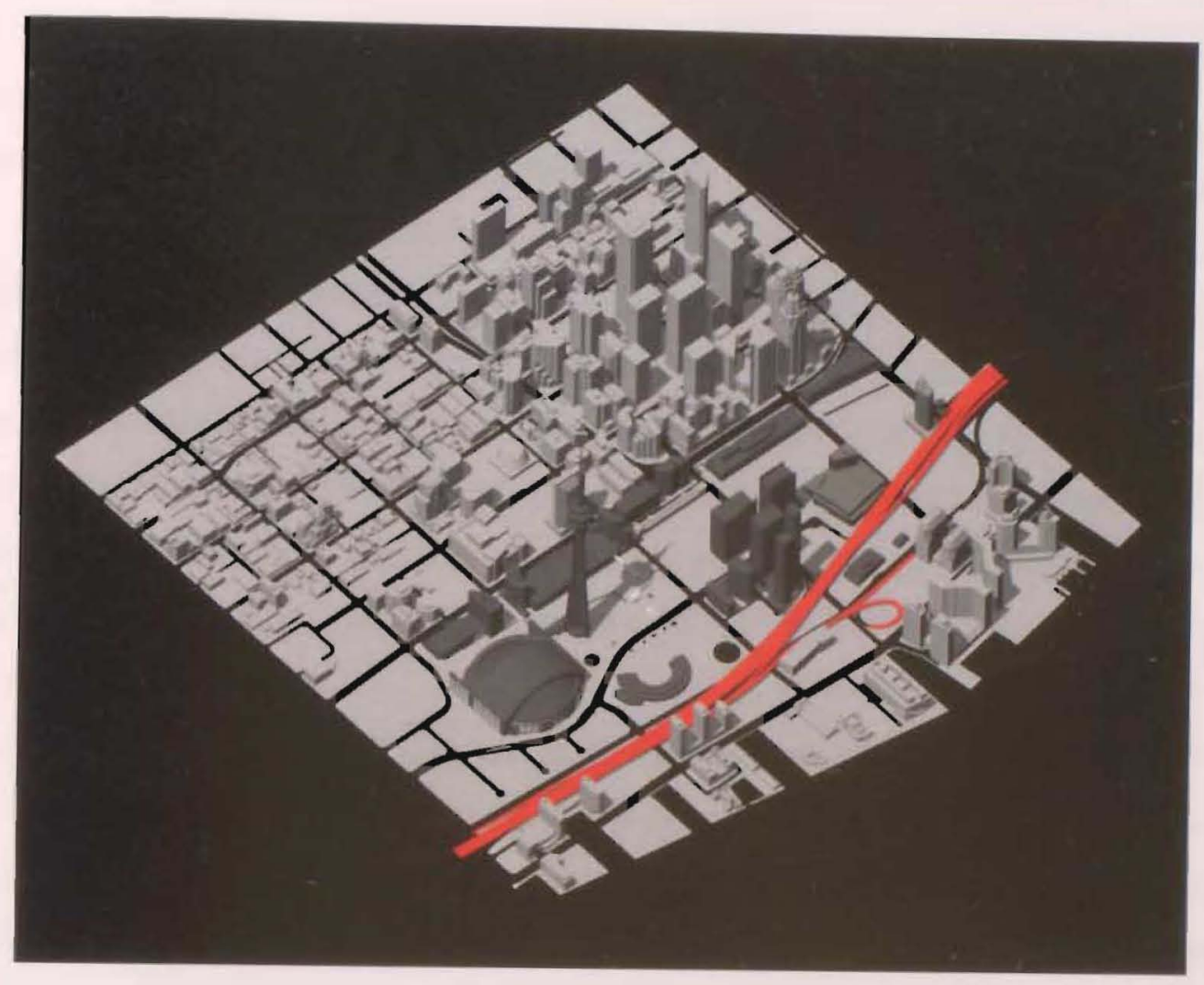

Figure 9.1.7 Gardiner Expressway.

\subsection{Central Railway Land Circulation}

The layout of roads, service entrances and building entrances has continued to enforce isolation of programmed elements and lack of attraction. Simcoe Street, York Street and Bay Street divide the site into 3 portions due to their function as arterial roads. Simcoe Street has become worse since upper Simcoe Street was connected by tunnel to Lower Simcoe Street where the MTCC's service and parking entrances are also located (Figure 9.2.1 \& 9.2.2).

Bremner Boulevard while wide, provides little use for its size during most days, leaving the site feeling empty. Bremner Boulevard's purpose as a connecting route from the ACC to Rogers Centre has been understated by poor ground level programming and destination links. Much of the open space at Bremner's east termination, Union Plaza has been consumed by new developments and the ACC's new west entrance expansion (Figure 9.2.3). Bremner's west termination around the Rogers Centre provides a lost destination with no real epicenter around the venue. During events at the Rogers Centre, tens of thousands of patrons fill the sidewalks 
and small plaza spaces with no real place to congregate in before an event. Due to the lack of spaces for the public to linger around at both the Rogers Centre and ACC, these venues witness a surge of users before and after events, leaving the area largely empty at all other times (Figure 9.2.4).

Exacerbating the problem of containing an active user is the limited existing park space that lack any sort of purpose other than to 'green' the otherwise dull area. The Roundhouse Park provides the most programmed park space in the area activated by historical train pieces, plaza space, treed landscape, and the Steam Whistle Brewery. The addition of an upscale Leon's furniture store into the existing roundhouse may provide a few more happenstance users, however the lack of prominent connections to the Roundhouse Park isolates the park space within the CRL (Figure 9.2.5).

Green space surrounding the CN Tower base and MTCC south building provide no other means than to deal with an interstitial space between two objects. The adjacent CN Tower Plaza provides a marginal use for incoming tourists to the CN Tower, but lacks little use for inhabitants of Toronto (see Chapter 4.0 So Many Issues). The greatest activity the CN Tower Plaza witnesses is during large events at the Roger Centre by providing a space to overflow patrons into. Union Station's Front Street plaza is heavily under utilized as a means to anchor Union Station as an important symbol within the city. Currently the space is small, plagued by heavy vehicular traffic and lacks space for users to linger comfortably. The combination of Roundhouse Park, Union Station Plaza, Union Station Front Street Plaza, CN Tower Plaza and adjacent green space provide little attraction for the general public and a fail to tie together the CRL (Figure 9.2.3).

Topographically the CRL contains a maze of changing elevations, skywalks, subterranean facilities, bridges, tunnels and stretches of inaccessible territories. The rail corridor produces much of these problems by creating 3 distinct elevation regions, Front Street, Rail Corridor, and Harbourfront. Front Street represents Toronto existing shoreline with all lands south of it being man-made. Front Street is at the same grade as the Great Hall of Union Station until it reaches the rail Corridor (Figure 9.2.6 \& Figure 9.2.7). The rail corridor rises a couple meters above the grade of Front Street to form the platforms of Union Station. Originally the rail corridor was to be below Front Street grade to facilitate in an overhead concourse, but costs prohibited this. The result was to artificially raise the land high enough to have a subterranean concourse. Access south across the inaccessible rail corridor is largely provided by Simcoe Street, York Street, and Bay Street tunnels and teamways (Figure 9.2.8). More obscure 
connections to the area south of the station are provide by the Skywalk over the rail corridor and the soon to be opened VIA concourse passage to Union Station Plaza (Figure 9.2.9 \& 4.2.14). Union Station also provides a tunnel from the Go Concourse to the ACC beneath the rail lands. MTCC provides a skywalk over the rail lands from the north building to south building and from the north building to $\mathrm{CN}$ Tower Centre. While all these connections are loosely open to the public, it is only the bridge from Front Street to the Rogers centre that provides a visually identifiable connection over the rail corridor, free to all users of Front Street (Figure 9.2.10 \& 4.2.13). The rail lands height effectively bisects the downtown from the harbourfront visually and physically with connections lacking visual cues to their apparent destination.

These oppressive conditions caused by the rail lands necessitate the need for a unifying medium to connect the fragmented nodes of the CRL. The medium would therefore have to negotiate varying topographical conditions; networks of new and old circulation routes; existing built fabric; large scale venues; and a regional transit hub. The end result would not only have to provide a connective tissue for the central railway lands, but would have to provide an urban space on which metropolitan and suburban users of the GTA could occupy.

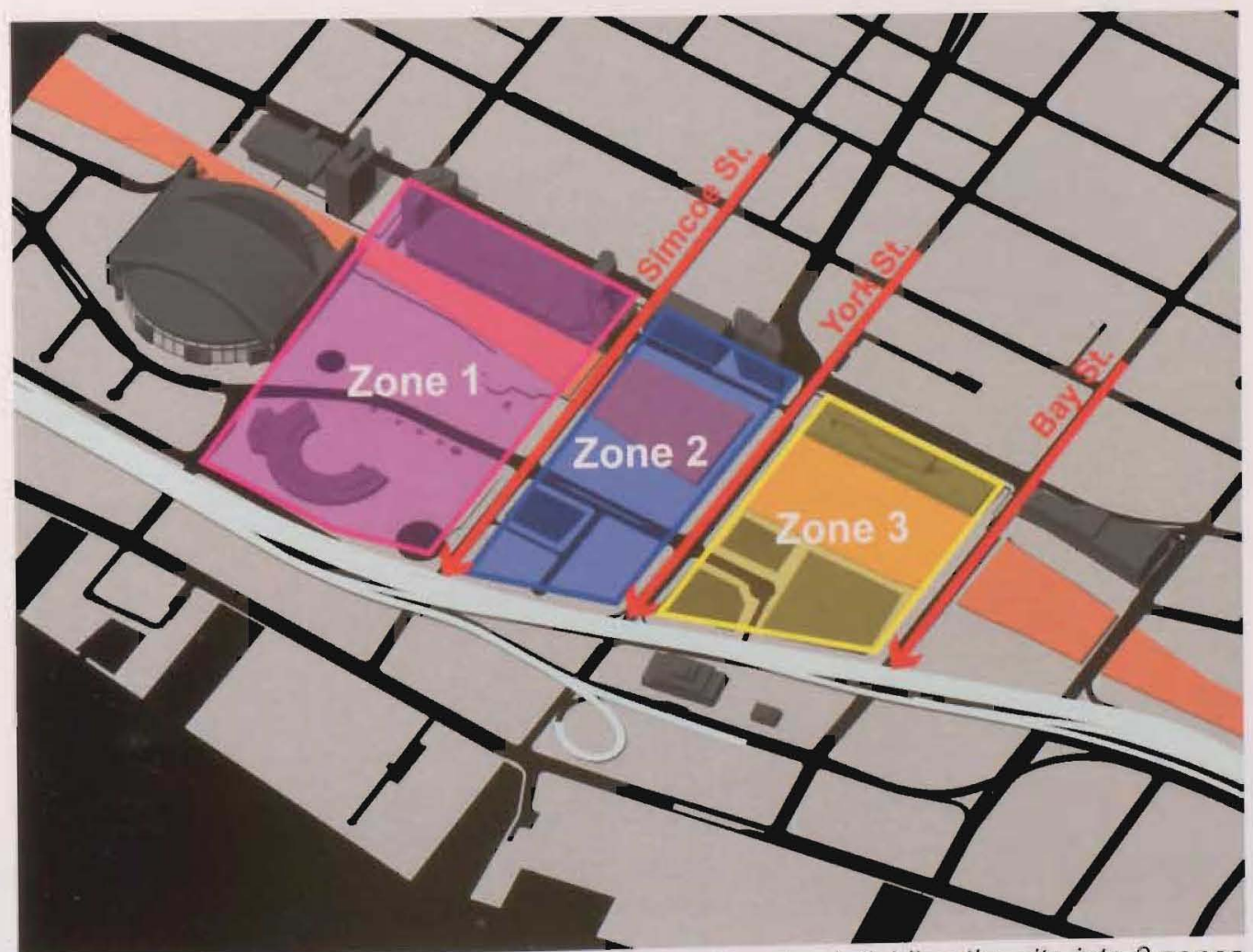

Figure 9.2.1 Simcoe Street, York Street and Bay Street subdividing the site into 3 zones. 


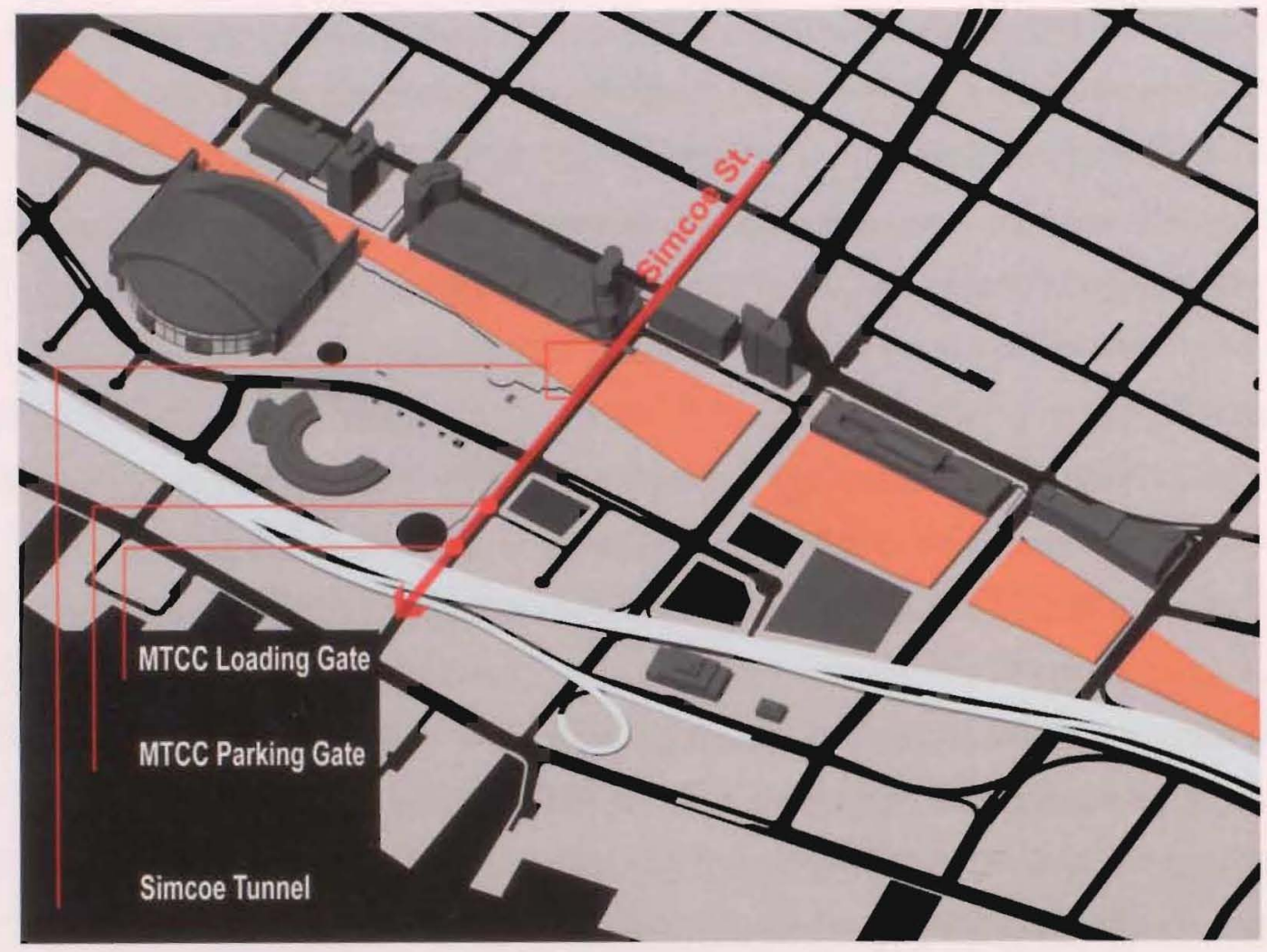

Figure 9.2.2 Simcoe Street and MTCC gates.

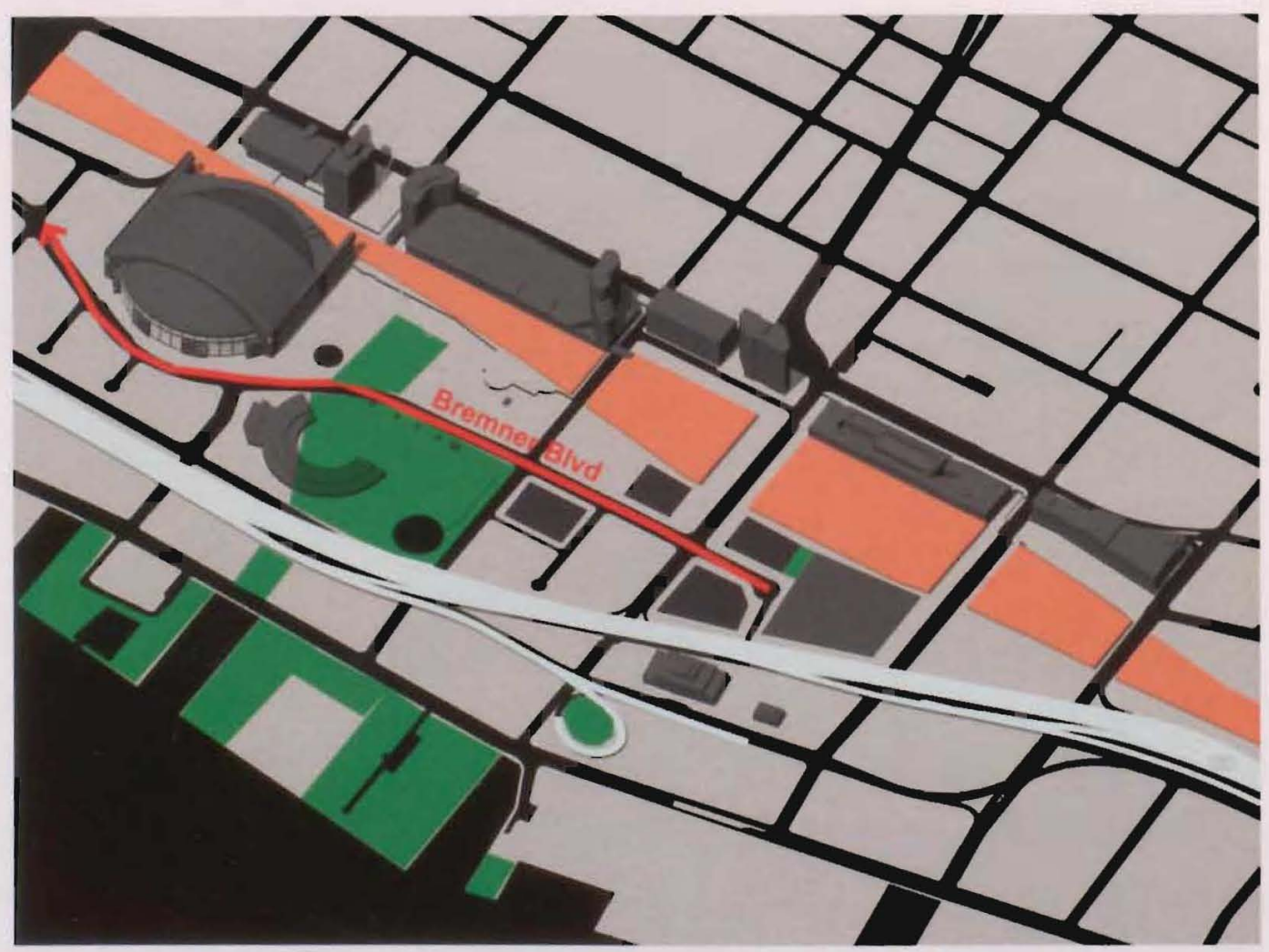

Figure 9.2.3 Bremner Boulevard with surrounding park spaces (note Bremner's termination at the ACC with a minor park space). 


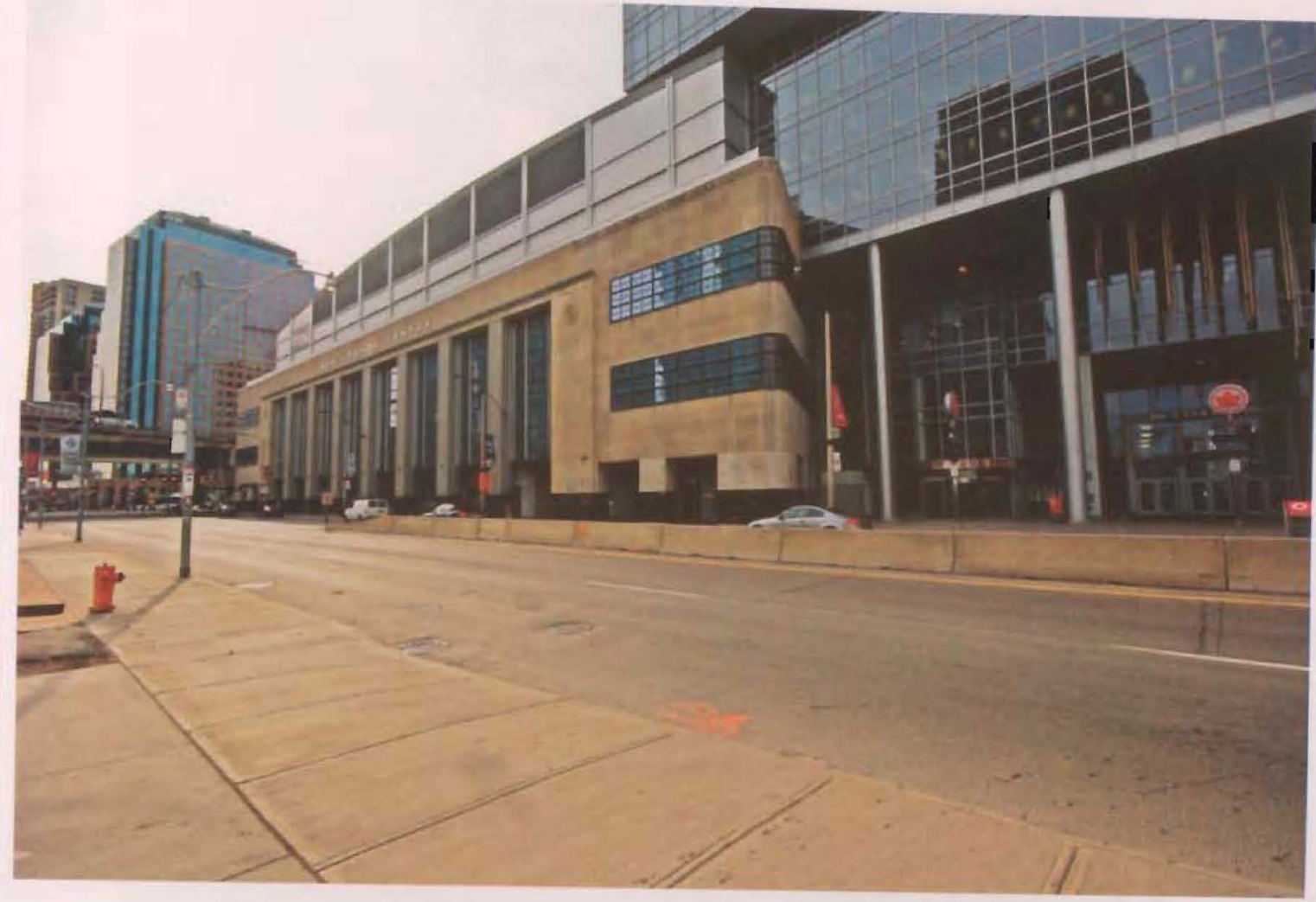

Figure 9.2.4 Typical day condition of the ACC devoid of users until an event is held.

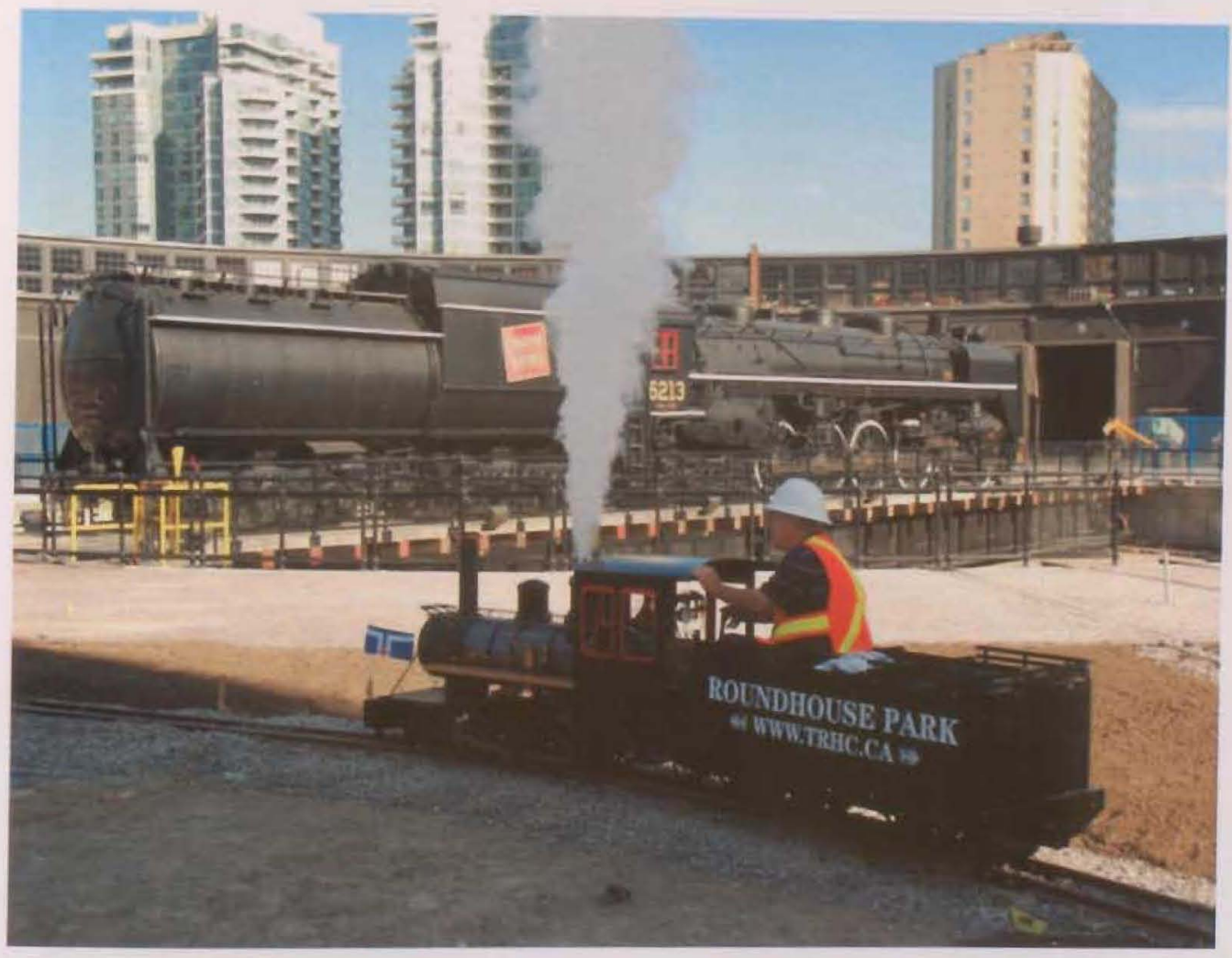

Figure 9.2.5 Roundhouse Park with new turntable display and miniature steam engine ride. 

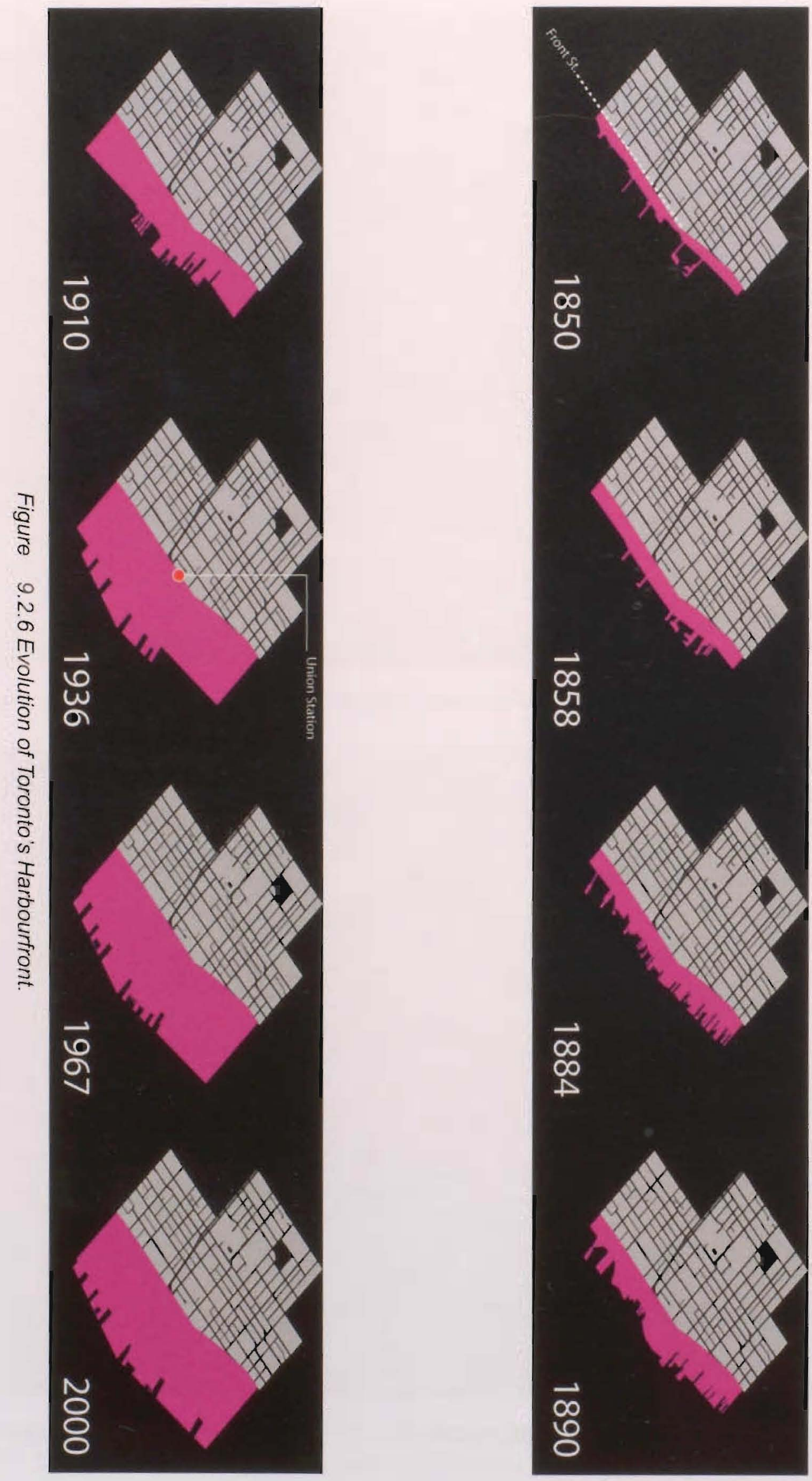


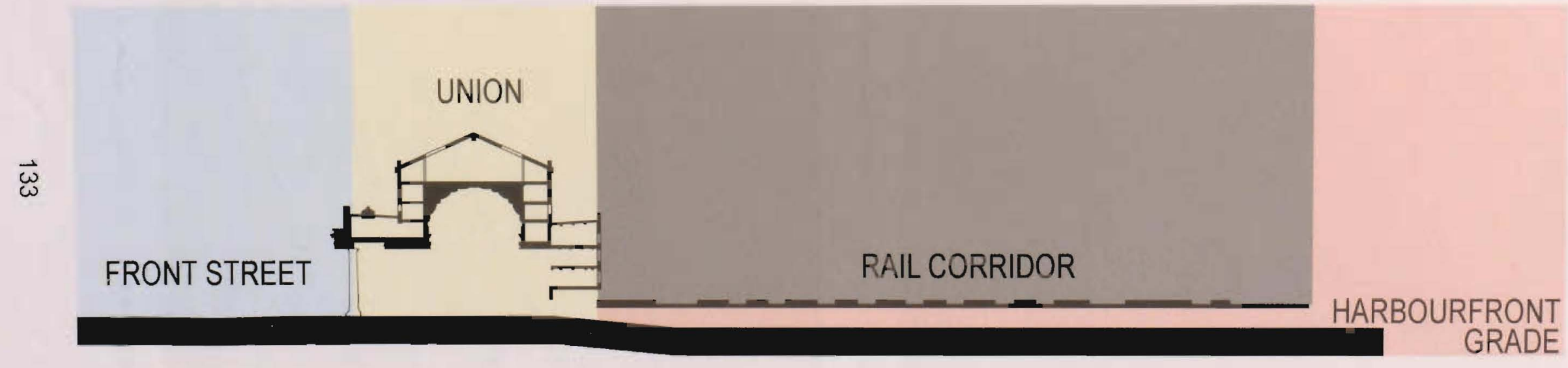

Figure 9.2.7 3 Elevation Regions 


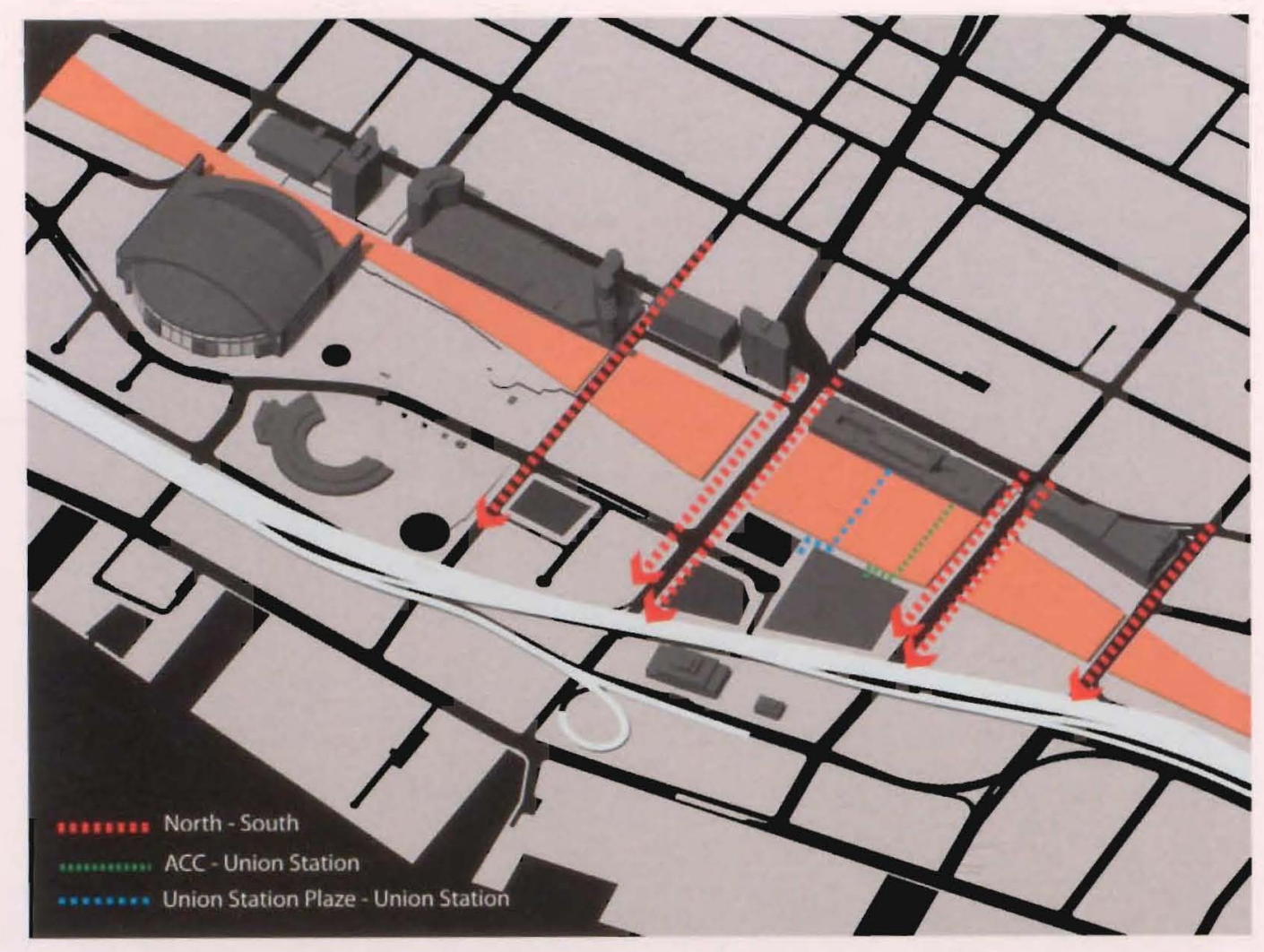

Figure 9.2.8 present north-South connections

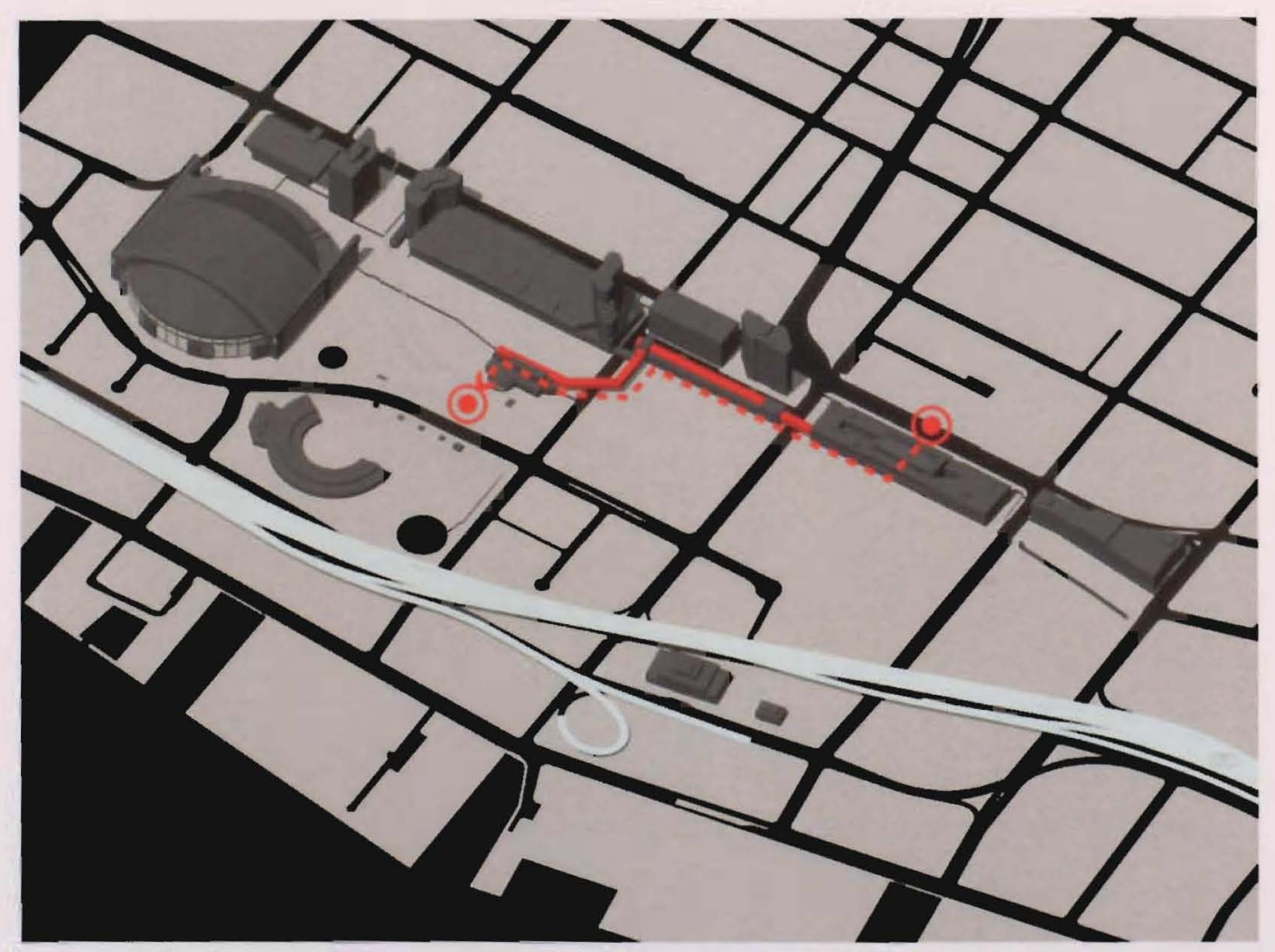

Figure 9.2.9 Skywalk connection from Union Station (RIGHT) to MTCC South building (LEFT) 


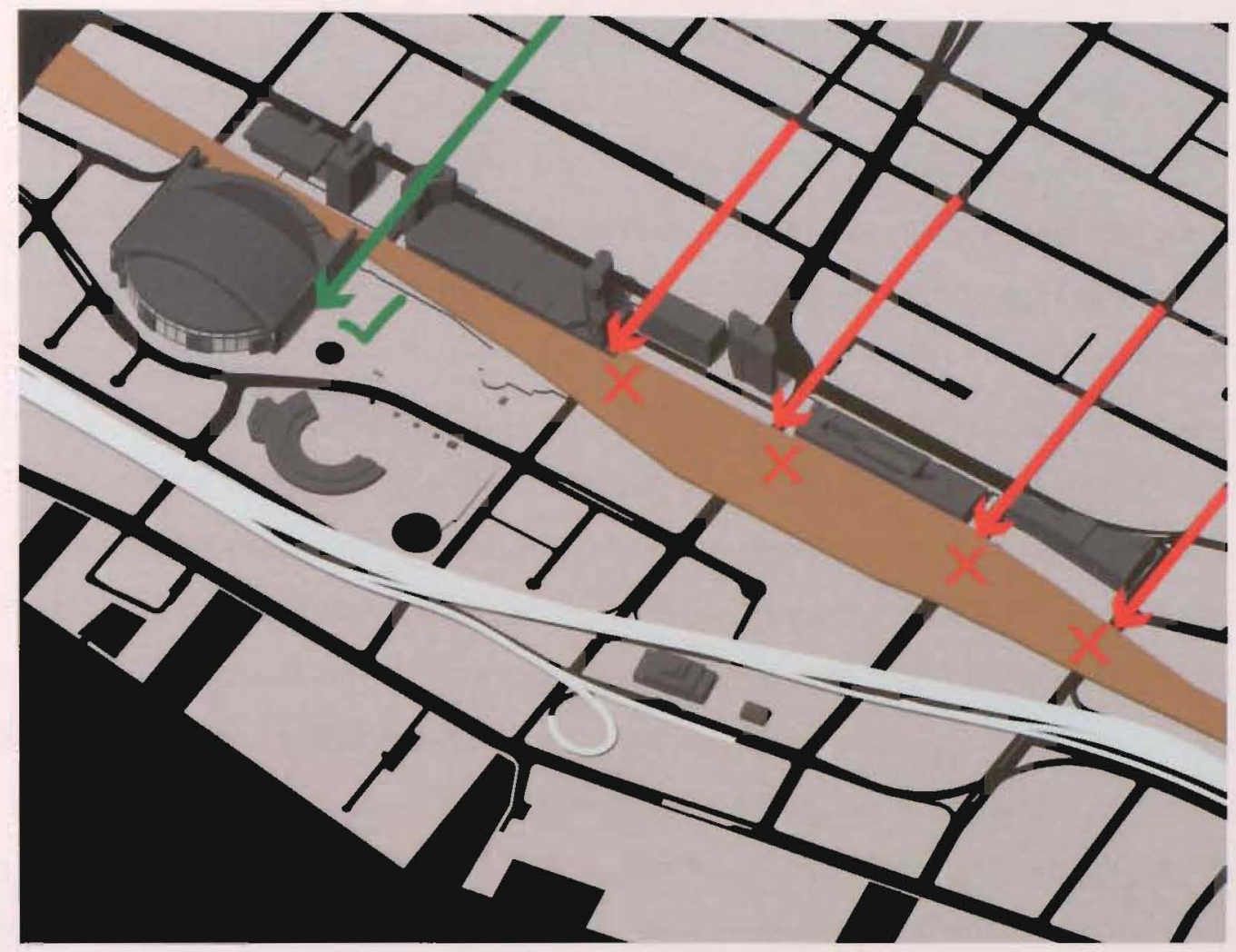

Figure 9.2.10 RED: no overpass, GREEN: Overpass (only one overpass, John Street Bridge) 
[136] 


\subsection{Intervention - the Surface}

An intervention of the CRL began with a notion that a continuous public surface was required to knit the multiple buildings, levels and landscape elements together into a cohesive vision. The continuous public surface functions as the medium for the laying out of a functional mix of programming to provide a framework for circulation trajectories to be mapped out upon. A surface was laid over the area and trimmed to fit into the remaining unused spaces that included rail corridor, parks, roads and parking lots \{Figure 10.0.1 to 10.0.7\}. Upon this surface all the existing routes were analyzed at all levels, revealing strong north-south connections due to the city's grid, but limited east-west and diagonal connections. From these routes, new trajectories were laid out to provide the most ideal node-to-node trajectories with an emphasis on pedestrian flow (Figure 10.0.8 \& 10.0.14).

The surface begins to take on the qualities of a navigable landscape that can begin to stitch together the various nodes of the CRL. A new functional mix of programming is introduced as linking elements for the new trajectories. The new circulation trajectories made precautions not to disrupt the ideal node-to-node connections or to drastically change existing programmed elements. Existing buildings were to continue to remain in their present location with only the MTCC south building receiving changes to provide more functional use. Diagrammatically the surface worked, but a flat, undifferentiated surface was clearly not sufficient enough accommodate varying topographical changes; connections requiring vertical and horizontal access; interaction between existing elements; and provisions for programming beneath the surface. To accommodate these factors, the surface was developed into a form that could provide the best logistical and formalistic solution. 


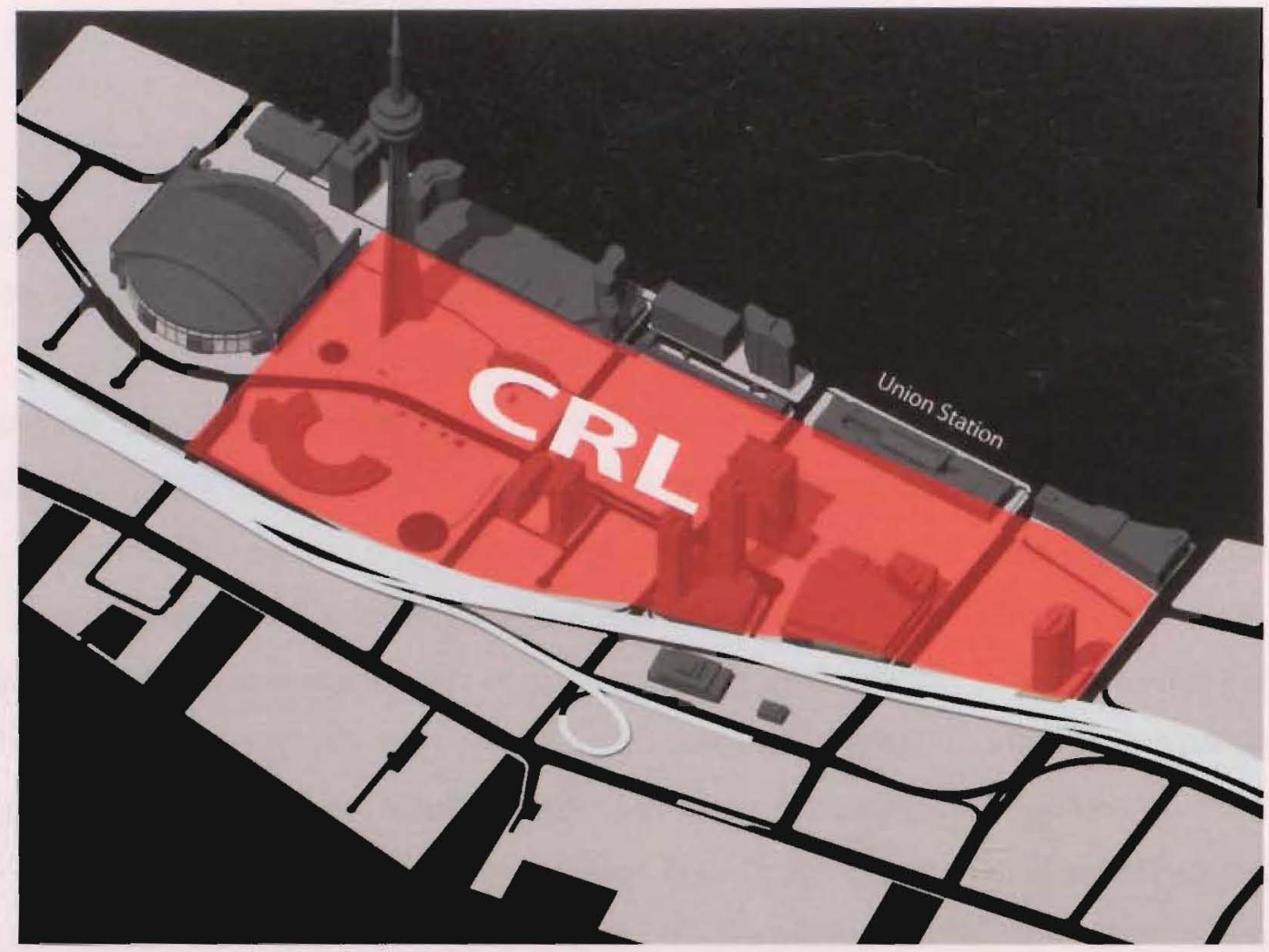

Figure 10.0.1 Central Railway Land district

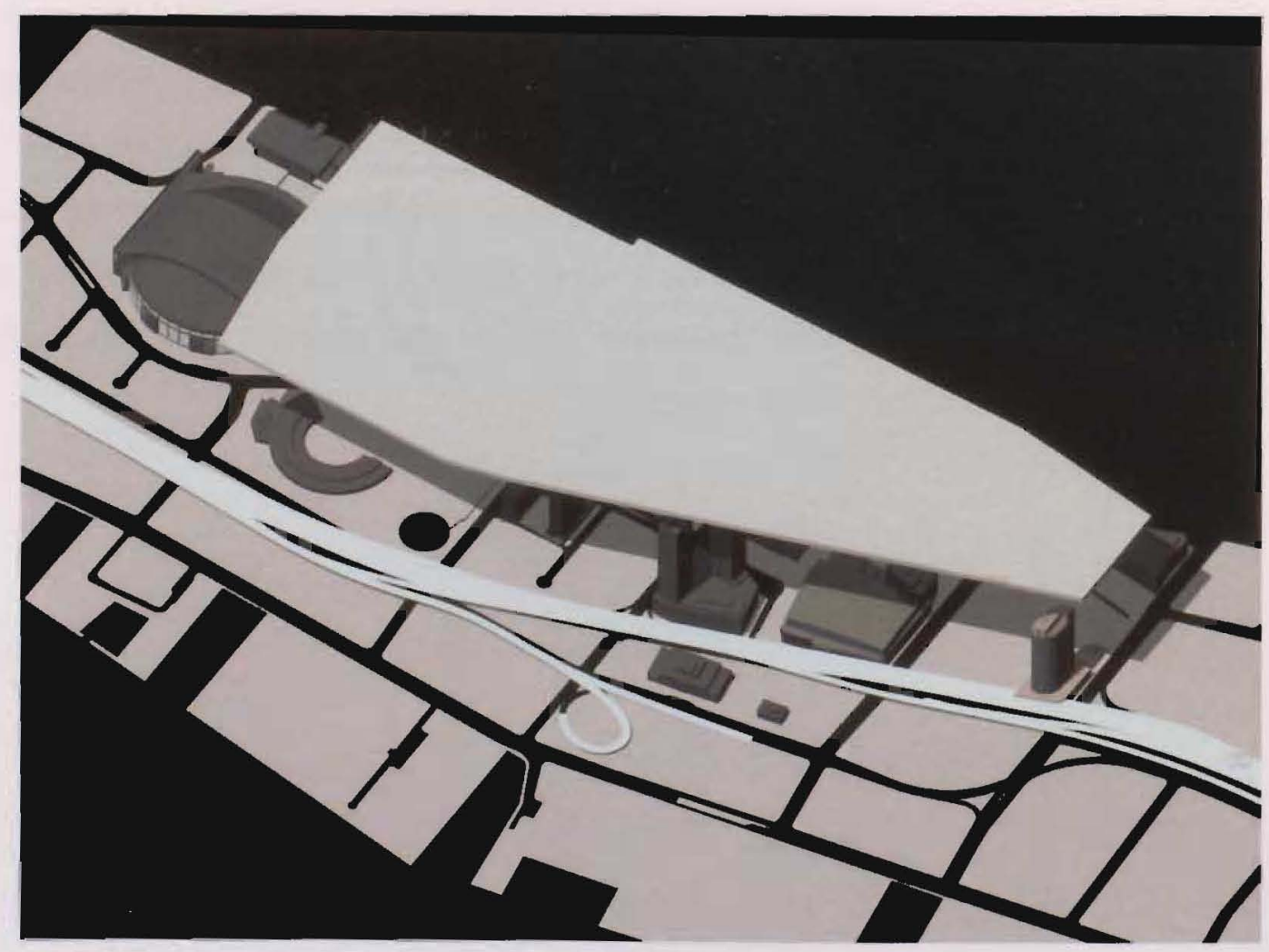

Figure 10.0.2 Surface generated by the extents of the CRL 


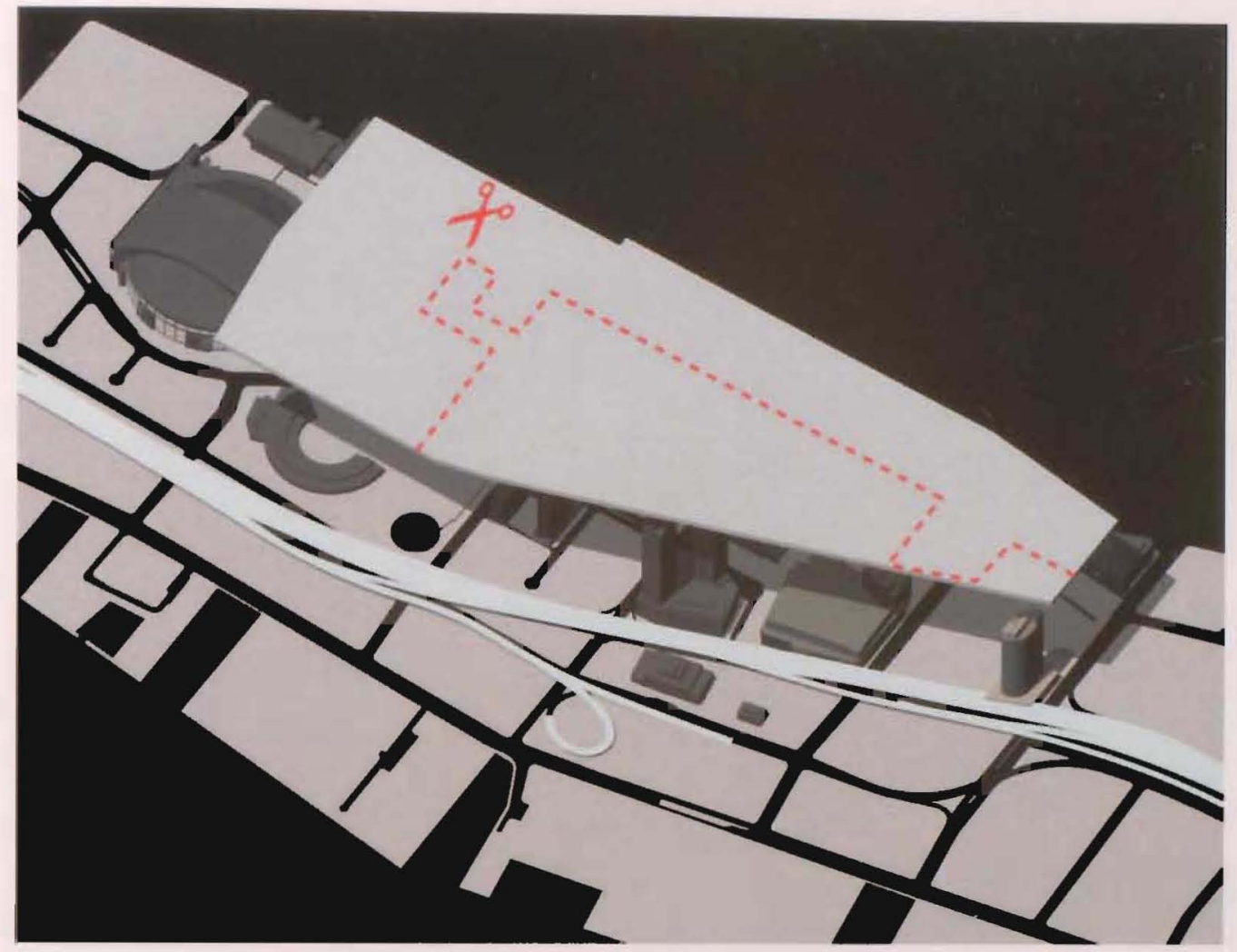

Figure 10.0.3 Spaces presently occupied by structures are cut from the surface.

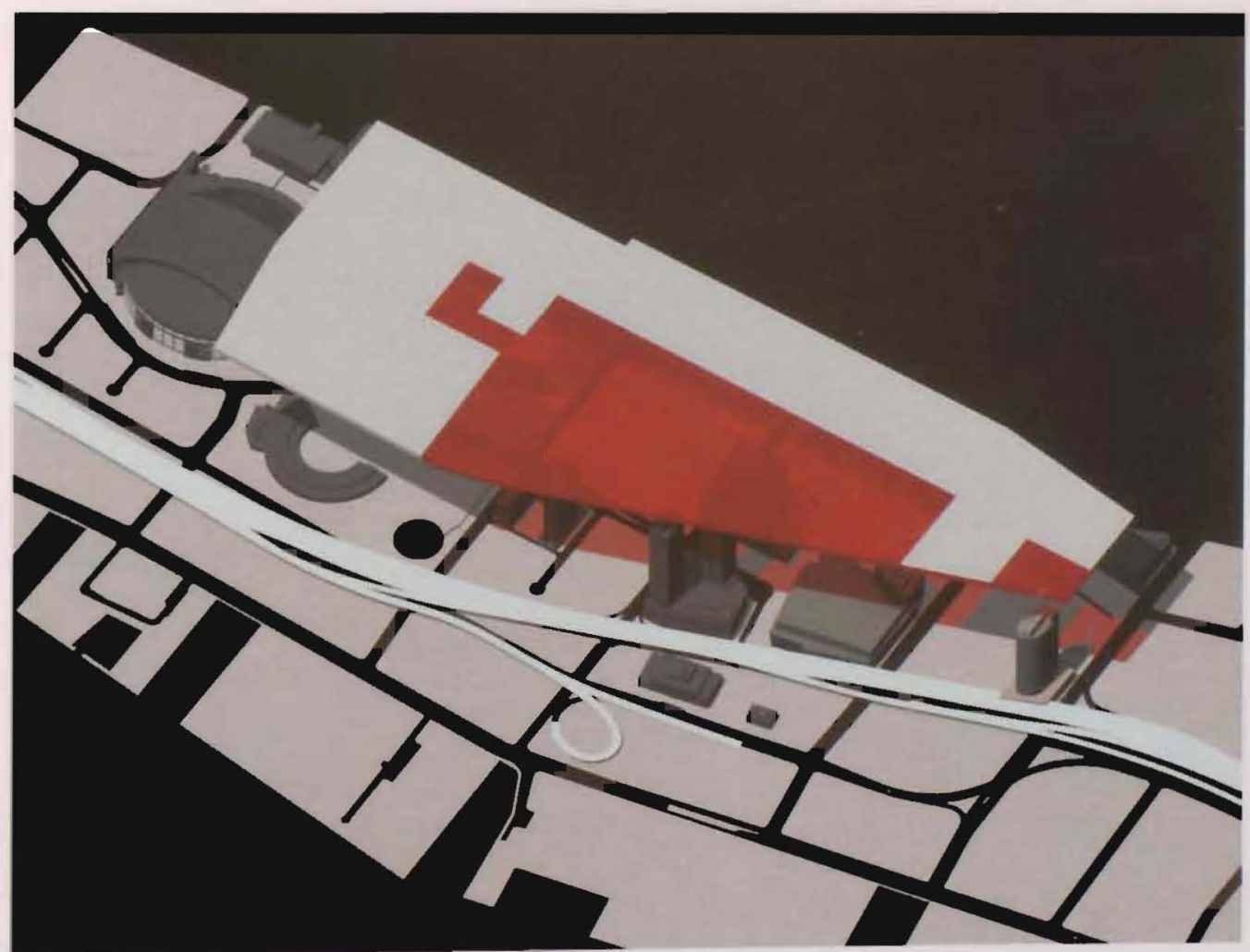

Figure 10.0.4 Removed element begins to define the surfaces extents and boundaries. 


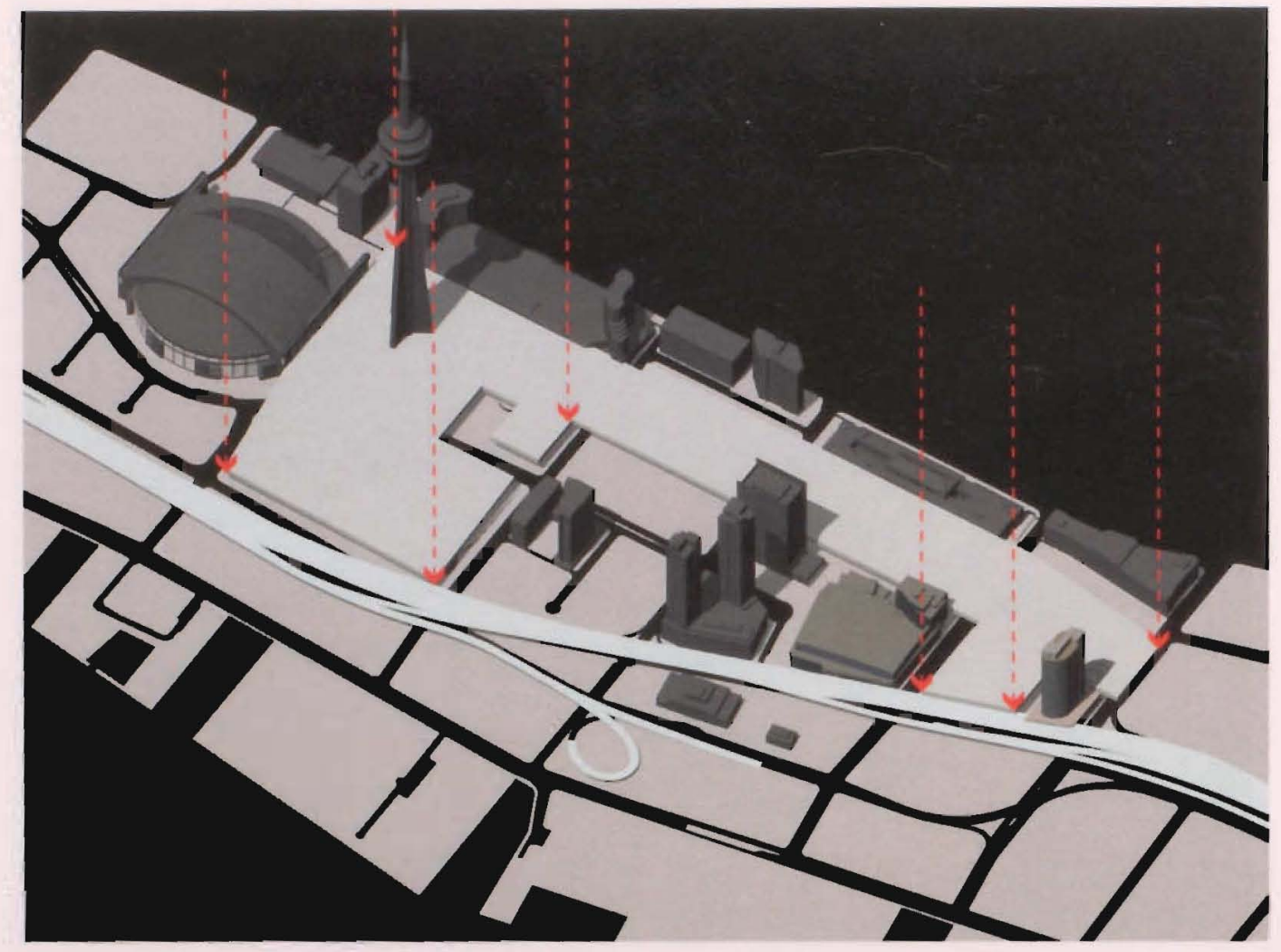

Figure 10.0.5 Surface dropped down over the CRL's underdeveloped territories.

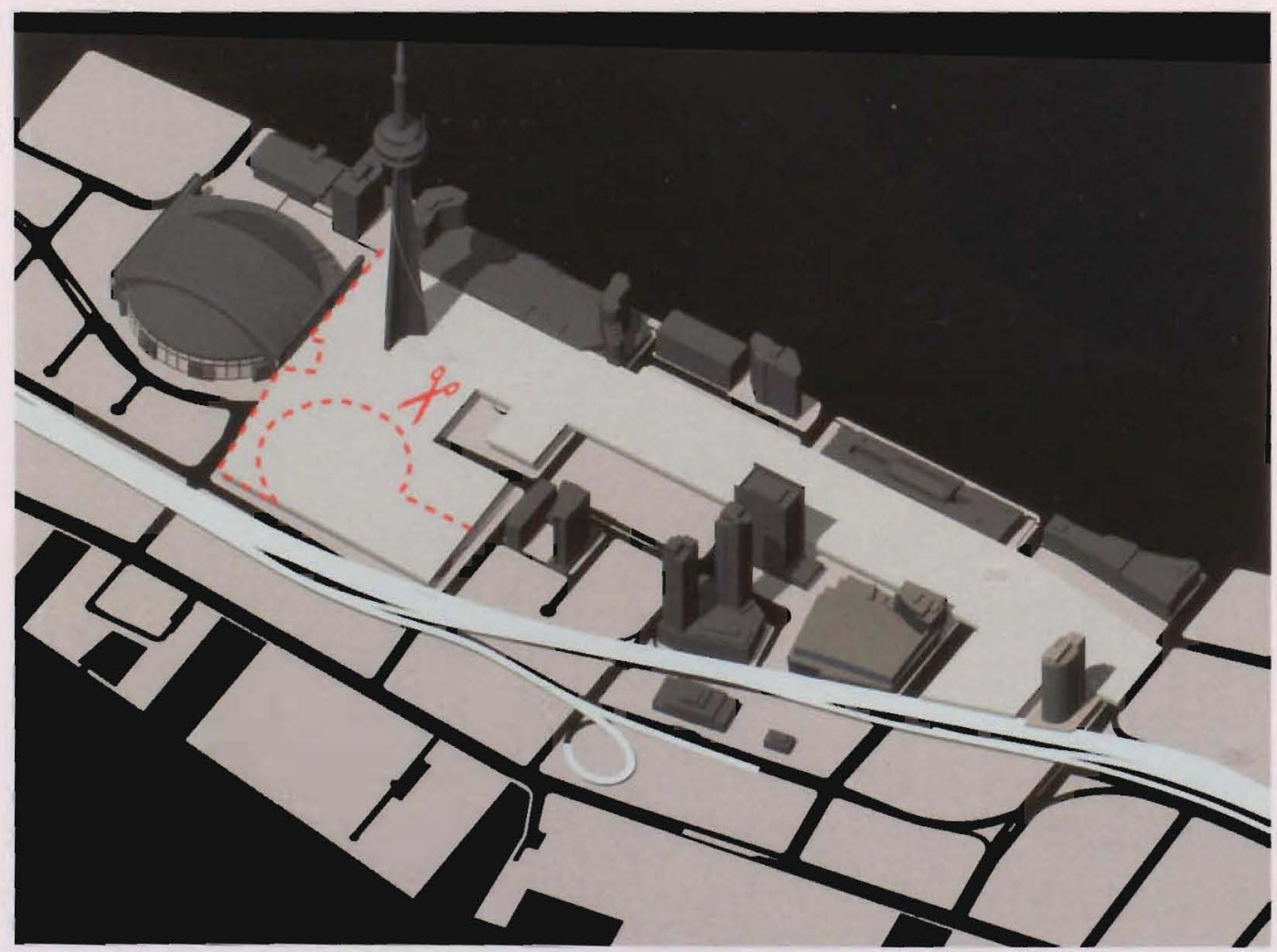

Figure 10.0.6 The existing Roundhouse Park defines the form of the southern edge. 


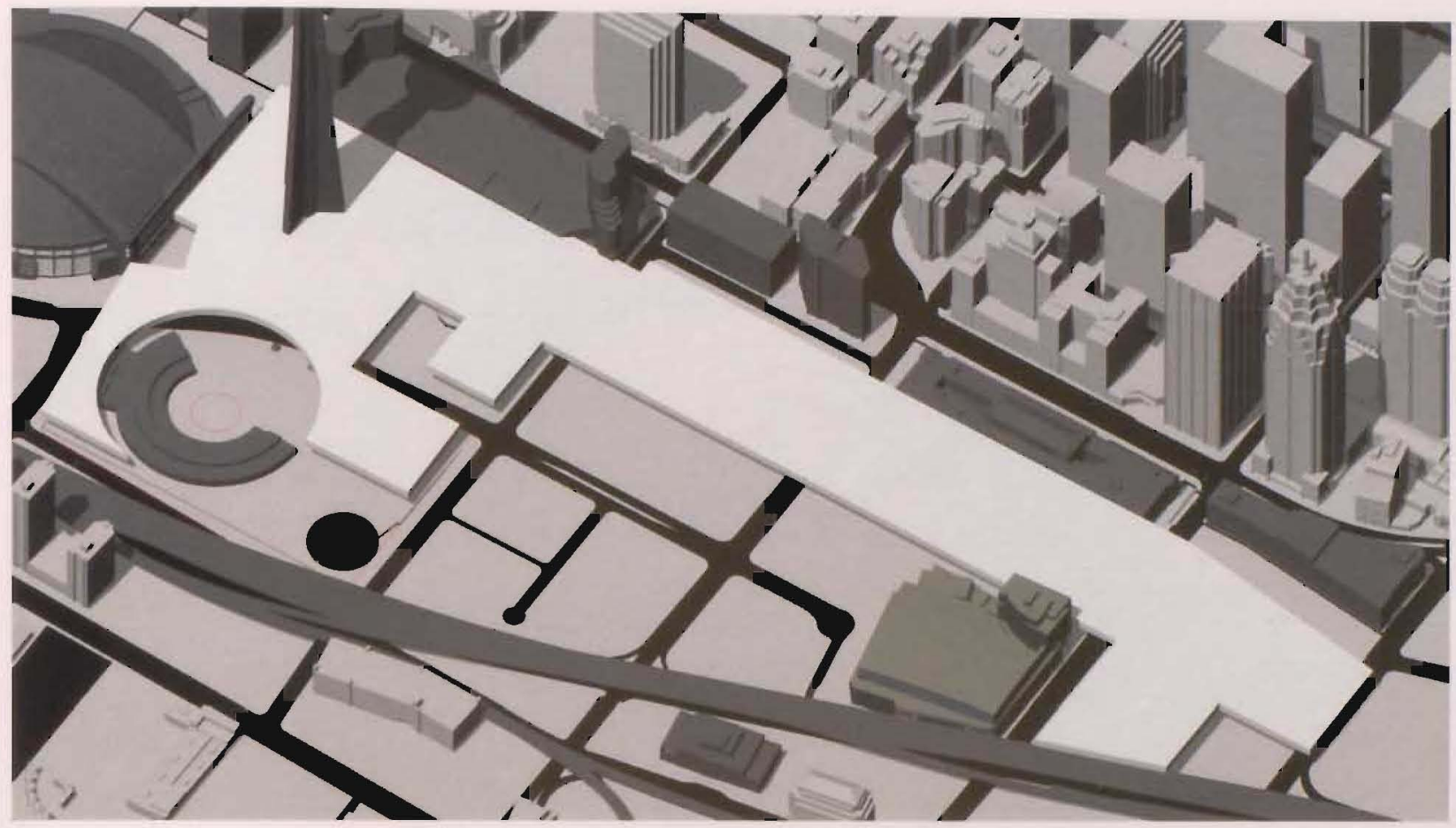

Figure 10.0.7 Final proto-form for the navigable surface.

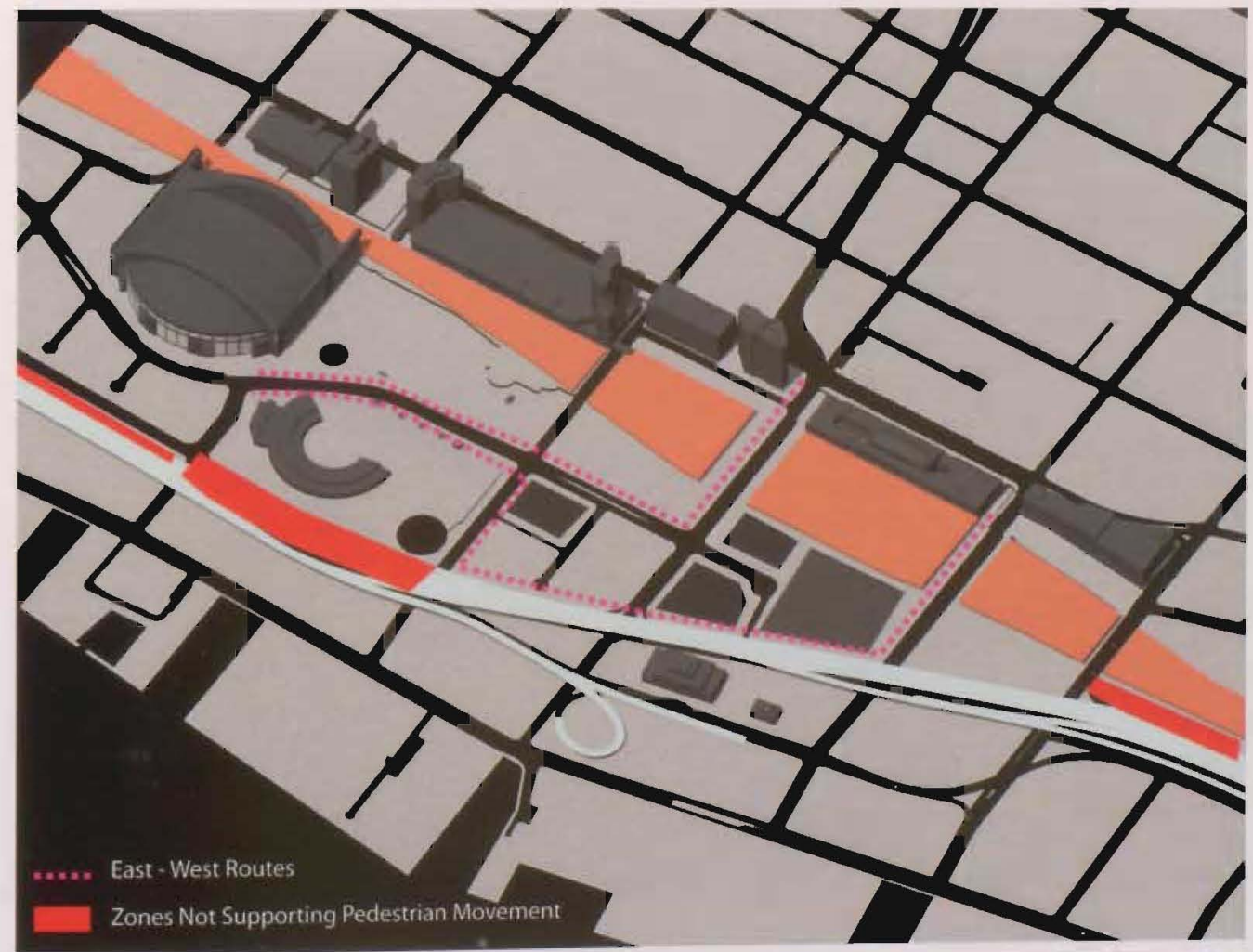

Figure 10.0.8 Existing north-south routes and areas not supporting pedestrian movements. 


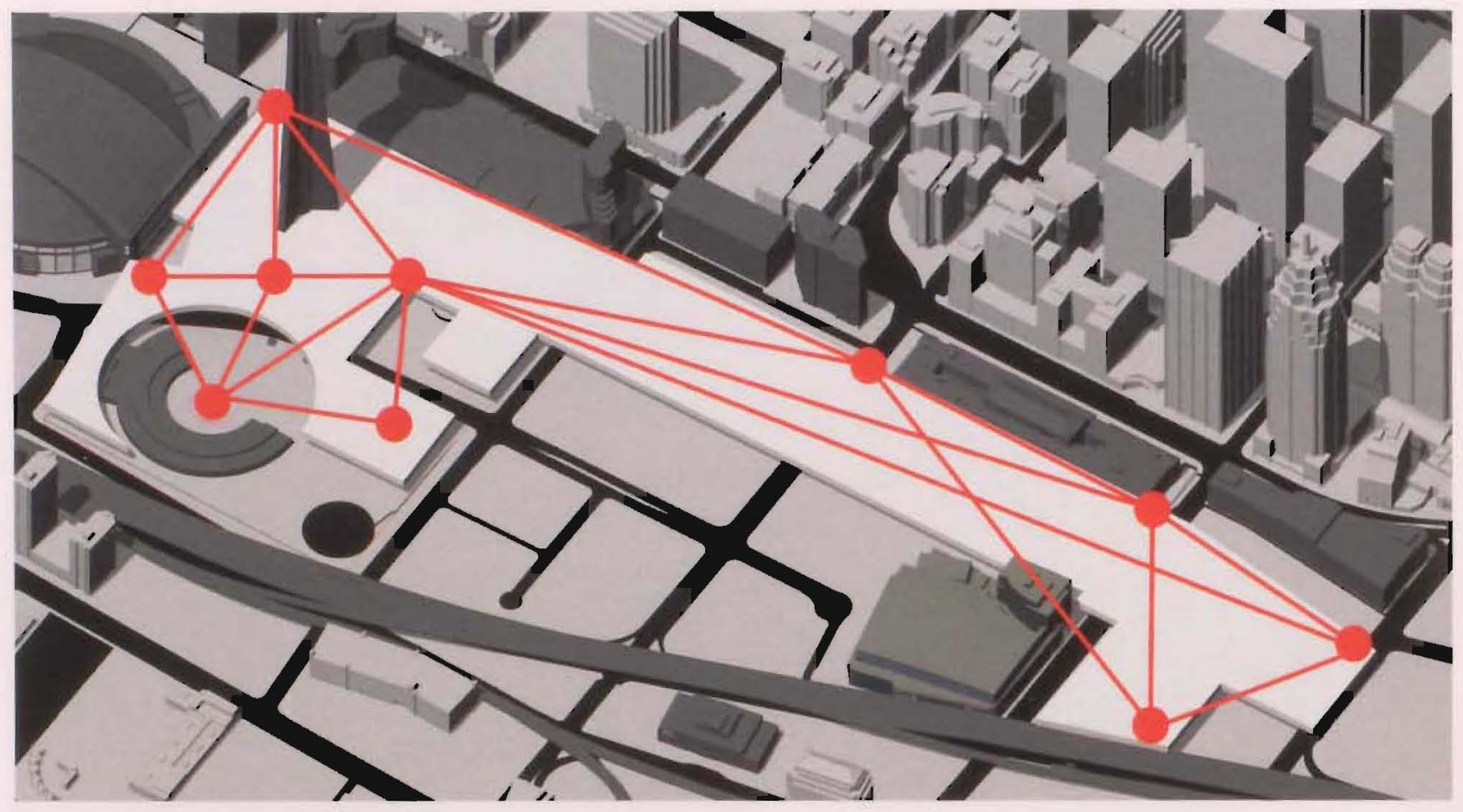

Figure 10.0.9 New trajectories developed to provide the most direct connections across the CRL Territory.

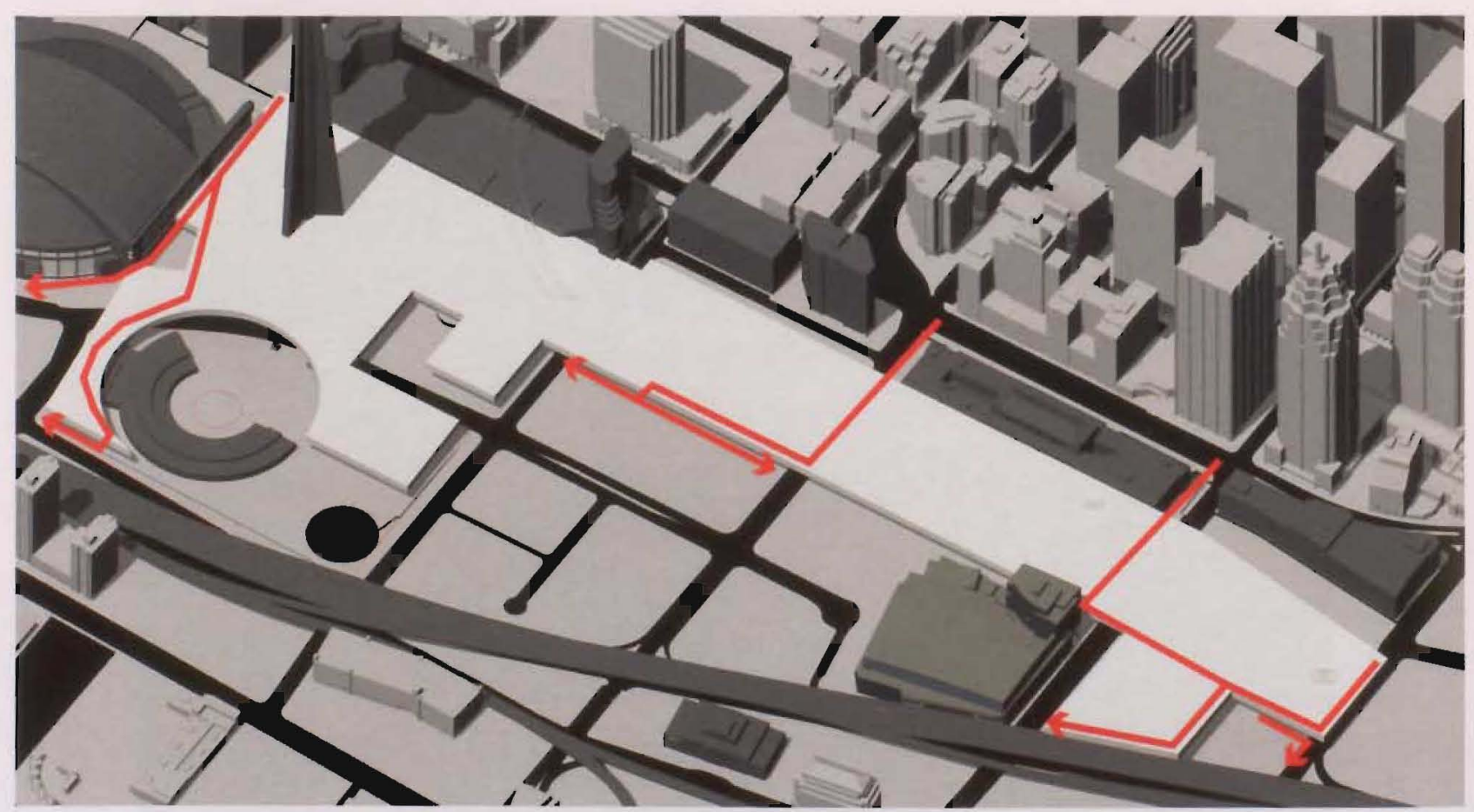

Figure 10.0.10 New North to South connections over top over the surface. 


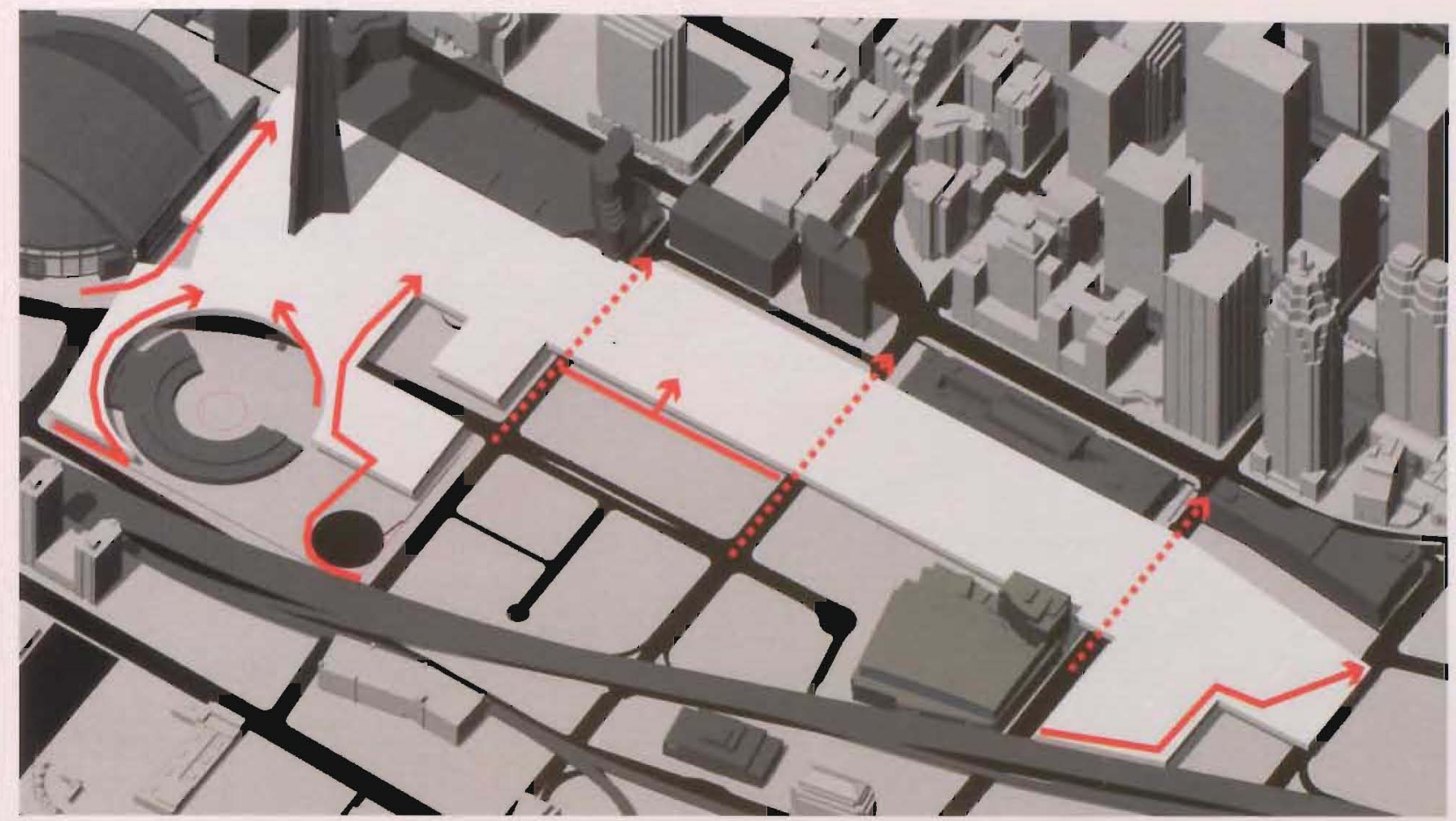

Figure 10.0.11 Increased South - North connections in conjunction with existing tunnels.

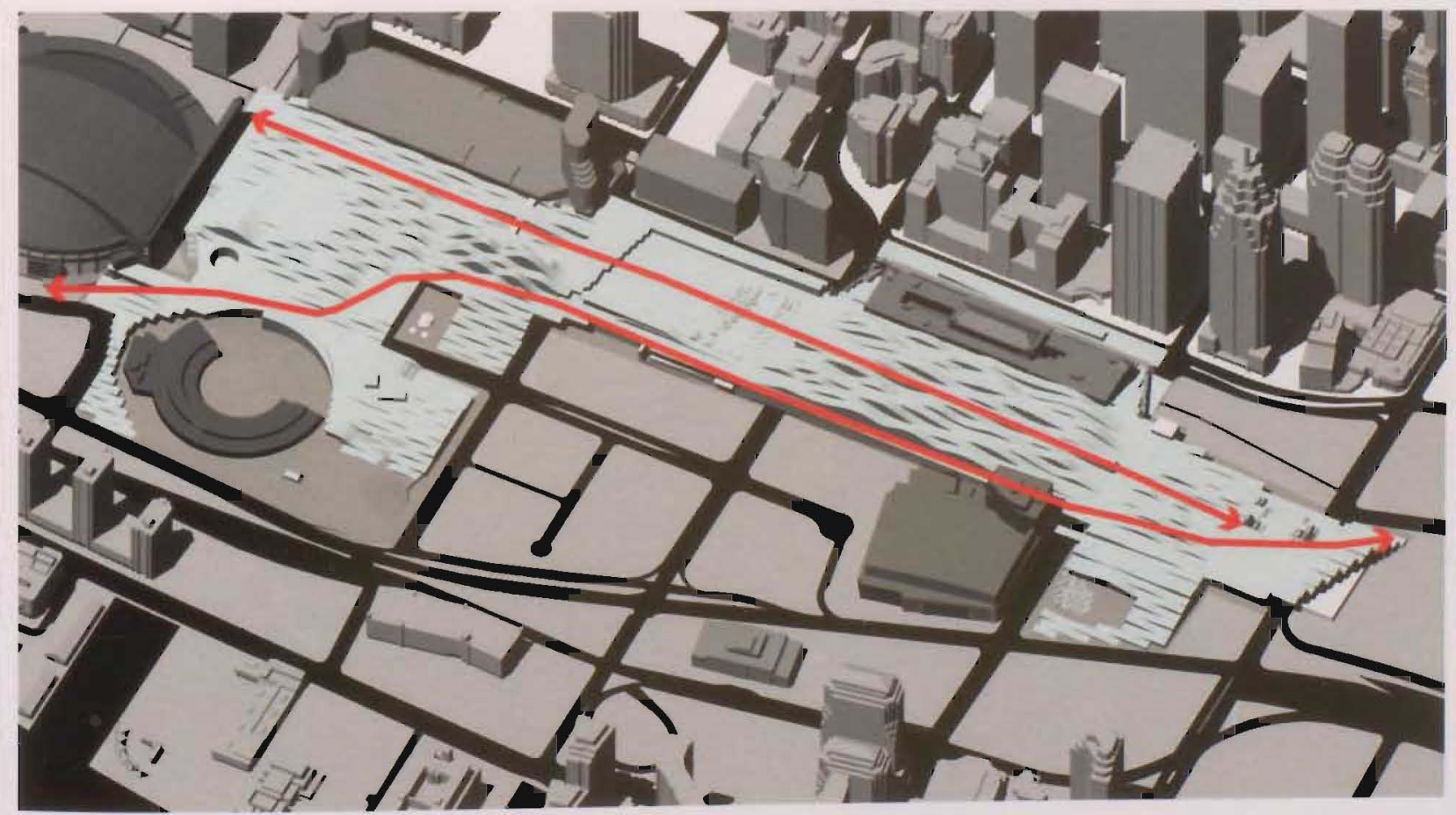

Figure 10.0.12 Direct East-West connections provided over the surface. 


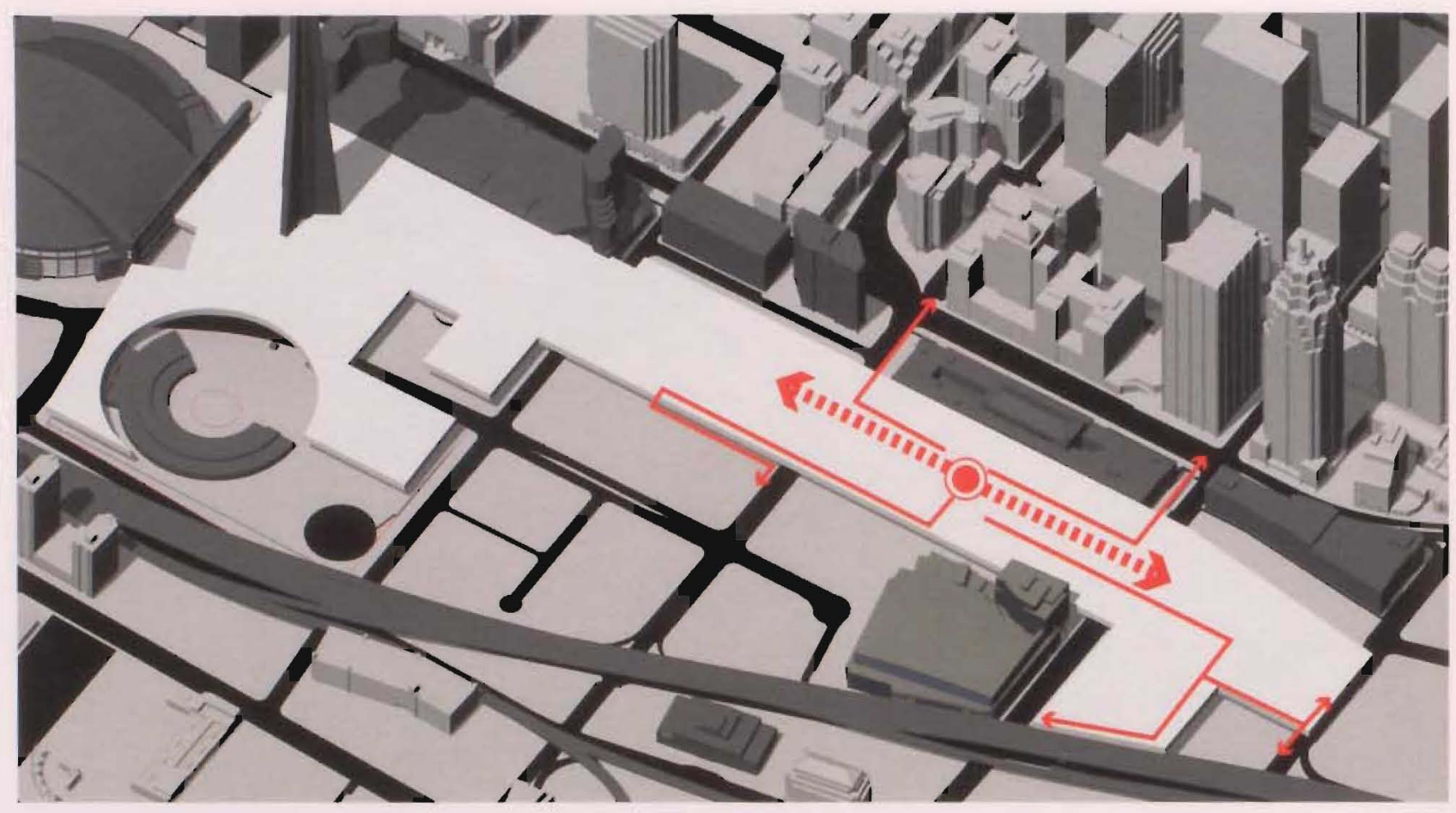

Figure 10.0.12 New central train hall provides multi-direction access to the CRL.

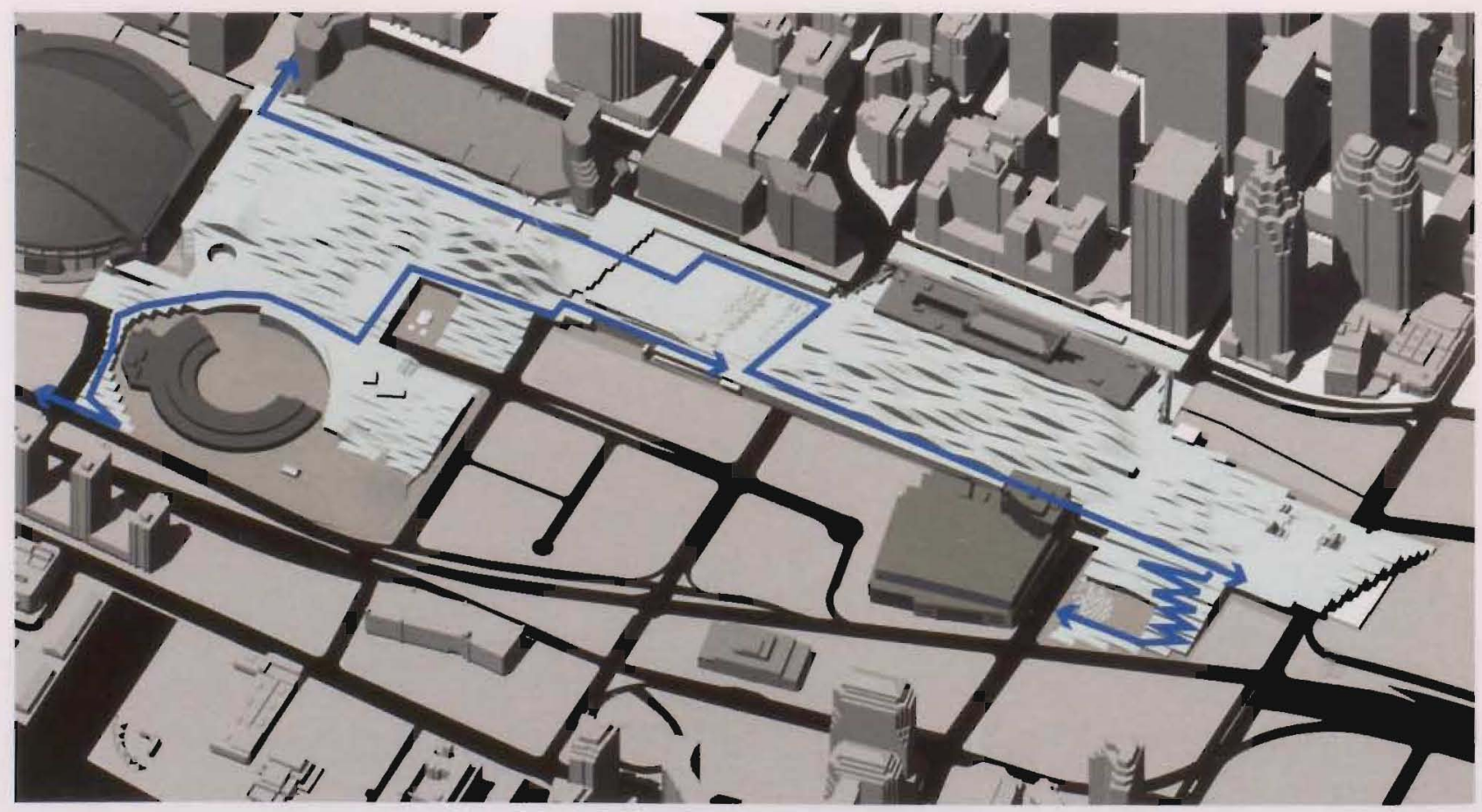

Figure 10.0.13 Vehicular access is provided through John St. Bridge and southern terraced sections of the surface. 


\subsection{Intervention - the Surface formally}

To provide the best logistical and formalistic solution a strong, consistent language was introduced to tie together the disparate urban elements. The surface was subdivided into 8-meter wide longitudinal ribbons coinciding with roughly the centre-to-centre distances of Union Station platforms (Figure 10.1.1). The division of the surface into these ribbons provides strong visual cues from underside to topside and are reminiscent of Toronto's shoreline growing strip-by-strip into Lake Ontario. Like a ribbon in the air, the strips of the intervention dip and rise to coincide with the various circulatory and programming requirements. A single ribbon may transform to form rolling landscapes, overpasses, water features, seating, natural lit interior spaces, stages or completely flatten out to form plazas and circulation routes (Figure 10.1.2 to 10.1.9). Some of the most dynamic surface formations occur at the intersections of new and old programmed spaces such as the trainshed, MTCC Expo building and CN Tower Plaza The ribbon surfaces of these areas rise and dip at much steeper angles to form dynamically lit spaces below the ribbons. The ribbons also allow for the creation of vertical points of entry and exit from programmed elements at lower levels by forming stairways, ramps, stramps (combination of stair and rarnp), and terraces (Figure 10.1.3 \& 10.1.10). These vertical points of entry and exit help solve the perfunctory ad hoc nature of the previous points of entry exit.

As a formal rule openings to programmed elements are only created where one ribbon moves away from another ribbon. This rational allows the users of the surface to perceive the ribbon as a continuous surface running the length of the site (Figure 10.1.11). Windows, entrances, and vertical surfaces are only perceived in the north-south perspectives, while the east-west perspectives provide the view of a continuous rolling surface. Formal requirements are kept simple to convey continuity over the entire intervention and to simplify the transition from downtown to waterfront. To differentiate various elements upon the surface, varying material palettes and ecosystems are deployed and will be expanded upon later. (See Figures 10.1.12 to 10.1.14 for detailed plans and Appendix A for full page spreads). 


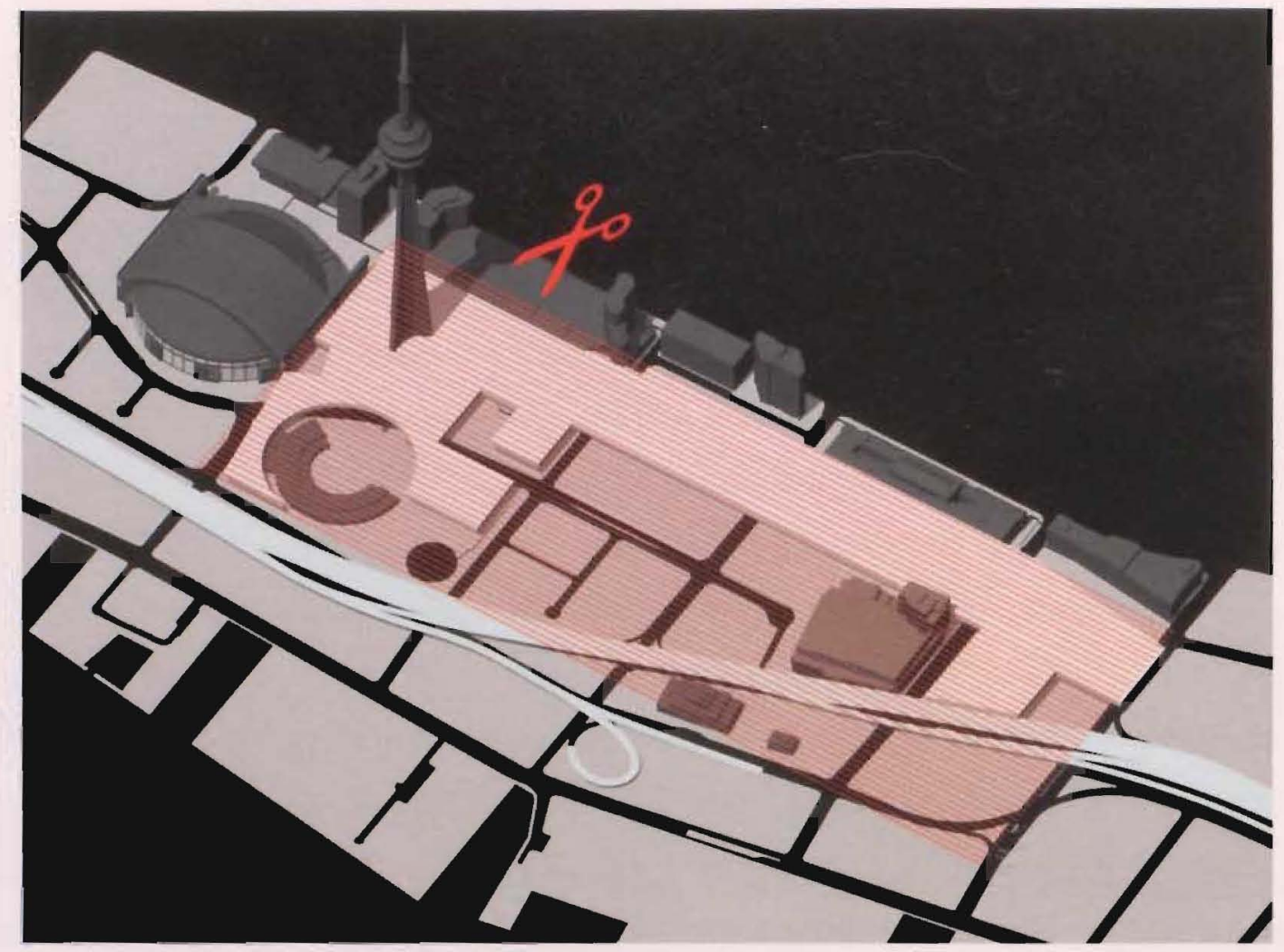

Figure 10.1.1 Surface is subdivided into $8 \mathrm{~m}$ wide strips to coincide with the centre-to-centre distances of Union Station's platforms. 

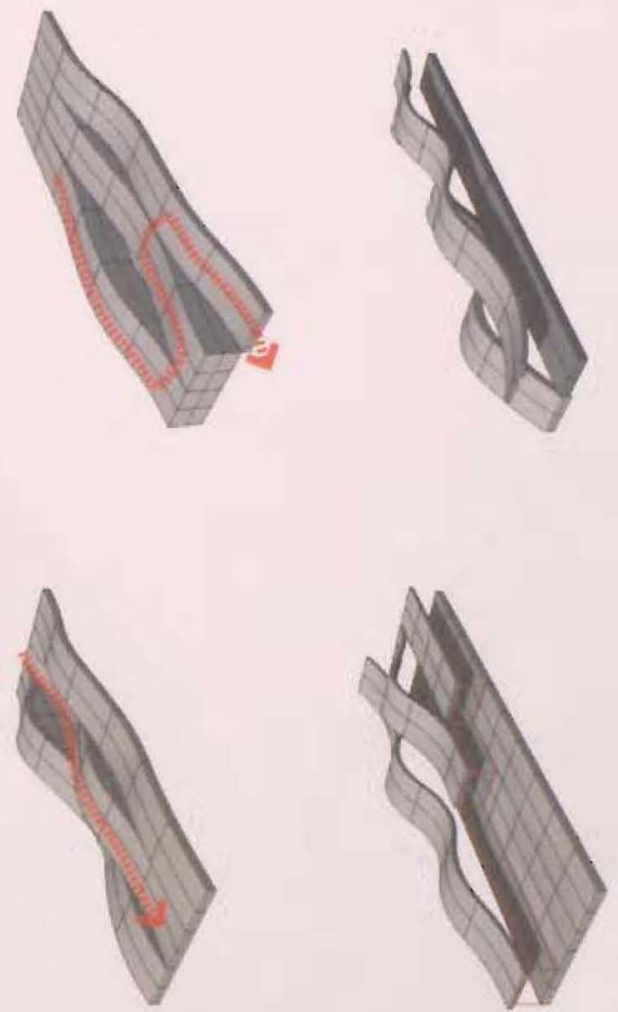

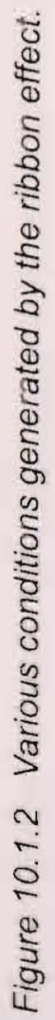
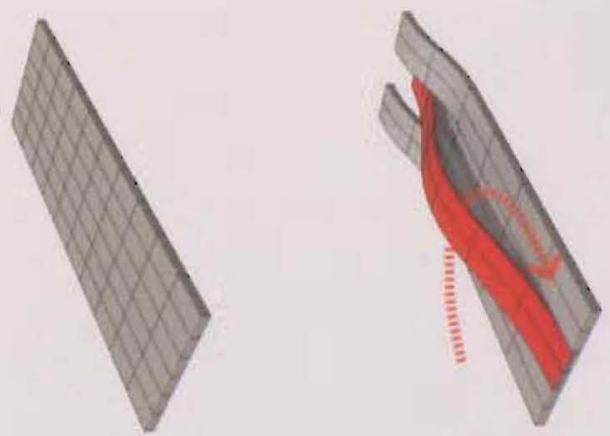


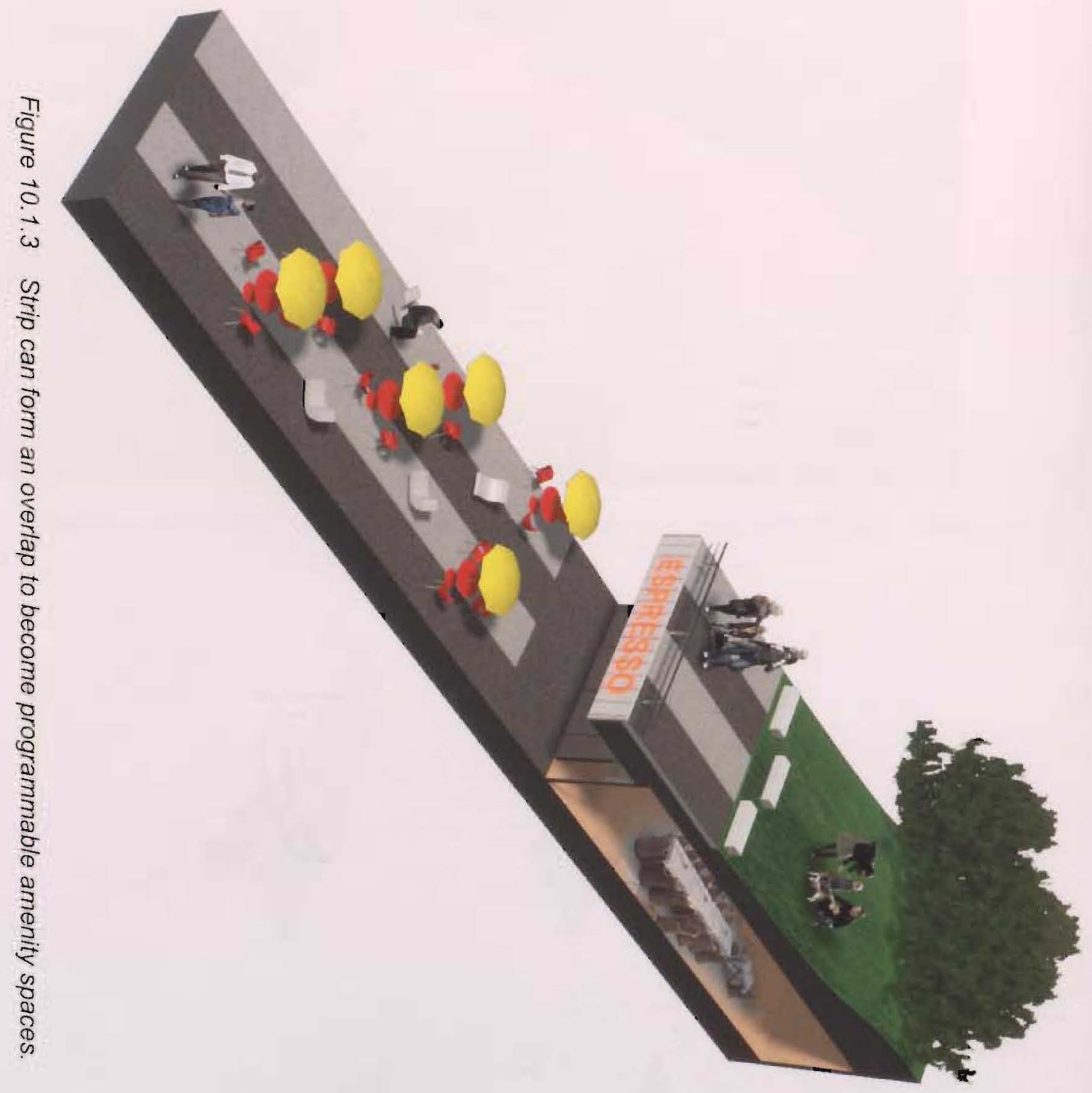




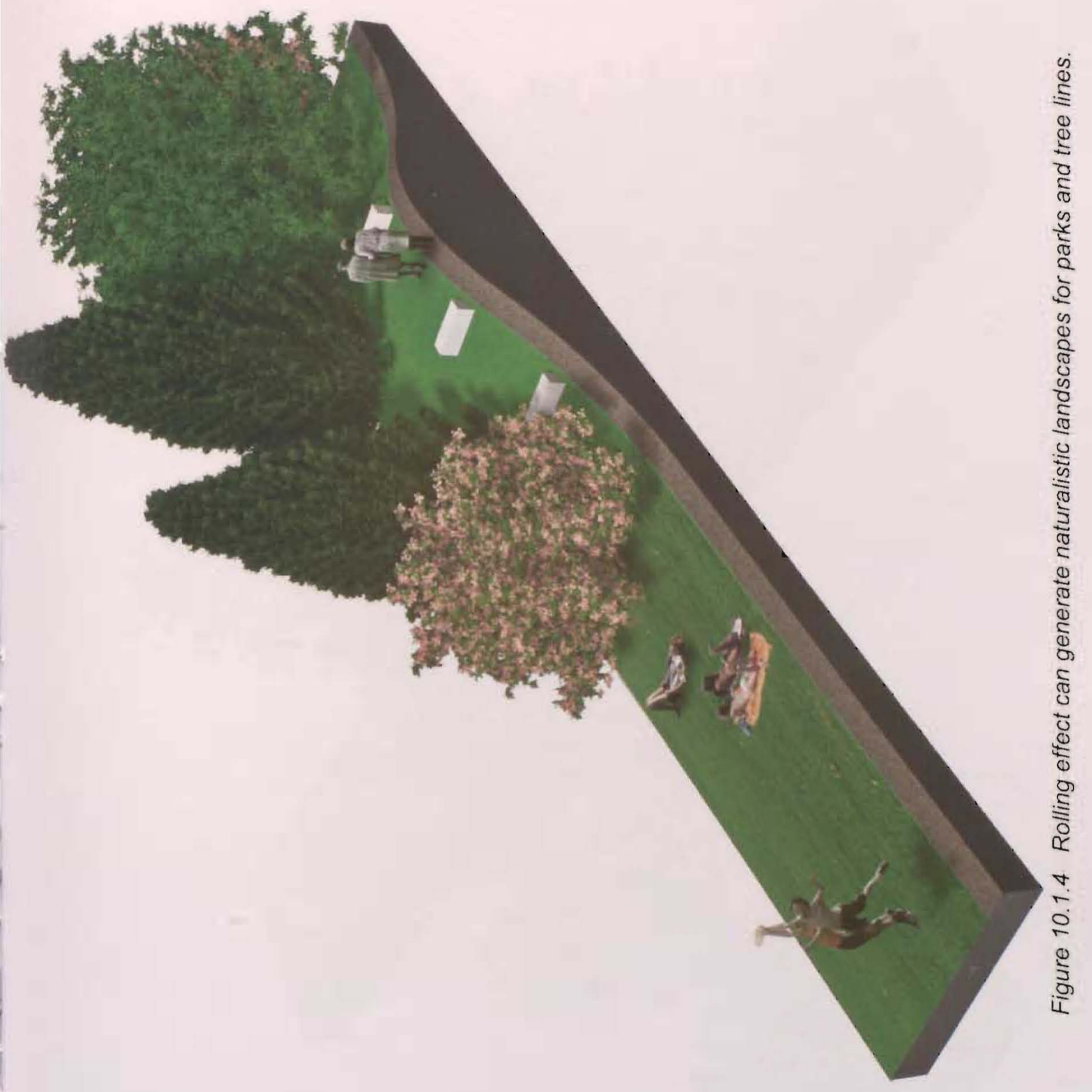




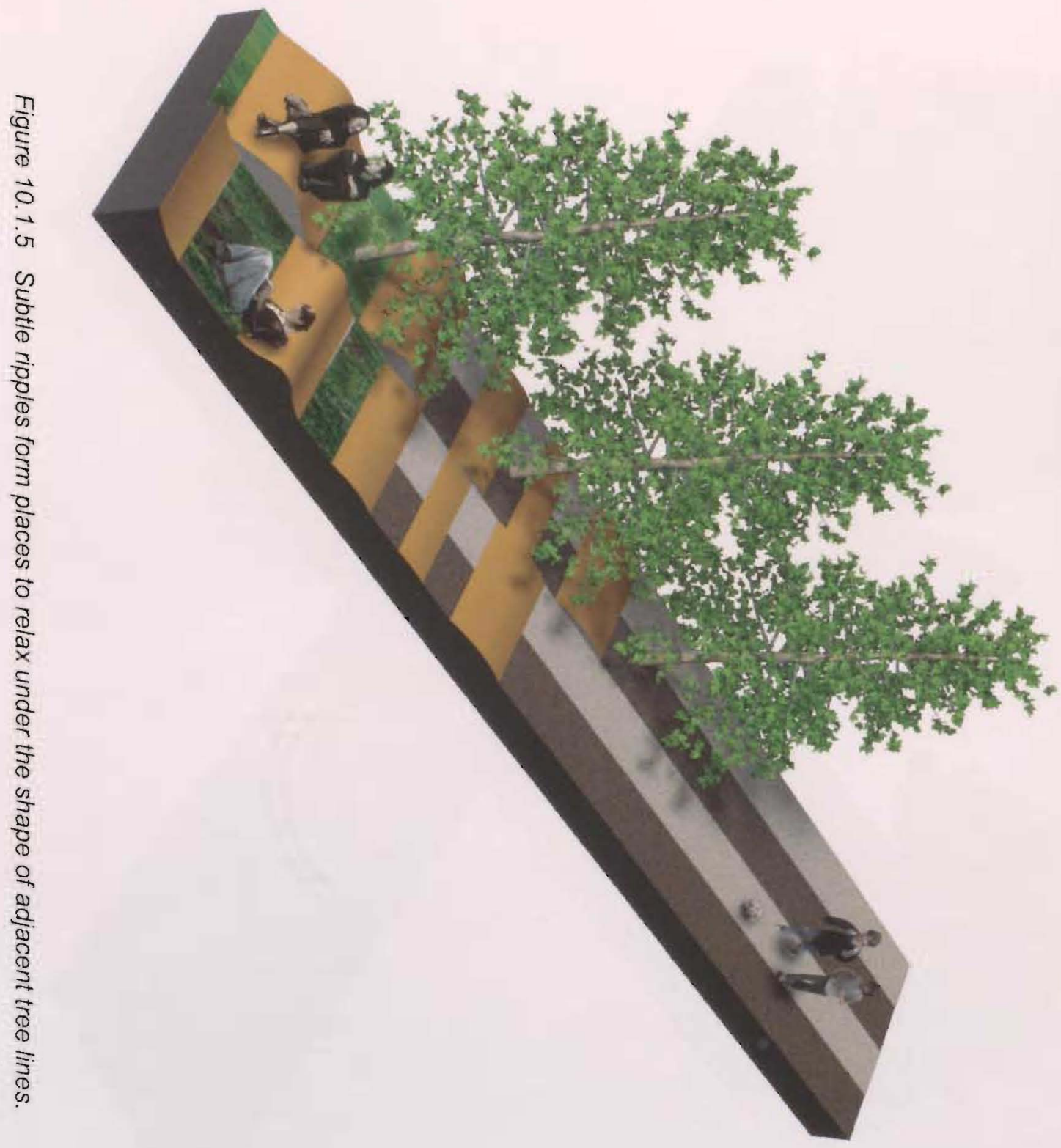




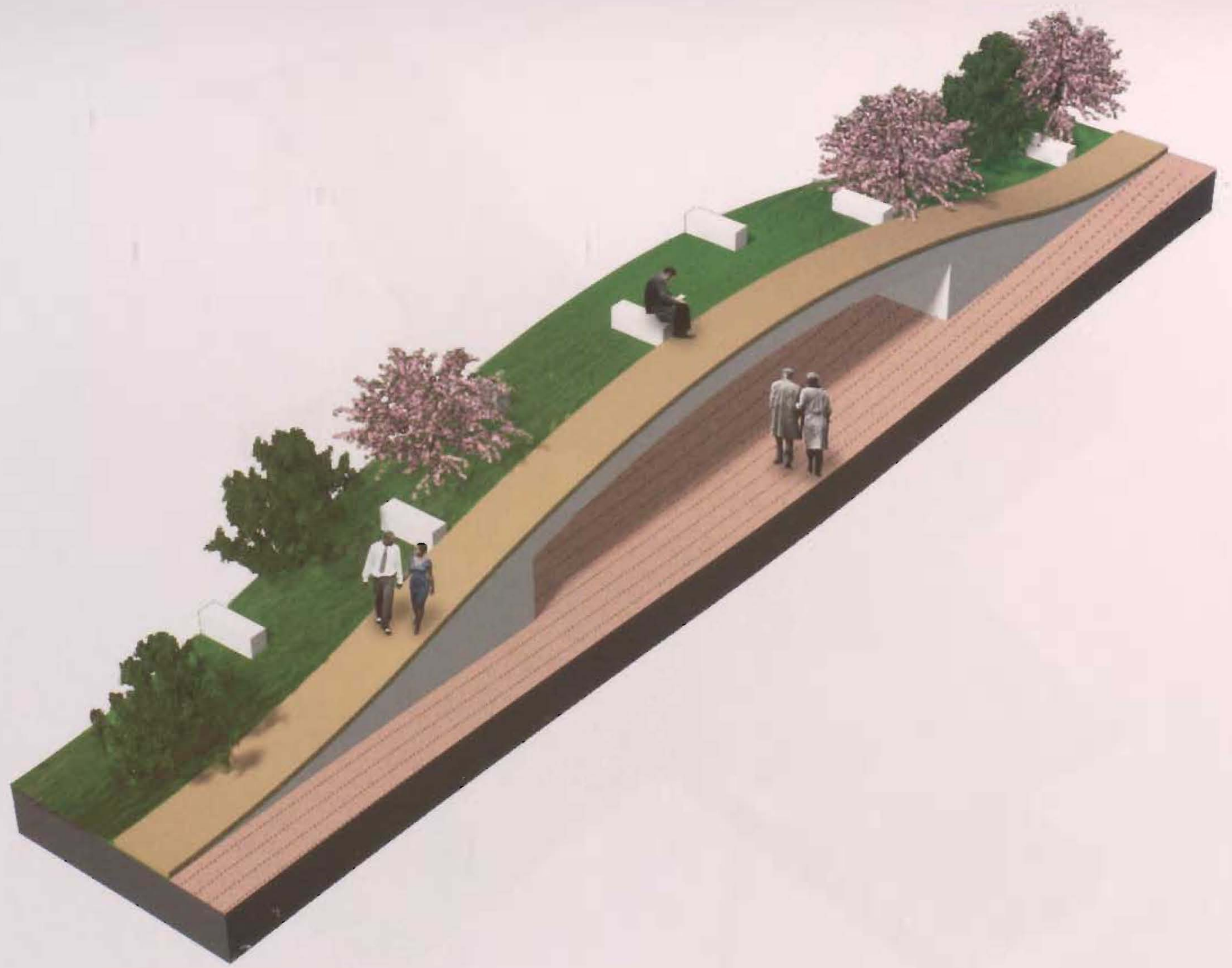

Figure 10.1.6 A separation of the surface can form bridges to provide multi-direction movement over the surface. 


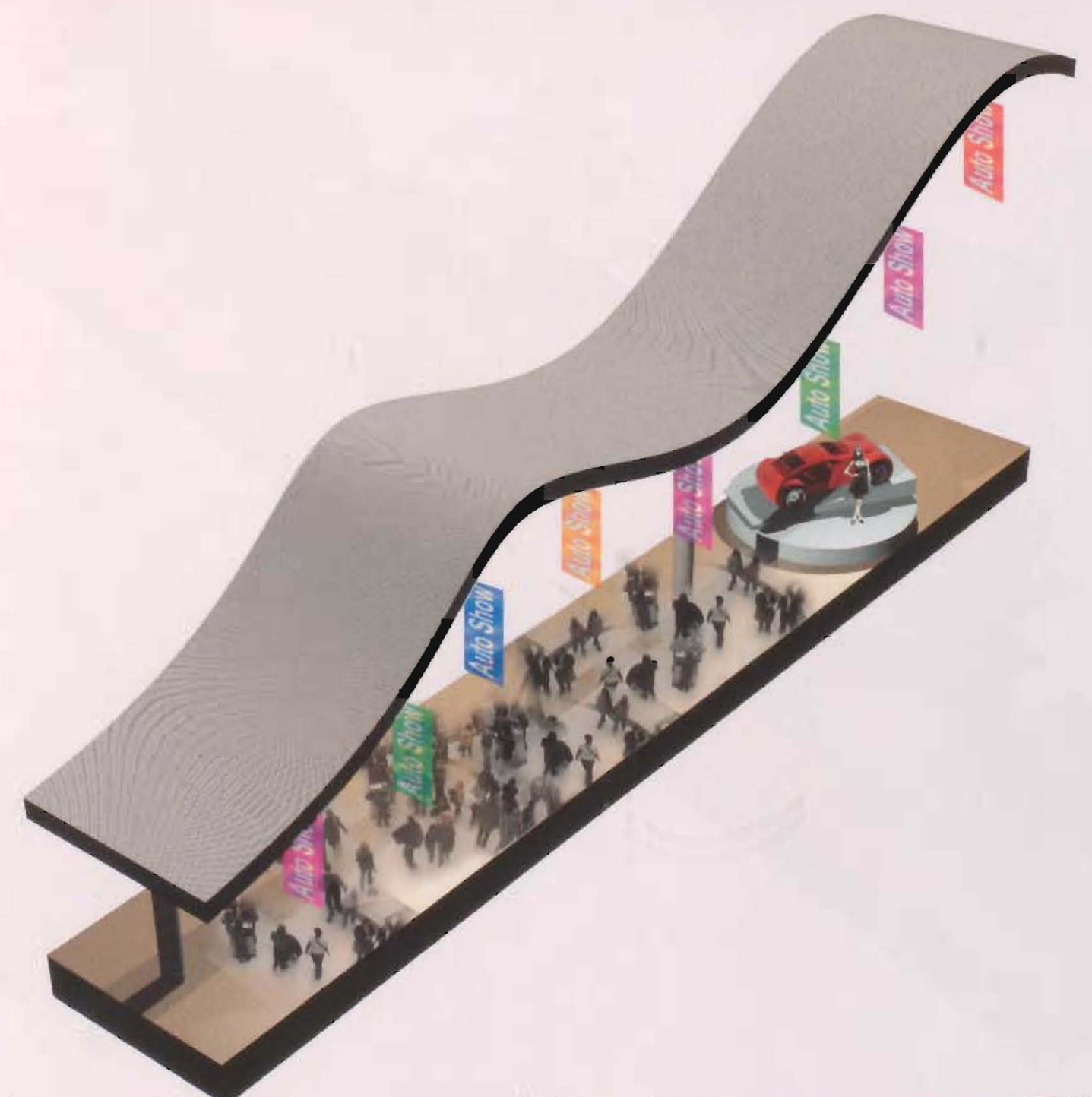

Figure 10.1.7 A larger separation of the surface can provide large interior spaces such as the new MTCC Expo Hall 


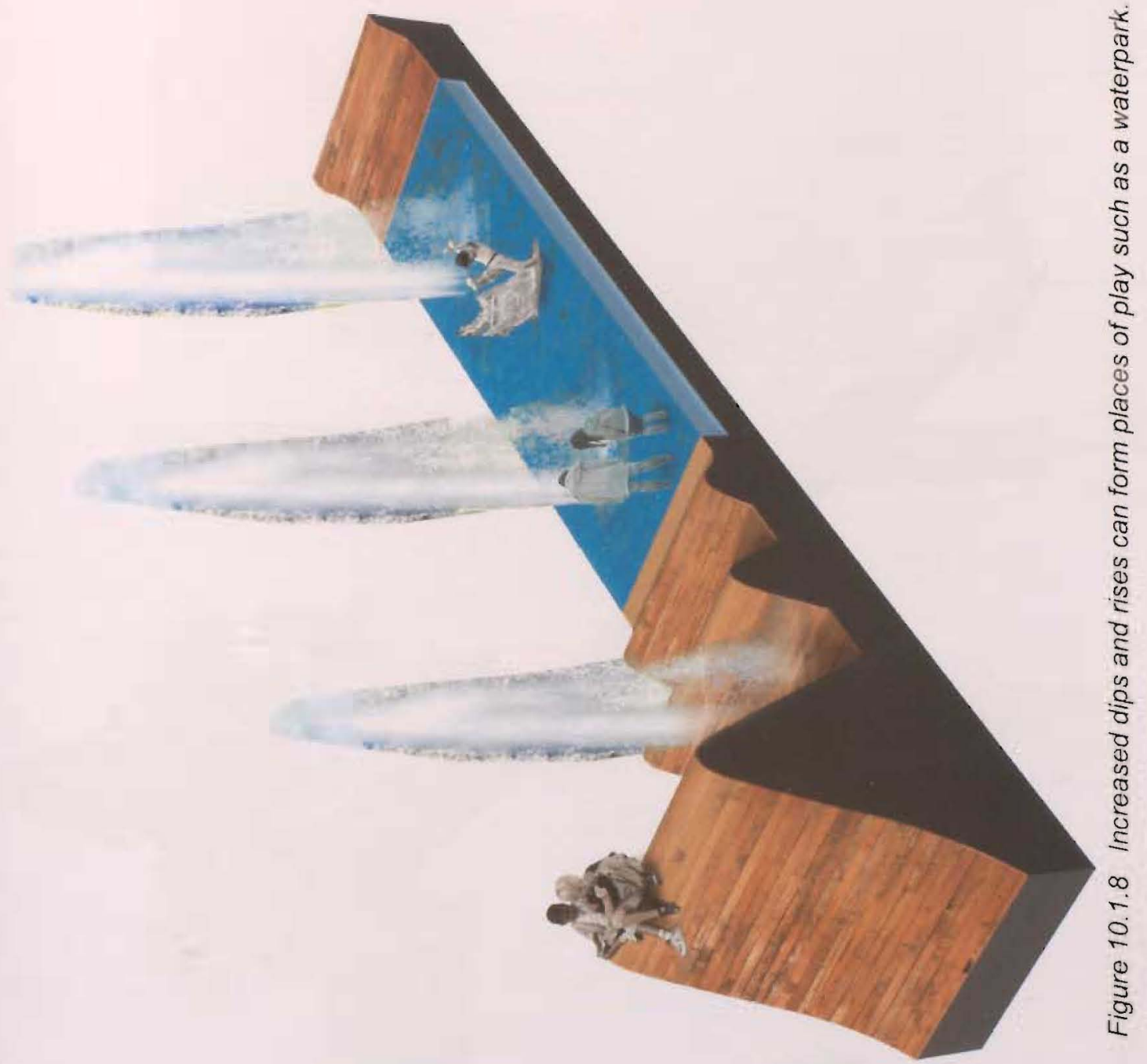




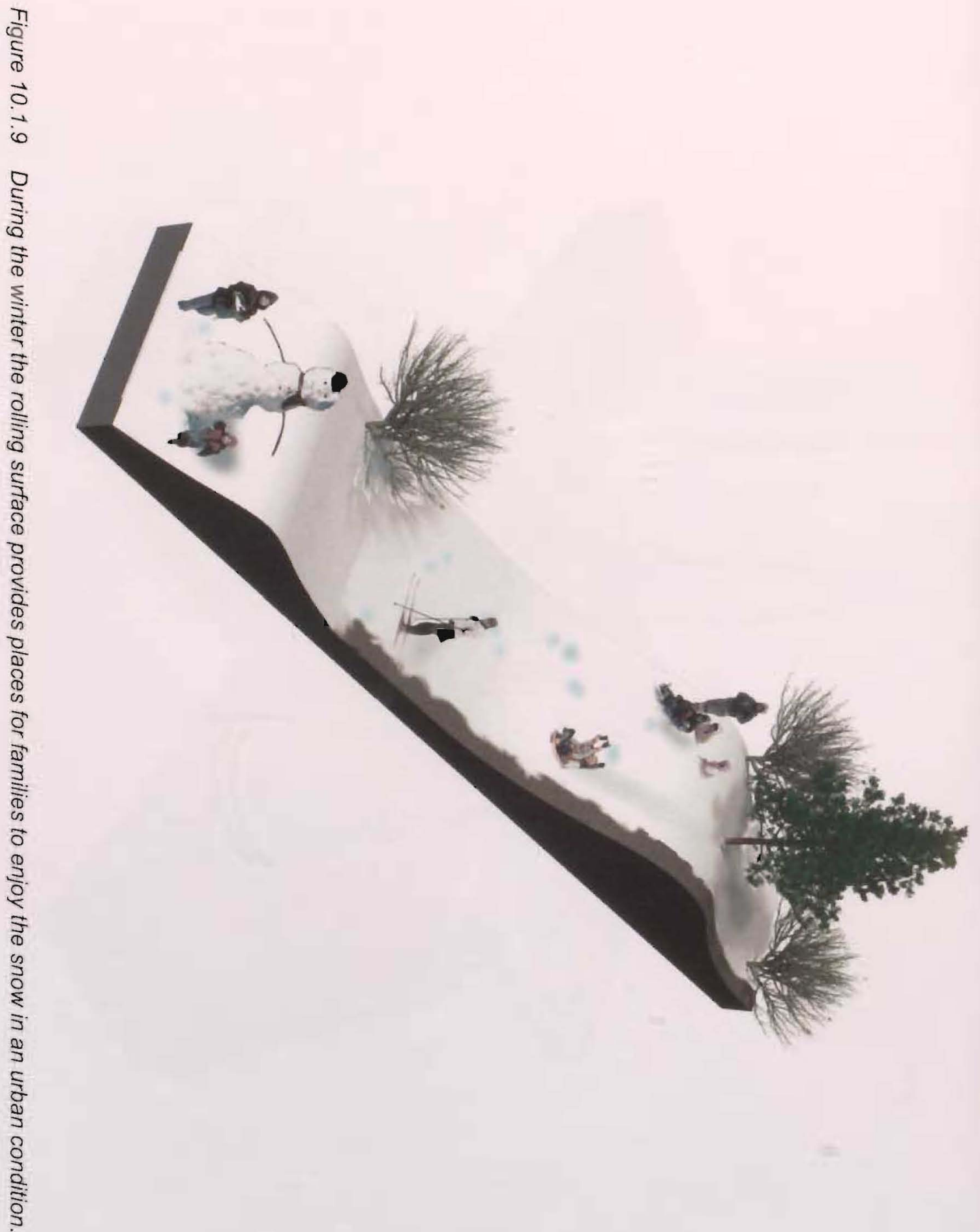



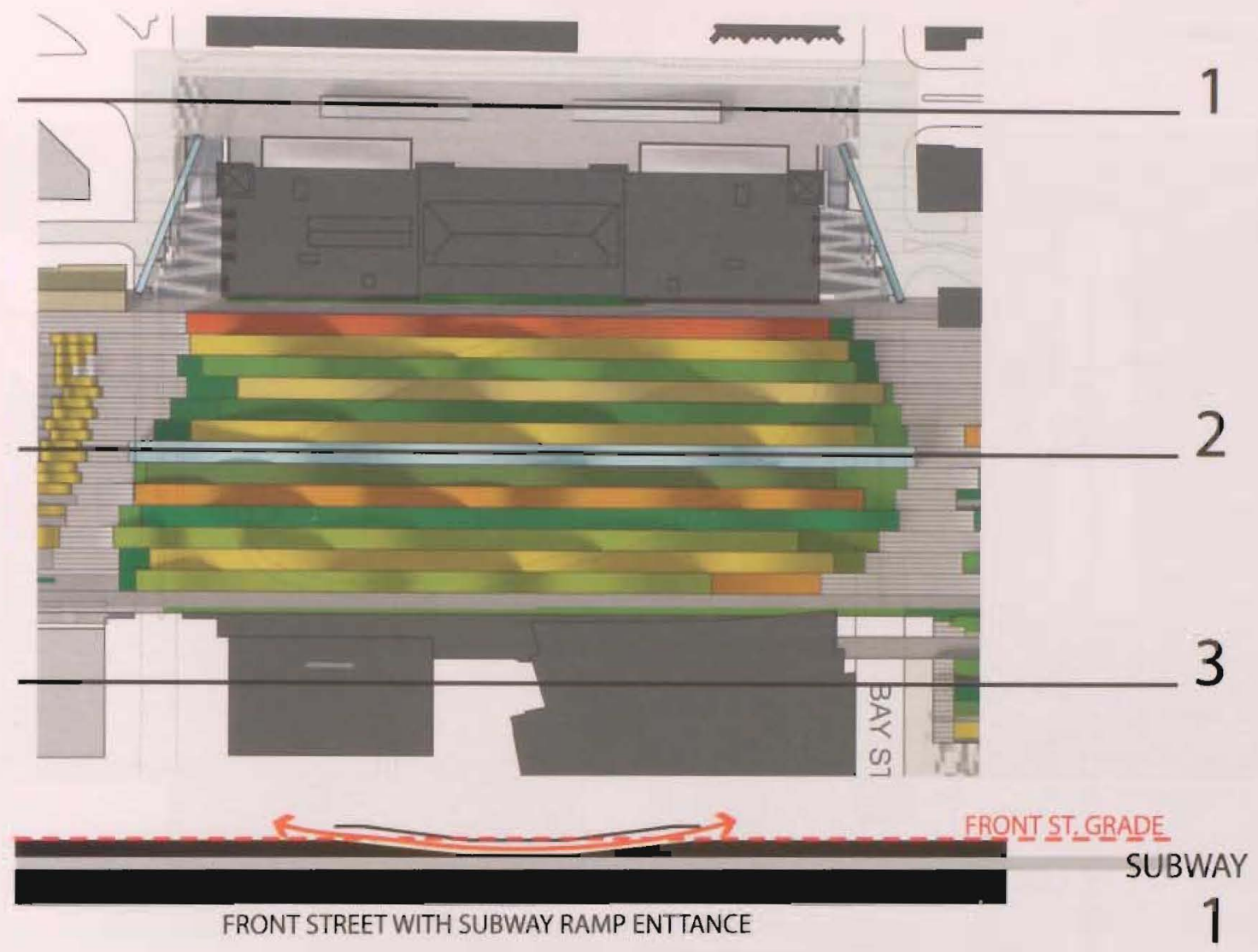

ERONT ST, GRADE

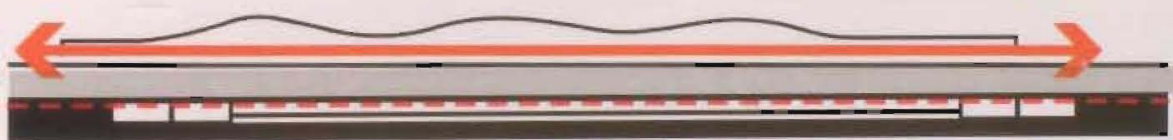

\section{RAIL CORRIDOR}

TRAIN HALL. WITH EAST-WEST CONCOURSE

2

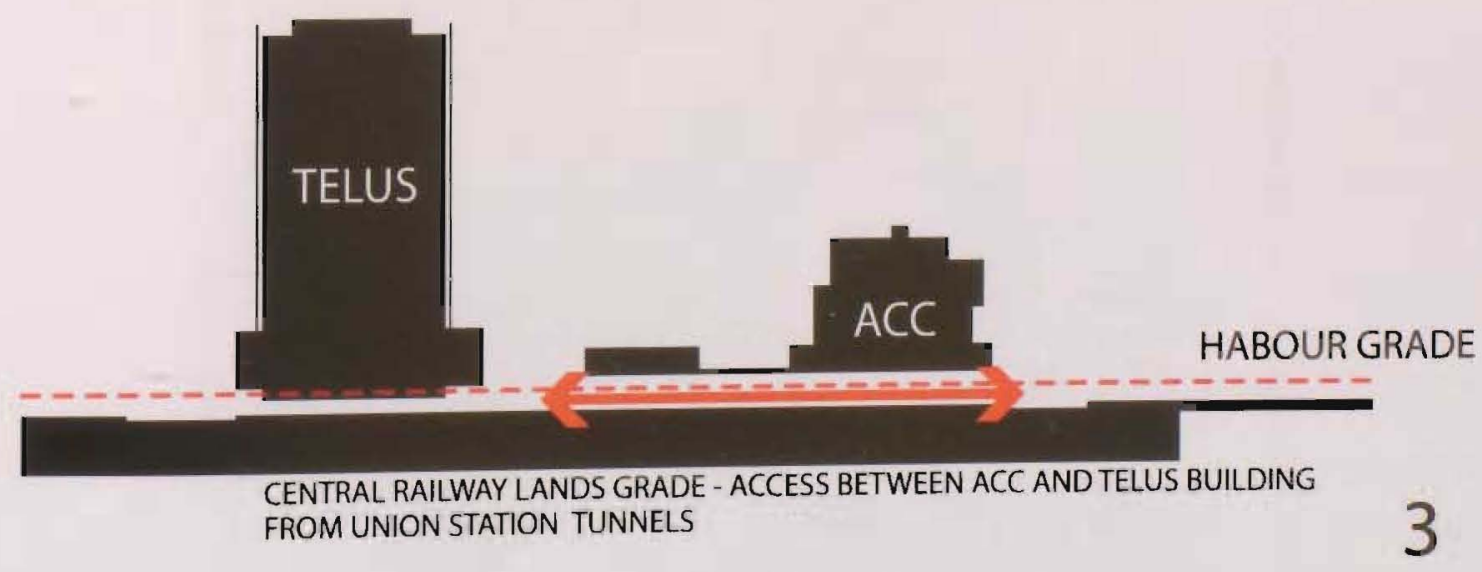

Figure 10.1.10 Sectional Variations from Front Street to Bremner Boulevard 


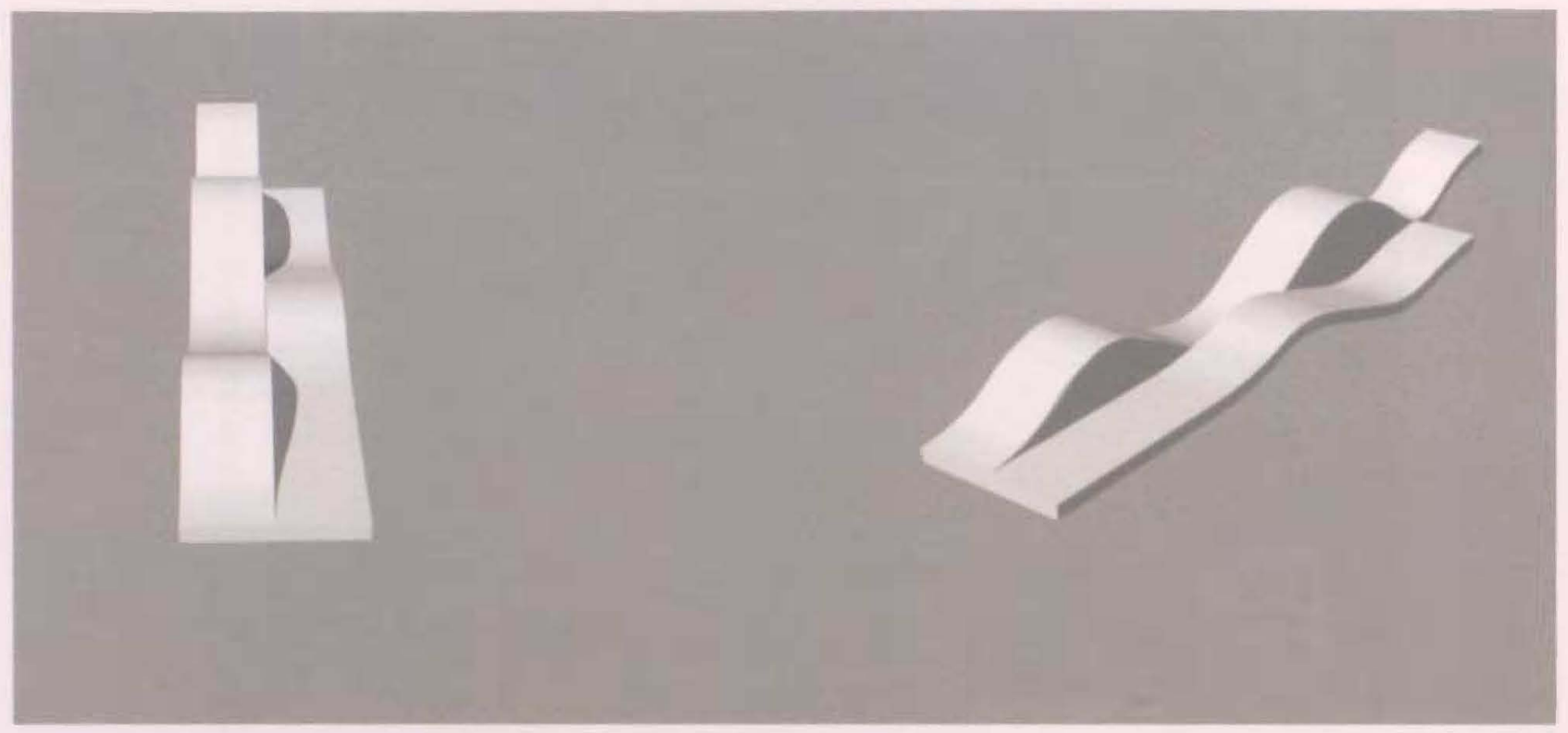

Figure 10.1.11 LEFT: east-west perspective reveals a continuous surface, RIGHT: continuous surface is broken up by subtle verticals. 


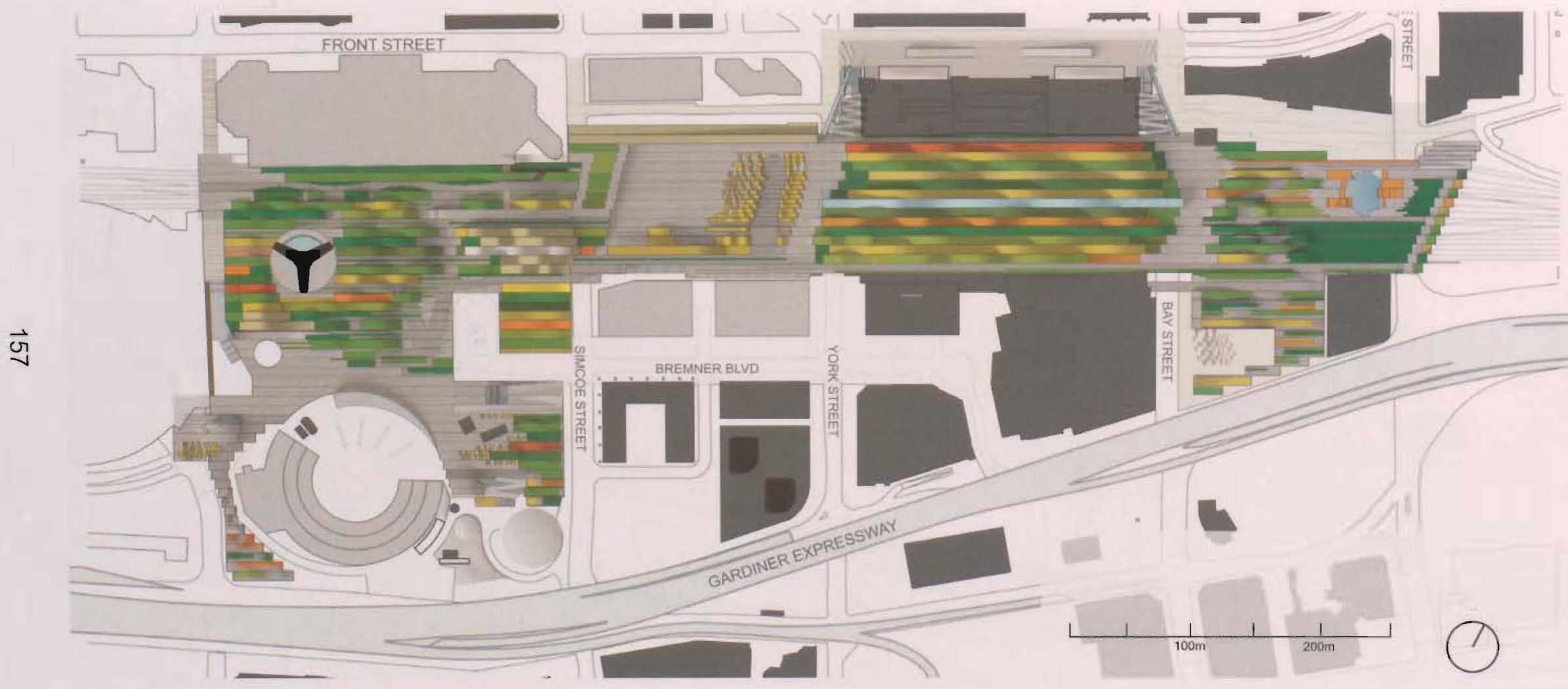

Figure 10.1.12 First Level: Multi colored strips represent various planting materials. (See Appendix A for larger plans) 


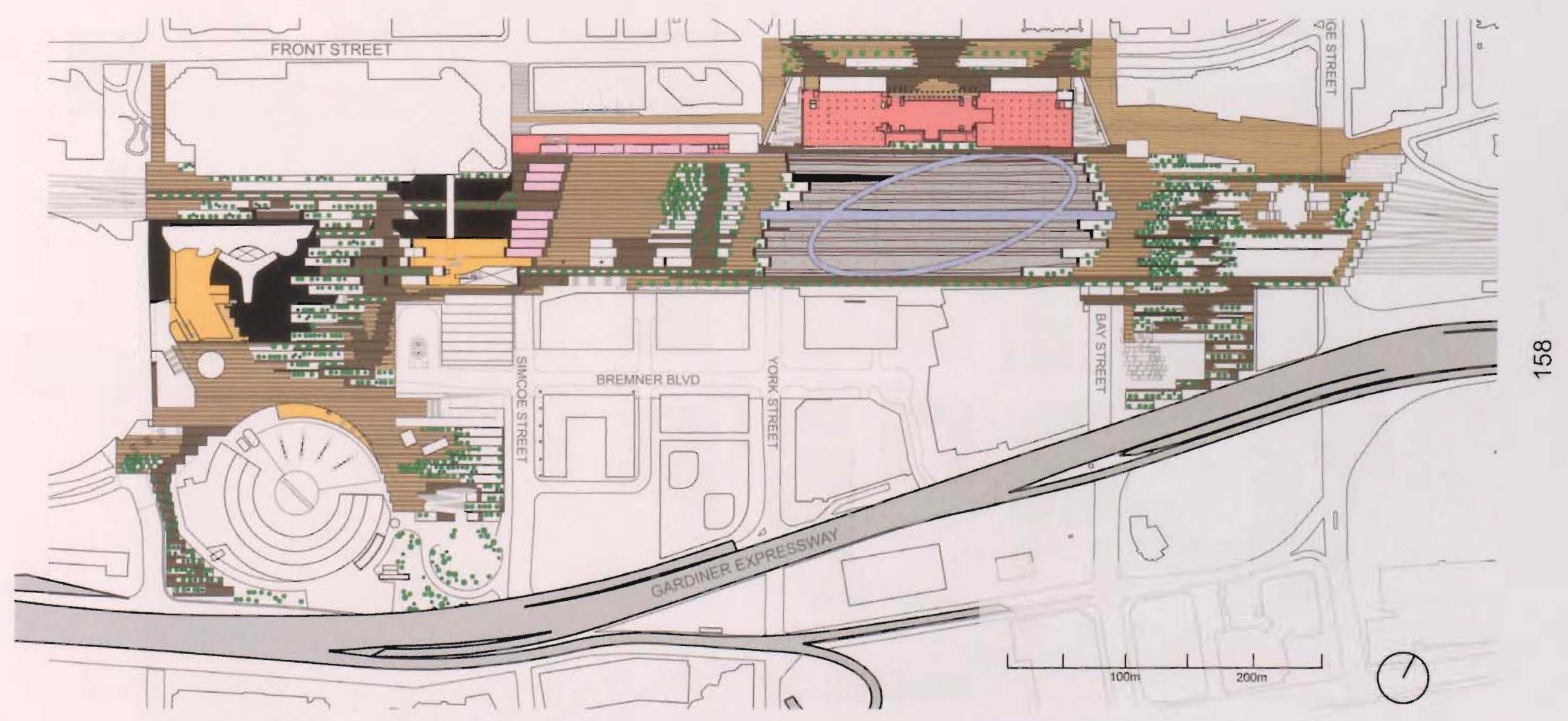

Figure 10.1.13 Sub Level: ORANGE: Interior public spaces, PURPLE: Amenity spaces, PINK: Union Station extents. 


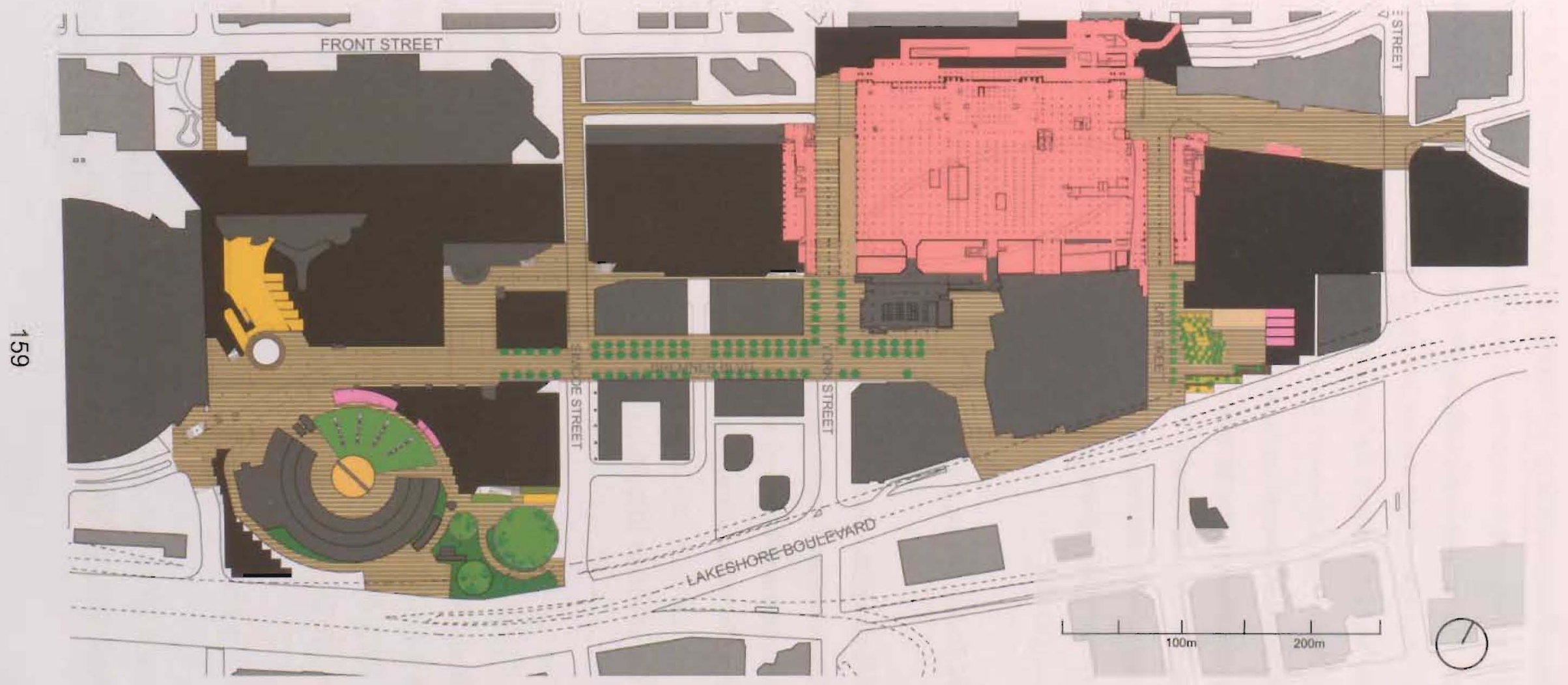

Figure 10.1.14 Base Level: PURPLE - Amenity spaces, PINK: Union Station Sub Level Extents, ORANGE: interior public spaces. 


\subsection{Intervention - Programming}

The surface intervention is primarily in the $X-Y$ plane with undulations into the $Z$ plane to create a distinct conditions along the surface \{parti diagram\}. Programming therefore is separated between first level, above surface and second level, below surface. First level programming was broken into circulatory space (spaces that are enjoyable to move through while providing primary and secondary trajectories to nodes in and around the surface); leisure space (open green spaces, gardens, and outdoor gallery); entertainment space (ACC Grandstand, outdoor stages, CN Tower Media Park); and play space (plazas, rolling hills, and water parks). All spaces contain within them the possibility of deploying flexible programs such as tents, stages and fairs \{Figures 10.2.1 to 10.2.6\}. There are 7 key areas of first level programming which include:

\subsubsection{CN Tower Media Park}

CN Tower Media Park - developed to enhance and expand on the LED light show of the CN Tower, the Media Park provides an illuminated media floor at the base of the tower; fog generators producing illuminated plumes of fog from a sunken portion of the surface; and fluctuating LED lit surfaces radiating away from the towers base (10.2.14).

\subsubsection{Roundhouse Info Plaza}

Roundhouse Info Plaza - located at the base of Media Park, Roundhouse Info Plaza acts as a transition space between the various venues and attractions in the area. The space is integrated with Rogers Centre providing spaces for patrons to gather pre-show. The space is also large enough to handle a large number of individuals to transition from the various venues. Situated to the south of the plaza is the new Roundhouse Kiosk providing users of the park information and to gain access to the second level (10.2.15).

\subsubsection{Roundhouse Park}

Roundhouse Park - is the existing Roundhouse Park that has been augmented by the new surface. The new surface frames the existing Roundhouse building while allowing users of 
the park to now view the various historical trains from the ground and elevated positions. The Roundhouse Kiosk provides formal access to the roundhouse building while a greened stramp forms a more leisurely decent to the existing park condition \{image\}

\subsubsection{MTCC Expo Building}

MTCC Expo Building - is a new show building for the Metro Toronto Convention Centre to provide exhibitors with a grand show space for coming attractions and permanent shows. The steep vaulting surfaces provide large, open spaces beneath for grand displays or dynamic spaces for events and gatherings. The Expo building integrates its self with the former South MTCC building allowing patrons to access ground level and the MTCC's existing sunken exhibit spaces and parking lots (10.2.8).

\subsubsection{CN Tower Plaza}

CN Tower Plaza - is now a covered space that has been shielded from the elements. The new plaza becomes a shopping arcade and entrance condition for the $\mathrm{CN}$ Tower, providing patrons with new services and spaces to linger in before and after touring the $\mathrm{CN}$ Tower. The covered plaza further provides adequate protection for guests of the 360 Degree Restaurant in the tower. Using existing stairs the plaza has access to all levels of the surface (10.2.9).

\subsubsection{Outdoor Gallery}

Outdoor Gallery - working in conjunction with the CN Tower Media Park, the Outdoor Gallery links the Rogers Centre with the Rail Line Plaza through a connector path flanked by subtle rolling mounds. Forming a promenade these mounds are topped with a series of largescale outdoor art pieces. Various moments along the undulating mounds permit individuals to walk up and interact with the pieces (10.2.14).

\subsubsection{Rail Line Plaza}

Rail Line Plaza - is a dedicated open space framed by restaurants and small entertainment venues. A large stage space provides ample space for large staged events, while 
acting as a lounge space for eventless days. The Plaza is tree covered to the east, shading the various undulated surfaces that provide outdoor seating. To the west is the entrance to the MTCC Expo building beneath the surface (10.2.16).

\subsubsection{Park Concourse}

Park Concourse - is an integrated park-concourse that provides access to the Union Station platforms and park space. The ribbons form a vaulted space over the platforms that bring in natural light and views to the park space. A ring concourse provides access to the various platforms through the use of escalators \{diagram/image\}. Two longitudinal sky lit promenades provide users views of the incoming trains and park spaces, with connections the east or west of the station. The new concourse provides new east-west connections allowing the existing concourses to focus on north-south connections through the PATH system (Figure 10.2.7, 10.2.10\& 10.2.11).

\subsubsection{Forested Meadow Park}

Forested Meadow Park - is large, multi-programmed green space containing rolling hills, forested sections, flat green spaces, gardens, outdoor seating and outdoor water park which plays double duty in the winter as an outdoor skating rink. While more intensive activities can play out in the rest of the Union Station complex, the Forested Meadow Park provides calm, leisure environments for its users with its semi secluding planning (Figure 10.2.12).

\subsubsection{ACC Grandstand}

ACC Grandstand - is located directly south of the Forested Meadow Park and is a large, stepped park space that acts in various rolls. The stepped topography of the park ensures a leisurely decent from the first level programming to second level programming. The stepped park encloses a sunken portion of the site to provide an area for ACC patrons to gather and celebrate before games and events. With a covered stage, venue spaces and various outdoor seating areas the ACC Grandstand provides a sound setting for pre-game shows. 


\subsubsection{Front Street Plaza}

Front Street Plaza - transforms Front Street between York Street and Bay Street into a pedestrian only plaza to show off the grandeur of the surrounding architecture. The new plaza opens up as a continuous surface from Union Station to the Royal York Hotel with a new subway connection located centrally in the plaza. A dedicated taxi lane along the north end of the plaza provides pick-up and drop-offs for the Royal York and Union Station. The plaza further performs as a way finding device allowing for arrivals at Union station to gain their bearings once exiting the station. The arrivals are greeted by clear sight lines to the surround buildings and direct access to subway and taxi services (10.2.13). 


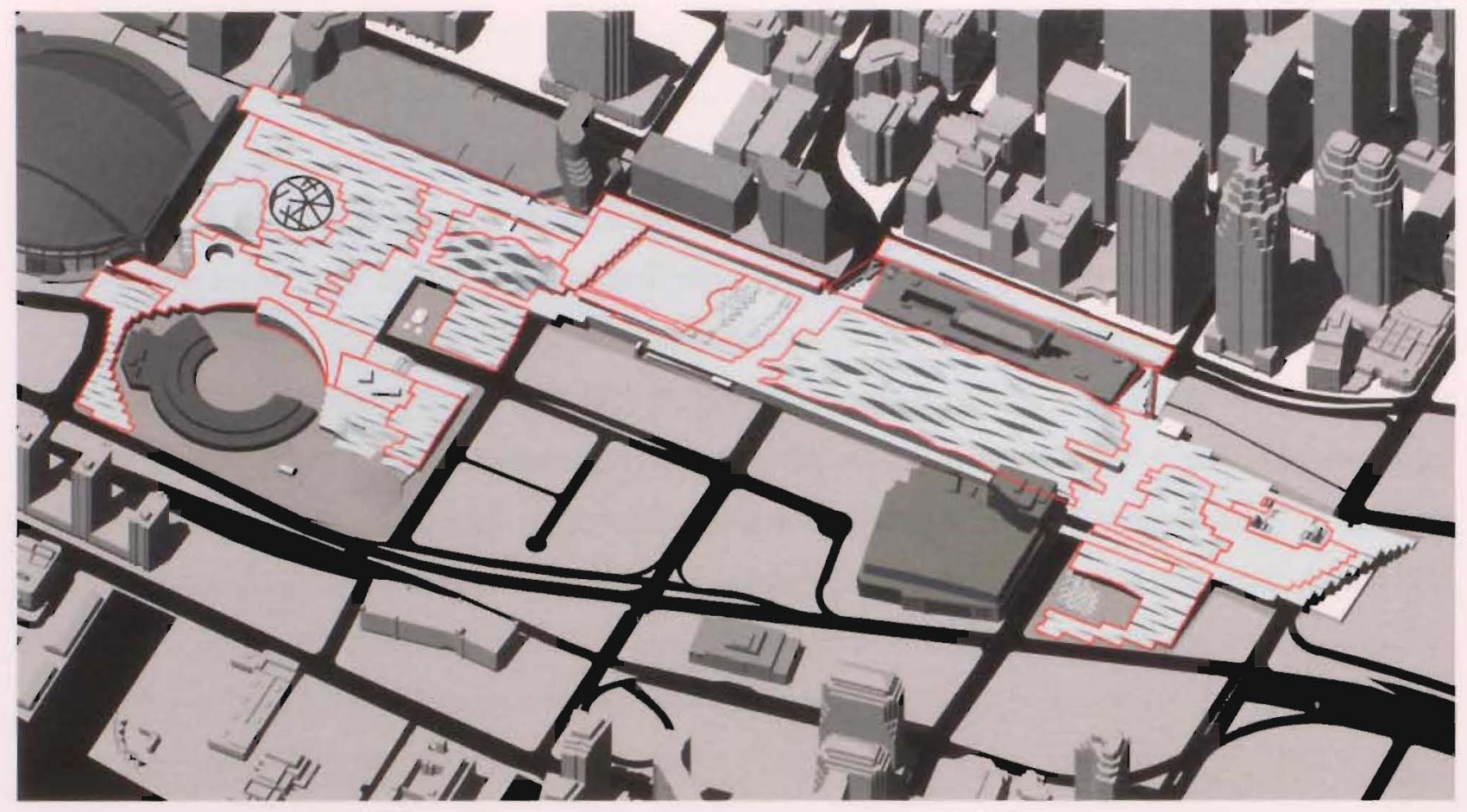

Figure 10.2.1 Major programmed areas outlined in RED.

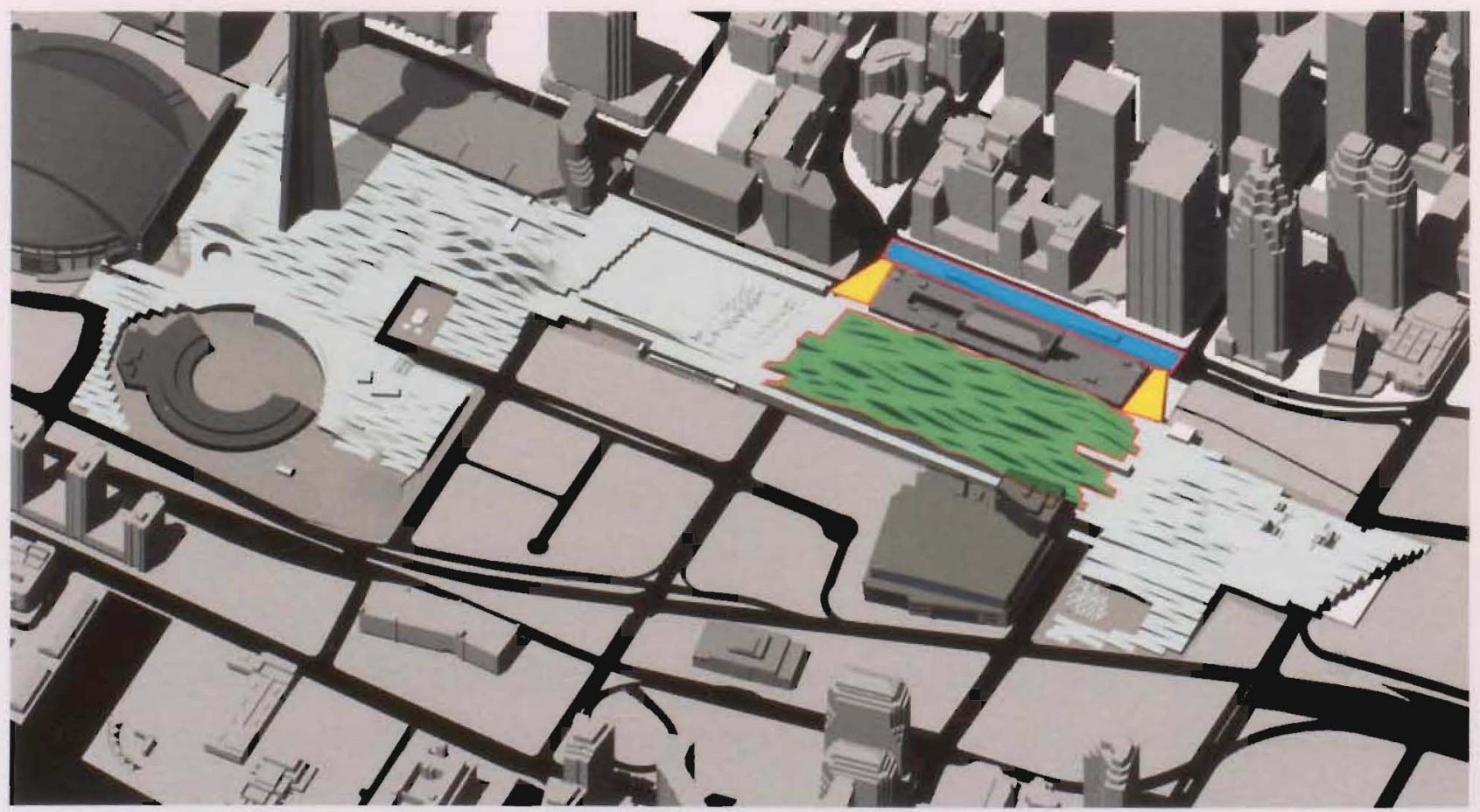

Figure 10.2.2 GREEN: Park Concourse, BLUE: Front Street Plaza, YELLOW: Stramp access from Front Street to top of surface. 


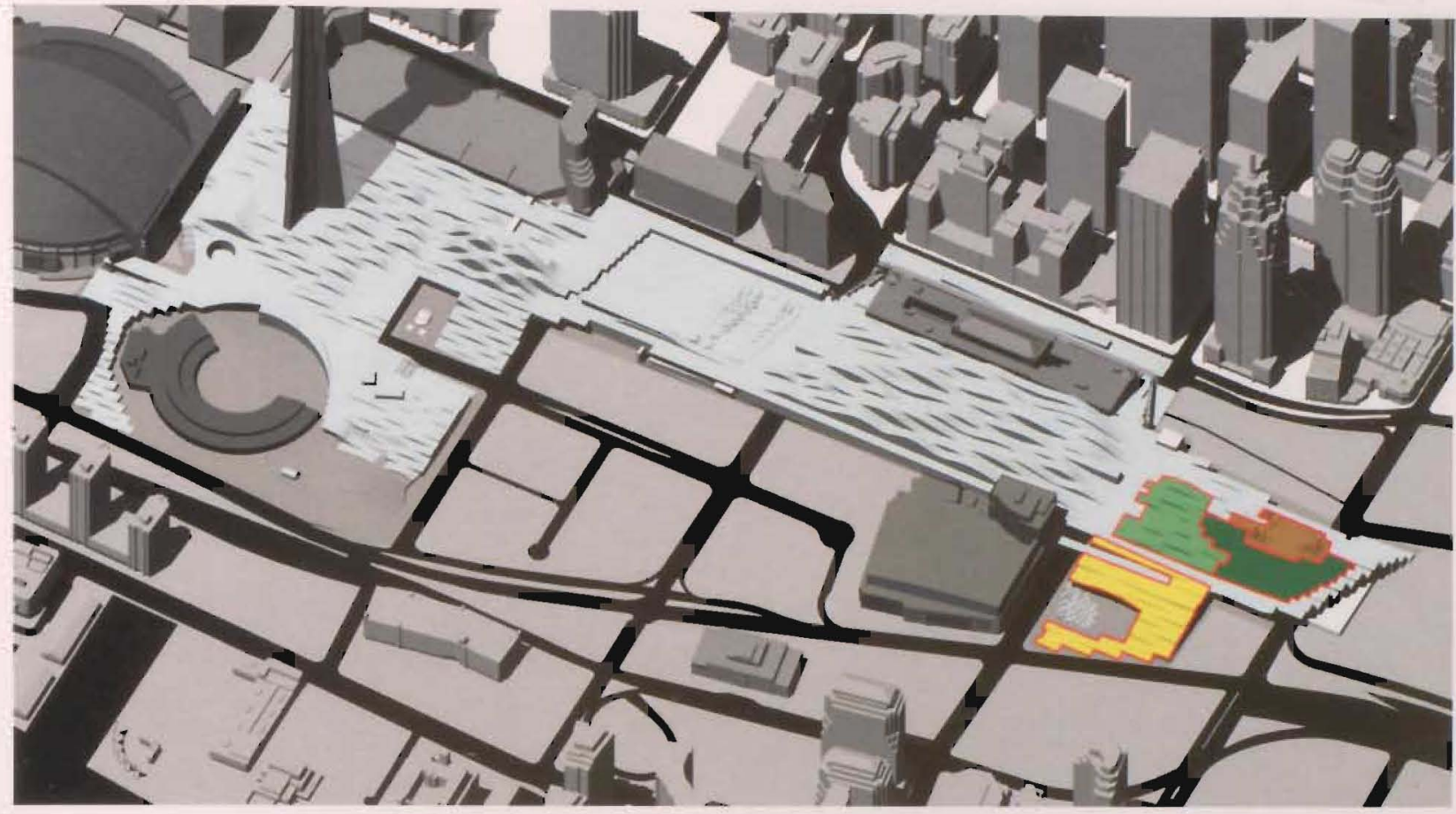

Figure 10.2.3 DARK GREEN: Field, LIGHT GREEN: Urban Forest, BROWN: Water Park (skating rink in winter), YELLOW: ACC Grandstand.

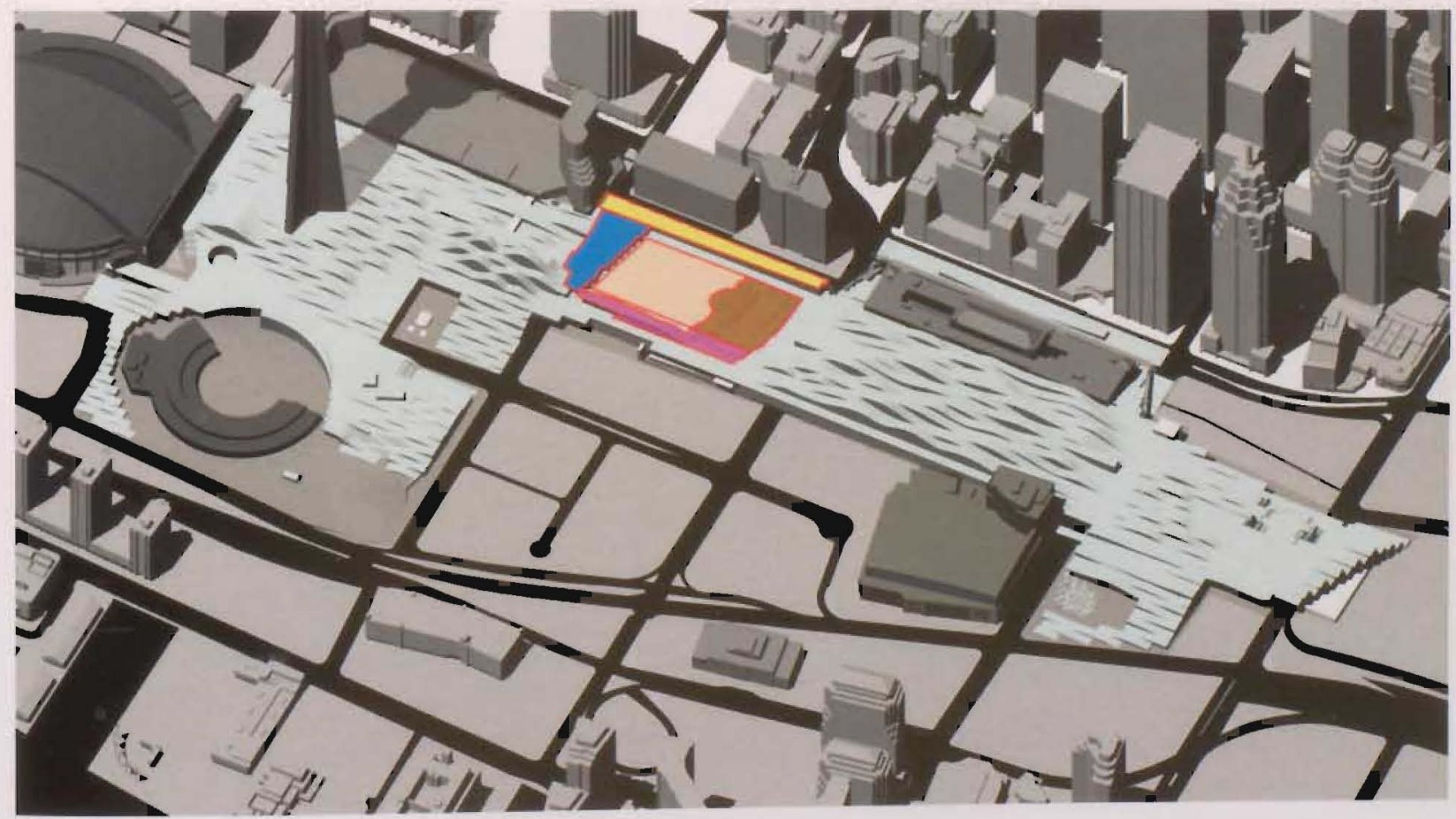

Figure 10.2.4 BLUE: Amenity space, BEIGE: Plaza, PURPLE: Stage, BROWN: Treeline and benches, YELLOW: Amenity spaces and integrated Skywalk connection. 


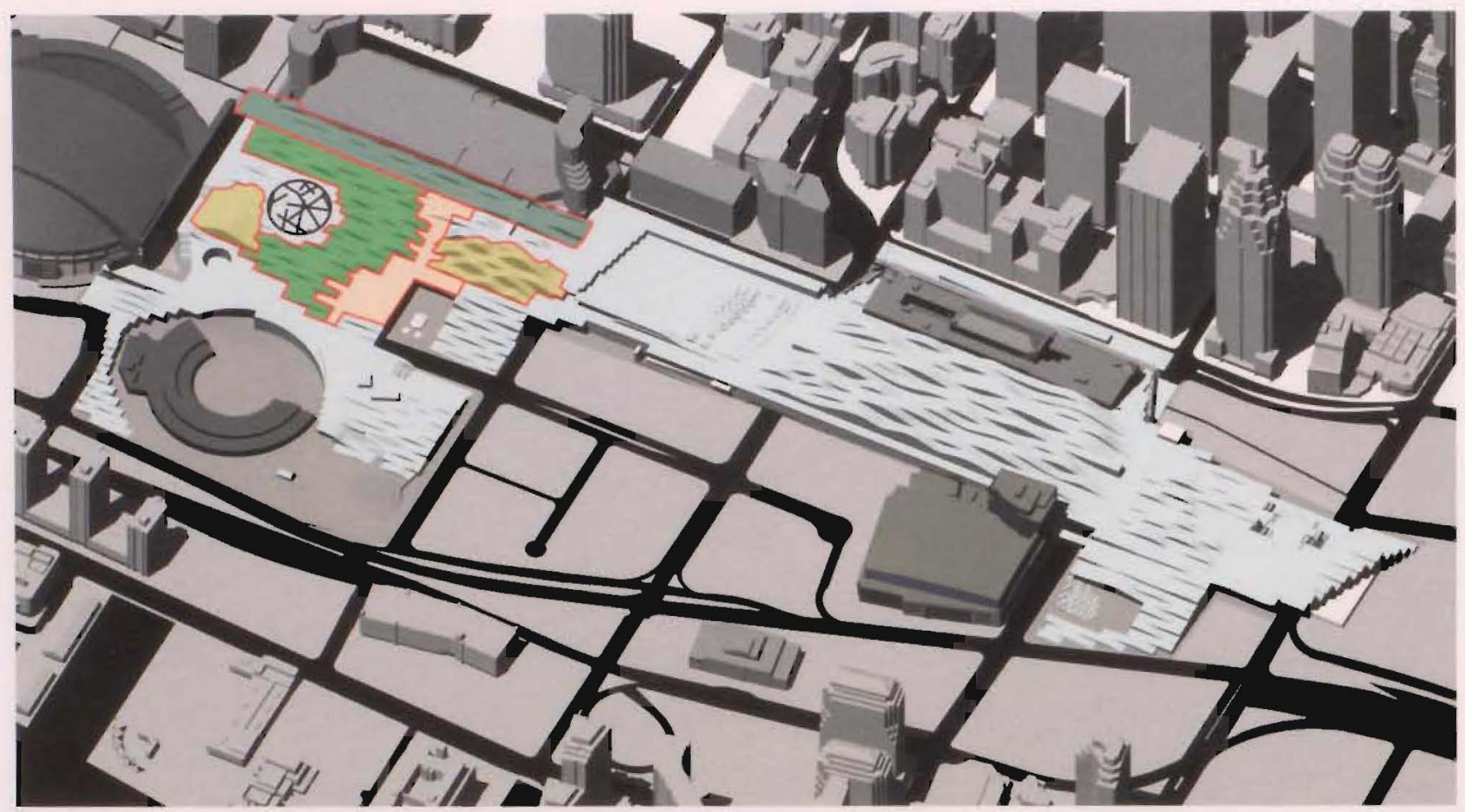

Figure 10.2.5 GREEN: Mixed gardens and ecosystems, BEIGE: North-South Plaza space, YELLOW: Enclosed public spaces

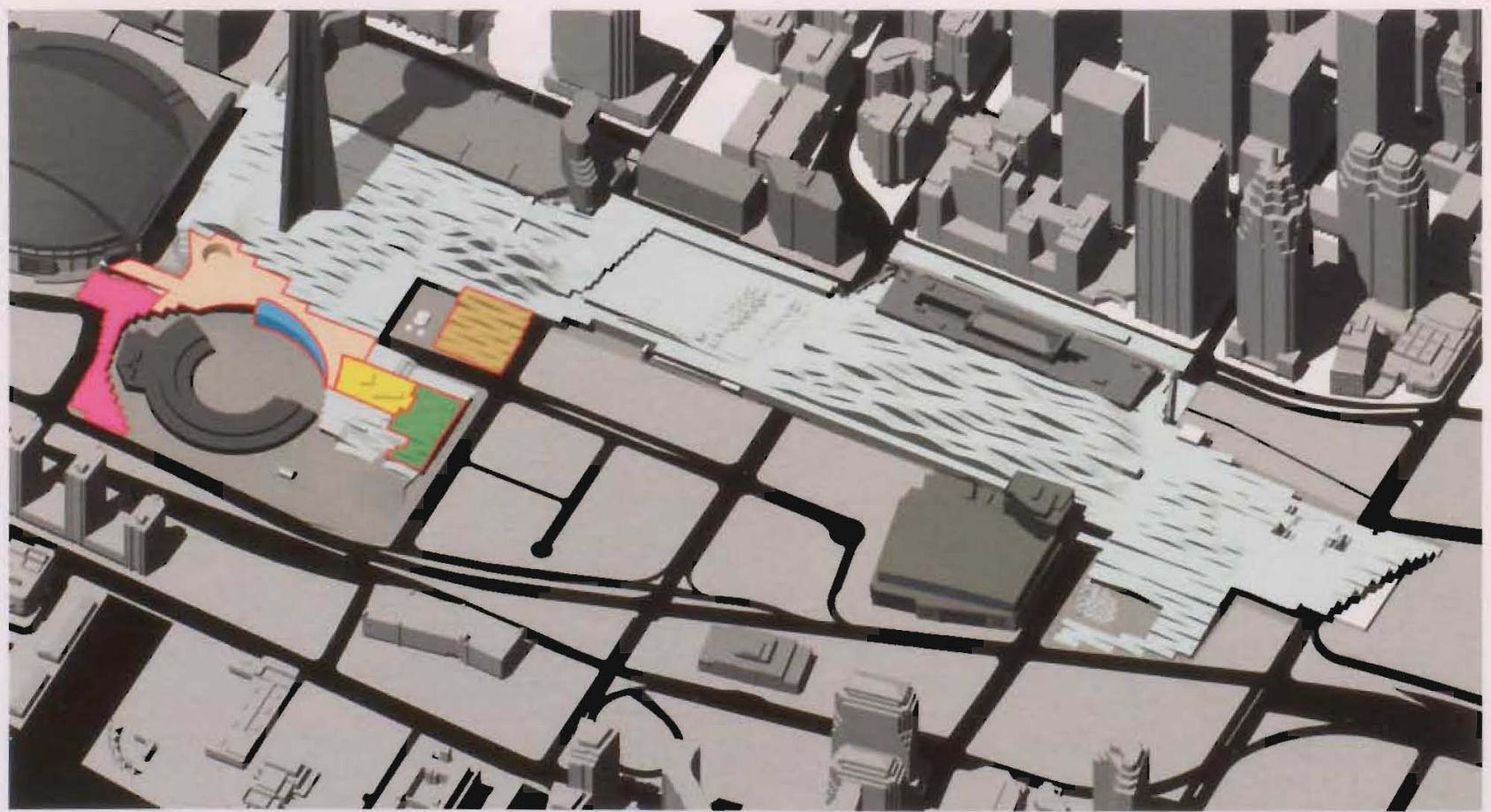

Figure 10.2.6 PURPLE: Terraced southern access, BEIGE: Plaza, YELLOW: Historical Train buildings, GREEN: Park space, LIGHT BROWN: water retention marsh. 


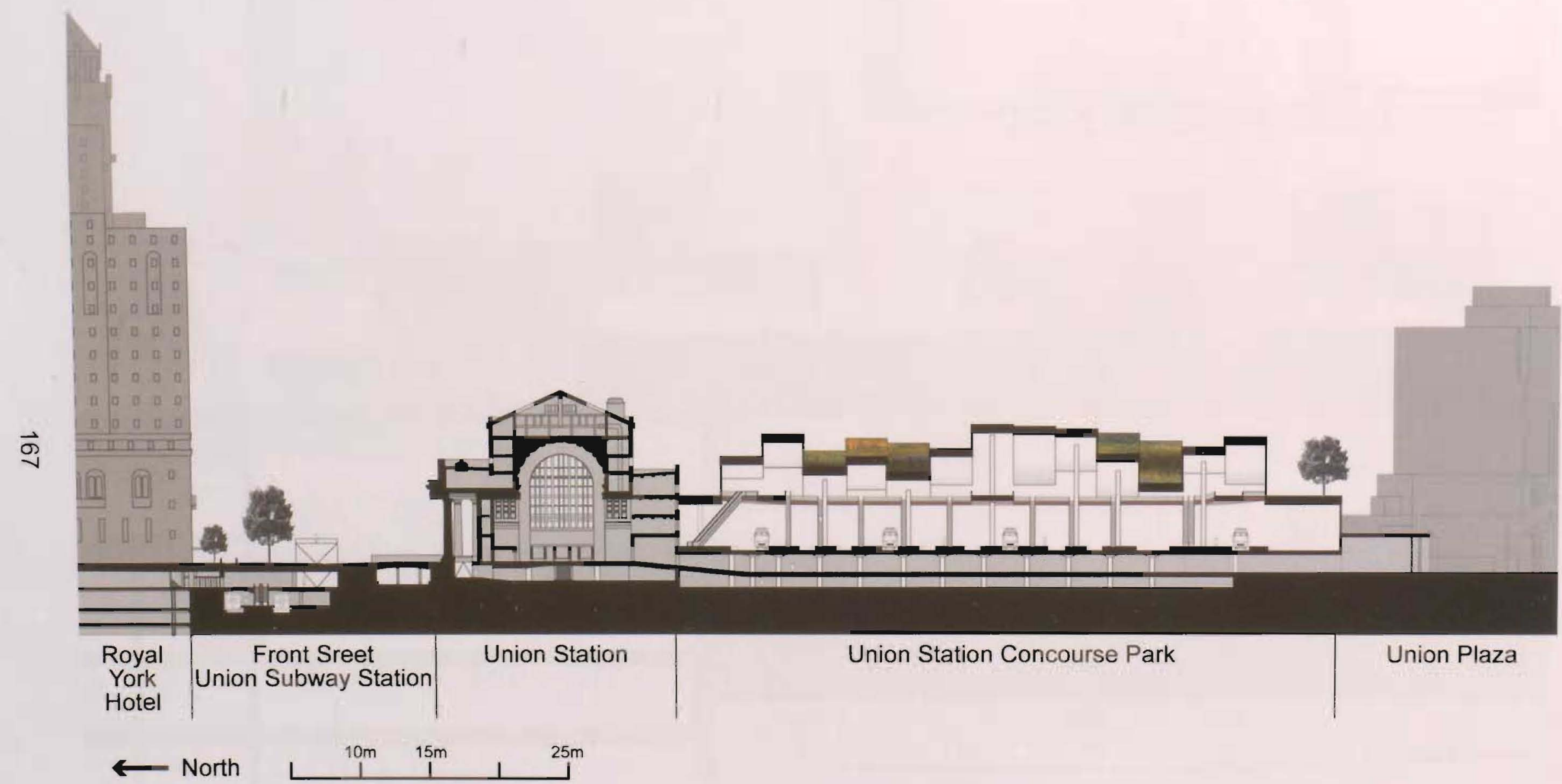

Figure 10.2.7 Section through Union Station from the Royal York to Air Canada Centre. 


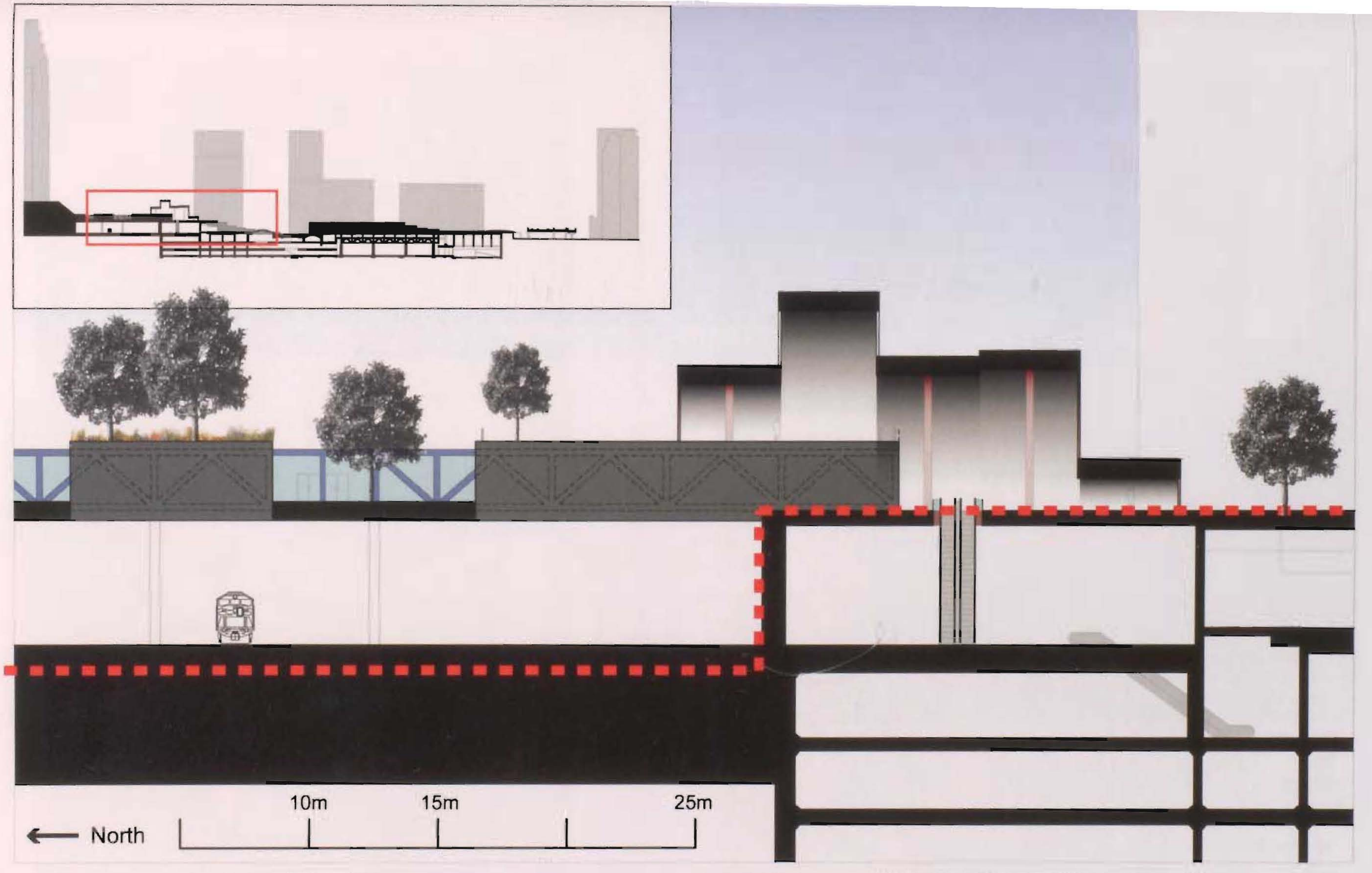

Figure 10.2.8 Section through new MTCC south building. RED DASHED LINE: Existing condition below. 

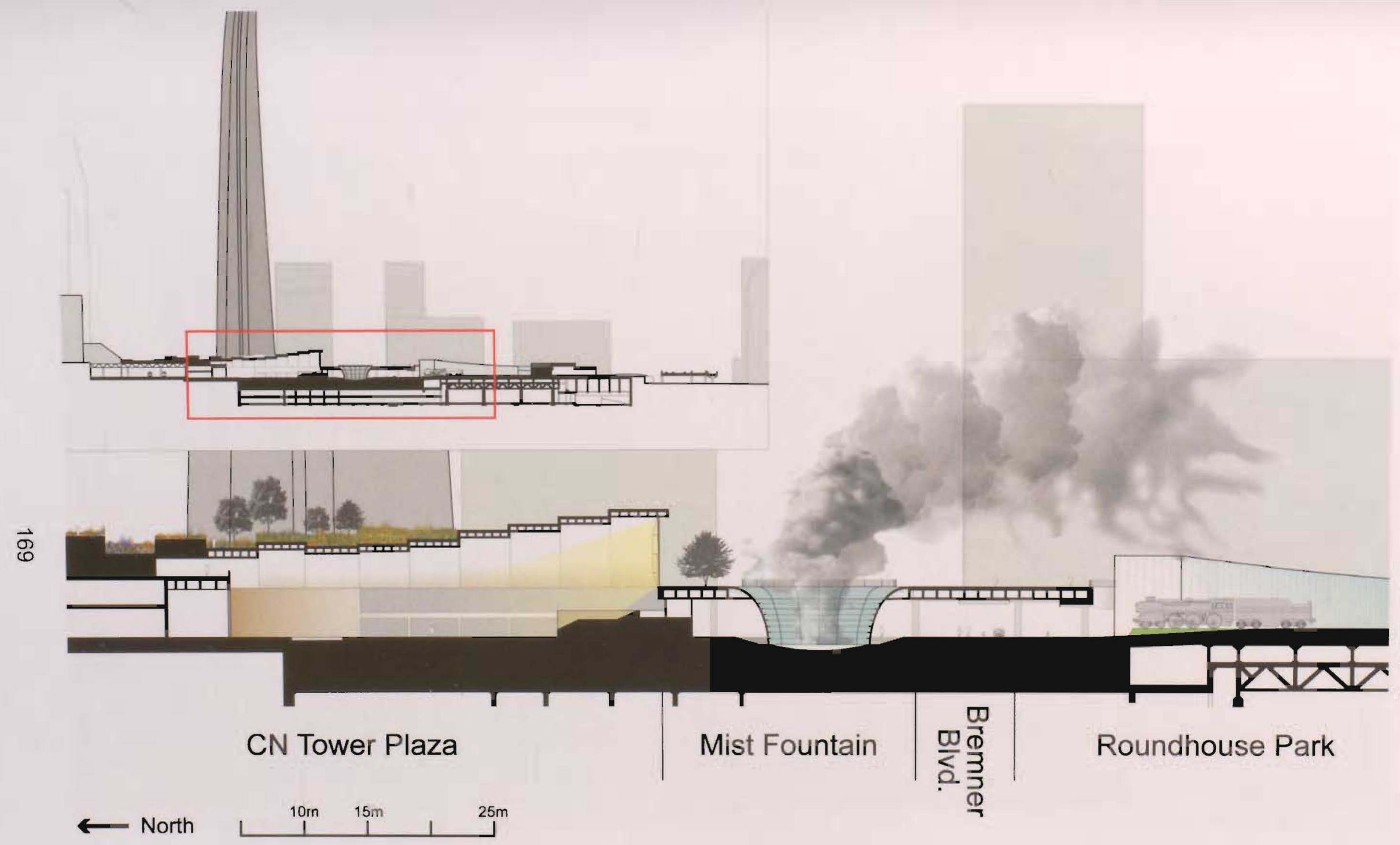

Figure 10.2.9 Section through CN Tower Plaza to Roundhouse Park. 


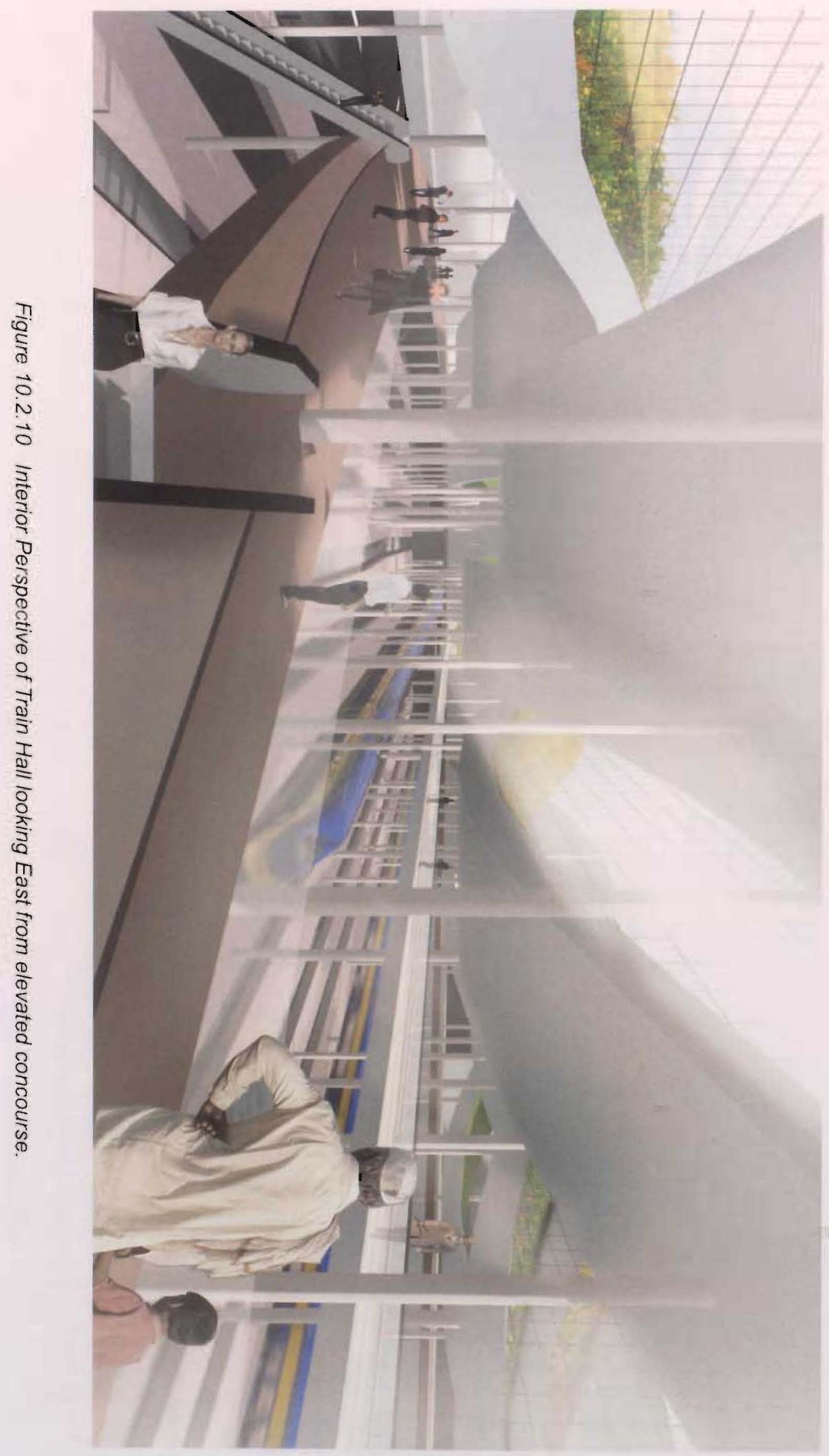




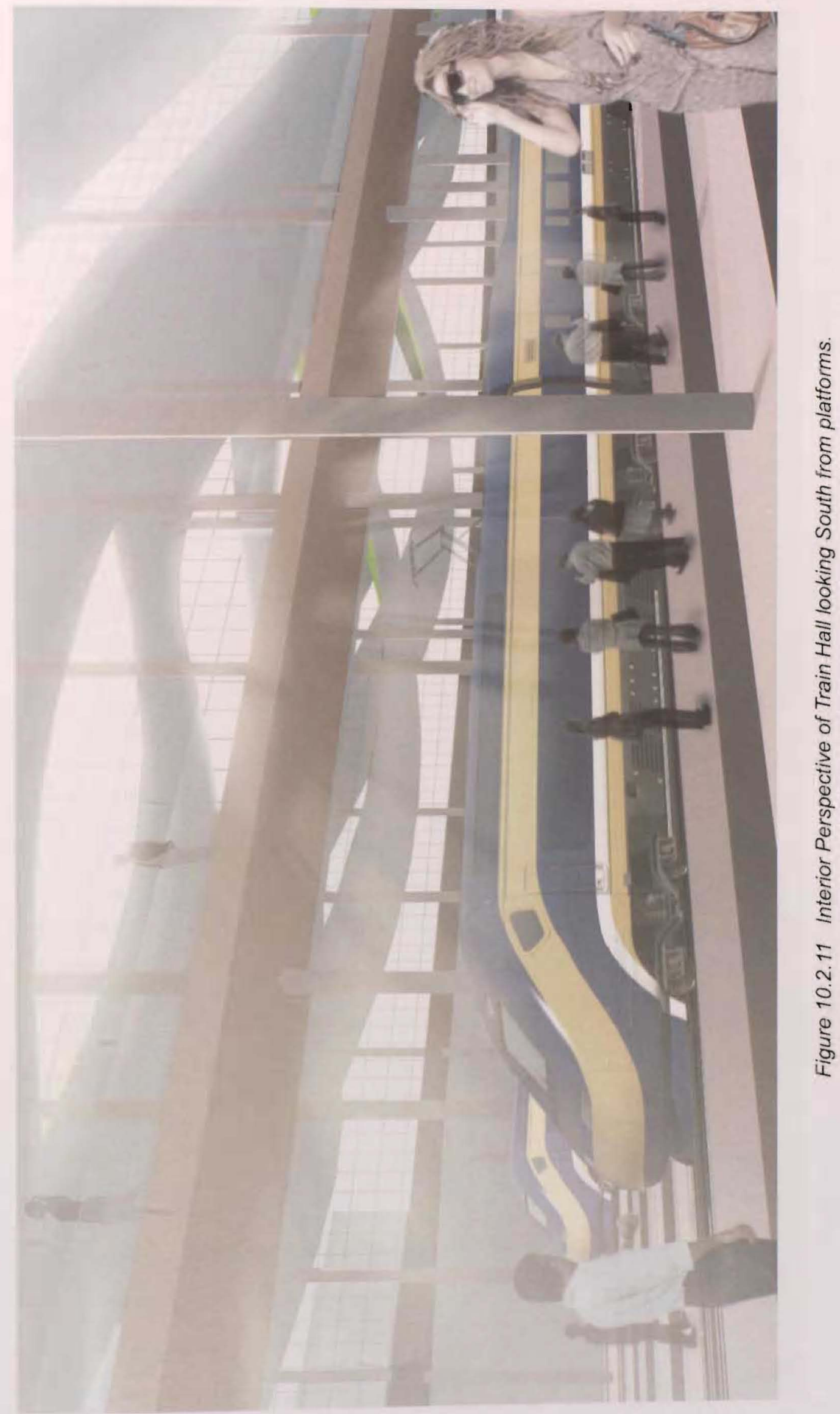




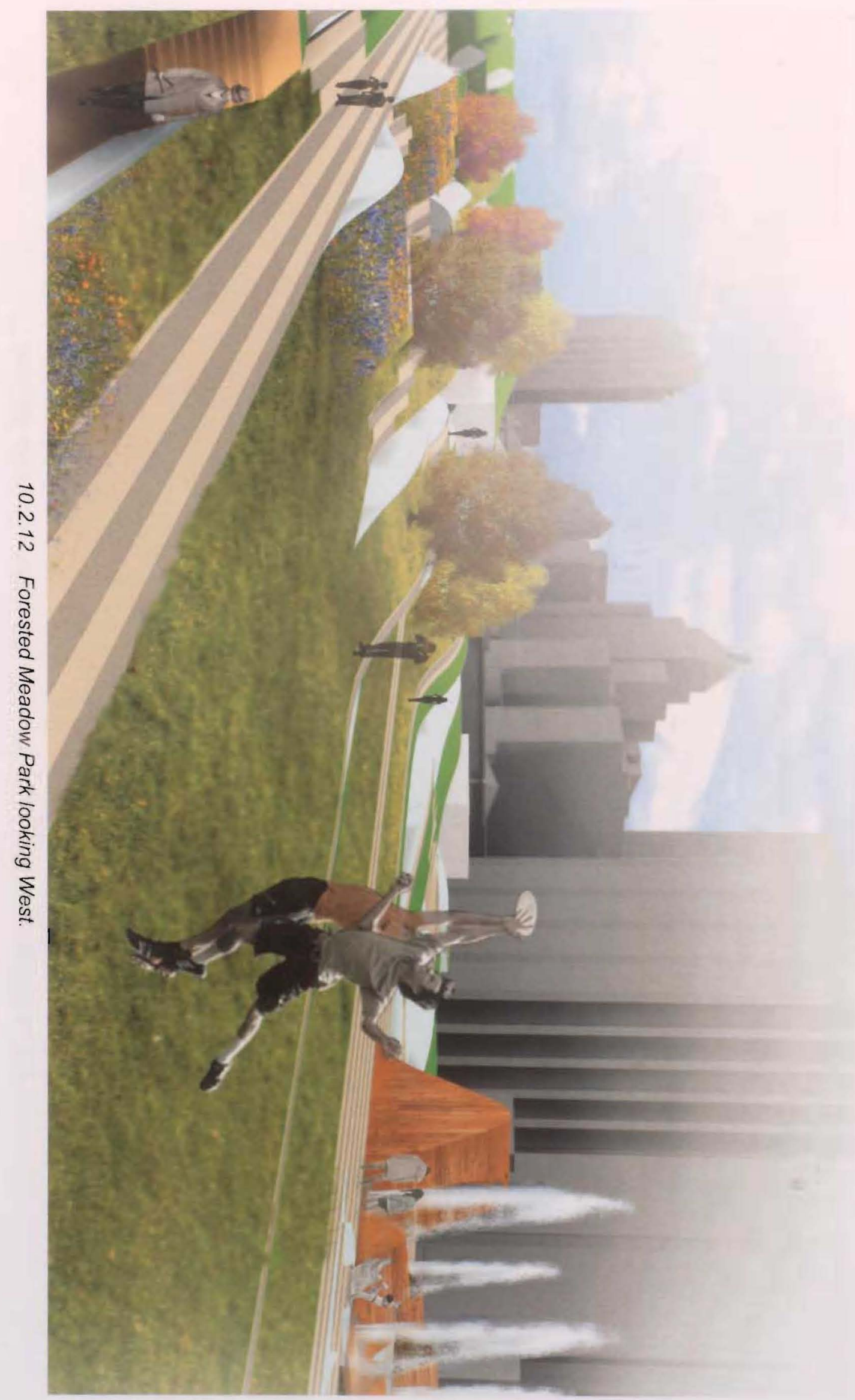




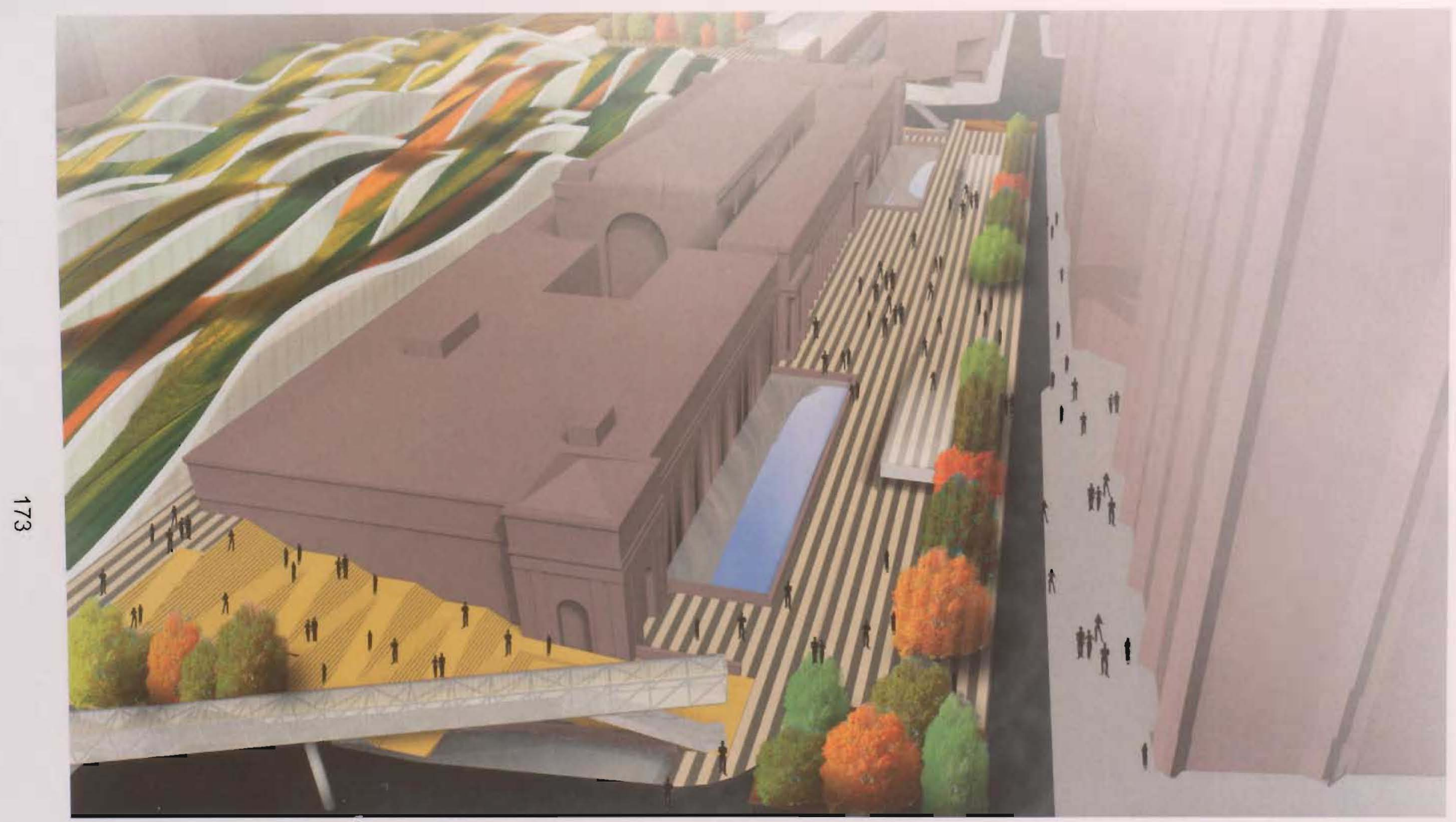

Figure 10.2.13 Front Street Plaza including stramp and escalators to access the park space above the rail corridor. 


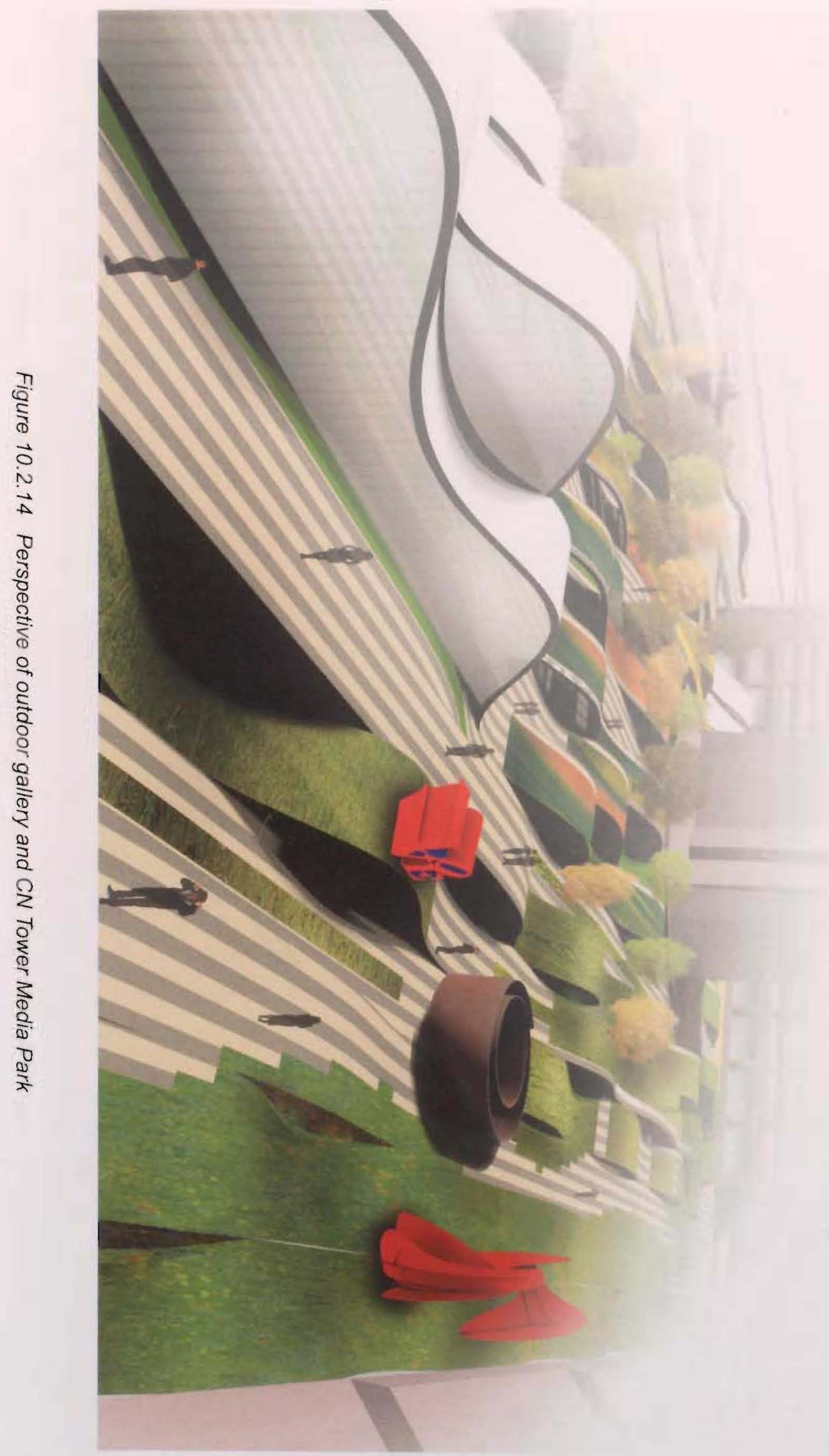




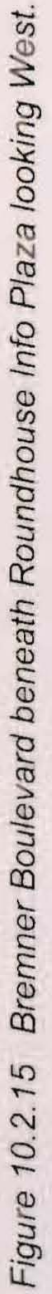

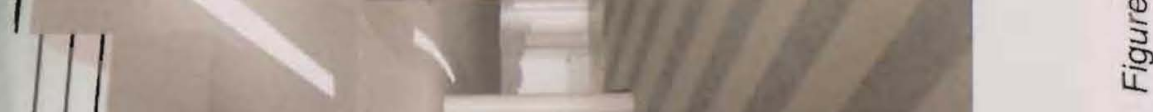




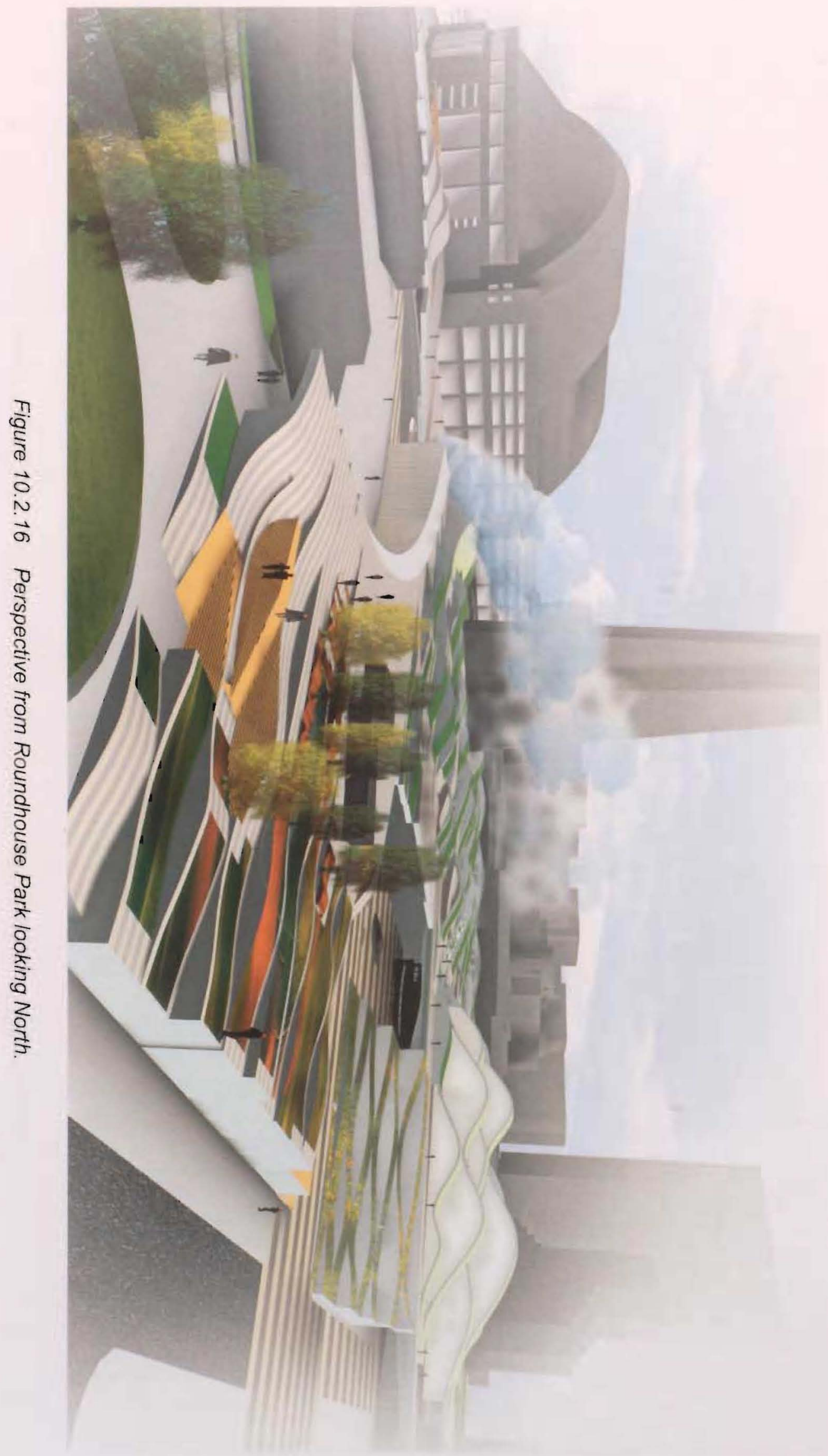




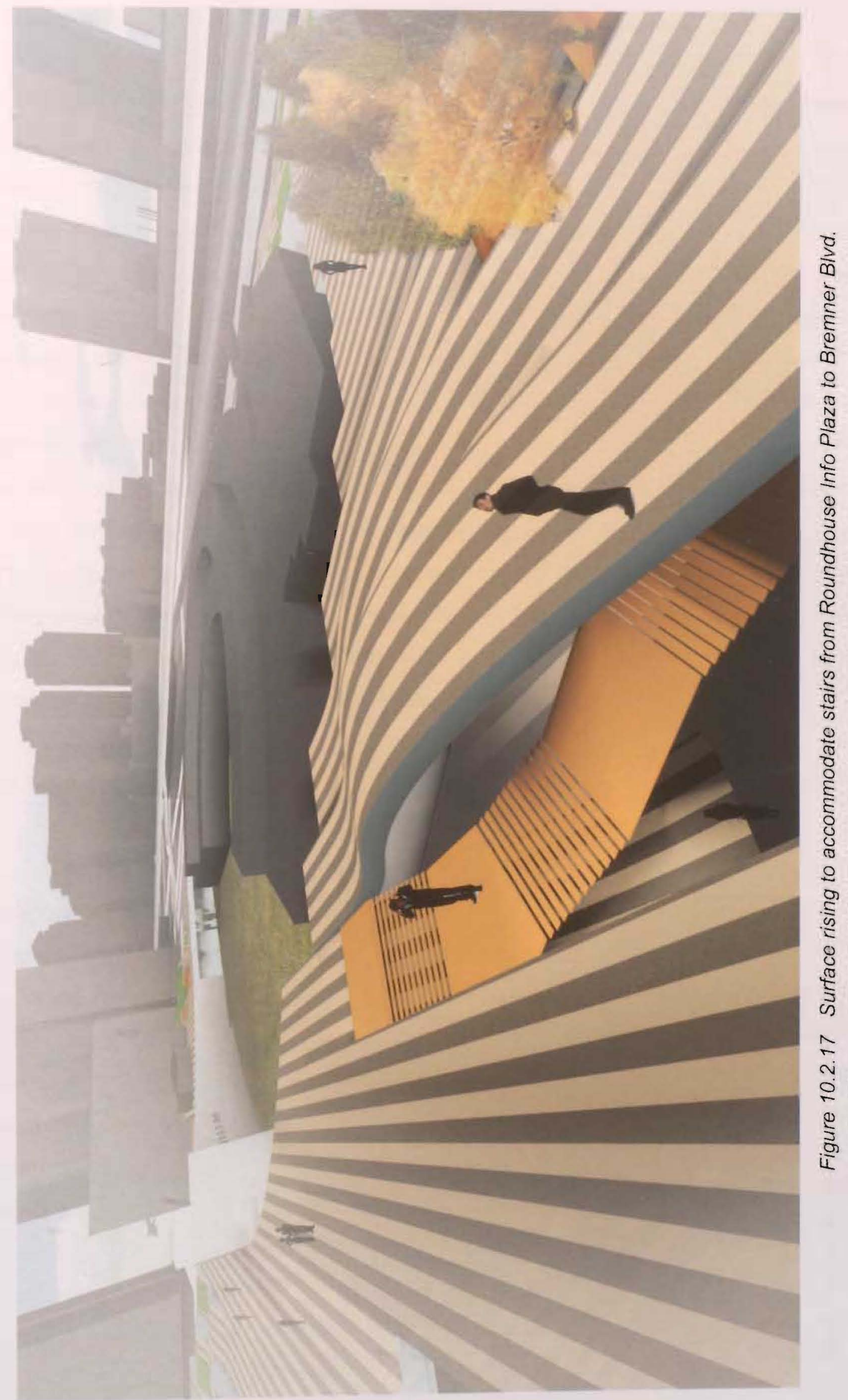




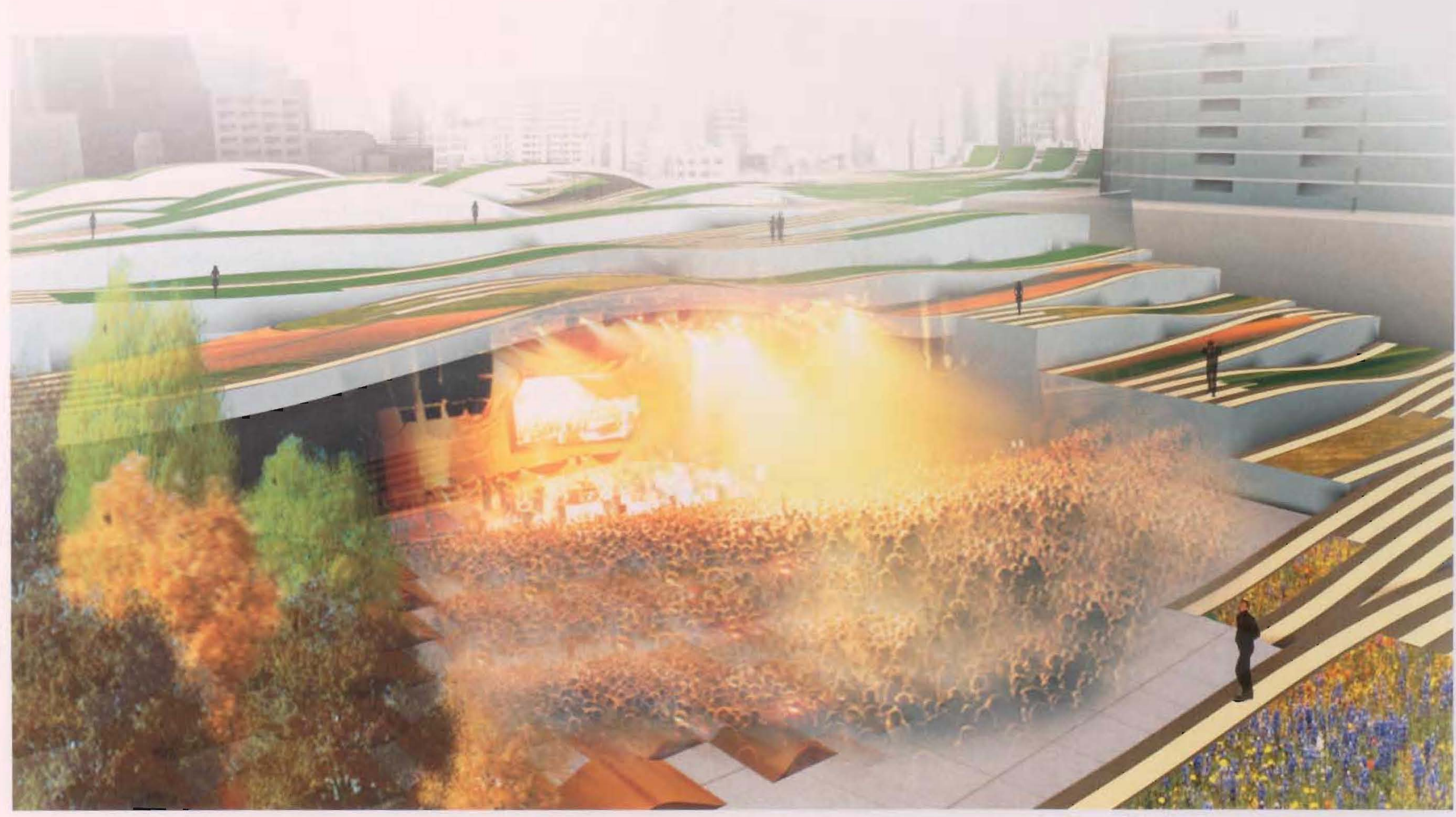

Figure 10.2.18 ACC Grandstand. A stage surrounded by tree lines and terraced landscaping. The terracing also provides vertical access to the park. 


\subsection{Materiality}

The ribbon surfaces of Central Railway Land Park are clad with various materials that denote specific conditions. Circulation trajectories are varied based on their hierarchy with the primary routes paved with long strips of multi-toned concrete pavers; minor routes paved with narrow strips of single toned pavers; and plazas are laid with wide pavers of various gradients to provide dynamic variation in large open spaces \{diagram\}. Green spaces on the ribbon surface vary with lawn-like conditions, field grass slopes, tree lines, fern undergrowth, and marsh ponds for water retention \{diagram\}. To anchor the naturalized conditions of the surfaces in their context, only local plantings are used on the site including species of Cedar, Birch, Maple, field grasses and marsh species. Steeper undulations of the surface cannot support vegetation and are thus clad in pale granites to mimic wind worn mounds found along waters edges.

Vertical elements created when a surface rises away from one another are restricted to a small material pallet in order to accentuate the strips. Glazed areas are primarily frosted glass channels with some areas utilizing transparent glazing. Remaining verticals are smooth surfaces of pale white concrete or concrete panel. The undersides of ribbons are pale white with long linear strips of illuminated panels to provide dynamic under-lighting and way finding \{image\}.

\subsection{Structure}

The structure of the ribbons is primarily a combination of steel space frames and concrete waffle grids. Concrete waffle grids are used on the lower lying portions of the surface such as around the Roundhouse and over Bremner Boulevard \{diagram\}. The train shed is supported by a space frame that transfers the roof loads to existing column locations in Union Station as to not disturb the conditions below the existing platforms \{diagram\}. Pre-tensioned post and beam systems are deployed on east and west side of the trainshed to provide the maximum load-to-span carrying capacities in order to not disturb the current rail placements \{diagram\}. Other surfaces carry the load directly onto the existing ground conditions through direct ground-to-ground connections or the utilization of retaining walls. 


\subsection{Final Remarks}

Central Railway Land Park is public landscape which functions as a continuous navigable surface to tie together isolated urban elements into a cohesive whole to create a social condenser for the entire GTA. On a regional scale Central Railway Land Park provides a vital point of entry for the 905 region into the urban core of the city by locating centrally in the transit network a large-scale public entertainment space. The present condition of a purely function point of entry to the city is replaced by an arcade-like terminal hall that blends a continuous park space from east to west, drawing together the various entertainment venues.

On a district scale the CRL's once bleak and unattractive condition is redeveloped into a cohesive urban park that provides potential links to the cities waterfont. Central Railway Land Park forms a transitional space between downtown core and the waterfront by creating a moment of pause between the two districts. Sharp transitions from downtown to waterfont are transformed into undulating park surfaces allowing pedestrians and cycles to navigate freely before choosing their final destination.

Currently the West Railway Lands (WRL) are transforming into mixed-use developments with a strip of park space from east to west that would allow Central Railway Land Park to tap into creating a continuous green zone from Yonge Street to Stratchen Avenue. The CRL's existing networks of roads, service lanes, car drop offs, and rail corridor are negotiated at various levels by the new park surface. As these elements are negotiated by the surface the apparent incoherence of the exiting condition is simplified and made logical by clear paths of travel, clear sight lines and common design aesthetic. The undulating and organic qualities of the surface act like an organ of movement grafted on top of the rail lands, tying together the $\mathrm{CRL}$. The weaving organic surfaces blur the distinction between interior and exterior public spaces implying the area is one continuous surface of park space.

At the core of the public landscape is the new terminal hall that provides visual connections to the city and park space, drawing visitors up into the city. Not only does the public landscape provide activities, park spaces and amenities for people of Toronto but it operates at the scale of the whole Greater Toronto area, who's growing network of regional rail services provides more convenient access to the city core. No longer will the CRL be a place to pass through, but will become a place to linger, connect to and celebrate the vibrancy of the city. 


\subsection{Bibliography}

Baird, G., \& Sampson, B. (1987). Harbourfront 2000: a report to the Futures Committee of Harbourfront. Baird/Sampson, Architects in association with Jones \& Kirkland, Architects.

Banham, R. (1976). Megastructure: Urban futures of the recent past. Great Britain: Thames \& Hudson Ltd.

Bertonlini, L., \& Spit, T. (1998). Cities on rails: The redevelopment of railways station areas. New York: E \& FN Spon.

Bruinsma, F., Pels, E., Priemus, H., Rietveld, P., \& van Wee, B. (Ed.). (2008). Railway development: Impacts on urban dynamics [Electronic Version]. Physica-Verlag Heidelberg.

Burmanje, W. J. F. (2006). Archldea [Electronic Version]. Archldea, No. 35. Retrieved November 20, 2008, from http://www.archidea.com/archidea/backissues.html.

Busquets, J. (Ed.). (2008). Olympic sculpture park for the Seattle Art Museum. Harvard Graduate School of Design.

Carr, A. (2005). Toronto Union Station historical structure report. Toronto: Foumier Gersovitz Moss \& Associes architectes. Retrieved October 10, 2008, from http://www.toronto.ca/union_ station/str_report.htm.

CBC News. (January 30, 2007). New pier opens at Toronto's Pearson airport. Retrieved November 26, 2008, from http://www.cbc.ca/canada/toronto/story/2007/01/30/pearson-terminal. html.

Cecilia, F. M., \& Levene, R., (Ed.). (2007). Elcroquis editorial: OMAVRem Koolhaas. Madrid: Premio COAM.

City of Toronto. (n.d.). Harbourfront parks and open space. Retrieved October 30, 2008, from http://www.toronto.ca/harbourfront/historical.htm. 
City of Toronto. (2007). TTC history. Retrieved November 27, 2008, from http://www.toronto.ca/ ttc/history.htm\#milestones.

Collins Language. (n.d.). Collins Language. Retrieved October 19, 2008, from http://www. collinslanguage.com/.

Davey, P. (2003). Underground station, Stuttgart, Germany: Ingenhoven Overdiek Architekten. The Architectural Review, Vol. 213, No. 1274, pp. 66-69.

Dawes, R. (Ed.). (2001). Modern trains and splendid stations, Italy: Merrell Publishers Limited.

Dehaene, M., \& de Cauter, L. (Ed.). (2008). Heterotopia and the city: Public space in a postcivil society. London: Routledge.

Deleuze, G., \& Guattari, F. (1987). A thousand plateaus: capitalism and schizophrenia.

Minneapolis [translated from Mille plateaux, v. 2 of Capitalisme et schizophrénie]: University of Minnesota Press.

Frank, K. A., \& Stevens, Q. (Ed.). (2007). Loose space: Possibility and diversity in urban life. New York: Routledge.

- Gilbert, R. (2008, January 28). Revitalizing Union Station: A Toronto showpiece for emerging railway age. Toronto Star. Retrieved November 20, 2008, from www.torontostar.com.

GWL Realty Advisors Inc., Brokerage. (n.d.). 18 York St. Retrieved November 26, 2008, from http://www.18york.com/.

Hume, C. (2007a, April 21). Some causes for concern in condo design. The Star. Retrieved November 23, 2008, from www.thestar.com. [is this the Toronto Star?

Hume, C. (2007b, June 16). Undercurrents: How do you spell creative bankruptcy? R-O-U-N-DH-O-U-S-E. The Star. Retrieved November 26, 2008, from www.thestar.com. 
Jacobs, J. (1961). The death and life of great American cities. New York: Vintage Books.

Kubo, M., Sakamoto, T., \& Ferre, A. (Ed.). (2002). The Yokohama project. Barcelona: Actar.

Kubo, M., \& Ferre, A. (Ed.). (2004). Phylogenesis: Foa's ark - foreign office architects. London: Actor.

Maple Leaf Square. (2008). The residences of Maple Leaf Square. Retrieved November 26, 2008, from http://www.mapleleafsquare.com/flash/main.htm.

Michel Foucault, Info. (2007). Michel Foucault. Of other spaces (1967), Heterotopias. Retrieved October 28, 2008, from http://www.foucault.info/.

National Geographic. (2008) Shinjuku Station, Tokyo, Japan, 1986. Retrieved November 26, 2008, from http://photography.nationalgeographic.com/photography/enlarge/shinjuku-station_ pod_image.html.

Stringer B., \& Barber, P. (1999). Turbulence in Smooth Space. Architectural Digest, Vol. 69, No. 7-8, pp. 88-89.

Swerling, G. (Ed.). (2004). Railway stations: From the gare de l'est to open Penn Station. Hong Kong: Electa Architecture.

Sutton Real Estate. (2008). ICE Condominium. Retrieved November 26, 2008, from http://www. suttonrealty.com/lce_Condo_in_Toronto/page_2071221.html.

Transit Toronto. (2007). Toronto transit. Retrieved November 26, 2008, from http://transit. toronto.on.ca.

UN Studio: Arnhem Central. (2006). Tokyo: GA Documents, Vol. 91, pp. 44-47. 
Union Station District Plan. (2006, May). Toronto: architectsAlliance. Retrieved October 10, 2008, from http://www.toronto.ca/union_station/district_plan.htm.

Union Station Master Plan. (2005, December). Toronto: Office for Urbanism; R. E. Millward \& Associates; Poulos \& Chung Limited. Retrieved October 10, 2008, from

http://www.toronto.ca/union_station/report.htm.

van Berkel, B., \& Bos, C. (2006). Design models: Architecture, urbanism, infrastructure. London: Thames \& Hudson.

Verband Region Stuttgart. (2007). METREX - Expert group - Major infrastructure in metropolitan regions [Electronic Version]. METREX Expert Group. Retrieved November 26 , 2008, from www.region-stuttgart.org. 


\subsection{Appendix A}

\section{Full Page Spreads}

Appendix A1: Top Level Layout Appendix A2: Mid Level Layout

Appendix A3: Base Level Layout 
[186] 


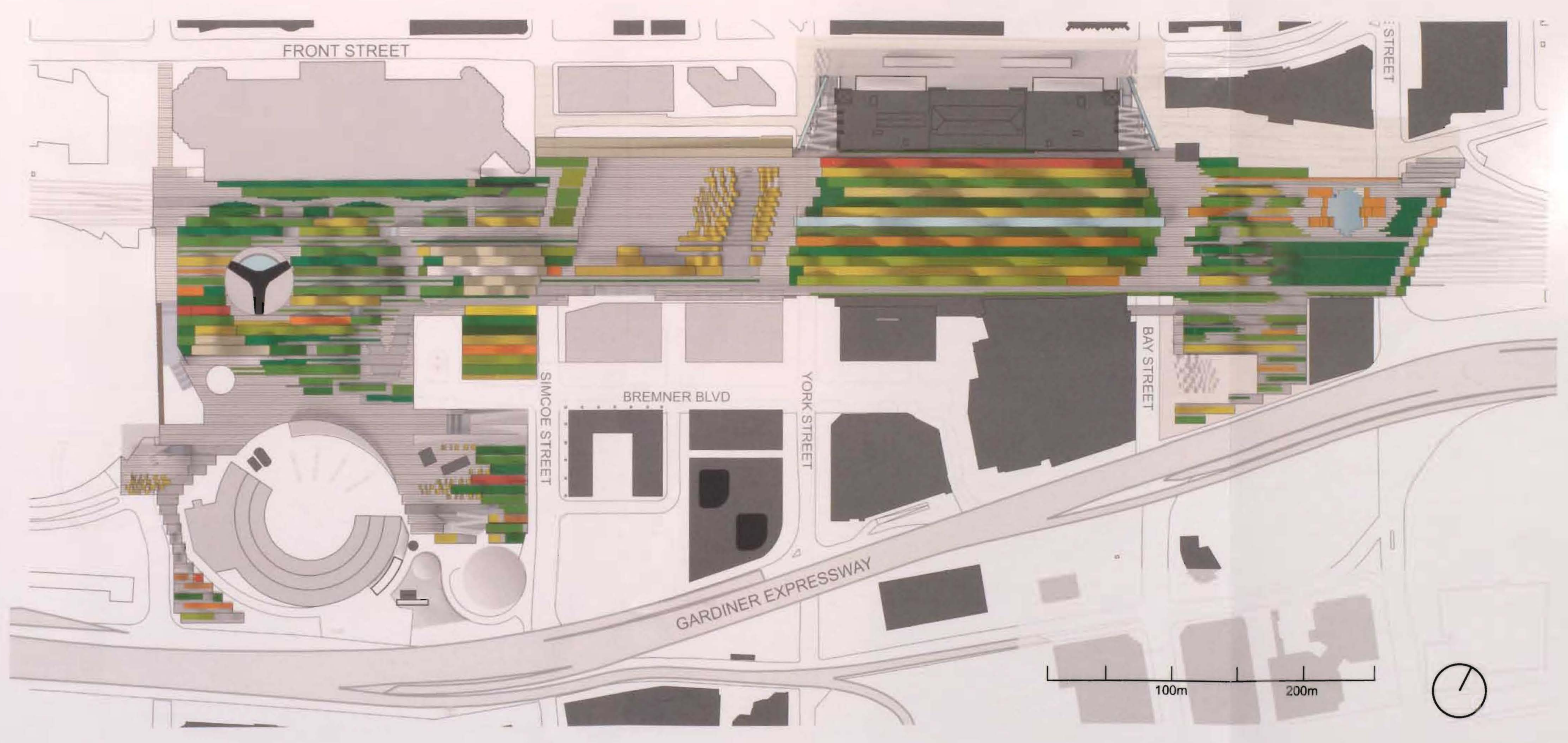


[188] 


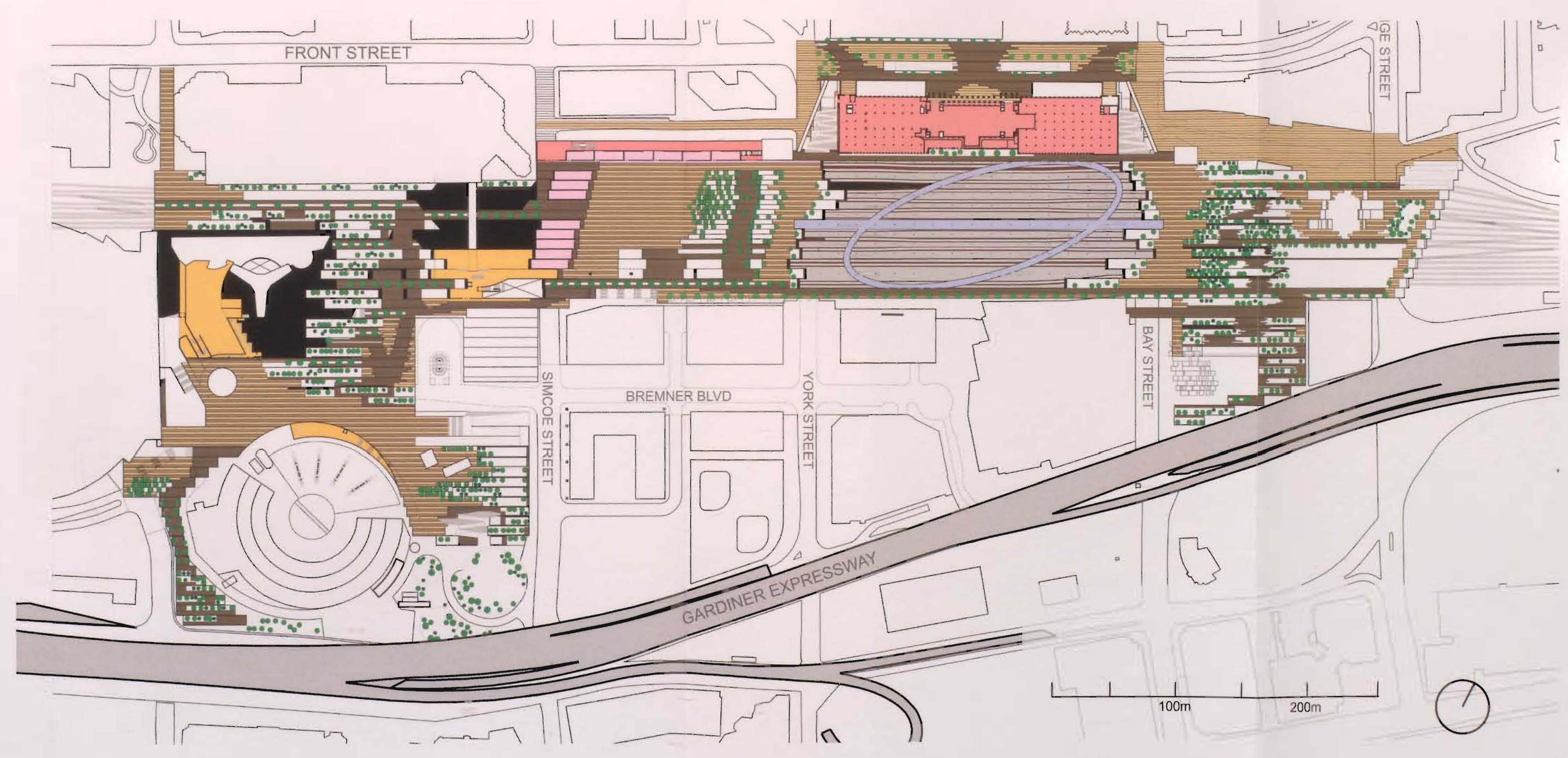


[190] 


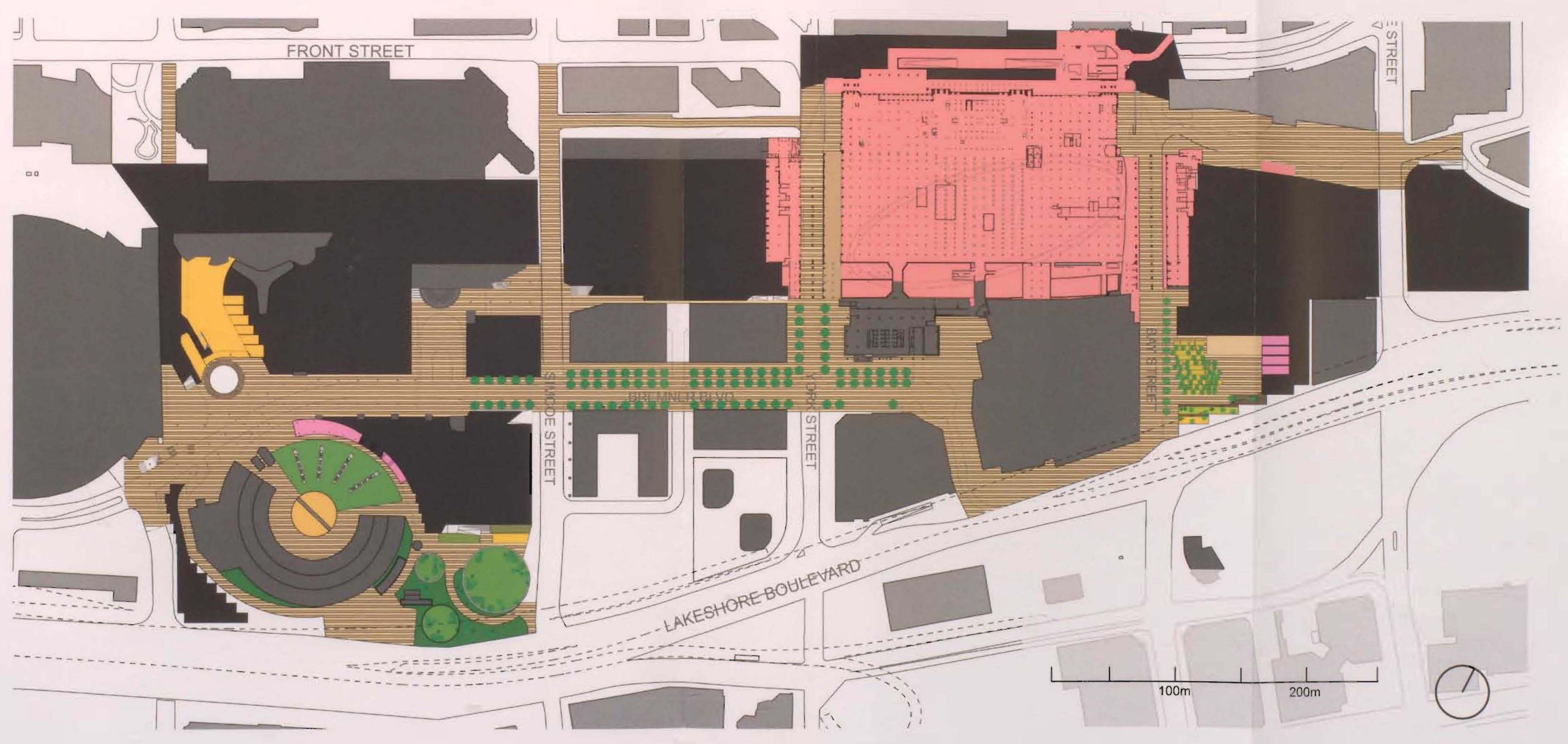

